\title{
THERMAL NUMERICAL SIMULATOR FOR LABORATORY EVALUATION OF STEAMFLOOD OIL RECOVERY
}

\author{
Topical Report \\ NIPER --495 \\ By \\ DE91 002238 \\ Partha Sarathi
}

April 1991

Work Performed Under Cooperative Agreement No. DE-FC22-83FE60149

Thomas B. Reid, Project Manager

Bartlesville Project Office

P. O. Box 1398

Bartlesville, OK 74005

U.S. Department of Energy
Assistant Secretary for Fossil Energy

Prepared by

IIT Research Institute

National Institute for Petroleum and Energy Research

P. O. Box 2128

Bartlesville, OK 74005 


\section{TABLE OF CONTENTS}

Page

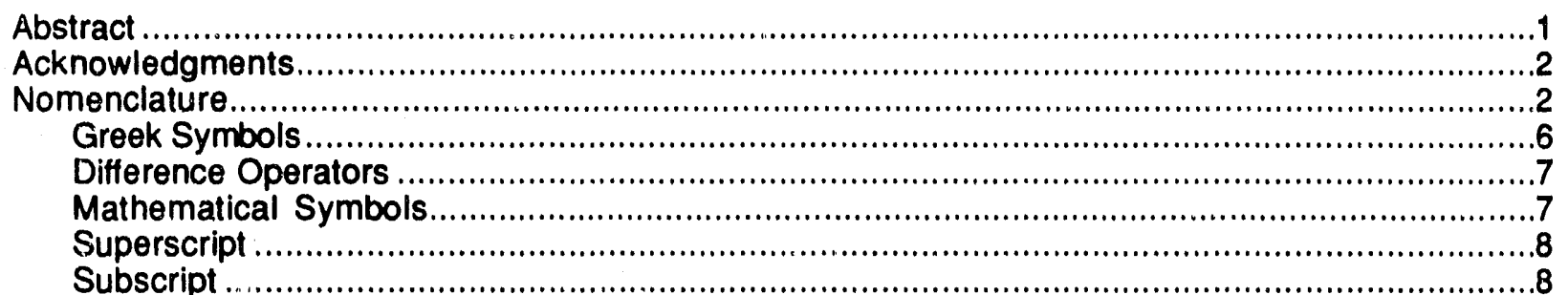

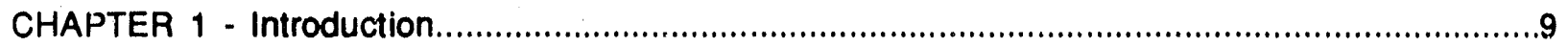

TABLES

1.1 - Distribution of components in fluid phases ...........................................................11

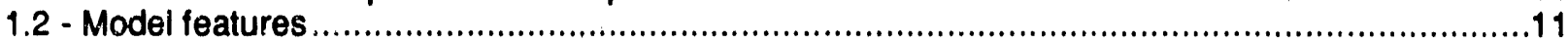

1.3 - Comparison of steamflood simulators - major features ....................................................12

1.4 - Comparison of steamflood simulators - treatment of rock and fluid properties.........................13

CHAPTER 2 - Literature Review.............................................................................

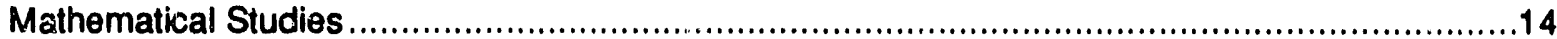

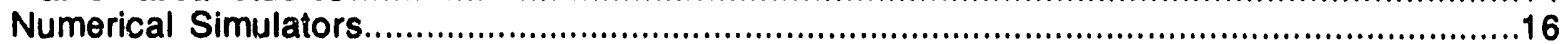

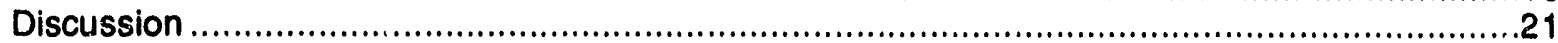

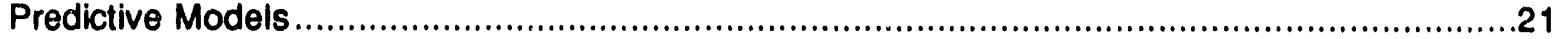

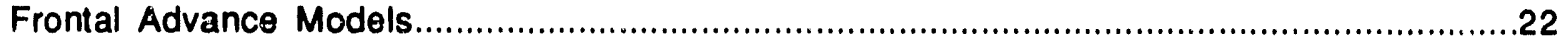

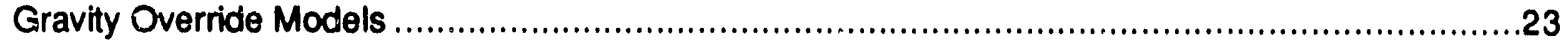

\section{TABLE}

2.1 - Main features of existing thermal simulators

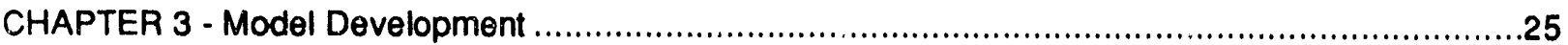

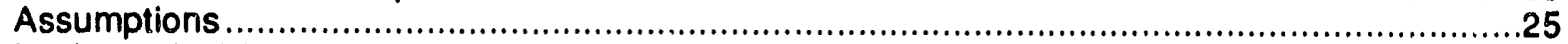

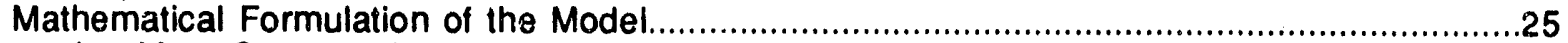

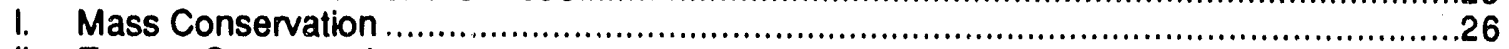

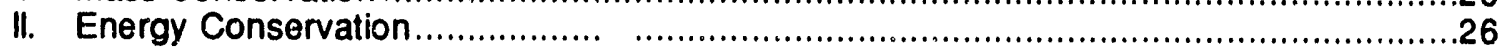

III. Phase Saturation Constraint .....................................................................................26

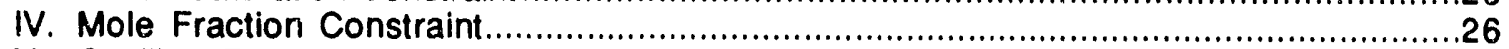

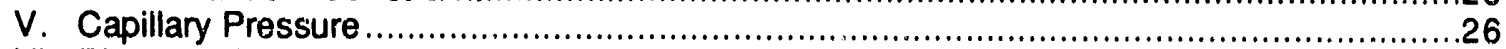

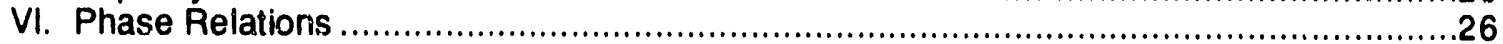

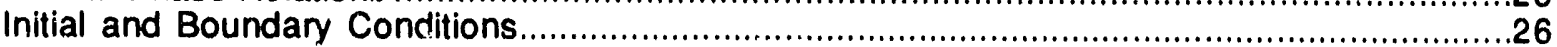

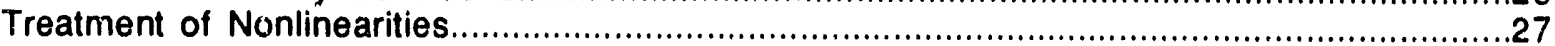

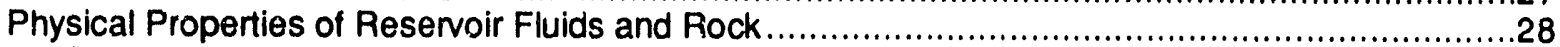

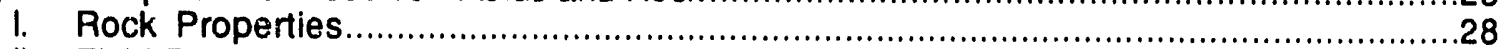

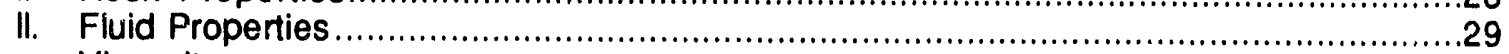

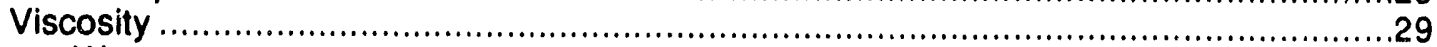

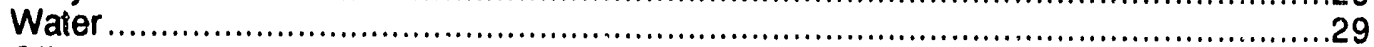

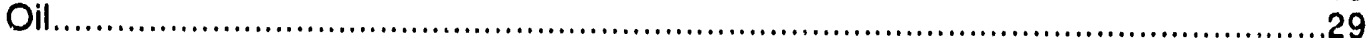

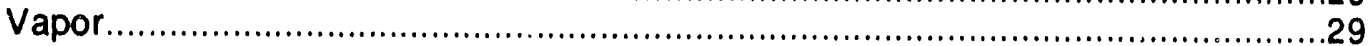

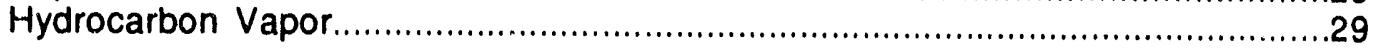




\section{TABLE OF CONTENTS - ContInued}

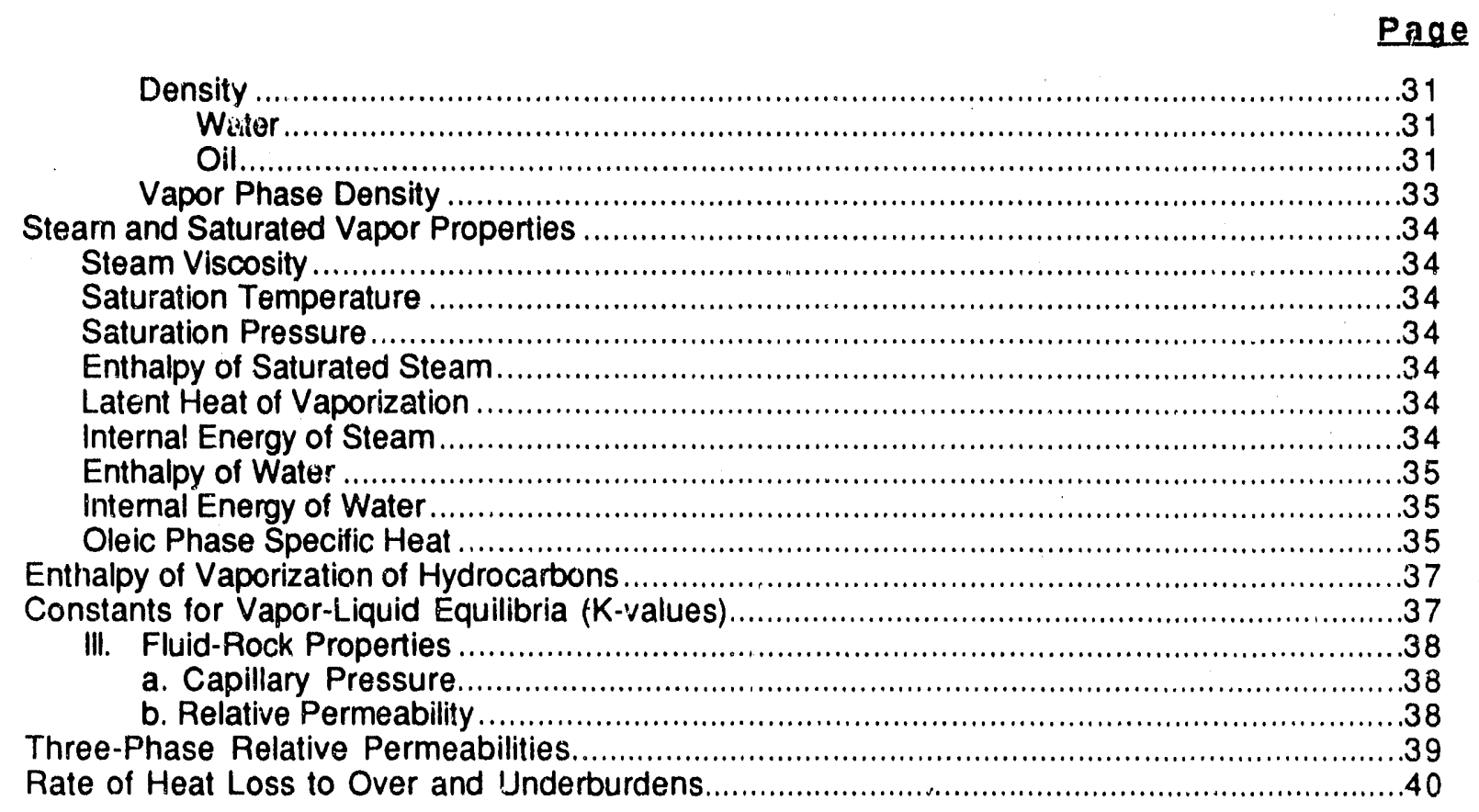

\section{TABLE}

3.1 - Functional dependence of physical properties.

CHAPTER 4 - Expansion of the Difference Equations and Method of Solution ..............................42

Expansion of Finite Difference Equations.........................................................................42

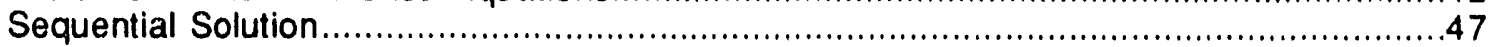

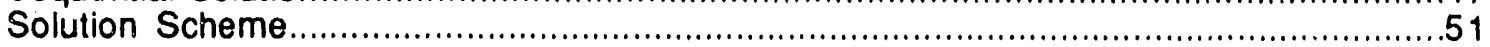

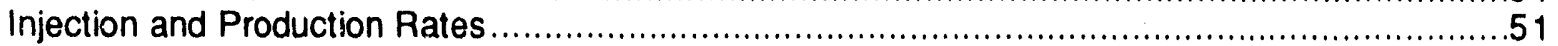

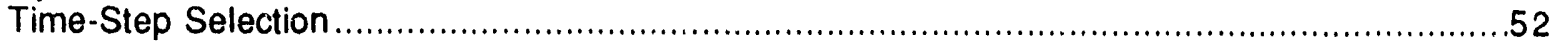

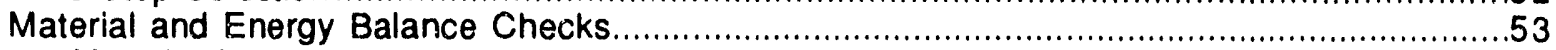

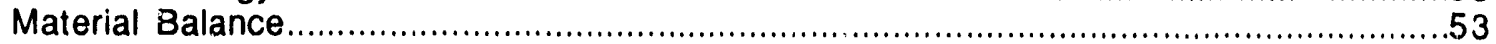

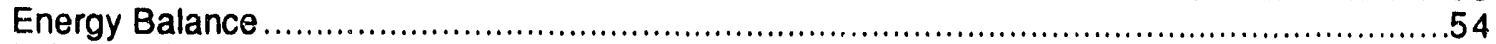

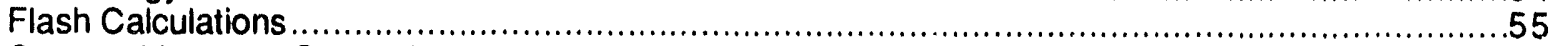

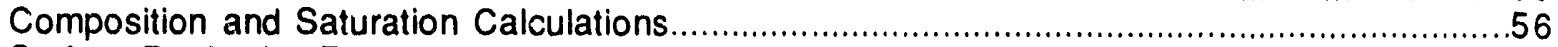

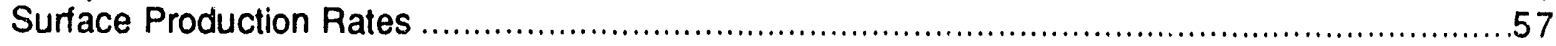

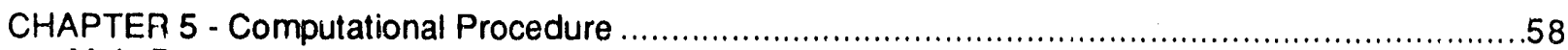

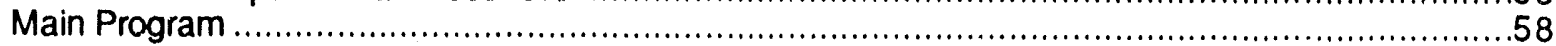

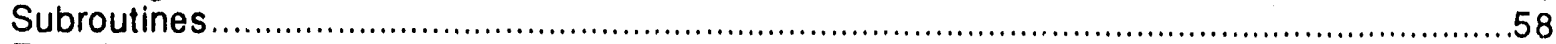

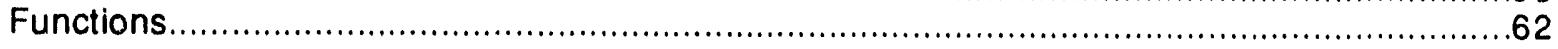

ILLUSTRATION

5.1 Schematic of logic in laboratory thermal numerical simulator ...........................................59

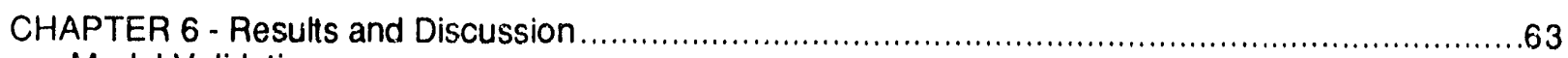

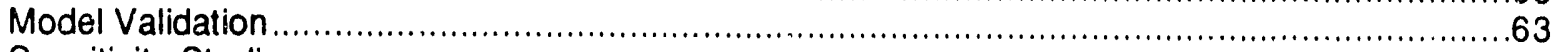

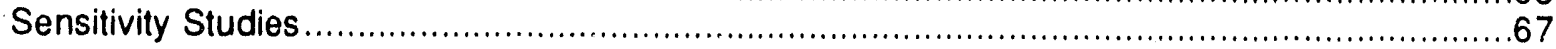




\section{TABLE OF CONTENTS - Continued}

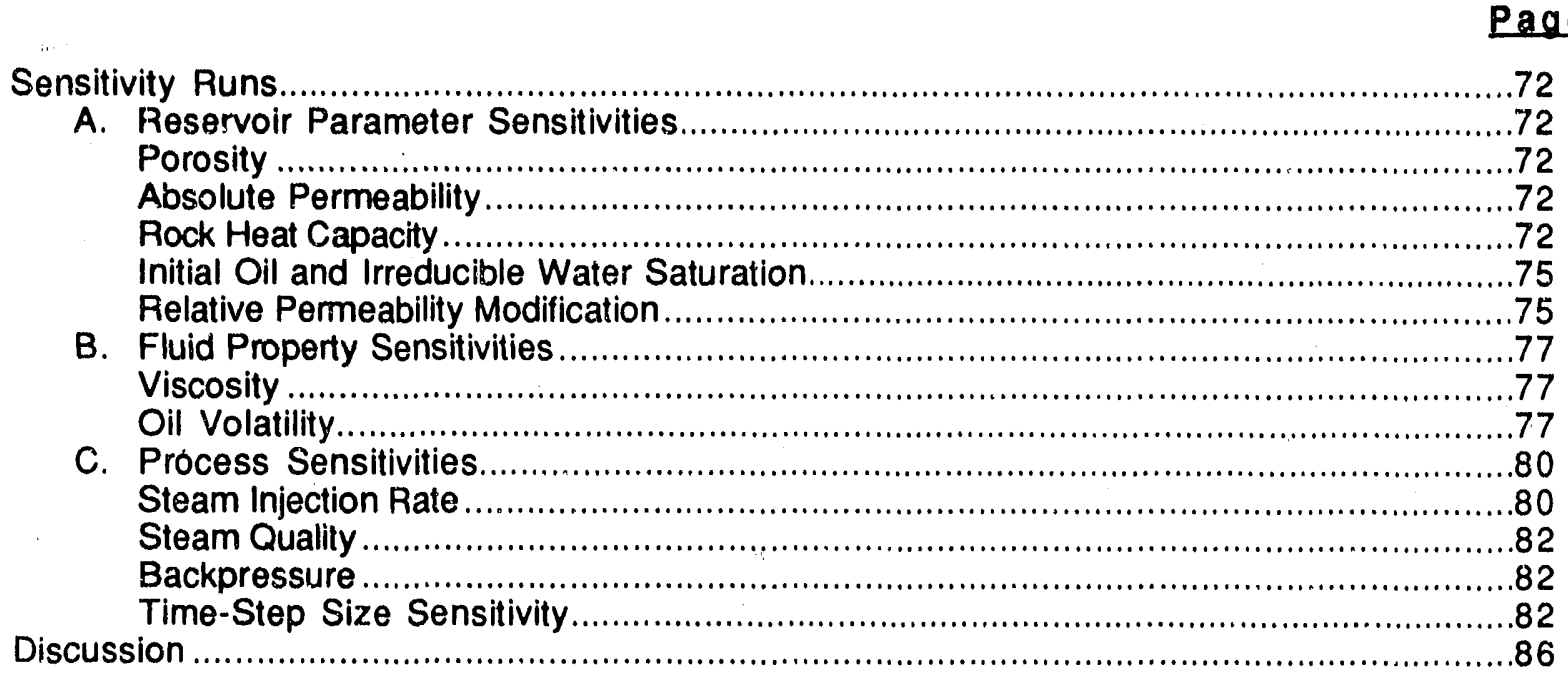

\section{ILLUSTRATIONS}

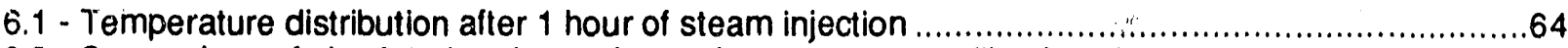

6.2 - Comparison of simulated and experimental temperature profiles for laboratory model after

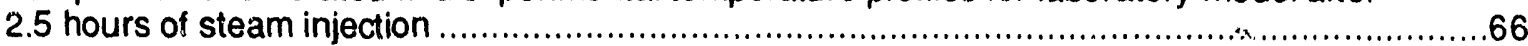

6.3 - Calculated and experimental oil recovery curves for laboratory experiments..............................66

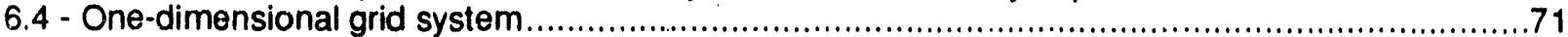

6.5 - Cumulative oil production histories — porosity sensitivity ............................................................ 74

6.6 - Cumulative oil production histories - absolute permeability sensitivity .................................74

6.7 - Cumulative oil production histories - rock heat capacity sensitivity .................................75

6.8 - Curnulative oil production histories - initial oil saturation sensitivity .........................................76

6.9 - Cumulative oil production - irreducible water saturation sensitivity ..........................................76

6.10 - Cumulative oil production histories - relative permeability sensitivity ................................78

6.11 - Cumulative oil production histories - oil viscosity sensitivity ..................................................79

6.12 - Cumulative oil production histories - oil volatility sensitivity ......................................................79

6.13 - Cumulative oil production histories - steam injection rate sensitivity ................................81

6.14 - Cumulative oil production histories — steam quality sensitivity ........................................83

6.15 - Cumulative oil production histories - backpressure sensitivity .............................................8 83

6.16 - Oil saturation profiles - time-step sensitivity runs .........................................................8. 84

6.17 - Water saturation profiles - time-step sensitivity runs .................................................... 84

6.18 - Absolute oil material balance errors - time-rtep sensitivity runs.............................................85

\section{TABLES}

6.1 - Data for Malcifeev's temperature distribution test.........................................................64

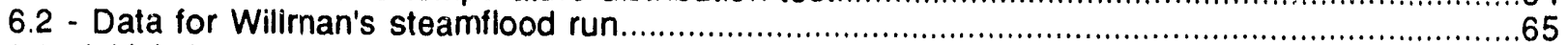

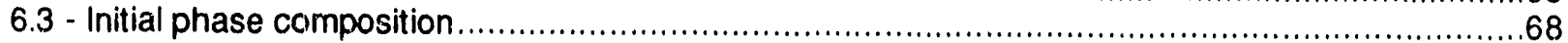

6.4 - Process and reservoir data (base case) ...................................................................................69

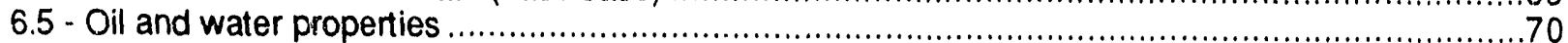

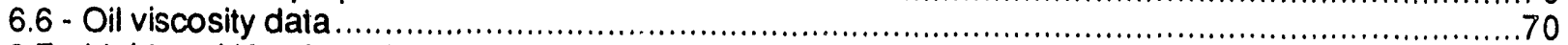

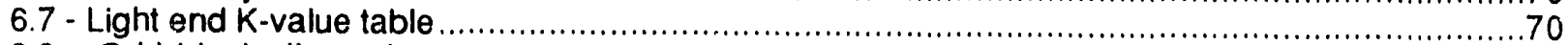

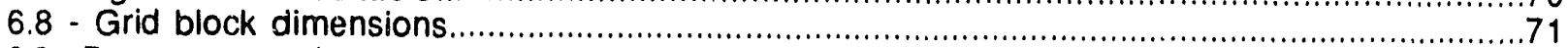

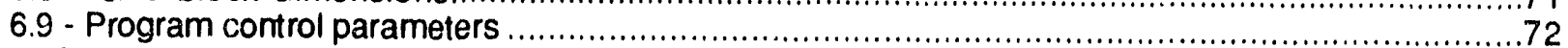

6.10 - Data for reservoir parameter sensitivity nuns ................................................................

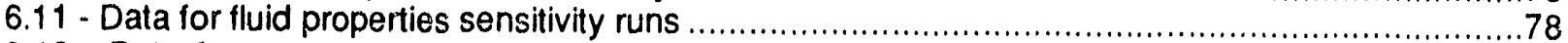

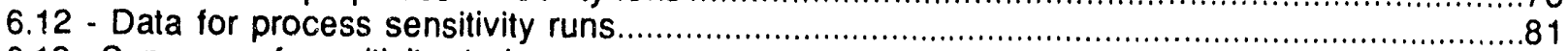

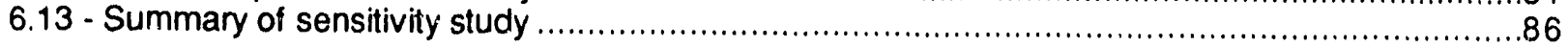




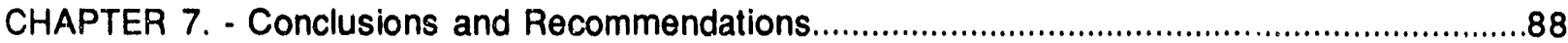

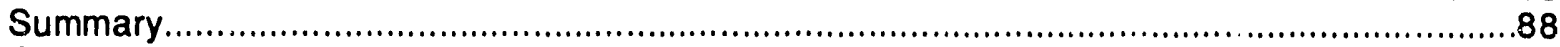

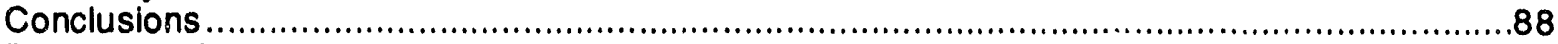

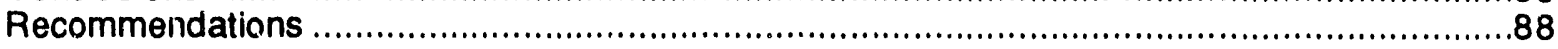

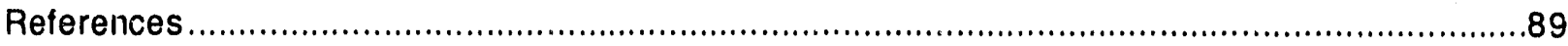

APPENDIX A - Derivation of Partial Differential Equations.......................................................94

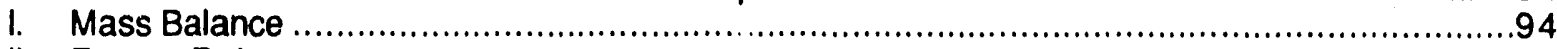

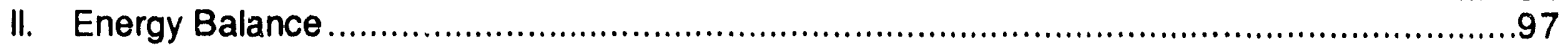

APPENDIX B - Finite Difference Form of the Model ..............................................................103

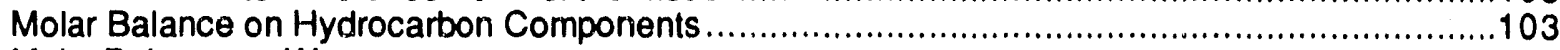

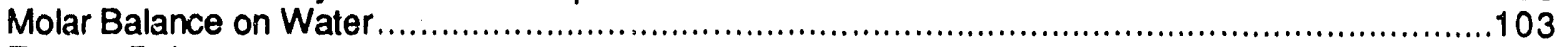

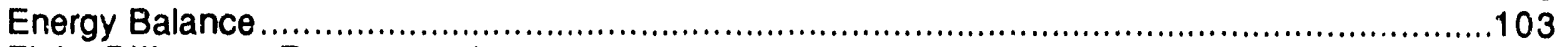

Finite Difference Representation .............................................................................104

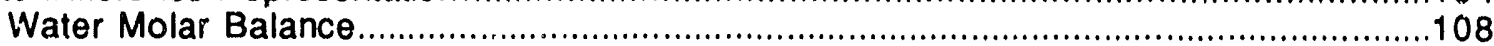

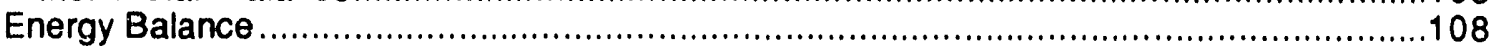

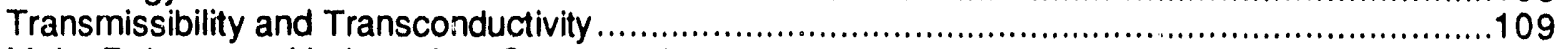

Molar Balance on Hydrocarbon Compounds ..............................................................111

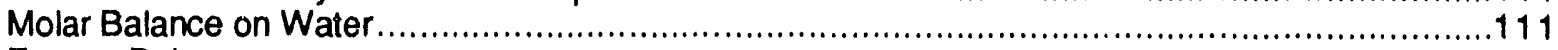

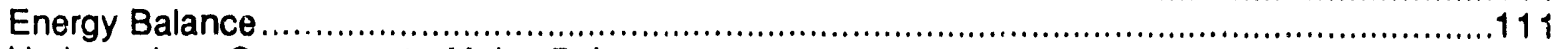

Hydrocarbon Components Molar Balance.....................................................................112

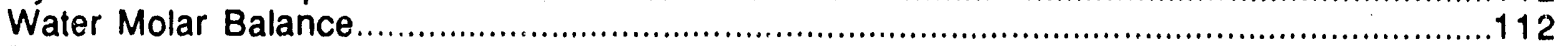

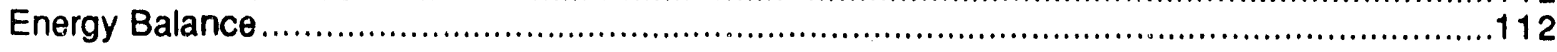

\section{ILLUSTRATIONS}

B.1 Diagramatic Representation of a Block Centered Grid System ........................................105

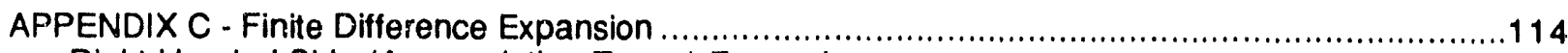

Right-Handed Side (Accumulation Terms) Expansion .....................................................114

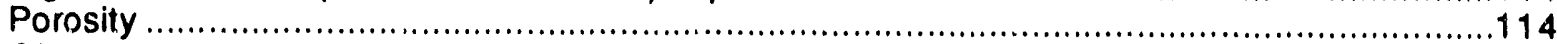

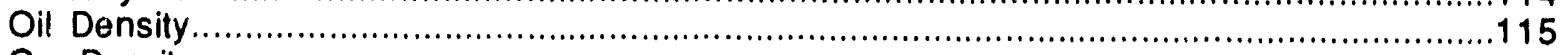

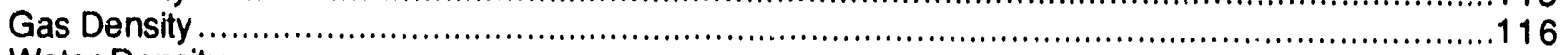

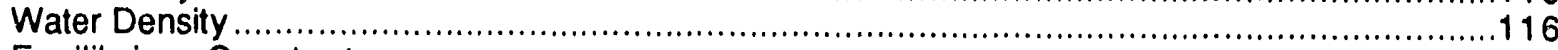

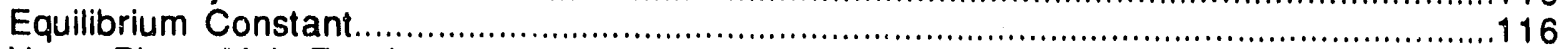

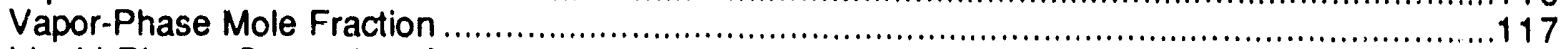

Liquid-Phase Saturation Constraint..........................................................................117

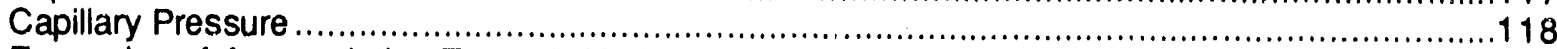

Expansion of Accumulation Terms in Hydrocarbon Molar Balance Equation.................................118

Expansion of Accumulation Terms in Water Balance Equation ......................................................121

Expansion of Accumulation Terms in Energy Balance Equation ..................................................123

Left-Hand (Flow Terms) Expansion ...................................................................................133

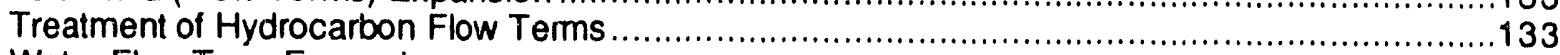

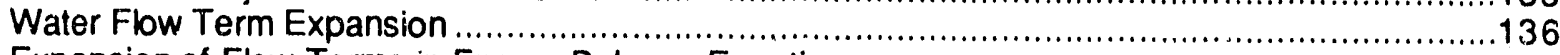

Expansion of Flow Terms in Energy Balance Equation .....................................................137

Implementation of Finite Difierence Expansion in the Present Model .........................................139 


\section{TABLE OF CONTENTS - Continued}

Page

Hydrocarbon Flow Terms.

139

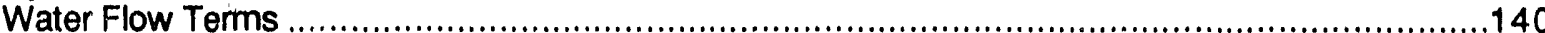

Flow Terms in the Energy Conservation Equation.............................................................. 140

APPENDIX D - Finite Difference Expansion of Flow Terms .................................................141

APPENDIX E - Derivation of the Pressure Equation.........................................................

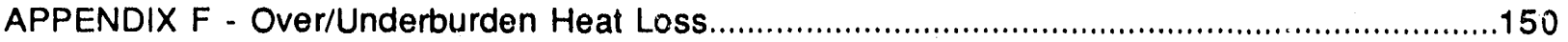




\title{
THERMAL NUMERICAL SIMULATOR FOR LABORATORY EVALUATION OF STEAMFLOOD OIL RECOVERY
}

\author{
By Partha Sarathi
}

\begin{abstract}
A thermal numerical simulator running on an IBM AT compatible personal computer is described. The simulator was designed to assist laboratory design and evaluation of steamflood oil recovery. An overview of the historical evolution of numerical thermal simulation, NIPER's approach to solving these problems with a desk top computer, the derivation of equations and a description of approaches used to solve these equations, and verification of the simulator using published data sets and sensitivity analysis are presented. This simulator was developed under DOE light and heavy crude oil research projects, $\mathrm{BE} 11 \mathrm{~A}$ and $\mathrm{BE11B}$, and development completes milestone 3 of BE11B in FY90.

The developed model is a three-phase, two-dimensional multicomponent simulator capable of being run in one or two dimensions. Mass transfer among the phases and components is dictated by pressure- and temperature-dependent vapor-liquid equilibria. Gravity and capillary pressure phenomena were included. Energy is transferred by conduction, convection, vaporization and condensation. The model employs a block centered grid system with a five-point discretization scheme. Both areal and vertical cross-sectional simulations are possible. A sequential solution technique is employed to solve the finite difference equations.

The model was validated by comparing the simulator results with published data. These initial comparisons showed that the model is capable of predicting qualitatively the performance trends of the published results. Sensitivity studies were conducted with respect to rock and fluid properties, process variables, and time-step size.

The study clearly indicated the importance of heat loss, injected steam quality, and injection rate to the process. Dependence of overall recovery on oil volatility and viscosity is emphasized. The process is very sensitive to relative permeability values. Time-step sensitivity runs indicated that the current version is time-step sensitive and exhibits conditional stability.

The model stability could be enhanced by employing a fully implicit formulation. However, memory requirements and the complexity of the simulator drastically increase with the use of a fully implicit formulation and direct solution technique. The system's memory constraints precluded the coding and testing of a fully implicit formulation on an IBM-AT type personal computer.
\end{abstract}




\section{ACKNOWLEDGMENTS}

This work was sponsored by the U.S. Department of Energy under cooperative agreement DEFC22-83FE60149 as task 2, project BE11B as stated in the work plan for FY90.

\section{NOMENCLATURE}

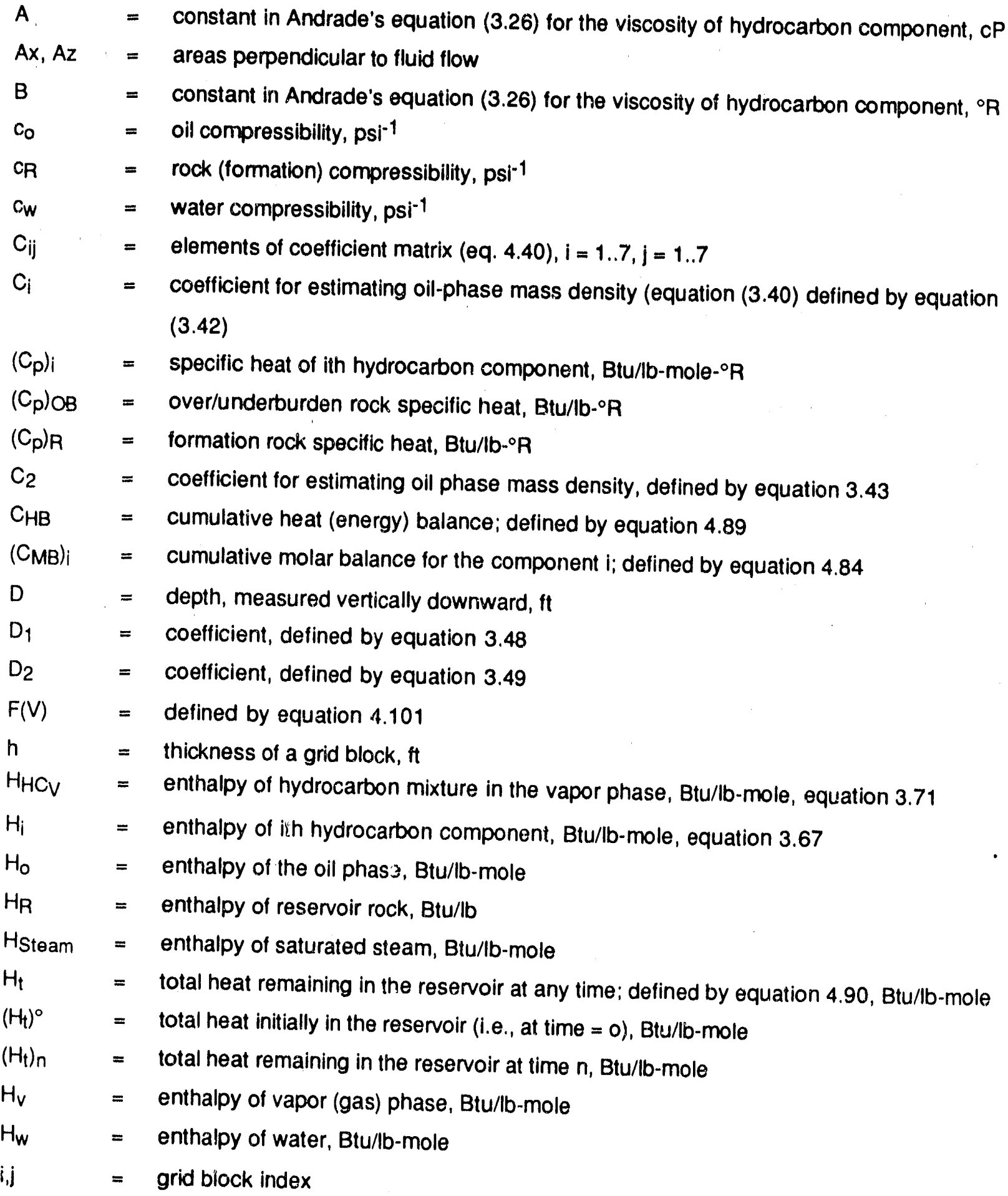




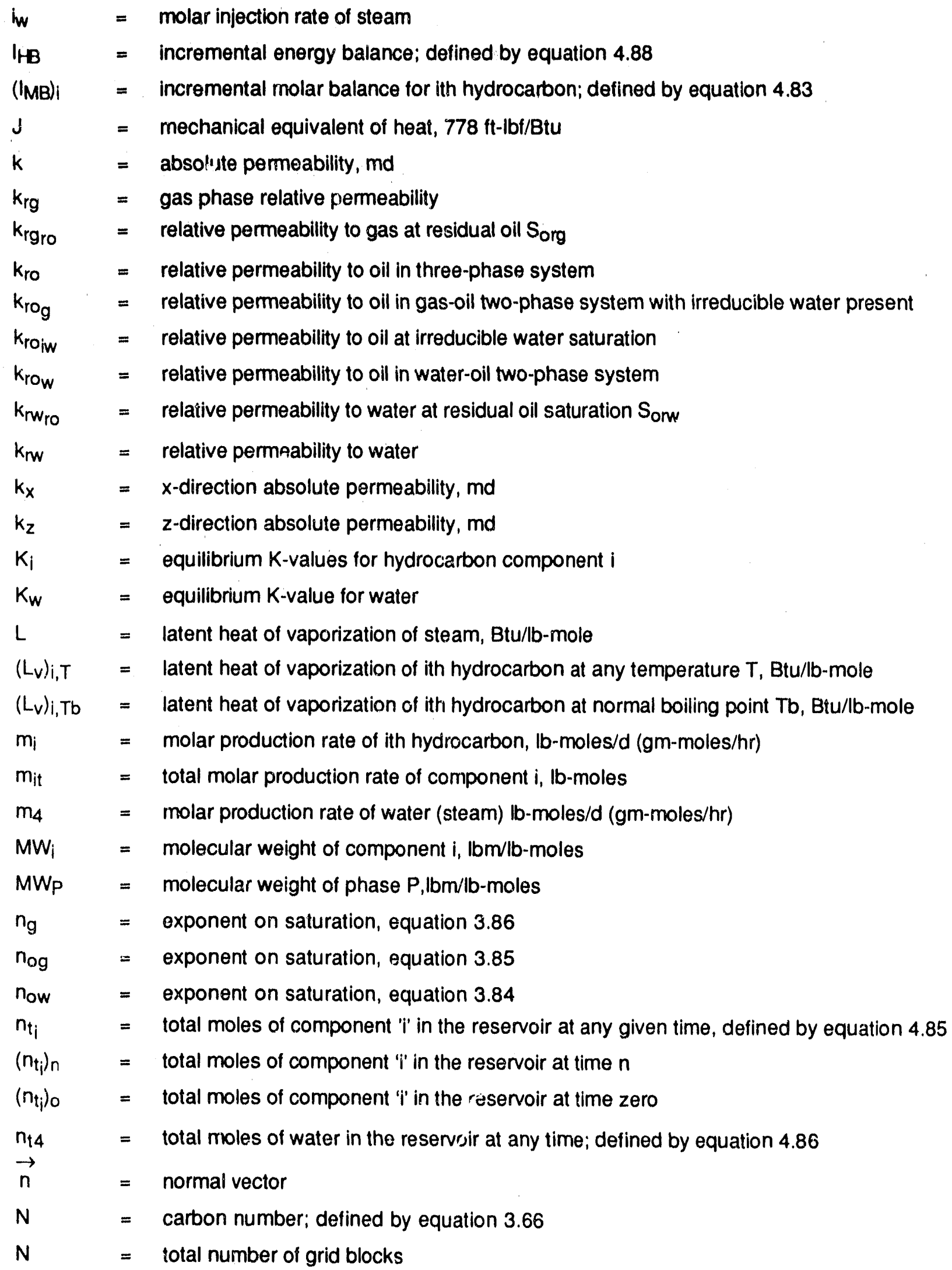




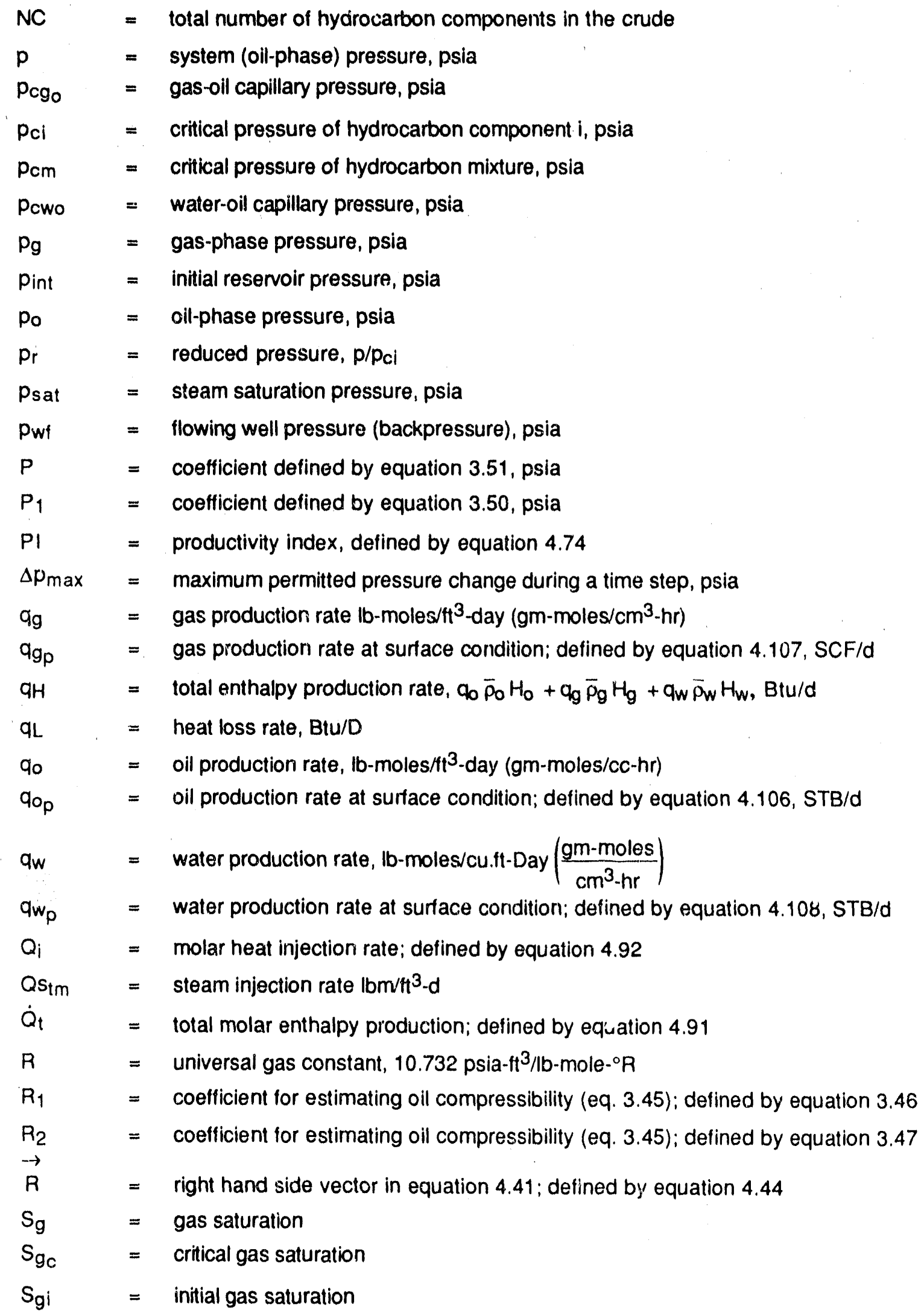




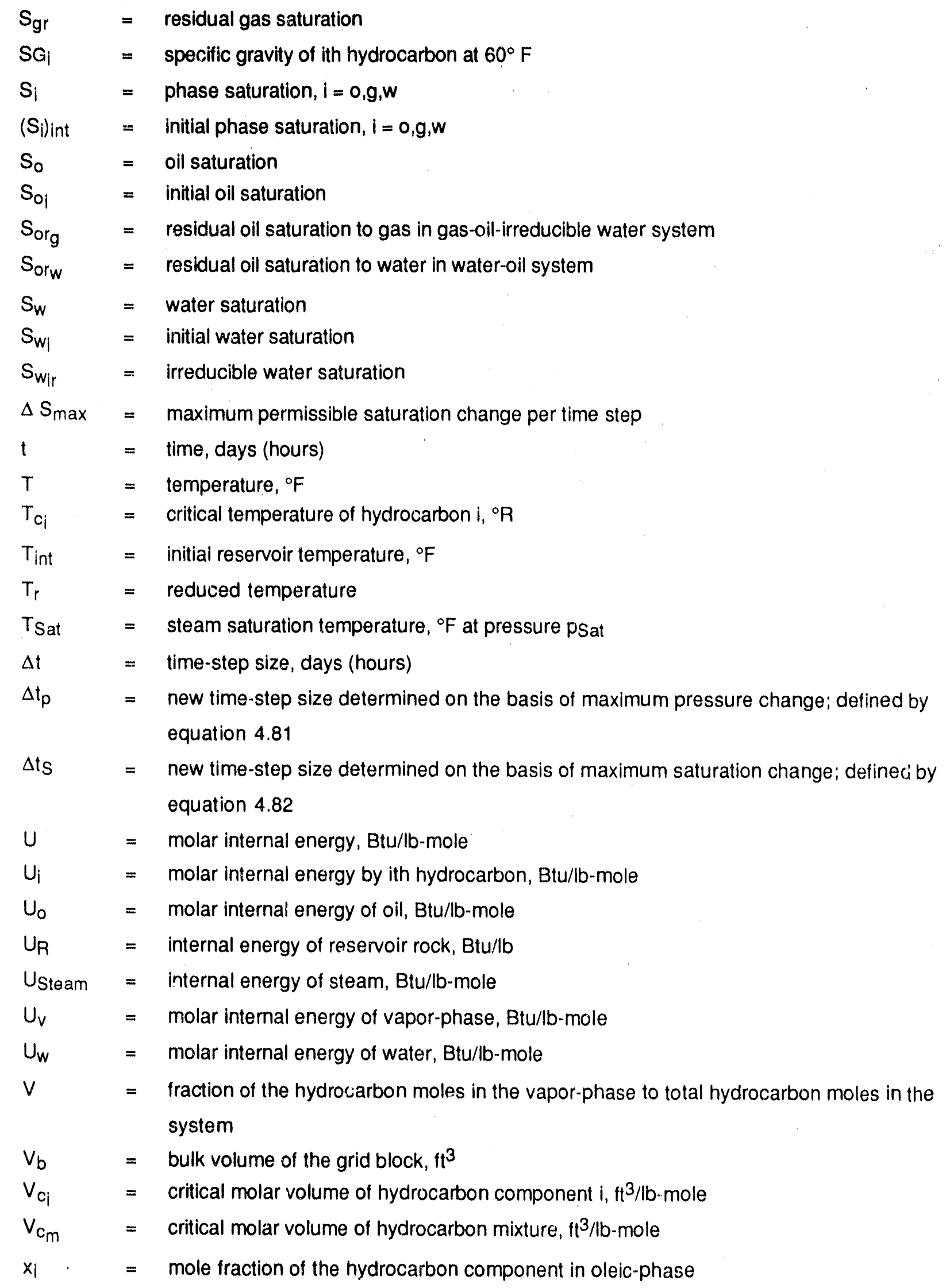




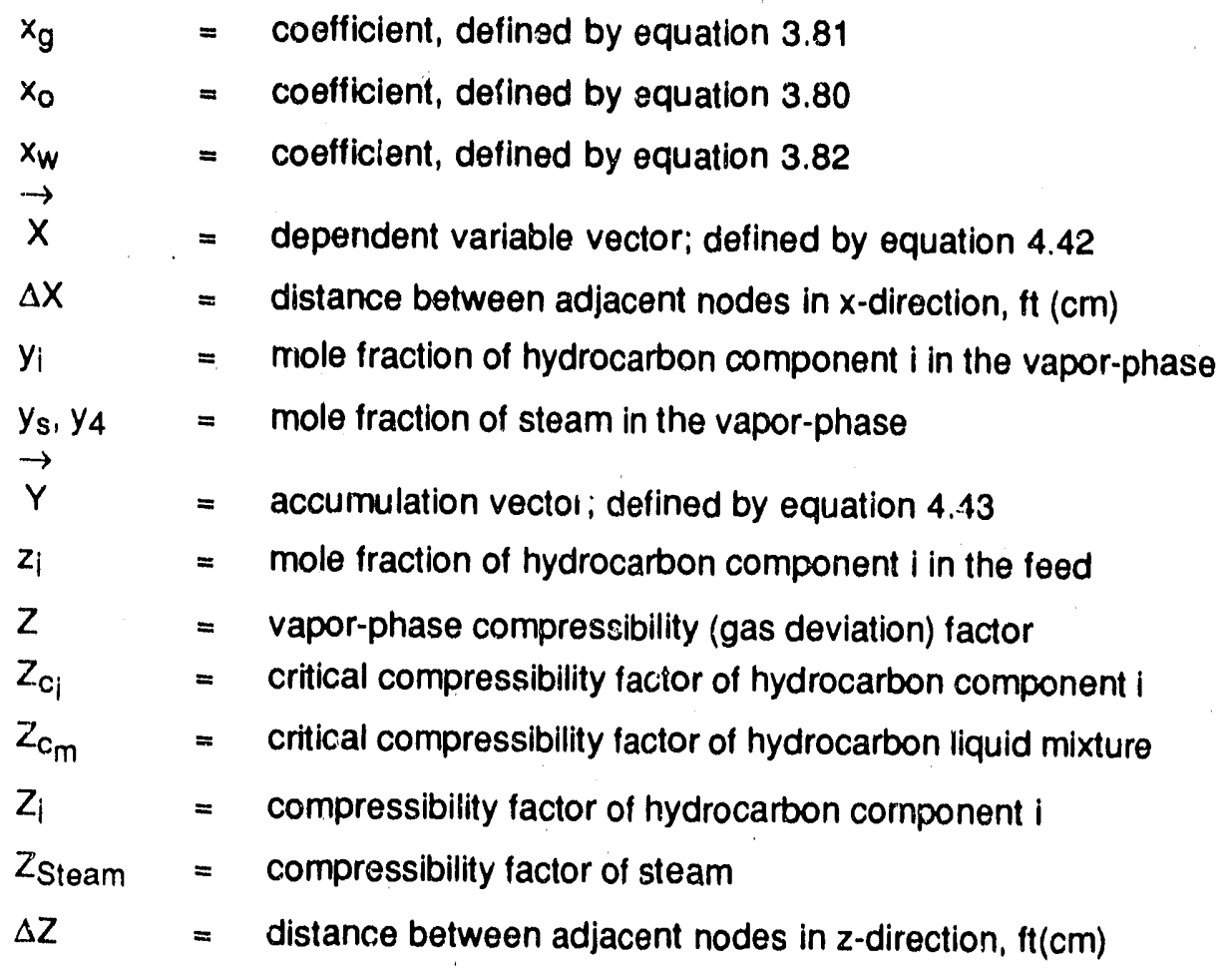

\section{Greek Symbols}

$=$ specific weight, psi/ft

$\delta=$ time difference operator, for example $\delta T=T^{n+1}-T^{n}$

$\Delta \quad=$ difference operator

$\rho=$ mass density, $\mathrm{Ib} / \mathrm{bt}^{3}$

$\left(\rho_{\mathrm{OB}}\right)=$ overburden rock density, $\mathrm{lbm} / \mathrm{ft}^{3}$

$\rho_{R}=$ reservoir formation density, $\mathrm{lbm} / \mathrm{tt}^{3}$

$\rho_{\text {Ref }}=$ reference density of oil at $60^{\circ} \mathrm{F} ; \mathrm{lbm} / \mathrm{t}^{3}$

$\bar{\rho}=$ molar density, $\mathrm{lb}-$ mole $/ \mathrm{ft}^{3}$

$\bar{\rho}_{\mathrm{cm}}=$ critical density of hydrocarbon mixture, lb-mole/ $\mathrm{tt}^{3}$

$\bar{\rho}_{\mathrm{g}} \quad=$ molar density of vapor-phase, $\mathrm{lb}-\mathrm{mole}_{\mathrm{e}} \mathrm{ft}^{3}$

$\bar{\rho}_{\mathrm{o}} \quad=$ molar density of oil-phase, lb-rnole $/ \mathrm{ft}^{3}$

$\bar{\rho}_{\mathrm{W}}=$ molar density of water-phase, $\mathrm{lb}-\mathrm{mole} / \mathrm{ft}^{3}$

$\bar{\rho}_{w s} \quad=$ molar density of steam, lb-mole $/ t^{3}$

$\mu_{\mathrm{g}} \quad=$ gas-phase viscosity, $\mathrm{CP}$

$\mu_{i} \quad=$ viscosity of hydrocarbon component $\mathrm{i}, \mathrm{cP}$

$\mu_{\mathrm{m}} \quad=$ viscosity of hydrocarbon mixture in gas-phase at high pressure, $\mathrm{CP}$; defined by equation 3.29

$\mu_{\mathrm{mi}}=$ viscosity of hydrocarbon mixture in gas-phase at one atmosphere pressure, $c P ;$ defined 
by equation 3.28

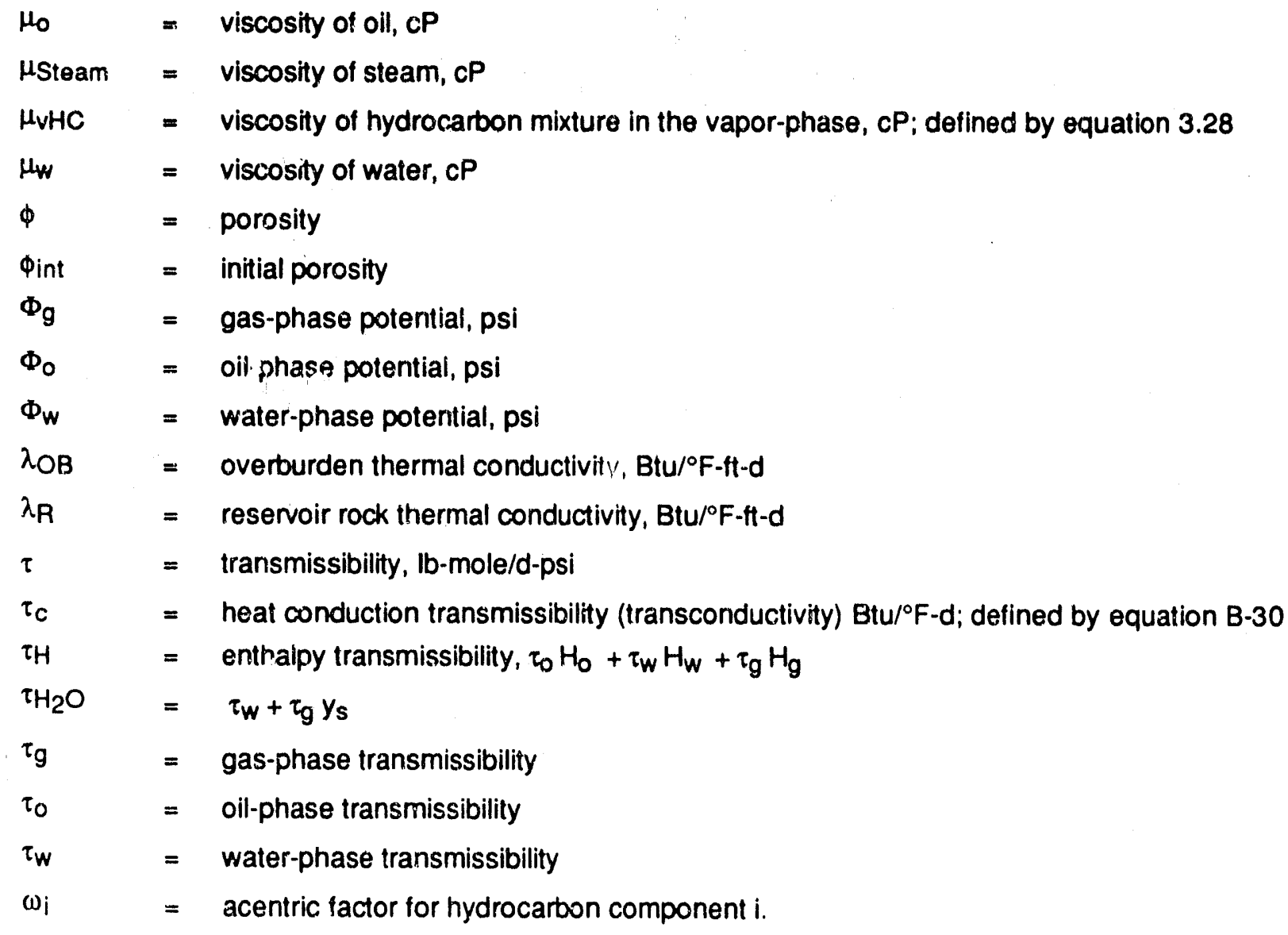

\section{Dlfference Operators}

$\Delta \cdot\left(\tau_{1} \Delta p_{0}\right)=\Delta_{x}\left(\tau_{1} \Delta_{x} \Delta p_{0}\right)+\Delta_{z}\left(\tau_{1} \Delta_{z} \Delta p_{0}\right)$

$\Delta_{x}\left(\tau_{1} \Delta_{x} \Delta p_{o}\right)=\left(\tau_{1}\right)_{i+1 / 2, j}\left(p_{o_{i+1, j}}-p_{o_{i, j}}\right)-\left(\tau_{1}\right)_{i-1 / 2, j}\left(p_{o_{i, j}}-p_{o_{i-1, j}}\right)$

\section{Mathematical_Symbols}

$\rightarrow$

$\nabla=$ divergence operator

$\partial \quad=$ partical differential operator

$\perp \quad=$ normal to

$\delta_{i j} \quad=$ Kronecker delta

$=1 \mathrm{i} i=\mathrm{j}$

$=\quad 0$ if $i \neq j$ 
Superscript

$$
\begin{array}{ll}
1 & =\text { iteration level } \\
n & =\text { old time level } \\
n+1 & =\text { new time level } \\
T & =\text { transpose } \\
- & =\text { identifying molar basis } \\
\rightarrow & =\text { identifying a vector }
\end{array}
$$

Subscripts

$$
\begin{array}{ll}
\mathrm{C} & =\text { conduction } \\
\mathrm{C} & =\text { critical } \\
\mathrm{g} & =\text { gaseous-phase } \\
\mathrm{gC} & =\text { critical gas } \\
\mathrm{H} & =\text { heat } \\
\mathrm{H}_{2} \mathrm{O} & =\text { water } \\
\mathrm{i} & =\text { hydrocarbon component number }\left(\mathrm{x}_{i}, \mathrm{y}_{i}, \mathrm{z}_{\mathrm{i}}\right) \\
\mathrm{L} & =\text { heat loss } \\
\mathrm{max} & =\text { maximum } \\
\mathrm{O} & =\text { oleic-phase } \\
\mathrm{OB} & =\text { overburden } \\
\text { Og } & =\text { oil-gas system } \\
\text { ow } & =\text { oil-water system } \\
\text { ref } & =\text { reference }
\end{array}
$$

8 


\section{CHAPTER 1. - INTRODUCTION}

Steamdrive, the most commonly used EOR process, has been used commercially for more than three decades to recover heavy oil from shallow resenvirs. However, heavy oil constitutes only about $10 \%$ of the total U.S. reserves, and it is suggested that steam can be used effectively to recover light oil under certain situations. Toward this end, NIPER initiated a light oil steamflood research project in 1984. The project deals with the identification of factors that have a direct bearing on the success of the process. Some of these factors are rock properties, crude oil composition, degree of steam override, sweep efficiency, steam quality, steam injection rate, and heat loss.

Models (both physical and nuınerical) are important tools in improving the conceptual understanding of one or more physical processes. In thermal processes, both numerical and physical models are used as complementary tools to obtain better insight into different mechanisms and evolve strategies which will economize and optimize the process.

This light oil steamflood project employs both physical and numerical models to help in understanding the complex steamflood process. Physical models are used for a variety of reasons: investigation of the displacement mechanisms and relative importance of process variables; impact of various physico-chemical effects and rock-fluid interactions at elevated temperature and pressure on the recovery; to study fluid-flow and heat transfer aspects; and to obtain data for calibration of numerical models.

Since physical models, like numerical models, are imperfect tools and are based on certain approximations and simplifications - they are built to meet certain limited objectives. F'unthermore, operation of physical models is both time-consuming and expensive. These constraints led to the need for developing mathematical schemes that simulate the light oil steamflood process. Numerical models are faster and cheaper to run than physical models and serve as an aid in understanding the nature of the process, in interpreting laboratory experiments, and improving the design of physical models. Furthermore, they have the experimental capability of discovery of phenomena. Executing computations under varied values of parameters may lead to discoveries usually unknown otherwise. Once calibrated, the numerical models can be used to study the impact of certain variables on the process which are too difficult or expensive to determine experimentally.

To supplement the findings of physical models and as an aid in engineering design, NIPER developed a numerical model. The primary objectives of this work were threefold: (a) to develop a predictive simulator that can rigorously model the complex phenomena that occurs during the steamflooding of the light oil bearing reservoirs; (b) to develop a model that can easily be modified by a researcher io better predict the performance of specific experiments; and $(c)$ to provide the private sector with a thermal simulator that can be used on a personal computer.

A number of reliable and sophisticated thermal simulators exist in the private sector. The purpose of the present model development is not to compete with commercial simulators but to provide a tool with 
which experimental objectives can be evaluated and can be used by independent operators as a preliminary engineering design tool.

The numerical and physical models will be used as complementary tools. The numerical model will be employed principally to interpret laboratory results and improve the design of experiments. The results of the physical model experiments will be used to calibrate the numerical model and to increase the confidence in the validity of simulator results. Once calibrated, the thermal simulator is expected to predict steamflood performance over a wide range of operating conditions and provide unlimited resources of experimentation and the ability to conduct parameter sensitivity tests which are not teasible in the laboratory. Such an endeavor is a prerequisite for adequate simulation of a steamflood process in a light oil reservoir.

The status of our attempt to develop a thermal numerical simulator is given. The developed model accounts for the three-phase flow of oil, water (condensed steam) and gas (steam and hydrocarbon vapors). The oleic-phase comprised of three components: light, intermediate and heavy ends. The mass transfer among the phases and components is dictated by pressure and temperature dependent vaporliquid equilibria.

Gravily and capillary pressure phenomena were included. Energy is transferred by conduction, convection, vaporization and condensation. The oil and water components were considered to be mutually insoluble. Table 1.1 illustrates the distribution of components in the three phases.

The model is two-dimensional, capable of being run in one or two dimensions. Both areal and vertical cross-sectional simulations are possible. Both regular and irregular grid block sizes may be modeled. The model employs a block centered grid system with a five-point discretization scheme. Automatic time-step control is featured. A sequential solution technique is employed to solve the finite difference equations. In this scheme, all of the primary variables were expressed in terms of pressure, and within an iteration, pressure is solved first and then the other variables in sequence. All of the variables were updated within each iteration. Table 1.2 lists the major features of the developed model. In tables 1.3 and 1.4, the salient features of the model are compared with those of published models.

The various aspects of the published steamflood models are reviewed and compared in chapter 2. The development of the mathematical model of the present steamflood simulator is presented in chapter 3. The procedures to calculate rock and fluid properties together with relevant discussions on the determination of phase distributions and compositions and estimation of heat loss to the surroundings are also presented in chapter 3 .

In chapter 4 , the finite difference representations and the sequential solution procedure employed in this simulator are presented. A discussion on time-step selection, heat and material balance calculations, and flash and saturation calculations are also presented in chapter 4.

A description of the computational procedures and a summary of the main features of the computer program which was developed during this investigation are presented in chapter 5 . 
TABLE 1.1 - Distribution of components in fluid phases

\begin{tabular}{lcccc|}
\hline & & & Phases \\
\cline { 3 - 4 } No. & Component & Aqueous & Oleic & Vapor \\
\cline { 3 - 5 } & Water & $\Gamma$ & - & $\Gamma$ \\
2. & Light oil & - & $\Gamma$ & $\Gamma$ \\
3. & - & $\Gamma$ & $\Gamma$ \\
4. & Heavy oil & - & $\Gamma$ & $\Gamma$ \\
\hline
\end{tabular}

TABLE 1.2 - Model features

\footnotetext{
... A two-dimensional semi-implicit finite difference simulator

... Describes the flow of three phases and four components (water and three hydrocarbon components)

... Gravity and capillary pressure phenomena are included

... Heat transfer in the porous medium is by conduction and convection

... Temperature dependent relative permeabilities

... Constant or variable porosity and permeability

... Interphase mass transfer is governed by pressure and temperature dependent equilibrium ratios

... Both regular and irregular grid block sizes can be specified

... Automatic time-step control feature

... Block centered grid system

... Sequential solution scheme

... Direct matrix solver

... Rock and fluid properties are functions of pressure, temperature and composition
} 
TABLE 1.3- Comparison of steamflood simulators - major features

\begin{tabular}{|c|c|c|c|c|c|c|c|c|}
\hline \multirow[t]{2}{*}{ Author } & \multirow[t]{2}{*}{ Dimensions } & \multirow[t]{2}{*}{ Phases } & \multicolumn{2}{|c|}{$\begin{array}{l}\text { Number of } \\
\text { components }\end{array}$} & \multirow[t]{2}{*}{$\begin{array}{c}\text { Steam } \\
\text { distillation }\end{array}$} & \multirow[t]{2}{*}{$\begin{array}{c}\text { Gravity } \\
\text { override }\end{array}$} & \multirow[t]{2}{*}{$\begin{array}{l}\text { Capillary } \\
\text { pressure }\end{array}$} & \multirow[t]{2}{*}{$\begin{array}{c}\text { Rock } \\
\text { compressibility }\end{array}$} \\
\hline & & & Oil & Gas & & & & \\
\hline Spillette $^{16}$ & 2 & 2 & 1 & 0 & no & yes & yes & yes \\
\hline Shutler ${ }^{17}$ & $* 1$ & 3 & 1 & 2 & no & yes & yes & no \\
\hline Shutler ${ }^{18}$ & 2 & 3 & 1 & 2 & no & yes & yes & no \\
\hline Vinsome $e^{20}$ & 3 & 3 & 1 & 2 & no & yes & yes & no \\
\hline Ferrer 25 & 2 & 3 & 3 & 4 & yes & yes & yes & yes \\
\hline Weinstein 22 & 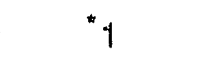 & 3 & 2 & 2 & no & no & no & yes \\
\hline Abdalla ${ }^{19}$ & 2 & 3 & 1 & 1 & no & no & yes & no \\
\hline Coats 21 & 3 & 3 & 1 & 1 & no & yes & yes & yes \\
\hline Coats 24 & 3. & 3 & 3 & 3 & yes & yes & yes & yes \\
\hline Coats 26 & 3 & 3 & 2 & 2 & yes & yes & yes & yes \\
\hline Lemonnier 73 & 3 & 3 & 1 & 1 & no & yes & yes & yes \\
\hline 1 to 74 & 1 & 3 & 1 & 1 & no & no & yes & no \\
\hline Grabowski75 & 3 & 3 & 3 & 5 & yes & yes & yes & yes \\
\hline Abu-Kassem 27 & 2 & 3 & 3 & 4 & yes & yes & yes & yes \\
\hline Rubin 28 & 1 & 3 & 2 & 4 & no & no & no & no \\
\hline Harding 30 & 2 & 3 & 2 & 5 & yes & yes & yes & yes \\
\hline "Ishimoto 31 & 1 & 3 & 3 & 3 & yes & yes & yes & yes \\
\hline "**Kasraie 33 & 3 & 3 & 3 & 3 & yes & yes & yes & yes \\
\hline Sarathi & 2 & 3 & 3 & 4 & yes & yes & yes & yes \\
\hline
\end{tabular}

- Two-dimensional heat conduction.

"* Equation of state based simulator. K-values are calculated using SRK EOS.

".. Other features include bottom water drive, thermal upgrading and non-Newtonian flow. Model permit both molecular and thermal diffusion. 
TABLE 1.4 - Comparison of steamflood simulators - treatment of rock and fluid properties

\begin{tabular}{|c|c|c|c|c|c|}
\hline Author & $\begin{array}{c}\text { Relative } \\
\text { permeability }\end{array}$ & $\begin{array}{l}\text { Oil } \\
\text { viscosity }\end{array}$ & $\begin{array}{c}\text { Gas } \\
\text { viscosity }\end{array}$ & $\begin{array}{c}\text { Oil } \\
\text { density }\end{array}$ & K-values \\
\hline Spillette & $\mathrm{Kr}(\mathrm{S})$ & $\mu_{0}(T)$ & $\mu_{g}(T, P)$ & $\rho_{o}(T)$ & NA \\
\hline Shutler & $\mathrm{Kr}(\mathrm{S})$ & $\mu_{0}(T, P)$ & $\mu_{\mathrm{g}}(T, P)$ & $\rho_{0}(T, P)$ & NA \\
\hline Shutler & $\mathrm{Kr}(\mathrm{S})$ & $\mu_{0}(T, P)$ & $\mu_{g}(T, P)$ & $\rho_{0}(T, P)$ & NA \\
\hline Vinsome & $\mathrm{Kr}(\mathrm{S})$ & $\mu_{0}(T)$ & $\mu_{g}(T)$ & $\rho_{o}(T, P)$ & NA \\
\hline Ferrer & $\mathrm{Kr}(\mathrm{S}, \mathrm{T})$ & $\mu_{0}(T)$ & $\mu_{g}(T)$ & $\rho_{0}(T, P)$ & $K(P, T)$ \\
\hline Weinstein & $\mathrm{Kr}(\mathrm{S})$ & $\mu_{0}(T, C)$ & $\mu_{g}(T)$ & $\rho_{o}(T, P, C)$ & NA \\
\hline Abdalla & $\mathrm{Kr}(\mathrm{S})$ & $\mu_{0}(T)$ & $\mu_{g}(T)$ & $\rho_{o}(\mathrm{~T})$ & NA \\
\hline Coats & $\operatorname{Kr}(\mathrm{S}, \mathrm{T})$ & $\mu_{0}(T)$ & $\mu_{g}(T)$ & $\rho_{\circ}(T, P)$ & NA \\
\hline Coats & $\mathrm{Kr}(\mathrm{S}, \mathrm{T})$ & $\mu_{0}(T, C)$ & $\mu_{g}(T, P, C)$ & $\rho_{o}(T, P, C)$ & $K(P, T)$ \\
\hline Coats & $\operatorname{Kr}(S, T)$ & $\mu_{0}(r, C)$ & $?$ & $\rho_{o}(T, P, C)$ & $K(P, T)$ \\
\hline Lemrnonier & $\mathrm{Kr}(\mathrm{S}, \mathrm{T})$ & $\mu_{0}(T)$ & $\mu_{g}(T)$ & $\rho_{o}(T, P)$ & NA \\
\hline Ito & $\operatorname{Kr}(S, T)$ & $\mu_{0}(T)$ & $\mu_{g}(T)$ & $\rho_{0}(T)$ & NA \\
\hline Grabowski & $\mathrm{Kr}(\mathrm{S}, \mathrm{T})$ & $\mu_{0}(T, P)$ & $\mu_{g}(T, P, C)$ & $\rho_{0}(T, P)$ & $K(P, T, C)$ \\
\hline Abu-Kassem & $\mathrm{Kr}(S, T)$ & $\mu_{0}(T)$ & $\mu_{g}(T, P)$ & $\rho_{0}(T)$ & $K(P, T)$ \\
\hline Rubin & $\mathrm{Kr}(\mathrm{S})$ & $\mu_{0}(T)$ & $\mu_{g}(T)$ & $\rho_{0}(t)$ & NA \\
\hline Harding & $\mathrm{Kr}(\mathrm{S}, \mathrm{T})$ & $\mu_{0}(T, C)$ & $\mu_{g}(T, P, C)$ & $\rho_{o}(T, P)$ & $K(P, T)$ \\
\hline Ishimoto & $\mathrm{Kr}(\mathrm{S}, \mathrm{T})$ & $\mu_{o}(T, C, P)$ & $\mu_{\mathrm{g}}(T, P, C)$ & $\rho_{0}(T, P, C)$ & $K(P, T, C)$ \\
\hline Kasraie & $\mathrm{Kr}(\mathrm{S}, \mathrm{T})$ & $\mu_{0}(T, P)$ & $\mu_{g}(T, P, C)$ & $\rho_{0}(T, P, C)$ & $K(P, T, C)$ \\
\hline Sarathi & $\mathrm{Kr}(\mathrm{S}, \mathrm{T})$ & $\mu_{0}(T, C)$ & $\mu_{g}(T, P, C)$ & $\rho_{0}(T, P, C)$ & $K(P, T)$ \\
\hline
\end{tabular}

Numerical results obtained by this simulator and discussion of these results are presented in chapter 6. Conclusions and recommendations are discussed in chapter 7. Derivations of the partial differential equations which describe mass and energy transport for ine system of interest in this work and their tinite difference representations are given in the appendices. 


\section{ChAPTER 2. - LITERATURE REVIEW}

Over the past two decades, numerical simulation has been developed into a strong predictive tool for the oil industry. The literature on the modeling aspects of a thermal process is rather extensive and a comprehensive review of the past work on the mathematical modeling of thermal processes is beyond the scope of this report. Instead, the evaluation of numerical modeling of the steam injection process is traced over the past three decades, and current and future problems are described. Only the most relevant papers are considered in this review.

Numerical modeling of the steamdrive process has been and is being studied in a number of different ways and can be divided into two broad categories:

(a) mathematical or analytical modeling, and

(b) numerical simulators.

\section{Mathematlcal Studles}

The steam displacement process is very complex. To completely describe the process, exact solutions to the several coupled nonlinear partial differential equations that describe the mass and heat transfer taking place must be determined. Such differential equations are too complex and impossible to solve analytically. However, several investigators have obtained semianalytical solutions after making a number of simplifying assumptions.

Lauwerier ${ }^{1}$ did the pioneer work in the area of hot fluid injection into porous media. His simplified analytical heat transport model was published in 1955. Using the assumptions that thermal conductivities are negiigible in the direction of flow and infinite over the longitudinal cross section of a reservoir, he derived the equations for temperature distributions in a reservoir and adjacent formation. His process involves the flowing of hot noncondensible fluid in a reservoir.

Rubinshtein ${ }^{2}$ extended Lauwerier's work by relaxing some of Lauwerier's assumptions. Marx and Langenheim, ${ }^{3}$ in 1959, using a different approach from Lauwerier, arrived at the same thermal efficiency description as Lauwerier. Their model is a lumped parameter model which is a heat-balance on the rate of heat injection, the rate of heat loss, and the rate of heat stored in the reservoir. The principal assumptions made by Marx and Langenheim are:

(1) local equilibrium of temperatures between fluids and solids;

(2) no vertical temperature variation within a reservoir;

(3) ternperature distribution within a reservoir is a step function;

(4) no heat conduction along the flow direction; and

(5) constant thermal conductivity for overburden and underburden.

Although Marx and Langenheim assumed radial flow and constant injection rate, Ramey 4 showed that these assumptions can easily be removed, and the Marx and Langenheim model should be valid for any two-dimensional flow geometry. Since Marx and Langenheim assumed that the heated region would 
remain constant at elevated temperature, this model is better suited for the steam injection process than the hot water injection process. The Marx and Langenheim model is good for calculating the heated volume and the sam swept zone with high injection rates.

Ramey ${ }^{5}$ pointed out that, for constant heat injection rate, the fraction of the injected heat lost to the adjacent formation given by the Marx and Langenheim model is the same as that given by the Lauwerier's ${ }^{1}$ hot water injection model and greater than that predicted by the Rubinshtein ${ }^{2}$ model. Rubinshtein considered the vertical temperature variation within a reservoir, whereas Marx and Langenheim and Lauwerier did not.

Willman and coworkers ${ }^{6}$ in 1961 proposed an analytical model to estimate steam swept volume for a radial system. Their model is similar to the Marx and Langenheim model and uses the Buckley-Laverett ${ }^{7}$ equation to estimate oil production from a hot water zone ahead of a steam zone. Hearn 8 in 1969 investigated the effect of latent heat injection on the steam swept volume. He argued that since at initial time the vertical heat loss is less than the latent heat injection rate, the Marx and Langenheim model is adequate to calculate the steam swept area. At later times, however, the total rate of vertical heat loss will become greater than the latent heat injection rate, and all of the injected latent heat is used to supply the vertical heat loss. Hence, the steam swept volume calculated by the Marx and Langenheim model is incorrect, and this volume should be considered to be the upper bound for the true swept volume.

Mandl and Volek ${ }^{9}$ in 1969 attempted to separate the steam-swept volume from the total heated volume by extending the Marx and Langenheim model. They considered the steam-swept volume calculated using the Marx and Langenheim model as the upper bound, and using the latent heat injection rate, they derived an expression to calculate the lower bound for steam-swept volume. In the development of their theory, they introduced the term "critical time," which they defined as the time after which condensation of steam occurs and the heat transfer from the steam zone to liquid zone becomes significant, i.e., heat flow changes from a largely conductive one to convective one. When the time is less than the critical time, the steam-swept volume is the same as that given by the Marx and Langenheim model. Since above the critical time the Marx and Langenheim model is inadequate for estimating steamswept volume, they developed an approximate solution to better describe steam zone growth.

In 1972, Shutler and Boberg ${ }^{10}$ developed a graphical method for calculating oil recovery by steamflooding while predicting the fluid saturation profiles and oil bank formation. The predicted values, however, were conservative and did not match experimental results.

In 1978, Myhill and Stegemeier ${ }^{11}$ proposed an approximate solution for steam zone heat efficiency. This solution was obtained by modifying the Mandl and Volek model. They employed a weighting factor for averaging the upper and lower bounds of the steam swept volume. This weighting factor was arbitrarily determined but gave reasonable values for steam zone thermal efficiencies at qualities greater than 0.3 .

In 1982, Yortsos and Gavalas ${ }^{12}$ presented an analytical model for calculating steam swept volume. This model was derived based on Marx and Langenheim and Mandl and Volek models. Before the critical 
time, the steam swept volume was calculated using the Marx and Langenheim equations. After the critical time, the rate of steam zone development was estimated using the proposed equations.

All of the models previously cited examine steamdrive performance largely from a heat flow approach and do not account for gravity override.

In 1983, Van Lookeren, ${ }^{13}$ using the segregated flow theory analyzed the degree of gravity override in linear and radial systems. He expressed vertical sweep efficiency in terms of gravity number. This gravity number was derived by assuming that the mass rate of flowing steam at certain vertical distance from a front is proportional to the steam swept volume. He claimed that his model checked favorably with scaled laboratory experiments.

\section{Numerical_simulators}

The immense complexity of the steamdrive process precluded the development of complete and exact analytical models; hence, numerical models were developed which utilize numerical techniques to solve the nonlinear partial differential equations that describe the process.

Several numerical steam injection process models have appeared in the literature during the past two decades and have continued to appear periodically. Farouq All and Ferrer ${ }^{14}$ have reviewed the current state of steam simulators and have identified the areas where research is needed. Aziz ${ }^{15}$ detailed the modeling requirements of the thermal oil recovery process. The following survey is designed to highlight the salient features of different steam injection simulators in chronological order. Table 2-1 gives a summary of several steamflood numerical simulators spanning the period 1969-1988.

The first numerical thermal fluid displacement simulator was presented by Spillette and Nielsen in 1968. ${ }^{16}$ They presented a two-dimensional cross-sectional model for hot waterflooding. Their model includes the effects of gravity and capillarity and neglects the presence of a gas phase. The mass balance and energy balance equations are solved separately. The solution scheme employed is highly unstable.

Shutler ${ }^{17-18}$ developed three-phase, one-and two-dimensional models of steam injection in 1969. The three-phase (oil, water, and gas) mass balance equations are solved simultaneously using the Newton-Raphson iteration scheme. The energy balance equation is solved separately using the alternating direction implicit procedure (ADIP). Mass transfer from the gas phase to the water phase is permitted to simulate condensation. His model does not permit the dissolution of gas in oil, and oil is assumed to be nonvolatile. The model also accounts for one-dimensional heat convection and twodimensional conduction in the oil sand and adjacent strata. 
TABLE 2.1. - Main features of existing thermal simulators

\begin{tabular}{|c|c|c|}
\hline Model & Features & Solution technique \\
\hline Shutler ${ }^{17}$ & $\begin{array}{l}\text { One-dimensional, three- } \\
\text { phase; accounts for } \\
\text { fluid flow, heat transfer, } \\
\text { three-phase relative } \\
\text { permeability, and } \\
\text { capillary pressure. }\end{array}$ & $\begin{array}{l}\text { Three-step solution } \\
\text { fechnique. Newtonian } \\
\text { iteration employed } \\
\text { for steam condensa- } \\
\text { tion term. }\end{array}$ \\
\hline Shutler 18 & $\begin{array}{l}\text { Three-phase, two-dimen- } \\
\text { sional steamflood model. } \\
\text { Considers effect of } \\
\text { gravity, reservoir } \\
\text { heterogeneity, and } \\
\text { nonuniform initial fluid } \\
\text { phase distribution. }\end{array}$ & $\begin{array}{l}\text { Three-stage solution } \\
\text { technique in each } \\
\text { time step to obtain } \\
\text { pressure and saturation, } \\
\text { then temperature and } \\
\text { finally gas composition. }\end{array}$ \\
\hline $\begin{array}{l}\text { Abdalla and } \\
\text { Coats } \\
\end{array}$ & $\begin{array}{l}\text { Three-phase steamflood. } \\
\text { Black (dead) oll. }\end{array}$ & $\begin{array}{l}\text { Explicit solution; } \\
\text { unstable for most } \\
\text { situations. }\end{array}$ \\
\hline Coats et al.21 & $\begin{array}{l}\text { Three-dimensional, three- } \\
\text { phase steam injection model. }\end{array}$ & $\begin{array}{l}\text { Simultaneous solution } \\
\text { of the mass and energy } \\
\text { balance equations. } \\
\text { Neglect steam } \\
\text { distillation effect. } \\
\text { No solution gas. } \\
\text { Accounts for gravity } \\
\text { override. }\end{array}$ \\
\hline Patel et al. ${ }^{37}$ & $\begin{array}{l}\text { One-dimensional radial steam } \\
\text { injection model. }\end{array}$ & $\begin{array}{l}\text { Fully implicit solution } \\
\text { of the pressure equation. } \\
\text { Very stable. }\end{array}$ \\
\hline $\begin{array}{l}\text { Ferrer and } \\
\text { Farouq Ali25 }\end{array}$ & $\begin{array}{l}\text { Two-dimensional, three-phase } \\
\text { multicomponent thermal, } \\
\text { compositional steam } \\
\text { injection model. }\end{array}$ & $\begin{array}{l}\text { The mass, heat, and } \\
\text { compositional } \\
\text { constraint equations } \\
\text { are solved sequentially. } \\
\text { Direct Solution technique. } \\
\text { Implicit pressure and } \\
\text { explicit production rate. } \\
\text { Slow to converge ard } \\
\text { conditionally stable. }\end{array}$ \\
\hline Weinstein et al. 22 & $\begin{array}{l}\text { One-dimensional, three-phase } \\
\text { steam simulation model. }\end{array}$ & $\begin{array}{l}\text { Semi-implicit formulation. } \\
\text { Sequential solution } \\
\text { technique. Marginally stable. }\end{array}$ \\
\hline Coats 26 & $\begin{array}{l}\text { Three-dimensional steamflooding } \\
\text { with distillation or solution gas. }\end{array}$ & $\begin{array}{l}\text { Three-dimensional, highly } \\
\text { implicit. Direct solution. } \\
\text { Highly stable. }\end{array}$ \\
\hline
\end{tabular}


TABLE 2.1. - Main features of existing thermal simulators - Continued

\begin{tabular}{|c|c|c|}
\hline Model & Feaiures & Solution technique \\
\hline Crookston et al. ${ }^{38}$ & $\begin{array}{l}\text { One-dimensional thermal } \\
\text { simulator, basically for fire } \\
\text { flooding. }\end{array}$ & $\begin{array}{l}\text { Semi-implicit; direct } \\
\text { solution technique. } \\
\text { Reasonably stable. }\end{array}$ \\
\hline Abou-Kassem 27 & $\begin{array}{l}\text { Two-dimensional, three-phase } \\
\text { compositional steam injection } \\
\text { model. Nine-point difference } \\
\text { scheme used to minimize grid } \\
\text { orientation effect. }\end{array}$ & $\begin{array}{l}\text { Fully implicit treatment } \\
\text { of all terms. Newtonian } \\
\text { formulation and Gaussian } \\
\text { elimination. Highly stable } \\
\text { but required excessive } \\
\text { computation and too slow. }\end{array}$ \\
\hline Coats 39 & $\begin{array}{l}\text { Three-dimensional, multiphase } \\
\text { thermal model. Can simulate } \\
\text { stearn and fireflood. }\end{array}$ & $\begin{array}{l}\text { Fully implicit direct solution } \\
\text { technique. Very stable. }\end{array}$ \\
\hline Ishimoto 31 & $\begin{array}{l}\text { One-dimensional, three-phase } \\
\text { equation of state compositional } \\
\text { steamflood model. }\end{array}$ & $\begin{array}{l}\text { Fully implicit direct solution } \\
\text { technique. Very slow. }\end{array}$ \\
\hline Harding 30 & $\begin{array}{l}\text { Two-dimensional steamflood } \\
\text { model that includes nitrogen and } \\
\text { carbon dioxide as steam additive. } \\
\text { Primarily to simulate laboratory } \\
\text { experiments. }\end{array}$ & $\begin{array}{l}\text { Highly implicit, direct } \\
\text { solution method. }\end{array}$ \\
\hline
\end{tabular}

Abdalla and Coats ${ }^{19}$ presented a two-dimensional, three-phase steamflood model in 1971. The gas phase assumed to consist only of steam when present. In this model, the implicit-pressure, explicitsaturation (IMPES) solution scheme was employed. Because of the approximate treatment of nonlinearities, the model was relatively unstable.

Vinsome 20 in 1974 presented a hot waterflooding/steam injection model which employed RungeKutta methods to stabilize the IMPES solution scheme. All physical properties of the fluids were expressed as analytical functions in order to help control the size of the program. Although the stabilized IMPES solution scheme is simpler than the fully implicit formulation, the method was computationally Inefficient and accuracy degraded over large time steps.

Coats and coworkers 21 in 1974 presented a three-phase (oll, water, and steam), three-dimensional numerical model for steam injection process. The mass and energy balance equations were solved simultaneously, eliminating the need to iterate on mass transfer terms. The model did not include temperature-dependent relative permeabilities or steam distillation effects but did include gravity and capillarity. 
Weinstein et al. ${ }^{22}$ in 1977 described a model that simulated two-dimensional heat transfer and onedimensional, three-phase fluid flow in multilayered reservoirs. The model accounts for steam condensation; however, it excludes gravity and capillary effects and does not consider temperature dependence of relative permeability. The model includes a two-dimensional heat transfer scheme to account for the overburden/underburden heat losses. The solution gas and distillation effects are accounted for using an explicit mass transfer rate between the oll and vapor. The sequential solution scheme of Spillette et al. ${ }^{23}$ is used for solving the equations. Recent work has shown that such solution procedures are less stable than a fully implicit scheme and may lead to convergence difficulties for a reasonably large time step.

As an improvement to his earlier model, Coats 24 presented a three-dimensional steam injection model in 1976. This model accounts for steam distillation, solution gas and temperature dependent relative permeability and uses a more implicit treatment of capillary pressures and transmissibilities. A onedimensional heat conduction model is utilized to account for the heat loss to the surrounding formations. The sequential solution method is basically used in this model.

In 1977, Ferrer and Farouq Ali25 described a two-dimensional compositional model for steam injection similar to that of Coats. ${ }^{24}$ Three hydrocarbon components and water are included in the formulation. The mass, heat, and compositional constraint equations are solved sequentially using a direct solution technique. The model is slow to converge and conditionally stable.

A highly implicit, three-phase, three-dimensional steamdrive model was presented by Coats 26 in 1978. The oil is treated as a two-component mixture to accommodate problems involving solution or inert gas or distillation. He employed a direct solution technique to solve the system of equations simultaneously. A variable substitution technique is incorporated into the simultaneous solution logic to maximize stability.

In 1981, Abou-Kassem ${ }^{27}$ presented a two-dimensional, three-phase fully implicit compositional steam injection model. A nine-point difference scheme is used instead of the conventional five-point difference scheme to minimize grid orientation effects. A sequential implicit scheme is used as the solution method. The use of nine-point scheme increases the computational work tremendously. Further, since a nine-point scheme becomes a 27-point scheme in three-dimensions, the amount of computation needed to obtain the solution tends to be astronomical.

Rubin and Buchanan ${ }^{28}$ described a general purpose three-dimensional, four-phase (oil, water, gas, and solid fuel) thermal simulator in 1983 for simulating hot water injection, steam injection, dry combustion, and wet combustion. The model accounts for fluid flow, heat transfer (convective and conductive), heat loss to adjacent strata, fluid vaporization/condensation and chemical reactions, and places no restriction on the number of oil, gas, or solid phase components that can be specified. The simulator employs an incomplete factorization method to solve the often ill-conditioned coefficient matrix. All the constrained 
equations are solved simultaneously. A fully implicit well model is coupled to the simulator, and reservoir conservation equations and well flow equations are solved together fully implicitly.

Also in 1983, Potempa29 presented a three-phase, three-dimensional noncompositional steamflood simulator that uses a numerical scheme which is an admixture of finite difference and finite element methods. Fluid properties are determined as a function of primary variables (pressure, temperature, and saturation), and mass mobilities are used to define fractional flow of phases.

Harding ${ }^{30}$ in 1986, described a highly implicit two-dimensional, three-phase compositional simulator designed to aid in the interpretation of one-dimensional laboratory steamflood experiments. Special features incorporated into the numerical model include provision for estimating heat losses from cylindrical cores, flanges, insulation, and conservation equations for steam. additives such as carbon dioxide and nitrogen. A direct solution method is used to solve simultaneously the mass and heat conservation equations.

Ishimoto et al. ${ }^{31}$ in 1986 presented a one-dimensional, fully implicit thermal compositional simulator for steam and hot water injection. This was the first model that employed an equation-of-state approach to tackle phase-behavior problerns. The advantages of this approach are that thermodynamic consistency is ssured in the estimation of phase fluid properties. Unlike other published simulators, they employed mass fraction constraints (instead of mole fraction constraints) in the conservation equations. The advantage of this approach is that it reduces the number of unknowns in each grid block. For example, for a three-component hydrocarbon system, the number of primary variables decreases from seven $\left(P, T, S_{W}\right.$, $\left.S_{g}, x_{1}, x_{2}, x_{3}\right)$ for a conventional formulation to five $\left(P, T, w_{1}, w_{2}\right.$ and $\left.w_{3}\right)$ for the mass fraction approach. The saturations are estimated from a knowledge of density and weight fractions. They also employ a variable substitution method to allow for different sets of unknowns, depending on the phase behavior. The major disadvantage of this model is that it is extremely slow and computationally expensive due to rigorous phase-behavior computation at each Newtonian iteration.

In 1987, Dogru et al. ${ }^{32}$ described a three-phase, three-dimensional noncompositional thermal simulator designed to handle large-scale field thermal projects. Kinetics and phase behavior relations were not modeled. A nine-point, finite-difference scheme is employed to reduce grid orientation effects. A preconditioned conjugate gradient solution technique is used for the fully coupled conservative equations.

Also in 1987, Kasraie 33 presented a three-phase, two-diniensional, multicomponent simulator capable of simulating steam injection phenomena in bottom water drive type reservoirs. Special features incorporated into the mathematical formulation included thermal upgrading, non-Newtonian flow, and foam flow. A fully implicit formulation was employed, and the resulting finite difference equations were solved using a block band matrix solver algorithm.

In 1988, Zhai et al. ${ }^{34}$ described a noncompositional (dead oil) thermal simulator capable of running on a personal computer. The model was designed to simulate hot water and steam injection processes in 
either Cartesian or radial geometry. A direct solution method (D4 Gaussian elimination) was used to solve the coefficient matrix. To improve the stability and accelerate convergence, they used an adaptive correction iterative scheme. Details of the algorithm were not discussed.

\section{Discussion}

Despite over two decades of experience and improvements in the development of thermal recovery simulators, numerical simulation of thermal recovery methods, (steam injection and in situ combustion) is still in a state of flux and more improvement is needed. Farouq Ali and Ferrer ${ }^{14}$ identified the following areas as requiring further elucidation: formation parting, relative permeability variation with temperature, phase behavior of the fluids, and emulsification of the oil-in-place. Abou-Kassem and Farouq Ali ${ }^{35}$ fouched upon a few items that need special attention during the development of a thermal simulator, and the difficulties likely to one encountered in addressing these problems. Some of these include: potential reversal, well model, grid block size, steam injection in fractures, etc. These are complex problems and can seriously impede the simulation run. While progress is being made in addressing some of these problems, several other problems may occur for which a clear solution is still not available. Another significant feature of the steam displacement process is that it is sensitive to grid orientation. Although several methods have been suggested in the literature to resolve this problem, none of them are completely satisfactory. The problem becomes hopeless when one tries to a model steam injection process for heterogeneous and anisotropic reservoirs and also for irregular grid. ${ }^{15}$ Steam displacement simulations also require sophisticated well control logic in the program, and none exist to date.

Other problems that plague all existing simulators are spurious numerical oscillation, in time and numerical dispersion. Numerical oscillation, which is most apparent in one-dimensional steam injection simulators, involves oscillation of pressure or saturation with time. Nume ical dispersion, which is prevalent in all numerical simulators, washes out steep gradients and fronts and leads to significant errors in the prediction of frontal advance rates. Both problems can be traced to the large gradients in primary variables which exist primarily in the vicinity of steam fronts. A number of other p:oblems encountered during the simulation of a thermal process are detailed by Esmail. 36

While thermal simulators have achieved a remarkable degree of siccess in simulating some very complex processes, further research and development are needed to make the models robust and reliable. Newer numerical solution iechniques are needed to minimize storage requirements and allow full scale field simulation.

\section{Predictive Models}

Although steamflood simulators can be used to forecast future reservoir performance and formulate operational sirategy, they are computationally expensive, and their accuracy and reliability depend on the accuracy of input data. The inherent sophistication of a thermal simulator makes it sensitive to rock and 
fluid properties, and geological information which is often unknown and must be estimated or defaulted from limited data. In addition, the complexity of a recovery process which involves flow and potential reversal and phase disappearance renders the equations of a thermal simulator difficult to solve. Moreover, large CPU time and convergence and numerical stability problems make thermal simulators expensive tools. Therefore, the sophisticated thermal simulators are inappropriate tools during the planning, screening, and preliminary design stage of a thermal project. Thus, the incentive exists to develop simple models for screening candidate reservoirs for steam projects and for forecasting reservoir behavior with less time and expense.

Several predictive models exist in the literature for predicting steamflood performance. These include empirical correlations and models based on analytical expressions. Empirical correlations can be useful for correlating data within a field and for predicting performance of similar reservoirs. However, use of these correlations for situations much different from the ones that led to their development can result in large errors. The accuracy of an analytical model depends on the assumpiions used to develop the expression. In the following paragraphs, a few selected published predictive models are reviewed. The selection is based on the popularity of these models and their usefulness as a screening and design tool.

The reported steamflood performance models can be divided into two categories: (a) onedimensional frontal advance modeis and (b) two-dimensional vertical $(x-z)$ displacement or gravity override models.

In frontal advance models, the steamdrive mechanism is modeled as a horizontal frontal displacement. These models assume vertical steam fronts; that is, the steam zone is assumed to grow horizontally, and the tendency of the steam to finger beyond the front is suppressed by condensation.

Gravity override models (also known as bypass models) recognize the tendency of steam to override an oil column and hence are more complicated to describe physically and mathematically. Gravity override models assume the principal direction of steam zone propagation to be vertically downward.

\section{Erontal_Advance Models}

In 1978, Myhill and Stegemeier ${ }^{11}$ presented a predictive model based on the Mandl and Volek theory. ${ }^{9}$ While this model permits quick estimates of steamflood performance for a specific reservoir, it is less useful as a preliminary design tool because of its inability to calculate fractional flow, oil bank volume, pressure drop, etc.

In 1980, Gomaa ${ }^{40}$ published a predictive model for calculating steamflood oil recovery and oil-steam ratios as a function of reservoir characteristics and operating conditions. The correlations are developed using a three-dimensional numerical steamflood simulator. Since only a limited range of data are used to develop the correlations, this model can be applied only to reservoirs with properties similar to those of Kern River (CA) field. 


\section{Gravity Overrlde Models}

Rhee and Doscher ${ }^{41}$ presented a predictive model in 1980 based on concepts of Marx and Langenheim ${ }^{3}$ and Van Lookeren. ${ }^{13}$ This model accounts for the effects of steam distillation and gravity override which are based on heat and material balance equations. In the model, the steam zone volume and shape are calculated by a rigorous heat balance. Steam overlay is estimated from the Van Lookeren theory. ${ }^{13}$ Steam distillation is calculated by a compositional method. Areal flow distributions are estimated using the Higgins and Leighton 72 streamtube model. Although the model has shown good agreement with experimental results, it is not easy to use and is almost as complicated as a numerical simulator.

Jones 42 in 1981 presented a simplified predictive model. Oil production rates are estimated by using a modified Myhill and Stegemeier ${ }^{11}$ expression. Van Lookeren's ${ }^{13}$ procedures are used to estimate steam injection rate. Empirical factors, based on field performance, are included to simulate the oil production history at a given steam injection rate.

Aydelotte and Pope ${ }^{43}$ and Arima 44 presented a predictive model in 1982 which aimed to predict steamflood performance more realistically than previous predictive models. In these models the reservoir is divided into four zones: (1) uninvaded zone, (2) oil bank zone, (3) hot liquid zone, and (4) steam zone. The model employs fractional flow theory and mass/energy balances to account for changes in oil cut, gas production, etc. Using an equation similar to Van Lookeren ${ }^{13}$ and Farouq Ali's ${ }^{45}$ empirical correlation, they accounted for the vertical and areal sweep efficiency in the model. This model is restricted to horizontal, homogeneous, isotropic and incompressible reservoirs, and only five-spot sweep correlations are included.

In 1984, Vugel 46 proposed a model that assumes a horizontal steamfront rather than a vertical steamfront assumption of frontal advance model. Such models, which assume instantaneous steam overlay, are called descending steam chest models. When the upward migrating steam reaches an impermeable barrier, further upward migration is halted, and the steam zone expands vertically downward. Crude oil production occurs as a result of steam flowing above and across the oil column.

Miller and Leung 47 extended Vogel's model to permit a complete rate versus time prediction. This model assumes that the oil viscosity reduction is entirely due to conductive heating of the oil layer, which is overlain uniformly by the steam zone. The model does not account for pressurization of the reservoir or other effects considered to be unimportant. Agreement between model results and field production history was reported to be good during the early times, but tends to be conservative for later times. Because of the nature of the oil production equation, the model can predict oil recovery accurately only if an accurate value of primary oil production rate is available. To improve the model's predictive capability, modifications were suggested by $\mathrm{Chen}^{48}$ and Boberg. ${ }^{49}$

Recently, Gajdica et al. ${ }^{50-51}$ proposed a semianalytical predictive model for linear and crosssectional systems. The model accounts for formation dip, formation compressibility, thermal expansion of 
formation, reservoir fluids, and stearr, overlay. The system of equations is solved by iterating on the injection well pressure. The model, designed to run on a personal computer, is reported to yield results comparable to those obtained using a numerical thermal simulator. 


\section{CHAPTER 3. - MODEL DEVELOPMENT}

Steamflooding an oil reservoir is a complex process which involves simultaneous flow of multiphase fluids (oil, gas, and water) and heat. The process is further complicated by interphase mass and energy transfer.

The mathematical model which simulates such a process and the assumptions involved are presented in this chapter. Correlations and expressions used to estimate rock and fluid properties are given. Discussions on the determination of phase distributions and compositions and the estimation of heat losses to the surroundings are also presented.

\section{- Assumptions}

The following assumptions are used in developing this model.

1. The flow is linear.

2. Thermal and phase equilibria are instantly reached within the grid concerned.

3. Oil and water are immiscible.

4. Mass transfer between oleic and gaseous phases for any hydrocarton component is described by the vapor-liquid equilibrium.

5. The mole fraction of steam in the gaseous phase to be computed as

$$
y_{s}=\frac{p_{s a t}}{p_{g}}
$$

6. Radiative heat transfer is assumed to be absent.

7. Heat transfer to the impermeable, adjacent strata (over and underburdens) is governed by the diffusivity equation.

8. The contribution of kinetic energy and the work done by viscous forces are negligible.

9. Hydrocarbon thermal cracking is ignored.

10. Presence of hydrocarbon in vapor phase has no effect on steam-water phase behavior.

11. Only the water component is injected into the reservoir.

12. Oleic phase is assumed to consist of three components.

13. When calculating phase equilibrium and properties, oleic phase pressure is used.

14. The heat losses through lateral reservoir boundaries are assumed to be zero.

\section{Mathernatical Formulation of the Model}

Appendix A contains derivations of the partial differential equations which describe mass and energy transport fo: ihe system of interest in this study. The equations which comprise the present model include a mass (molar) balance for each component, the energy balance, mole fraction and saturation constraints, capillary pressure relations and phase equilibria relations. The finite difference equivalent of the model conservation equations are derived in appendix $B$ and summarized as follows: 


\section{Mass Conservation}

Hydrecarbon Compenents

$$
\begin{aligned}
& \Delta\left[\tau_{0} x_{i}\left(\Delta p_{o}-\gamma_{o} \Delta D\right)+\tau_{g} y_{i}\left(\Delta p_{g}-\gamma_{o} \Delta D\right)\right]+q_{o} x_{i} \bar{\rho}_{o}+q_{g} y_{i} \bar{\rho}_{g} \\
& =\frac{v_{b}}{\Delta t} \delta\left[\phi\left(x_{i} \bar{\rho}_{o} S_{o}+y_{i} \bar{\rho}_{g} S_{g}\right)\right], i=1,2,3
\end{aligned}
$$

Water

$$
\begin{aligned}
& \Delta\left[\tau_{w}\left(\Delta p_{w}-\gamma_{w} \Delta D\right)+\tau_{g} y_{s}\left(\Delta p_{g}-\gamma_{g} \Delta D\right)\right]+q_{w} \bar{\rho}_{w}+q_{g} y_{s} \bar{\rho}_{g}= \\
& \frac{V_{b}}{\Delta t} \delta\left[\phi\left(\bar{\rho}_{w} s_{w}+y_{s} \bar{\rho}_{g} s_{g}\right)\right]
\end{aligned}
$$

II. Energy Conservation

$$
\begin{aligned}
& \Delta\left(\tau_{H} \Delta p_{o}\right)+\Delta\left(\tau_{c} \Delta T\right)-q_{L}-q_{H} \\
& =\frac{V_{b}}{\Delta t} \delta\left[\phi\left(\bar{\rho}_{W} S_{W} U_{W}+\bar{\rho}_{O} S_{O} U_{O}+\bar{\rho}_{g} S_{g} U_{g}\right)+(1-\phi)\left(\rho C_{p}\right)_{R} T\right]
\end{aligned}
$$

\section{Phase Saturation Censtraint}

$S_{O}+S_{g}+S_{W}=1.0$

IV. Mole Fraction Constraint

$$
\begin{array}{ll}
\sum_{i=1}^{3} x_{i}=1.0 \quad \text { Oleic Phase } \\
\sum_{i=1}^{3} y_{i}+y_{s}=1.0 & \text { Vapor Phase }
\end{array}
$$

V. Caplllary Pressure

$$
\begin{aligned}
& p_{c_{W O}}=p_{o}-p_{W} \\
& p_{c_{g o}}=p_{g}-p_{o}
\end{aligned}
$$

Vi. Phase Relations

$$
y_{i}=K_{i} \quad x_{i}, i=1,2,3
$$

\section{Initial and Boundary Conditions}

To complete the mathematical formulation, we specify the initial and boundary conditions. In this study, a closed or no flow boundary is used. 
The initia! conditions are:

$$
\begin{aligned}
& p(X, Z, 0)=P_{\text {int }} \\
& T(X, Z, 0)=T_{\text {int }} \\
& S_{i}(X, Z, 0)=\left(S_{i}\right) \text { int } l=0, g, W
\end{aligned}
$$

and at over/underburden

$$
T(X, Z, 0)=T_{\text {int }}
$$

The boundary conditions are:

At the reservoir boundary

$$
\begin{aligned}
& \frac{\partial p}{\partial x}=0 \\
& \frac{\partial p}{\partial z}=0
\end{aligned}
$$

At the reservoir boundary, the no flow condition is incorporated by setting permeability (or transmissibility) to zero.

At outflow boundaries:

$$
\begin{aligned}
& p_{0}=p_{0} \\
& p_{0}=p_{g}=p_{W} \\
& \overrightarrow{\nabla T} \cdot \vec{n} \mid \perp \Omega_{0}=0
\end{aligned}
$$

and at inflow boundaries

$$
p_{0}=p_{0}(t)
$$

When injecting steam

$$
Q_{s t m}=Q_{s t m}(t)
$$

\section{Ireatment of Nenlinearitles}

The partial differential equations describing the steam injection process include several nonlinear functions. For owiaining a meaningful and stable solution, these nonlinear terms must be handled properly. The nonlinearities involved in a steam model are either weak nonlinearities such as density, 
viscosity, and enthalpy or strong nonlinearitles such as relative permeabillties, capllary pressure, and phase behavior. 26 The handling of nonlinear terms involves both space and time.

In this study, the nonlinearities such as density, viscosity enthalpy, and mole fraction of each phase are approximated in space using one point upstream welghting scheme; i.e.,

$$
x_{1+1 / 2}=\left\{\begin{array}{l}
x \mid \text { for flow from block } \mid \text { to } i+1 \\
x_{1+1} \text { for flow from block } 1+1 \text { to } 1
\end{array}\right.
$$

where $x$ stands for density, viscosity, enthalpy or phase mole fraction. Relative permeabilities are also evaluated using upstream weighting.

For time approximation density, viscosity, and the relative permeabilities are evaluated at time level $n$ (at the old time-step),

\section{Physical Properties of Reservoir Fluids and Rock}

The functional dependences of physical propertles are given in table 3.1.

\section{Rock Properties}

The rock properties that are needed for reservoir thermal simulators are: absolute permeability $(k)$, density $\left(\rho_{R}\right)$, porosity $(\phi)$, rock compressibility $\left(C_{R}\right)$, thermal conductivities $\left(\lambda_{R}\right)$ and speciflc heat $\left(C_{P_{R}}\right)$.

Absolute permeability, rock density, rock compressibility, and specific heat are taken as constants. Porosity is expressed as a function of pressure, l.e.,

$$
\phi=\phi_{\operatorname{lnt}}\left[1+C_{R}\left(p-p_{\text {int }}\right)\right]
$$

Rock internal energy is estimated following Crookston ${ }^{38}$ as

$$
U_{R}=C_{P_{R}}\left(T-T_{\text {int }}\right)
$$

The use of initial reservoir temperature, $T_{\text {int }}$ instead of reference temperature, $T_{\text {ref }}$ or even omitting $T_{r e f}\left(T_{i n t}\right)$ should not produce any error since we are interested in the time changes of $U_{R}$ rather than their absolute value. ${ }^{27}$ Note that equation 3.22 is an expression for rock enthaipy, $H_{R}$, rather than internal energy, $U_{R}$. The rock internal energy, $U_{R}$, is actually

$$
U_{R}=H_{R}-\frac{p}{J_{\rho R}}
$$

Since the term $\frac{p}{J_{P R}}$ in equation 3.23 is negligibly small, all investigators have neglected this term. 
Formation thermal conductivity is a function of temperature, water saturation, and porosity and is given by

$$
\lambda_{\text {Sat, }}(T)=6.3604425\left[\exp \left(0.6 \rho R+0.6 S_{W}\right)\right] T^{-0.55}
$$

where

$\lambda_{\text {Sat. }}(T)=$ thermal conductivity of partially water saturated rock at temperature, $T$, Btu/hr-ft- ${ }^{\circ} \mathrm{F}$

$$
\mathrm{T}=\text { Temperature }^{\circ} \mathrm{K}
$$

The above empirical correlation was developed by Tikhomirov 53 and was recommended by Farouq All. 52

\section{Eluld Propertles}

\section{A. Viscosity}

Water:

Water viscosity is considered a function of temperature only and calculated using Yao's ${ }^{54}$ correlation:

$$
\begin{aligned}
& \mu_{W}=159.5 \mathrm{~T}^{-1.182,}, \mathrm{CP} \\
& T=\text { temperature, }{ }^{\circ} \mathrm{F}
\end{aligned}
$$

Qil:

Oil component viscosities are calculated from expressions of the following type

$$
\mu_{0}=A \exp (B / T)
$$

and oleic-phase viscosity is determined as in Crookston et al. ${ }^{38}$ using the Arrhenius type equation

$$
\mu_{0}=\prod_{i=1}^{N C} x_{i} \mu_{i}
$$

\section{Vaper:}

\section{Hydrocarbon Vapor:}

Vapor phase pure component viscosities are all calculated as functions of temperature using equation 3.26.

The viscosity of vapor phase hydrocarbon mixture $\left(\mu_{\mathrm{VHC}}\right)$ at atmospheric pressure is then calculated using the Herning and Zipperer 55 equation. 


$$
\mu_{V H C}=\frac{\sum_{l=1}^{N C} \mu_{i} y_{i} \sqrt{M W_{i}}}{\sum_{i=1}^{N C} y_{i} \sqrt{M W_{i}}}
$$

Where

$\mu \quad=$ pure component viscosity, $\mathrm{CP}$

$M W_{i}=$ pure component molecular weight

$y_{1}=$ component i mole fraction in the vapor phase.

A pressure correction is then applied to equation (3.28) using the method of Dean and Stiel.56

$\left(\mu_{m}-\mu_{v H C}\right) C_{m}=$

$0.000108\left(e^{1.439} \rho_{r m}-\theta^{-1.111} \rho_{r m}{ }^{1.858}\right)$

Where

$\mu_{m}=$ high pressure mixture viscosity, $\mathrm{cP}$

$\mu_{\mathrm{vHC}}=$ mixture viscosity at one atmosphere (from equation 3.28)

$\rho_{\mathrm{m}}=$ pseudo reduced mixture density

$=\rho_{m} / \rho_{c_{m}}$

$C_{m}=\left(T_{c}\right)_{m i}^{0.16667}(M W)_{m}^{-0.5}\left(p_{c}\right)_{m}^{-0.6667}$

$\rho_{c_{m}}=\left(p_{c}\right)_{m} / R\left(T_{c}\right)_{m}\left(Z_{c}\right)_{m}$

$\left(z_{c}\right)_{m}=\sum_{i=1}^{N} y_{i} z_{q}$

$\left(p_{c}\right)_{m}=\sum_{i=1}^{N C} y_{i} p_{c_{i}}$

$\left(T_{c}\right)_{m}=\sum_{i=1}^{N C} y_{i} T_{a}$ 


$$
(M W)_{m}=\sum_{l=1}^{N C} y_{l}(M W)_{1}
$$

The above procedure was used by $L$, rokston et at. 38

Steam viscosity is estimated using equation 3.56. The vapor phase viscosity is then computed as

$$
\mu_{g}=\mu_{m}+\mu_{\text {støam }} y_{s} \sqrt{18}
$$

\section{Denslty}

\section{Water:}

The mass density of water is assumed to be function of temperature and pressure and calculated using Tortike and Farouq All's 57 correlation.

$$
\begin{aligned}
\rho_{W}(T) & =236.372-1.29187 T+0.00378125 T^{2}-5.40258 \times 10^{-6} T^{3} \\
& +3.74277 \times 10^{-9} T^{4}-1.01916 \times 10^{-12} T^{5}
\end{aligned}
$$

Where $\rho_{w}(T)=$ density of water at temperature $T$, lbın/ou ft.

$$
T=\text { temperature, }^{\circ} \mathrm{R}
$$

A pressure correction is then applied to equation 3.38 .

$$
\rho_{W}(T, p)=\rho_{W}(T)\left[1+C_{W}\left(p-\rho_{\text {int }}\right)\right]
$$

$\rho_{W}(T, p)=$ density of water at temperature $T$, and pressure $p$

$C_{W} \quad=$ water compressibility, $\left.P_{s}\right|^{-1}$

\section{ㅇl:}

The mass density of oil is treated as a function of pressure, temperature and oil phase composition and computed using Gros's 58 correlations.

$$
\rho_{o}(T)=\rho_{\text {Ref }}-C_{1}(T-60)+C_{2}(T-60)^{2}
$$

Where

$$
\begin{aligned}
\rho_{\text {Ref }} & =\text { reference density of oil at } 60^{\circ} \mathrm{F} \mathrm{lbm} / / \mathrm{t}^{3} \\
T & =\text { temperature, }{ }^{\circ} \mathrm{F}
\end{aligned}
$$


Reference density is computed as

$\rho_{R_{\theta \mid}}=62.4278 \sum_{i=1}^{N C} W_{i} S G_{\mid}$

$W_{1}=$ weight fraction of component I in olelo phase

$=x_{i} M W_{i} / \sum_{i=1}^{N C} x_{i} M W_{i}$

$S G_{\mid}=$speciflo gravity of component $\mid$at $60^{\circ} \mathrm{F}$

$C_{1}=0.0133+152.4\left(\rho_{\text {Ref }}\right)^{-2.45}$

$C_{2}=0.0000081-0.0622 \times 10^{-}\left(0.0764 \rho_{O_{R A f}}\right)$

A pressure correction is then applied to equation 3.40

$\rho_{0}(T, p)=\rho_{0}(T)\left[1+C_{0}\left(p-p_{\text {int }}\right)\right]$

$\rho_{o}(T, p)=$ oll density at temperature $T$ and pressure $p$

$\mathrm{C}_{0}=$ oll compressibility, $\mathrm{ps}^{-1}$

The oil compressibility is calculated from 59

$$
\begin{aligned}
& C_{0}=\left(\frac{R_{1}}{R_{2}}-1.0\right) / \Delta p \\
& R_{1}=\rho_{O_{\text {Ref }}}+D_{1} P_{1}-D_{2} P_{1}^{2} \\
& R_{2}=\rho_{R_{\text {Ref }}}+D_{1} P-D_{2} P^{2} \\
& D_{1}=0.167+16.181 \times 10^{\circ}\left(0.0425 \rho_{O_{\text {RAf }}}\right) \\
& D_{2}=0.00299+2.63 \times 10^{\circ}\left(0.0603 \rho_{O_{\text {RAf }}}\right) \\
& P_{1}=(p+\Delta p / 1000, p \text { in Psia } \\
& P \quad=p / 1000
\end{aligned}
$$

Co will be the average oll compressibility between $P$ and $P 1$.

In the program $\Delta p$ has been defaulted to 100 psia. 


\section{Vapor Phase Density}

The molar density of vapor phase is a function of pressure, temperature and composition and computed using real gas law, l.e.,

$$
\bar{\rho}_{g}=p / Z R T
$$

Where $\quad \bar{\rho}_{g}=$ vapor phase density lb-mole/cu ft

$$
\begin{aligned}
& R=\text { Gas constant }=10.731 \frac{P_{s i}-t^{3}}{\mid b-m_{0} \theta^{\circ} R} \\
& Z=\text { Gas deviation (compressibility) factor. }
\end{aligned}
$$

The hydrocarbon vapor phase component deviation factor $\left(Z_{i}\right)$ is estimated using Papay's equation. 60

$$
Z_{i}=1 \cdot \frac{3.52 p_{r}}{10^{0.9813} T_{r}}+\frac{0.274 p^{2}}{10^{0.8157} T_{r}}
$$

Where $\quad p_{r}=$ reduced pressure $=p / p_{c_{i}}$

$$
T_{r}=\text { reduced temperature }=T / T_{C_{1}}
$$

The steam compressibility factor (Zsteam) is calculated as ${ }^{61}$

$$
\begin{aligned}
& \left(Z_{\text {Steam }}\right)=1.012-4.461 \times 10^{-4} \mathrm{~T}+2.98 \times 10^{-6} \mathrm{~T}^{2}-1.663 \times 10^{-8} \mathrm{~T}^{3} \\
& T=\text { temperature },{ }^{\circ} \mathrm{C} .
\end{aligned}
$$

The vapor phase compressibility iactor is then given by

$$
Z=\sum_{i=1}^{3} y_{i} Z_{i}+Z_{\text {Steam }} y_{s}
$$

$y_{s}=$ mole fraction of steam in vapor phase. 


\section{Steam and Saturated Vapor Propertles}

Many correlations are avallable for calculating steam properties. In this work, Tortike and Farouq All's ${ }^{57}$ correlations were used to estimate saturated steam properties as a function of pressure and temperature. These correlations are valid only within the steam saturation envelope.

\section{Steam Viscosity}

$$
\begin{aligned}
\mu_{\text {Steam }}= & -0.546807+3.83050 \times 10^{-3} \mathrm{~T}-1.04938 \times 10^{-5} \mathrm{~T}^{2} \\
& +1.42291 \times 10^{-8} \mathrm{~T}^{3}-9.49798 \times 10^{-12} \mathrm{~T}^{4} \\
& +2.49747 \times 10^{-15} \mathrm{~T}^{5}
\end{aligned}
$$

Where

$$
\begin{aligned}
\text { MSteam } & =\text { Steam viscosity, } \mathrm{cP} \\
T & =\text { temperature, }{ }^{\circ} \mathrm{R}
\end{aligned}
$$

\section{Saturation Temperature ( $\left.^{\circ} \mathrm{R}\right)$ :}

$$
\begin{aligned}
T_{\text {Sat }}= & 561.435+33.8866 \ln p+2.18893(\ln p)^{2} \\
& +0.0808998(\ln p)^{3}+0.0342030(\ln p)^{4} \\
p \quad= & \text { Pressure in Psia }
\end{aligned}
$$

\section{Saturation Pressure (osia)}

$$
\begin{aligned}
P_{\text {Sat }}= & {\left[-66.9421+0.485086 \mathrm{~T}-1.33944 \times 10^{-3} \mathrm{~T}^{2}\right.} \\
& +1.71599 \times 10^{-6} \mathrm{~T}^{3}-9.93039 \times 10^{-10} \mathrm{~T}^{4} \\
& +2.29394 \times 10^{-13} \mathrm{~T}^{5} \\
\mathrm{~T}= & \text { temperature, }{ }^{\circ} \mathrm{R} .
\end{aligned}
$$

\section{Enthalpy of Saturated Steam (Btu/lbm)}

$$
\begin{aligned}
\text { Hsteam } & =-9469.85+87.2545 \mathrm{~T}-0.299668 \mathrm{~T}^{2} \\
& +5.43610 \times 10^{-4} \mathrm{~T}^{3}-5.46484 \times 10^{-7} \mathrm{~T}^{4} \\
& +2.88759 \times 10^{-10} \mathrm{~T}^{5}-6.28068 \times 10^{-14} \mathrm{~T}^{6} \\
\mathrm{~T} & =\text { temperature }^{\circ} \mathrm{R}
\end{aligned}
$$

\section{Latent Heat of Vaporlzatlon (Btu/lbm)}

$$
\begin{aligned}
L= & {\left[1,327,940+1,134.53 T-5.04327 T^{2}\right.} \\
& \left.+5.15204 \times 10^{-3} T^{3}-2.13711 \times 10^{-6} T^{4}\right]^{1 / 2}
\end{aligned}
$$




\section{InternaL Eneros of Steam (Btu/lbm)}

$$
U_{\text {Stoam }}=H_{\text {Steam }}-144.0 \times \mathrm{p} /(\rho \text { Steam } \times 777.649)
$$

\section{Enthalpy of Water (Btu/lbm)}

$$
\begin{aligned}
\text { Hw }= & 10,174.2-87.4729 \mathrm{~T}+0.301147 \mathrm{~T}^{2}-5.38409 \times 10^{-4} \mathrm{~T}^{3} \\
& +5.33392 \times 10^{-7} \mathrm{~T}^{4}-2.77814 \times 10^{-10} \mathrm{~T}^{5} \\
& +5.95201 \times 10^{-14} \mathrm{~T}^{6}
\end{aligned}
$$

Internal Eneroy of Water (Btu/lbm)

$$
U_{w}=H_{w}-\left(144.0 \times p /\left(\rho_{w}(T, p) \times 777.649\right)\right)
$$

\section{Qleic Phase Speciflc Heat}

The hydrocarbon component specific heat at constant pressure $(C p)$ is considered a function of temperature and computed using Hadden's correlation. 62

$$
C P_{i}=a+b T_{r}+C T_{r}^{2}+d T_{r}^{3}+N\left(\Delta a+\Delta b T_{r}+\Delta c T_{r}^{2}+\Delta d T_{r}^{3}\right)
$$

$$
\begin{aligned}
& \text { Where } \begin{aligned}
C P_{i}= & \text { heat capacity of component } i \text { at constant pressure } \\
& \text { Cavgm }- \text { mole }-{ }^{\circ} \mathrm{K}\left(\text { Btu/lb-mole }-{ }^{\circ} \mathrm{R}\right) \\
\mathrm{T}_{\mathrm{r}}= & \text { reduced temperature } \\
\mathrm{N}= & \text { carbon number }
\end{aligned}
\end{aligned}
$$

$a, b, c, d$ elc. are constants and are given below. These constants are for normal alkanes with $N>5$.

$$
\begin{aligned}
& a=0.84167 \\
& b=-1.47040 \\
& c=1.67165 \\
& d=-0.59198 \\
& \Delta a=-0.003826 \\
& \Delta b=-0.000747 \\
& \Delta c=0.041126 \\
& \Delta d=-0.013950
\end{aligned}
$$


The carbon number $\mathrm{N}$ is computed as

$$
N=\operatorname{Int} .\left(\left(M W_{i}+6 .\right) / 14 .\right)
$$

The oil component enthalpy is computed as

$$
H i=C p_{i} \times\left(T-T_{\text {ref }}\right) \text { Btu/lb-mole }
$$

and oil phase enthalpy is given by

$$
H_{0}=\sum_{i=1}^{N C} x_{i} H_{i}
$$

The oil component internal energy is gil en by

$$
U_{i}=H_{i}-\left(p \times 144.0 / \rho_{i}(T) \times 777.649\right)
$$

and oil phase internal encrgy is computed as

$$
U_{0}=\sum_{i=1}^{N C} x_{i} U_{i}
$$

The hydrocarbon vapor phase enthalpy is calculated as

$$
H_{H C V}=\sum_{i=1}^{N C} y_{i} H
$$

and the vapor phase enthalpy is

$$
H_{V}=H_{H C V}+y_{s} H_{\text {Steam }}
$$

The hydrocarbon vapor phase internal energy is computed as

$$
U_{H C V}=\sum_{i=1}^{N C} y_{i} U_{i}
$$

and the vapor phase internal energy is

$$
U_{V}=U_{H C V}+y_{S} U_{\text {Steam }}
$$




\section{Enthalpy of Vaporization of Hyorocarbons}

The enthalpy of vaporization of hydrocarbon $I$ is estimated using Chipman's modification of Kistyakowsky equation. 63

$$
\left(L_{v}\right)_{i, T_{b}}=1.014 T_{b_{i}}\left(8.75+4.571 \log _{10} T_{b_{i}}\right)
$$

Where

$\left(L_{v}\right)_{i, T_{b}}=$ latent heat of vaporization of component $\mathrm{i}$ at normal boiling point, Cal/gm-mole

$T_{b_{i}} \quad=$ normal boiling point of component $i,{ }^{\circ} \mathrm{K}$

The latent heat of vaporization at any other temperature $T$ is then computed using Theisen's correlation. ${ }^{63}$

$$
\left(L_{v}\right)_{i, T}=\left(L_{v}\right)_{i, T_{b}}\left(\frac{T_{G_{i}}-T}{T_{c}-T_{b i}}\right)^{0.38}
$$

\section{Constants for Vaper-Llquild Equilibrla (K-yalues)}

The equilibrium constants for a hydrocarbon component $i, K_{i},(i=1,2,3)$ is specified in tabular form as a function of both pressure and temperature independent of composition. A tabie look up routine conducts a binary search in a two-dimensional table and the $K$-values at the desired pressure and temperature is obtained using either by linear interpolation or by spline interpulation.

The water component $K$-value is calculated as

$K_{w}=p_{\text {sat }} / p$

Where $p_{\text {sat }}=$ water $($ Steam $)$ saturation pressure, psia.

Phase appearance and disappearance was handled using Crookston's ${ }^{38}$ method which was later modified by Abou-Kassem. 64 Following the approach of Abou-Kassem, we write:

$$
\begin{aligned}
& K_{i}=\widehat{K}_{i} x_{0} x_{g}, \quad i=1,2,3 \\
& K_{w}=\widehat{K}_{w} x_{w} x_{g}
\end{aligned}
$$

Where

$$
\begin{aligned}
& x_{0}=\frac{S_{0}}{S_{0}+E_{0}} \\
& x_{g}=\frac{S_{g}+E_{g}}{S_{g}+10^{-30}}
\end{aligned}
$$




$$
x_{w}=\frac{S_{w}}{S_{w}+E_{w}}
$$

Where $E_{0}, E_{g}$ and $E_{w}$ are small numbers of the order $10^{-5}$ and $\widehat{K}_{i}$ are temperature and pressure dependent $\mathrm{K}$-values. The effect of adjusting $\mathrm{K}$-values in this fashion is to create a situation in which individual phases are not allowed to disappear completely, but a small portion of each phase is maintained at all conditions.

\section{Fluid-Rock Propertles}

The fluid rock properties to be discussed here are capillary pressure and relative permeabilities.

\section{a. Caplllary Pressure:}

The capillary pressure data for the oil-water system and gas-oil system are read in tabular form. The effect of temperature on capillary pressure is neglected. The oil-water capillary pressure, $p_{c_{w o}}$ is assumed to be a function of water saturation only, while the gas-oil capillary pressure, Pcgo $_{\text {go }}$ assumed to be a function of both water and oil saturation. The capillary pressure data are fitted to splines for purposes of interpolation.

\section{b. Relative Permeability}

Two-phase relative permeabilities are calculated using the method suggested by Coats. ${ }^{24}$ The working equations account for the effect of temperature on relative permeabilities. The correlations of Coats take the following form.

$$
\begin{aligned}
& k_{r w}=k_{r_{w r o}}(T)\left[\frac{S_{w}-S_{W_{i r}}(T)}{1-S_{O_{W}}(T)-S_{W_{i r}}(T)}\right]^{n_{W}} \\
& k_{\text {row }}=k_{r_{\text {oiw }}}(T)\left[\frac{1-S_{O_{n N}}(T)-S_{w}}{1-S_{o_{w}}(T)-S_{w_{i r}}(T)}\right]^{n_{\text {ow }}} \\
& k_{r_{o g}}=k_{r_{\text {oiw }}}(T)\left[\frac{1-S_{W_{i r}}(T)-S_{O_{r g}}(T)-S_{g}}{1-S_{w_{i r}}(T)-S_{o_{r g}}(T)}\right]^{n_{o g}} \\
& k_{r_{g}}=k_{r_{g r o}}(T)\left[\frac{S_{g}-S_{g_{c}}}{1-S_{W_{i r}}(T)-S_{o_{r g}}(T)-S_{g_{c}}}\right]^{n_{g}}
\end{aligned}
$$

Where

$$
k_{r_{w r o}}(T)=\text { relative permeability to water at residual oil saturation at temperature } T
$$


$\mathrm{k}_{\mathrm{rgro}}(\mathrm{T})=$ relative permeability to gas at residual oll saturation at temperature $T$

$k_{r_{\text {oiw }}}(T)=$ relative permeability to oil at irreducible water saturation at temperature $T$

$S_{W_{i r}}(T)=$ irreducible water saturation at temperature $T$

$S_{O_{r w}}(T)=$ residual oil saturation to water at temperature $T$

$\mathrm{S}_{\mathrm{Org}}(T)=$ residual oil saturation to gas at temperature $T$

$\mathrm{S}_{\mathrm{gc}_{\mathrm{c}}} \quad=$ critical gas saturation

$n_{w}, n_{o w}, n_{o g}, n_{g}=$ exponents on saturation.

The temperature dependent parameters such as $k_{r w r o}(T)$ are assumed to be linear functions of temperature.

eg. $x=A+B\left(T-T_{\text {ref }}\right)$

\section{Three-Phase Relatlve Permeabllities}

In this study, three-phase relative permeabilities are synthesized from two-phase relative permeabilities using Stone's ${ }^{65}$ method.

The following assumptions are made in developing Stone's method:

1. The water relative permeability is a function of water saturation only and does not depend on the relative proportions of oil and gas phases. Hence,

$$
k_{r w}=k_{r w}\left(S_{w}\right)
$$

2. The gas relative permeability is a function of gas saturation only and does not depend on the relative proportions of oil and water phases. Thus,

$$
k_{r g}=k_{r g}\left(S_{g}\right)
$$

3. The oil relative permeability is a function of both water and gas saturations, i.e.,

$$
k_{\text {ro }}=k_{\text {ro }}\left(S_{w}, S_{g}\right)
$$

Using these assumptions, $k_{r w}$ and $k_{r g}$ are obtained from two-phase oil-water and oil-gas relative permeability data. $k_{r o}$ is obtained from the following relationships. This is a modified form of Stone's original equation. 27

$$
k_{r_{0}}=k_{r_{\text {oiw }}}(T)\left[\left(\frac{k_{r_{\text {ow }}}}{k_{r_{\text {oiw }}}(T)}+k_{r_{w}}\right)\left(\frac{k_{r_{\text {og }}}}{k_{r_{\text {oiw }}}(T)}+k_{r_{g}}\right)-\left(k_{r w}+k_{r g}\right)\right]
$$




\section{Bate of Heat Loss to Over and Underburdens}

The injected steam heats the oil reservoir which, as a result, loses heat to the surrounding formations. Coats, et al. ${ }^{21}$ have found that lateral heat conduction in the adjacent strata has no effects on reservoir temperature. Hence, it is assumed that conduction only occurs normal to the top and to the bottom of the reservoirs. Heat losses in the laboratory 2-D model are assumed to follow the same trend as in reservoirs and obey the one-dimensional heat flow by conduction.

It is assumed that the formation is rectangular and of uniform thickness. Thermal conductivity and heat capacity of the overburden/underburden strata are considered to be constant.

The one-dimensional heat conduction equation can be written as:

$$
\frac{\partial^{2} T}{\partial Y^{2}}=\frac{\rho_{O B} C_{p O B}}{\lambda_{O B}} \frac{\partial T}{\partial t}
$$

Where $\left(\rho_{O B}\right),\left(C_{p_{O B}}\right)$ and $\left(\lambda_{\circ B}\right)$ are the density, specific heat, and thermal conductivity of the overburden and underburden rocks.

As shown by Coats 21 equation 3.92 gives reasonably accurate results. Equation 3.92 is solved by finite difference approximation. Smaller grid size is used close to the reservoir while larger grid size is used away from the reservoir. The resulting finite difference equations for a given block are shown in appendix $F$. Direct elimination is used to solve the resulting tridiagonal system of equations. 
TABLE 3.1 - Functional dependence of physical properties

\begin{tabular}{|c|c|c|}
\hline Variable & Definition & Functional dependence \\
\hline$\phi$ & Porosity & $\mathrm{p}$ \\
\hline$\lambda$ & Formation thermal conductivity & $T, S_{W_{1}} \phi$ \\
\hline$\mu_{w}$ & Aqueous phase viscosity & $\mathrm{T}$ \\
\hline$\mu_{0}$ & Oleic phase viscosity & $T, x_{1}, x_{2}, x_{3}$ \\
\hline$\mu_{g}$ & Vapor phase viscosity & $p, T, y_{1}, y_{2}, y_{3}, y_{s}$ \\
\hline$\rho_{w}$ & Aqueous phase density & $p, T$ \\
\hline$\rho_{0}$ & Oleic phase density & $p, T, x_{1}, x_{2}, x_{3}$ \\
\hline$\rho_{g}$ & Vapor phase density & $p, T, y_{1}, y_{2}, y_{3}, y_{s}$ \\
\hline$H_{w}$ & Aqueous phase enthalpy & $\mathrm{T}$ \\
\hline$H_{0}$ & Oleic phase enthalpy & $T, x_{1}, x_{2}, x_{3}$ \\
\hline$H_{g}$ & Vapor phase enthalpy & $T, y_{1}, y_{2}, y_{3}, y_{s}$ \\
\hline K & Equilibrium ratios & $p, T$ \\
\hline$k_{r w}$ & Aqueous phase relative permeability & $T, S_{W}$ \\
\hline kro & Oleic phase relative permeability & $T, S_{W}, S_{g}$ \\
\hline $\mathrm{k}_{\mathrm{rg}}$ & Vapor phase relative permeablity & $T, S_{g}$ \\
\hline$(M W)_{0}$ & Oleic phase molecular weight & $x_{1}, x_{2}, x_{3}$ \\
\hline$(\mathrm{MW})_{\mathrm{g}}$ & Vapor phase molecular weight & $y_{1}, y_{2}, y_{3}, y_{s}$ \\
\hline$U_{W}$ & Aqueous phase internal energy & $T$ \\
\hline$\cup_{0}$ & Oleic phase internal energy & $T, x_{1}, x_{2}, x_{3}$ \\
\hline$U_{g}$ & Vapor phase internal energy & $T, y_{1}, y_{2}, y_{3}, y_{s}$ \\
\hline$U_{R}$ & Rock internal energy & $\mathrm{T}$ \\
\hline$\left(C_{p}\right)_{o}$ & Oleic phase specific heat & $T, x_{1}, x_{2}, x_{3}$ \\
\hline$\left(C_{p}\right)_{g}$ & Vapor phase specific heat & $T, y_{1}, y_{2}, y_{3}, y_{s}$ \\
\hline
\end{tabular}




\section{CHAPTER 4. - EXPANSION OF THE DIFFERENCE EQUATIONS AND METHOD OF SOLUTION}

The mathematical model presented in chapter 3 must be solved numerically because of the nonlinearity and complexity of the equations Involved. In this chapter, the finite difference representation of the mathematical model, the expansion of the finite difference equations in time and space, and their method of solution are summarized. The detals are presented in appendices $C, D$, and $E$. The finite difference methods presented here are similar to those presented by Coats 24 to solve a system of equatlons representing steamflood process.

\section{Expansion of Finite Difference Equations}

The finite difference representation of the partial differential equations describing the steamflood process are presented in chapter 3 (eqs. 3.1 to 3.9). The steamflood problem considered in this study consists of three independent variables, $x, z$, and $t$, and seven dependent variables: $x_{1}, x_{2}, x_{3}, S_{w}, S_{g}, T$ and $p$. As in any finite difference simulator, the objective is to determine values of the primary (dependent) variables at a new time, $t=t+\Delta t$, l.e., $x_{1}(t+\Delta t), x_{2}(t+\Delta t), x_{3}(t+\Delta t), S_{w}(t+\Delta t), S_{g}(t+\Delta t), T(t+\Delta t)$, and $p(t+\Delta t)$ given the values of the dependent varlables at time $t, i, \theta_{1}, x_{1}(t), x_{2}(t), x_{3}(t), S_{w}(t), S_{g}(t), T(t)$, and $p(t)$.

In the present study, the seven finite difference equations 3.1 to 3.7 are expanded in terms of the seven primary variables. The unknowns solved are the changes in the primary variables rather than the primary variables themselves. The unknowns are as follows:

$$
\begin{aligned}
& \delta x_{1}=x_{1}(t+\Delta t)-x(t) \\
& \delta x_{2}=x_{2}(t+\Delta t)-x(t) \\
& \delta x_{3}=x_{3}(t+\Delta t)-x(t) \\
& \delta S_{w}=S_{w}(t+\Delta t)-S_{w}(t) \\
& \delta S_{g}=S_{g}(t+\Delta t)-S_{g}(t) \\
& \delta T=T(t+\Delta t)-T(t) \\
& \delta p=p(t+\Delta t)-p(t)
\end{aligned}
$$

A central difference scheme (midway between $t$ and $t+\Delta t$ ) is used to convert the partlal differential equations into the corresponding finite difference approximation. The finite difference approximations constitute a set of nonlinear algebraic equations in the unknown values of the primary variables at $t+\Delta t$. These equations are solved by writing Taylor's series expansion for all nonlinear terms and retaining only the constant and the linear term of these expansions. This process lends itself readily to generating equations in $\delta x_{1}, \delta x_{2}, \delta x_{3}, \delta S_{w}, \delta S_{g}, \delta T$, and $\delta p$. Solutions for these equations are obtained by a direct method. 
The algebra involved in deriving these equations to be solved is long and tedious and is covered in detail in appendices C, D and E. Appendix $C$ contains the details of the expansion of the basic equations and their simplification. Following is an example of the expansion of the product term on the right-hand side of equation 3.1.

To obtain the greatest rellability, it is essentlal that product of terms, each of which is a function of one or more primary variables, be expanded in a consistent manner. For example:

$$
\delta\left(\phi S_{0} \rho_{0} x_{1}\right)=\phi^{n+1} \delta\left(S_{o} \rho_{0} x_{1}\right)+\left(S_{0} \rho_{o} x_{1}\right)^{n} \delta \phi
$$

Expanding the first term on the right-hand side of equation 4.2 gives

$$
\delta\left(S_{0} \rho_{0} x_{1}\right)=S_{0}^{n+1} \delta\left(\rho_{0} x_{1}\right)+\left(\rho_{0} x_{1}\right)^{n} \delta S_{0}
$$

and $\delta S_{0}=-\delta S_{w}-\delta S_{g}$

The molar balance equations (eqs. 3.1-3.3) for the hydrocarbon component 1 is written after expansion as

$$
\begin{aligned}
C_{11} \delta x_{1} & +C_{i 2} \delta x_{2}+C_{i 3} \delta x_{3}+C_{i 4} \delta S_{w}+C_{i 5} \delta S_{g}+C_{i 6} \delta T+C_{17} \delta p_{0} \\
& =\Delta\left[\left(\tau \delta x_{1}+\tau g y_{1}\right) \Delta \delta p_{o}\right]+\Delta\left[\tau_{0} x_{1} \Delta \Phi_{o}+\tau_{g} y_{i} \Delta \Phi_{g}\right]^{n} \\
& +q 8 x_{i} \bar{\rho}_{o}+q g y_{1} \bar{\rho}_{g}, l=1,2,3
\end{aligned}
$$

In equation 4.5, the oll pressure is taken implicitly in the right-hand side. Transmissibility, capillary pressure and production, and injection rates are taken explicitly.

Let

$$
\tau=\tau 8 x_{1}+\tau y_{1} y_{1} \quad i=1,2,3
$$

and

$$
R_{l}=\Delta\left[\tau_{0} x_{i} \Delta \Phi_{0}+\tau_{g} y_{i} \Delta \Phi_{g}\right]^{n} \dot{+}+q \delta x_{i} \bar{\rho}_{0}+q_{g} y_{1} \bar{\rho}_{g}, \quad I=1,2,3
$$

Then equation 4.5 can be writien as

$$
\begin{aligned}
C_{i 1} \delta x_{1} & +C_{12} \delta x_{2}+C_{13} \delta x_{3}+C_{i 4} \delta S_{w}+C_{15} \delta S_{g}+C_{i 6} \delta T+C_{17} \delta p_{0} \\
& =\Delta\left(\tau_{i} \Delta \delta p_{0}\right)+R_{11} \quad i=1,2,3
\end{aligned}
$$

The coefficients $C_{i j}$ in equation 4.8 are obtained from equation $C-45$ in the appendix $C$. 
Thus,

$C_{\mid j}=\frac{V_{b}}{\Delta t}\left[\phi^{n+1}\left\{\left(S_{o} \bar{\rho}_{o}\right)^{n}+K_{l}^{n+1}\left(S_{g} \bar{\rho}_{g}\right)^{n}\right\}\right] \delta_{\mid j} \delta x_{j}+\frac{V_{b}}{\Delta t}\left(\phi S_{o} x_{l}\right)^{n+1}\left(\frac{\partial \vec{\rho}_{o}}{\partial x_{j}}\right) \delta x_{j} \quad l=1,2,3 \quad \quad \quad=1,2,3$

Where $\delta_{\| l}$ is the Kronecker delta defined by

$$
\begin{aligned}
& \delta_{i]}=\left[\begin{array}{l}
1 \text { for } l=] \\
{[0 \text { for } l \neq j}
\end{array}\right. \\
& C_{14}=-\frac{V_{b}}{\Delta t}(\phi x)^{n+1} \bar{\rho}_{0}^{n} \quad I=1,2,3 \\
& C_{15}=\frac{V_{b}}{\Delta t}\left[\phi^{n+1}\left\{\left.y\right|^{n+1} \rho_{g}^{n}-x_{\mid}^{n+1} \rho_{0}^{n}\right] \quad l=1,2,3\right. \\
& C_{i 6}=\frac{V_{b}}{\Delta t}\left[\left(\phi S_{0} x_{i}\right)^{n+1}\left(\frac{\partial \bar{\rho}_{o}}{\partial T}\right)_{p}^{l}+\left(\phi S_{g} y_{i}\right)^{n+1}\left(\frac{\partial \bar{\rho}_{g}}{\partial T}\right)_{p}^{l}+\phi^{n+1}\left(S_{g} \bar{\rho}_{o} x_{i}\right)^{n}\left(\frac{\partial K_{i}}{\partial T}\right)_{p}^{l}\right] \quad l=1,2,3 \\
& C_{i 7}=\frac{V_{b}}{\Delta t} l\left(\phi S_{0} x_{i}\right)^{n+1}\left(\frac{\partial \bar{\rho}_{o}}{\partial p}\right)_{T}^{l}+\left(\phi S_{g} y_{i}\right)^{n+1}\left(\frac{\partial \bar{\rho}_{g}}{\partial p}\right)_{T}^{l}+\phi^{n+1}\left(S_{g} \bar{\rho}_{g} x_{i}\right)^{n}\left(\frac{\partial K_{i}}{\partial p}\right)_{T}^{l} \\
& \left.+\phi_{\text {int }} C_{R}\left\{\left(S_{o} \bar{\rho}_{o} x_{i}\right)^{n}+\left(S_{g} \bar{\rho}_{g} y_{i}\right)^{n}\right\}\right] \quad l=1,2,3
\end{aligned}
$$

The molar balarice equation for water (eq. 3.4) can be written as

$\mathrm{C}_{41} \delta \mathrm{x}_{1}+\mathrm{C}_{42} \delta \mathrm{x}_{2}+\mathrm{C}_{43} \delta \mathrm{x}_{3}+\mathrm{C}_{44} \delta \mathrm{S}_{\mathrm{w}}+\mathrm{C}_{45} \delta \mathrm{S}_{\mathrm{g}}+\mathrm{C}_{46} \delta \mathrm{T}+\mathrm{C}_{47} \delta \mathrm{p}_{\mathrm{o}}$

$$
=\Delta\left(\tau H_{2} O \Delta \delta p_{0}\right)+R_{4}
$$

Coefficients $\mathrm{C}_{4 \mid}$ are obtained from equation $\mathrm{C}-60$ in appendix $\mathrm{C} . \tau_{\mathrm{H}_{2}} \mathrm{O}$ and $\mathrm{R}_{4}$ are defined under the same assumptions as those for equations 4.6 ana 4.7 . Thus,

$$
\begin{aligned}
& C_{4 j}=0.0 \quad j=1,2,3 \\
& C_{44}=\frac{V_{b}}{\Delta t}(\phi)^{n+1}\left(\bar{\rho}_{w}\right)^{n} \\
& C_{45}=\frac{V_{b}}{\Delta t}\left(\phi y_{s}\right)^{n+1} \bar{\rho}_{g}^{n} \\
& C_{46}=\frac{V_{b}}{\Delta t}\left[\left(\phi S_{w}\right)^{n+1}\left(\frac{\partial \bar{\rho}_{w}}{\partial T}\right)_{p}^{\prime}+\left(\phi S_{g} y_{s}\right)^{n+1}\left(\frac{\partial \bar{\rho}_{g}}{\partial T}\right)_{p}^{\prime}+\phi^{n+1}\left(S_{g} \overline{\rho_{g}}\right)^{n}\left(\frac{\partial K_{4}}{\partial T}\right)_{p}^{\prime}\right]_{p}
\end{aligned}
$$




$$
\begin{aligned}
& C_{47}= \frac{V_{b}}{\Delta t}\left\{\left(\phi S_{W}\right)^{n+1}\left(\frac{\partial \bar{\rho}_{W}}{\partial p}\right)_{T}+\left(\phi S_{g} y_{s}\right)^{n+1}\left(\frac{\partial \bar{\rho}_{g}}{\partial p}\right)_{T}^{l}+\phi^{n+1}\left(S_{g} \bar{\rho}_{g}\right)^{n}\left(\frac{\partial K_{4}}{\partial p}\right)_{T}^{1}\right. \\
&\left.+\phi i n t C_{R}\left\{\left(S_{W} \bar{\rho}_{W}\right)^{n}+\left(S_{g} \bar{\rho}_{g} y_{s}\right)^{n}\right\}\right] \\
& \tau_{H_{2} O}= \tau_{W}+\tau_{g} y_{s} \\
& R_{4}=\Delta\left(\tau_{W} \Delta \Phi_{W}+\tau_{g} y_{s} \Delta \Phi_{g}\right)^{n}+q_{W} \bar{\rho}_{W}+q_{g} y_{s} \bar{\rho}_{g}
\end{aligned}
$$$$
\text { and }
$$

The energy balance equation 3.5 is also expanded in terms of unknown varlables. Thus,

$C_{51} \delta x_{1}+C_{52} \delta x_{2}+C_{53} \delta x_{3}+C_{54} \delta S_{W}+C_{55} \delta S_{g}+C_{56} \delta T+C_{57} \delta p_{o}$

$$
=\left(\tau_{H} \Delta \delta p_{o}\right)+R_{5}
$$

The coefficients $C_{5}$ are obtained from equation $C_{-}-95$ in appendix $C_{\text {. }} \tau_{H}$ and $R_{5}$ are defined as in equations 4.6 and 4.7 . Then

$$
\begin{aligned}
& C_{5 j}=\frac{V_{b}}{\Delta t}\left[\left(\phi S_{o} \bar{\rho}_{0}\right)^{n+1} \sum_{j=1}^{3}\left(\frac{\partial U_{0}}{\partial x_{j}}\right)^{l}+\left(\phi s_{0}\right)^{n+1} U_{o}^{n}\left(\frac{\partial \bar{\rho}_{o}}{\partial x_{j}}\right)^{\prime}+\left(\phi s_{g} \bar{\rho}_{g}\right)^{n+1} \sum_{j=1}^{3}\left(\frac{\partial U_{g}}{\partial y}\right)^{l} K_{j}^{n+1}\right] \quad j=1,2,3 \\
& C_{54}=\frac{V_{b}}{\Delta t}\left[\phi^{n+1}\left(\bar{\rho}_{w} U_{W}\right)^{n}-\phi^{n+1}\left(\bar{\rho}_{0} U_{0}\right)^{n}\right] \\
& C_{55}=\frac{V_{b}}{\Delta t}\left[\phi^{n+1}\left(\bar{\rho}_{g} U_{g}\right)^{n}-\phi^{n+1}\left(\bar{\rho}_{o} U_{0}\right)^{n}+\left(\phi y_{s}\right)^{n+1}\left(\bar{\rho}_{g} U_{g}\right)^{n}\right] \\
& C_{56}=\frac{V_{b}}{\Delta t}\left[\left(\phi S_{0} \bar{\rho}_{0}\right)^{n+1}\left(\frac{\partial U_{0}}{\partial T}\right)_{p}^{l}+\left(\phi S_{0}\right)^{n+1} U_{0}^{n}\left(\frac{\partial \bar{\rho}_{0}}{\partial T}\right)_{p}^{l}+\left(\phi S_{g} \bar{\rho}_{g}\right)^{n+1} l\right. \\
& \left.\sum_{\mid=1}^{3} x^{p}\left(\frac{\partial U_{g}}{\partial y_{l}}\right)^{l}\left(\frac{\partial K_{i}}{\partial T}\right)_{p}^{l}+\left(\frac{\partial U_{g}}{\partial T}\right)_{y}^{l}\right)+\left(\phi S_{g}\right)^{n+1} U_{g}^{n}\left(\frac{\partial \bar{\rho}_{g}}{\partial T}\right)_{p}^{l} \\
& +\left(\phi S_{W}\right)^{n+1} U_{W}^{n}\left(\frac{\partial \bar{\rho}_{W}}{\partial T}\right)_{p}^{l}+\left(\phi S_{W} \bar{\rho}_{W}\right)^{n+1}\left(\frac{d U_{W}}{d T}\right)^{\prime}+\left(\phi S_{g} \bar{\rho}_{g} y_{s}\right)^{n+1}\left(\frac{d U_{s}}{d T}\right)^{\prime} \\
& +\left(\phi S_{g} y_{s}\right)^{n+1} U_{s}^{n}\left(\frac{\partial \bar{\rho}_{g}}{\partial T}\right)_{p}^{l}+\phi^{n+1}\left(S_{g} \bar{\rho}_{g} U_{s}\right)^{n}\left(\frac{\partial K_{4}}{\partial T}\right)_{p}^{l} \\
& +\left(\rho C_{p}\right) R\left(1-\phi^{n+1}\right)
\end{aligned}
$$




$$
\begin{aligned}
& C_{57}=\frac{V_{b}}{\Delta t}\left[\left(\phi S_{o}\right)^{n+1} U_{0}^{n}\left(\frac{\partial \bar{\rho}_{o}}{\partial p}\right)_{T, x}^{1}+\left(\phi S_{g} \bar{\rho}_{g}\right)^{n+1}\left\{\sum_{\mid=1}^{3} x \Gamma^{n}\left(\frac{\partial U_{g}}{\partial y_{l}}\right)_{j}^{l}\left(\frac{\partial K_{l}}{\partial p}\right)_{T}^{\prime}\right\}\right. \\
& +\left(\phi S_{g}\right)^{n+1} \cup_{g}^{n}\left(\frac{\partial \bar{\rho}_{g}}{\partial p}\right)_{T}^{l}+\left(\phi S_{W}\right)^{n+1} u_{W}^{n}\left(\frac{\partial \bar{\rho}_{W}}{\partial p}\right)_{T}^{l} \\
& +\left(\phi S_{g} y_{s}\right)^{n+1} U_{s}^{n}\left(\frac{\partial \bar{\rho}_{g}}{\partial p}\right)_{T}^{l}+\phi^{n+1}\left(S_{g} \bar{\rho}_{g} U_{s}\right)^{n}\left(\frac{\partial K_{4}}{\partial p}\right)_{T}^{l} \\
& \left\{\left(S_{o} \bar{\rho}_{o} U_{o}\right)^{n}+\left(S_{g} \bar{\rho}_{g} U_{g}\right)^{n}+\left(S_{w} \bar{\rho}_{W} U_{W}\right)^{n}+\left(S_{g} \bar{\rho}_{g} y_{s} U_{s}\right)^{n}\right\} \\
& \left.\phi \text { int } C_{R}\right]
\end{aligned}
$$

and

$$
R_{5}=\Delta\left(\tau_{H} \Delta \Phi_{0}\right)^{n}+\left(\tau_{0} \Delta T^{n+1}\right)+Q_{H} \cdot Q_{L}^{n+1}
$$

Where $T^{n+1}$ and $Q L^{n+1}$ are used as the latest iterate value.

The oleic phase composition constraint is given by

$\mathrm{C}_{61} \delta \mathrm{x}_{1}+\mathrm{C}_{62} \delta \mathrm{x}_{2}+\mathrm{C}_{63} \delta \mathrm{x}_{3}+\mathrm{C}_{64} \delta \mathrm{S}_{\mathrm{w}}+\mathrm{C}_{65} \delta \mathrm{S}_{\mathrm{g}}+\mathrm{C}_{66} \delta \mathrm{T}+\mathrm{C}_{67} \delta \mathrm{p}_{\mathrm{o}}=0$

The coefficients $C_{6]}$ are obtained from equation $\mathrm{C}-96$ in appendix $C$. Thus,

$$
\begin{array}{ll}
C_{6 j}=1 & j=1,2,3 \\
C_{6 k}=0.0 & k=4,5,6,7
\end{array}
$$

and $R_{6}=0.0$

Finally, the gas phase mole fraction constraint can be written as

$C_{71} \delta x_{1}+C_{72} \delta x_{2}+C_{73} \delta x_{3}+C_{74} \delta S_{w}+C_{75} \delta S_{g}+C_{76} \delta T+C_{77} \delta p_{0}=0$

The coefficients $\mathrm{C}_{7 \text { j }}$ are obtained from equation $\mathrm{C}-99$ in appendix $\mathrm{C}$. Thus,

$$
\begin{aligned}
& C_{7 j}=K^{n+1} \quad J=1,2,3 \\
& C_{74}=C_{75}=0.0
\end{aligned}
$$




$$
\begin{aligned}
& C_{76}=\sum_{i=1}^{3} x^{n}\left(\frac{\partial K_{i}}{\partial T}\right)_{p}^{l}+\left(\frac{\partial K_{4}}{\partial T}\right)_{p}^{1} \\
& C_{77}=\sum_{i=1}^{3} x^{\prime}\left(\frac{\partial K_{i}}{\partial p}\right)_{T}^{l}+\left(\frac{\partial K_{4}}{\partial p}\right)_{T}^{1}
\end{aligned}
$$

and $\mathrm{R}_{7}=0.0$

Expressions for computing the flow vector $R_{1}, i=1,7$ are given in appendix $D$.

\section{Sequentlal Solution}

Equations $4.8,4.15,4.23,4.30$ and 4.34 are seven equations in the seven unknowns $\delta x_{1}, \delta x_{2}, \delta x_{3}, \delta S_{w}, \delta S_{g}, \delta T$, and $\delta p_{0}$ and can be represented for any particular grid block by

$$
\left[\begin{array}{lllllll}
\mathrm{C}_{11} & \mathrm{C}_{12} & \mathrm{C}_{13} & \mathrm{C}_{14} & \mathrm{C}_{15} & \mathrm{C}_{16} & \mathrm{C}_{17} \\
\mathrm{C}_{21} & \mathrm{C}_{22} & \mathrm{C}_{23} & \mathrm{C}_{24} & \mathrm{C}_{25} & \mathrm{C}_{26} & \mathrm{C}_{27} \\
\mathrm{C}_{31} & \mathrm{C}_{32} & \mathrm{C}_{33} & \mathrm{C}_{34} & \mathrm{C}_{35} & \mathrm{C}_{36} & \mathrm{C}_{37} \\
\mathrm{C}_{41} & \mathrm{C}_{42} & \mathrm{C}_{43} & \mathrm{C}_{44} & \mathrm{C}_{45} & \mathrm{C}_{46} & \mathrm{C}_{47} \\
\mathrm{C}_{51} & \mathrm{C}_{52} & \mathrm{C}_{53} & \mathrm{C}_{54} & \mathrm{C}_{55} & \mathrm{C}_{56} & \mathrm{C}_{57} \\
\mathrm{C}_{61} & \mathrm{C}_{62} & \mathrm{C}_{63} & \mathrm{C}_{64} & \mathrm{C}_{65} & \mathrm{C}_{66} & \mathrm{C}_{67} \\
\mathrm{C}_{71} & \mathrm{C}_{72} & \mathrm{C}_{73} & \mathrm{C}_{74} & \mathrm{C}_{75} & \mathrm{C}_{76} & \mathrm{C}_{77}
\end{array}\right]\left[\begin{array}{c}
\delta_{\times 1} \\
\delta_{\times 2} \\
\delta_{\times 3} \\
\delta \mathrm{S}_{\mathrm{W}} \\
\delta \mathrm{S}_{\mathrm{g}} \\
\delta T \\
\delta \mathrm{p}_{0}
\end{array}\right]=\left[\begin{array}{c}
0 \\
\Delta\left(\tau_{1} \Delta \delta \mathrm{p}_{0}\right) \\
\Delta\left(\tau_{2} \Delta \delta \mathrm{p}_{0}\right) \\
\Delta\left(\tau_{3} \Delta \delta \mathrm{p}_{0}\right) \\
\Delta\left(\tau_{\mathrm{H}_{20}} \Delta \delta \mathrm{p}_{0}\right) \\
\Delta\left(\tau_{H} \Delta \delta \mathrm{p}_{0}\right) \\
0
\end{array}\right]+\left[\begin{array}{c}
R_{1} \\
R_{2} \\
R_{3} \\
R_{4} \\
R_{5} \\
R_{6} \\
R_{7}
\end{array}\right]
$$

Where $C_{i j}, R_{i}, \tau_{1}, \tau_{w}$, and $\tau_{H}$ have been previously defined. Equation 4.40 can be expressed in matrix form as

$$
C \vec{X}=1 \vec{Y}+\vec{R}
$$

The matrices $\mathrm{C}$ and $\mathrm{I}$ are the coefficients $\mathrm{Clj}$ matrix and the identity matrix of order seven, respectively. The column vectors $\vec{X}, \vec{Y}$ and $\vec{R}$ are defined as follows:

$$
\begin{aligned}
& \vec{X}=\left[\delta x_{1}, \delta x_{2}, \delta x_{3}, \delta S_{w_{1}} \delta S_{g}, \delta \mathrm{T}, \delta p_{0}\right]^{\top} \\
& \vec{Y}=\left[0, \Delta\left(\tau_{1} \Delta \delta p_{0}\right), \Delta\left(\tau_{2} \Delta \delta p_{0}\right), \Delta\left(\tau_{3} \Delta \delta p_{0}\right), \Delta\left(\tau_{H_{2} O} \Delta \delta p_{o}\right), \Delta\left(\tau H \Delta \delta p_{0}\right), 0\right]^{\top}
\end{aligned}
$$

and

$$
\vec{R}=\left[R_{1}, R_{2}, R_{3}, R_{4}, R_{5}, R_{6}, R_{7}\right]^{\top}
$$


Gaussian elimination is used to transform equation 4.41 into

$$
U \vec{X}=L \vec{Y}+\vec{R}^{\prime}
$$

Where matrices $U$ and $L$ are upper and lower triangular matrices, respectively, and defined as

$$
U=\left[\begin{array}{ccccccc}
C_{11} & C_{12} & C_{13} & C_{14} & C_{15} & C_{16} & C_{17} \\
& U_{22} & U_{23} & U_{24} & U_{25} & U_{26} & U_{27} \\
& & U_{33} & U_{34} & U_{35} & U_{36} & U_{37} \\
& & & U_{44} & U_{45} & U_{46} & U_{47} \\
& 0 & & & U_{55} & U_{56} & U_{57} \\
& & & & & U_{66} & U_{67} \\
& & & & & &
\end{array}\right]
$$

and

$$
L=\left[\begin{array}{cccccccc}
1 & & & & & & \\
L_{21} & 1 & & & & 0 & \\
L_{31} & L_{32} & 1 & & & & \\
L_{41} & L_{42} & L_{43} & 1 & & & \\
L_{51} & L_{52} & L_{53} & L_{54} & 1 & & \\
L_{61} & L_{62} & L_{63} & L_{64} & L_{65} & 1 & \\
L_{71} & L_{72} & L_{73} & L_{74} & L_{75} & L_{78} & 1
\end{array}\right]
$$

and $\vec{R}$ is a column vector given by

$$
\vec{R}^{\prime}=\left[R_{1}^{\prime}, R_{2}^{\prime}, R_{3}^{\prime}, R_{4}^{\prime}, R_{5}^{\prime}, R_{6}^{\prime}, R_{7}^{\prime}\right]^{\top}
$$

The procedure to obtain terms of $U, L$ and $R^{\prime}$ is summarized below.

$$
\alpha_{M K}=\frac{U_{M K}}{U_{K K}}, K=1,6 \text { and } M=K+1,7
$$

Then

$$
\begin{array}{ll}
L_{M N}=L_{M N}-\alpha_{M K} U_{K N} & N=1, K \\
U_{M N}=U_{M N}-\alpha_{M K} U_{K N} & N=M, 7
\end{array}
$$

and

$$
R_{M}^{\prime}=R_{M}^{\prime}-\alpha_{M K} R_{K}^{\prime} \quad N=M, 7
$$


Initially $U_{M N}, L_{M N}$ and $R_{K}$ are equal to the elements of the matrices $I, C$ and vector $\vec{R}$, respectively.

The last equation of the system of equations 4.45 is

$$
\begin{gathered}
U_{77} \delta p_{0}=L_{72} \Delta\left(\tau_{1} \Delta \delta p_{0}\right)+L_{73} \Delta\left(\tau_{2} \Delta \delta p_{0}\right)+L_{74} \Delta\left(\tau_{3} \Delta \delta p_{0}\right) \\
+L_{75} \Delta\left(\tau_{H_{2 O}} \Delta \delta p_{0}\right)+L_{76} \Delta\left(\tau_{H} \Delta \delta p_{0}\right)+R_{7}^{\prime}
\end{gathered}
$$

This is a paraiolis difference equation in pressure of the type commonly encountered in reservoir simulation probı sms. Equation 4.53 can be written in compact notation as

$$
U_{77} \delta p_{0}=\Delta\left(\tau \Delta \delta p_{0}\right)+R_{7}^{\prime}
$$

Where

$$
\tau=L_{72} \tau_{1}+L_{73} \tau_{2}+L_{74} \tau_{3}+L_{75} \tau_{H_{2 O}}+L_{76} \tau_{H}
$$

In the interest of clarity, we have dropped the subscript ' $O$ ' in $p$

As shown in appendix $E$, equation 4.53 can be written as the following five-point finite difference equation:

$$
\begin{aligned}
U_{77} \delta p^{n+1}=A S_{j} & \left(\delta p_{i, j-1}^{n+1}-\delta p_{i, j}^{n+1}\right)+A W_{i}\left(\delta p_{i-1, j}^{n+1}-\delta p_{i, j}^{n+1}\right)+A E_{i}\left(\delta p_{i+1, j}^{n+1}-\delta p_{i, j}^{n+1}\right) \\
& +A N_{j}\left(\delta p_{i, j+1}^{n+1}-\delta p_{i, j}^{n+1}\right)+R_{7}^{\prime}
\end{aligned}
$$

Equation 4.56 may be written in the form

$$
\begin{aligned}
& \begin{array}{ll}
A S_{j} \delta p_{i, j-1}^{n+1}+A W_{i} \delta p_{i-1, j}^{n+1}+A E_{i} \delta p_{i+1, j}^{n+1}+A N_{j} \delta p_{i, j+1}^{n+1}+E \delta p_{i, j}^{n+1}=B \\
\text { Where } \\
\text { and } & B=-\left(A S_{j}+A W_{i}+A E_{i}+A N_{j}+U_{77}\right) \\
B & =-R_{7}
\end{array}
\end{aligned}
$$

Coefficients AS, AW, AE and AN are defined in appendix $E$.

Equation 4.56 called the "pressure equation" yields a penta diagonal system of linear equation. A direct method (D-4 Gaussian Elimination) is used to solve the pressure equation.

Once the pressure equation 4.56 is solved for pressure, the other uniknowns are calculated by back substitution. Thus, the remaining six unknowns are calculated by: 


$$
\begin{aligned}
& \delta T=\frac{1}{U_{66}}\left[L_{62} \Delta\left(\tau_{1} \Delta \delta p\right)+L_{63} \Delta\left(\tau_{2} \Delta \delta p\right)+L_{64} \Delta\left(\tau_{3} \Delta \delta p\right)+\right. \\
& \left.L_{65} \Delta\left(\tau_{H_{20}} \Delta \delta p\right)+\Delta\left(\tau_{H} \Delta \delta p\right)-U_{67} \delta p+R_{6}^{\prime}\right] \\
& S S_{g}=\frac{1}{U_{55}}\left[L_{52} \Delta\left(\tau_{1} \Delta \delta p\right)+L_{53} \Delta\left(\tau_{2} \Delta \delta p\right)+L_{54} \Delta\left(\tau_{3} \Delta \delta p\right)\right. \\
& +\Delta\left(\tau_{H_{2 O}} \Delta \delta p\right)-U_{56} \delta T-U_{57} \delta p+R_{5 l}^{\prime} \\
& \delta S_{w}=\frac{1}{U_{44}}\left[L_{42} \Delta\left(\tau_{1} \Delta \delta p\right)+L_{43} \Delta\left(\tau_{2} \Delta \delta p\right)+\Delta\left(\tau_{3} \Delta \delta p\right)-U_{45} \delta S_{g}\right. \\
& \left.U_{46} \delta T-U_{47} \delta p+R_{4}^{\prime}\right] \\
& \delta x_{3}=\frac{1}{U_{33}}\left[L_{32} \Delta\left(\tau_{1} \Delta \delta p\right)+\Delta\left(\tau_{2} \Delta \delta p\right)-U_{34} \delta S_{w}-U_{35} \delta S_{g}\right. \\
& \left.-U_{36} \delta T-U_{37} \delta p+R_{3}^{\prime}\right] \\
& \delta x_{2}=\frac{1}{U_{22}}\left[\Delta\left(\tau_{1} \Delta \delta p\right)-U_{23} \delta x_{3}-U_{24} \delta S_{w}-U_{25} \delta S_{g}-U_{26} \delta T\right. \\
& \left.-U_{27} \delta p+R_{2}^{\prime}\right] \\
& \delta x_{1}=\frac{1}{U_{11}}\left[-U_{12} \delta x_{2}-U_{13} \delta x_{3}-U_{14} \delta S_{w}-U_{15} \delta S_{g}-U_{16} \delta T\right. \\
& \left.-U_{17} \delta P+R_{1}^{\prime}\right]
\end{aligned}
$$

Finally, the unknowns at the new time level $(n+1)$ are obtained

$$
\text { r } \begin{aligned}
p^{n+1} & =p^{n}+\delta p \\
T^{n+1} & =T^{n}+\delta T \\
S_{g}^{n+1} & =S_{g}^{n}+\delta S_{g} \\
S_{w}^{n+1} & =S_{w}^{n}+\delta S_{w} \\
\text { and } \quad x_{j}^{n+1} & =x_{i}^{n}+\delta x_{i} \quad i=1,2,3
\end{aligned}
$$




\section{Solutlon Scheme}

The solution procedure is now summarized for a time-step:

1. The coefficients $C_{i j}$ are calculated using values at the end of previous time-step. For the first time-step, values at the initial conditions were used.

2. Next, the coefficient matrix is transformed to upper and lower triangular matrices using Gaussian elimination.

3. From the elements of upper and lower triangular matrices generate pressure equation 4.56, one for each grid block. Solve the resulting $N$ equations for $\delta p_{0}$ using the reduced band-width (D-4) direction solution technique. 66

4. Using equations 4.60 through 4.65 , calculate the other unknowns for each grid block by back substitution.

5. Next calculate the latest iterate values as

$$
p^{l+1}=p^{n}+\delta p^{n+1}, T^{1+1}=T^{n}+\delta T^{n+1}, \text { etc. }
$$

6. Update physical properties, transmissibility and so forth, using the latest iterate values.

7. Calculate $C_{i j}, \vec{\tau}$ and $\vec{R}$ using the latest iterate values.

8. Repeat steps 2 through 7 until $\left|\delta p^{l+1}-\delta p^{\prime}\right|$ and $\left|\delta T^{l+1}-\delta T^{\prime}\right|$ is less than specified tolerances for all grid blocks. Here the superscript 1 is iteration number.

9. Determine pressure, temperature and saturation profiles, fluid and energy injection/production history and material/energy balance errors.

10. Go to next time-step.

Usually four to five iterations suffice for a time-step.

\section{Injection and Production Rates}

The model accounts for injection of hot water or steam at constant rates. An injection or production well may exist at any grid block. 
Production occurs against a specified back pressure. Explicit production rates are used in the present study. The volumetric production rates of individual phases are calculated by:

$$
\begin{aligned}
& q_{0}=\operatorname{PI}\left(p_{0}-p_{w t}\right) \frac{k_{r o}}{\mu_{0}} \\
& q_{w}=\operatorname{PI}\left(p_{0}-p_{w t}\right) \frac{k_{w w}}{\mu_{w}} \\
& q_{g}=\operatorname{PI}\left(p_{0}-p_{w t}\right) \frac{k_{r g}}{\mu_{g}}
\end{aligned}
$$

In 1-D and in 2-D cross sectional simulation, the flow is linear and productivity index (PI) is given by

$$
\mathrm{PI}=\frac{\xi \sqrt{k_{x}} k_{y} \Delta Z h}{\Delta X / 2}
$$

Where $\xi$ is a constant and depends on the unit of flow rate and permeability.

When the flow rate ' $q$ ' is expressed in $\mathrm{H}^{3} / \mathrm{d}$ and ' $\mathrm{k}$ ' is in md, $\xi=0.006436$. When ' $q$ ' is in cc/hr and ' $k$ ' is in $\mathrm{md}, \xi=7566.274$.

Molar producing rates from wells producing from a single layer can be written for hydrocarbon components as

$$
m_{i}=-c_{b} \bar{p}_{0} x_{i}-q_{g} \bar{p}_{g} y_{i} \quad i=1,2,3
$$

and for water

$$
m_{4}=-q_{w} \bar{p}_{w}-q_{g} \bar{\rho}_{g} y_{s}
$$

Molar injection rate for water (steani) is specified as

$$
m_{4}=-i_{w} \bar{P}_{w_{s}}
$$

\section{Time-Ster Selection}

For nonlinear equations, the amount of truncation error introduced by time-step size is a degree of the nonlinearity of the reservoir equation. By controlling the time-step size, more accurate results are obtained in the simulator. The restrictions of the time-step are also related with changes in pressure and saturations. In the current model, conditional stability due to the explicit calculations of relative permeabilities, capillary pressure and production rates impose limitations on the permissible time-step. 
Diaz, 67 Vinsome, ${ }^{20}$ and Coats ${ }^{26}$ discussed this subject in detail for thermal simulators. In this study, the time-step size is adjusted using limiting pressure and saturation changes $\Delta \mathrm{p}_{\max }$ and $\Delta \mathrm{S}_{\max }$, respectively.

$$
\Delta S_{\max }^{n+1}=\max \left\{\frac{S^{n+1}-S^{n}}{S^{n}}\right\}
$$

and $\Delta p_{\max }^{n+1}=\max \left\{\frac{p^{n+1}-p^{n}}{p^{n}} \mid\right\}$

The limiting values of saturation and pressure are then compared with equations 4.78 and 4.79 . If these limits are exceeded, the time-step is repeated with a new time-step size. The new time-step size is determined from the following formulation:

$$
\Delta t^{n+1}=\min \left(\Delta t_{p}, \Delta t_{s}\right)
$$

where

$$
\Delta t_{p}=\Delta t^{n+1} \frac{\Delta p l i m}{\Delta p_{\max }}
$$

and $\Delta t_{s}=\Delta t^{n+1} \frac{\Delta S_{l i m}}{\Delta S_{\max }}$

In equation 4.81 and $4.82 \Delta t^{n+1}$ is the current time-step size.

\section{Material and Energy Balance Checks}

The results obtained with the finite difference scheme are checked for the conservation of mass and energy ait the end of each time-step. These criteria provide a means of control on the consistency of the solutions.

\section{Materlal Balance}

The incremental molar balance for the hydrocarbon component $i$ is represented by

$$
\left(I_{M B}\right)_{i}=\frac{\left(n_{t_{i}}\right)^{n}-\left(n_{t_{i}}\right)^{n+1}}{m_{i_{i}} \Delta t}
$$

The cumulative molar balance for the hydrocarbon component $i$ is represented by

$$
\left(C_{M B}\right)_{i}=\frac{\left(n_{t_{i}}\right)^{p}-\left(n_{t_{j}}\right)^{n+1}}{\sum_{j=1}^{n+1} m_{i_{i}} \Delta t_{j}}
$$


Where

$\left(n_{t}\right)^{n}=$ total moles of component $i$ in the reservoir at time $n$

$\left(n_{t}\right)^{\rho}=$ total moles of component $i$ initially in the reservoir (i.e. at time o)

$\mathrm{m}_{\mathrm{it}}=$ total molar producing rate of component $\mathrm{l}$.

The total moles of the hydrocarbon component $i$ in the reservoir at any given time are calculated as

$$
n_{t \mid}=\sum_{\substack{\text { all reservoir } \\ \text { blocks }}} v_{p}\left(\bar{\rho}_{o} S_{o} x_{i}+\bar{\rho}_{g} S_{g} y_{i}\right) \quad i=1,2,3
$$

Where $V_{p}$ is the grid pore volume, and for water

$$
n_{t_{4}}=\sum_{\substack{\text { all } \\ \text { bloservoir } \\ \text { blocks }}} v_{p}\left(\bar{\rho}_{w} s_{w}+\bar{\rho}_{g} s_{g} y_{s}\right)
$$

The total molar production rate for component $i$ is given by

$$
n_{i t}=\sum_{\substack{\text { all reservoir } \\ \text { blocks }}} m_{i} \quad i=1,2,3,4
$$

Where $m_{i}$ is the molar production rate of component $i$.

\section{Energy Balance}

The incremental and cumulative heat balances are represented by

$$
I H B=\frac{\left(H_{t}\right)^{n}-\left(H_{t}\right)^{n+1}}{\dot{Q}_{t} \Delta t}
$$

and

$$
C_{H B}=\frac{\left(H_{t}\right)^{0}-\left(H_{t}\right)^{n+1}}{\sum_{m=1}^{n+1} \dot{Q}_{t_{m}} \Delta t_{m}}
$$

Where

$\left(H_{t}\right)^{n}=$ total energy remaining in the reservoir at time $n, B t u / l b-m o l e$.

$\left(H_{t}\right)^{\rho}=$ total energy initially in the reservoir, Btu/lb-mole (i.e. at time o). 
The total heat in the reservoir at any given time is computed by

$$
H_{t}=\sum_{\substack{\text { all reservoir } \\ \text { blocks }}}\left[V_{b}(\hat{i}-\phi) \rho_{R} C_{R} T+V_{b} \phi\left\{\bar{\rho}_{o} S_{o} H_{0}+\bar{\rho}_{w} s_{w} H_{w}+\bar{\rho}_{g} S_{g} H_{g}\right\}\right]
$$

The total molar heat production rate from the reservoir is estimated as follows:

$$
\dot{Q}_{t}=\sum_{\substack{\text { all } \\ \text { bloservoir }}}\left(q_{0} \bar{p}_{0} H_{0}+q_{w} \bar{\rho}_{w} H_{w}+q_{g} \bar{p}_{g} H_{g}\right)-\dot{Q}_{i}+\dot{Q}_{L}
$$

Where

$$
\begin{gathered}
\dot{Q}_{i=}=\text { molar heat injection rate and is given by } \\
\dot{Q}_{i}=i_{w} \bar{P}_{w s} H_{s_{i}}
\end{gathered}
$$

\section{Elash Calculation}

A flash calculation is performed to estimate the composition of oil and gas phase in equilibrium at any pressure and temperature. The basic equations used are the mole fraction constraints equations viz

$$
\begin{aligned}
& \sum_{i=1}^{3} z_{i}=1.0 \\
& \sum_{i=1}^{3} x_{i}=1.0
\end{aligned}
$$

and

$$
\sum_{i=1}^{4} y_{i}=1.0
$$

If $V$ is the number of moles of vapor in one mole of hydrocarbon system, then a molar balance for component i.yields

$$
z_{1}=(1-V) x_{i}+V_{y_{1}}
$$

Using the equilibrium ratio definition $K_{i}=y_{1} / x_{i}$ the liquid and vapor mole fractions can be obtained from equation 4.96 as

$$
x_{i}=\frac{z_{i}}{1+V\left(K_{i}-1\right)}
$$

$$
i=1,2,3
$$

and 


$$
y_{1}=\frac{K_{1} z_{1}}{1+V\left(K_{i}-1\right)}
$$

$$
1=1,2,3
$$

Water component is assumed to exist only in the water and gas phases; consequently

$$
\sum_{i=1}^{4} y_{i}-\sum_{i=1}^{3} x_{i}=-y_{4}=-y_{s}
$$

combining equations $4.97,4.98$, and 4.99 , we have

$$
\sum_{i=1}^{3} \frac{k_{i} z_{i}}{1+V\left(k_{i}-1\right)}-\sum_{i=1}^{3} \frac{z_{i}}{1+V\left(k_{i}-1\right)}+y_{s}=0.0
$$

Equation 4.100 can be written as

$$
F(V)=\sum_{i=1}^{3} \frac{z_{i}\left(K_{i}-1\right)}{1+V\left(K_{i}-1\right)}+y_{s}=0.0
$$

The Newton-Raphson iterative scheme is used to solve equation 4.101 for $V$. The basic relationship is

$$
V^{n+1}=V^{n}-\frac{f(V)^{n}}{f^{\prime}(V)^{n}}
$$

Where

$$
f^{\prime}(V)^{n}=\frac{d}{d V} f(V)
$$

Initially $V$ is chosen as 0.5

\section{Composition and Saturation Caiculations}

The composition of hydrocarbon systems is assumed to be known initially for each grid block in the reservoir. A flash calculation is performed at the reservoir condition to obtain total moles of gas at equilibrium condition and the oil and gas compositions are computed (equations 4.97 and 4.98). The initial oil saturation is given by

$$
S_{0}=\frac{(1-V)}{(1-V)+V\left(\bar{\rho}_{0} / \rho_{g}\right)}\left(1-S_{W}\right)
$$

and the gas saturation is calculated from

$$
S_{g}=1.0-S_{0}-S_{W}
$$




\section{Surface Production Rates}

A flash calculation is performed on the produced fluids to obtain oil and gas production rates. Since the total composition and moles of the produced fluids are known, the phase production rates can be calculated. Thus, phase production rates are given by

$$
9_{0 p}=\frac{(1-V) \delta n_{t}}{5.615 \bar{\rho}_{o_{s}} \Delta t}
$$

Where $\delta n_{t}=$ total moles of fluid produced during the time step

and $\quad \bar{\rho}_{\mathrm{o}_{\mathrm{s}}}=$ molar density of oll at surface condition

$$
q_{\mathrm{p}}=\frac{379 \vee \delta_{n t}}{\Delta t}
$$

and $q_{w_{p}}=\frac{q_{w} \bar{\rho}_{w_{r}}}{5.615 \bar{\rho}_{w_{s}}}$

Where

$$
\begin{aligned}
& \bar{\rho}_{w_{r}}=\text { molar density of water at reservoir condition. } \\
& \bar{\rho}_{W_{S}}=\text { molar density of water at surface condition. }
\end{aligned}
$$

In the above $q_{o_{p}}$ and $q_{w_{p}}$ are given in STB/D and $q_{g_{p}}$ in SCF/D. 


\section{ChAPTER 5. - COMPUTATIONAL PROCEDURE}

A FORTRAN computer program PCSIPS (Pseudo Compositional Steam Injection Process Simulator) was written to numerically simulate a steamdrive process by the model described in the foregoing chapters.

This program has the following features:

(i) It is an IMPES type model.

(ii) It accepts both regular and irregular grid size distributions.

(iii) The program was written for two-dimensional block-centered reotangular coordinates,

(iv) It implements the automatic time-step control.

(v) It can simulate hot water and steam injection operations.

(vi) It accepts a maximum of three hydrocarbon components.

In its present form, the code has sufficient storage for $10 \times 5$ grid spacing. The program was compiled using the Microsoft FORTRAN compiler version 5.0 and tested in an IBM PC-AT type machine, equipped with a math coprocessor. The sequence of execution in the main program is shown in figure 5-1. The coding consists of a main program, 27 subroutines, and one function subroutine. The main features of the different program units are briefly described in the following paragraphs.

\section{Main Proaram}

This is the driver routine. In the main program, the simulation is started by reading in the necessary data together with controls and switches. The main program regulates the general flow of the computations and writes the results in the output file.

\section{SUBROUTINES}

BEAD1: This subroutine reads and prints initial reservoir and fluid data. These include porosity, permeability, reservoir thickness, grid sizes, number and maximum permitted number of blocks in the $x$ and $z$ direction, number of blocks to represent the overburden, initial reservoir pressure and temperature, initial fluid saturation, initial hydrocarbon composition, well information, surface information, program and time-step control parameters.

BEAD2: $\quad$ This subroutine reads and prints all data needed for physical properties calculation. These include parameters for calculating the viscositles and densities of oil, water and gas, parameters for calculating steam propertles, thermal conductivities, heat capacitles, molecular weights of hydrocarbon components, heats of vaporization, K-values, the relative permeability and capillary pressure data. 


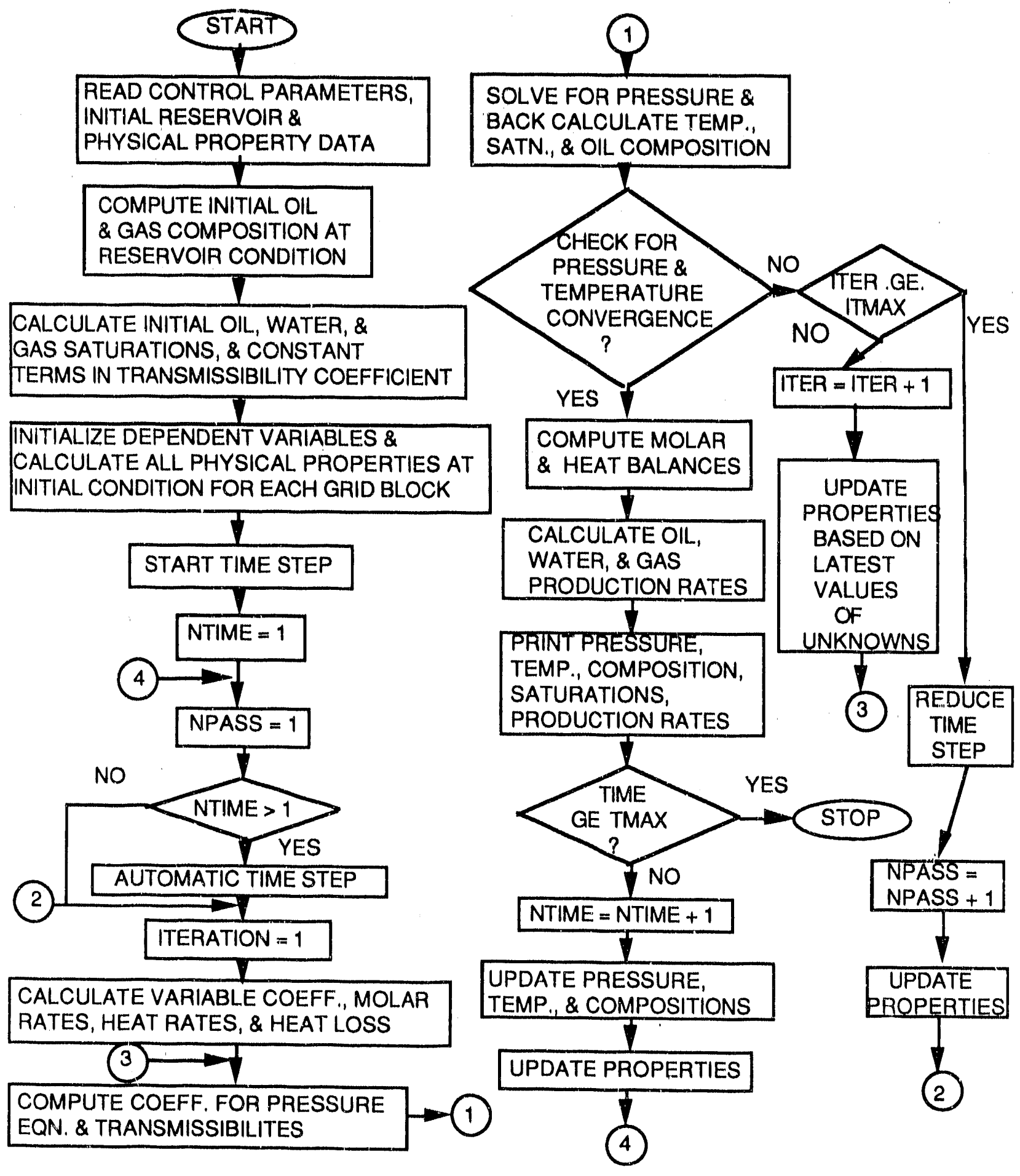

FIGURE. 5.1. - Schernatic of logic in laboratory thermal numerical simulator. 
BLOCKDATA: This subroutine Initiallizes certain varlables and assigns values to varlous constants such as factors for converting fleld values to laboratory values.

INITIAL.: This subroutine calculates rock-fluid propertles at initial reservoir conditions. It also calculates the initial pressure, temperature, saturation and composition distribution. All terms which remain constant in the program during a run such as block volumes, elevation, normalized form of relative permeabilities, the initlal moles in place, initlal energy in place and other items are calculated in this subroutine.

PROPEB: This subroutine calculates dunsities, viscosities, internal energies, $K$-values, relative permeabilities, capillary pressure and all other pressure/temperature/saturation dependent properties at the conditions of each grid block. This routine also calculates the partlal derivatives of various functions at the latest iterate values. Such functions include density, internal energies, enthalples and others.

EQBCONS: This subroutine performs a table look-up to determine the $\mathrm{K}$ values for a given pressure and temperature. The derivatives of $\mathrm{K}$ w.r.t. pressure and temperature are also calculated.

CTRAN: This subroutine computes the constant parts of transmissibilities and transconductivities.

ELASH: This subroutine performs a two-phase vapor-liquid equilibrium calculation at a given pressure and temperature ( $\mathrm{p} \& T)$, and calculates phase compositions.

LININTP: $\quad$ This is a calling program to perform a 2-D linear interpolation of K-value tables.

LIN2D: $\quad$ 2-D linear interpolation subroutine.

LAGRAN: This subroutine calculates the first derivatives of a function at a given point using Lagrange's interpolation formula.

SPLINE: This is a calling program to perform 2-D cubic spline interpolation of $K$-values and relative permeabilities.

CUBSPL: This subroutine computes the coefficients used in the cubic splines interpolation of a given set of data.

SEARCH: This subroutine performs a binary search to locate the proper interval for a point in a twodimensional table. 
LINTP: $\quad$ This subroutine performs a linear interpolation from tabulated data.

COEFE: Thls subroutine formulates the acoumulation term coefficient matrix and the right-hand side vector. Gaussian elimination procedure is used to transform the coefficient matrix into upper and lower triangular matrices.

COEFPM: This subroutine computes the coefflcients for the pressure equation and sets up the coefficlent matrix for each grid blook.

SUBST: This subroutine determines the current cell block temperature, phase saturation and composition.

D4IN: This subroutine reorders the coefficient matrix on alternating diagonals (D-4 ordering).

Q4: This subroutine solves the D-4 ordered matrix by Gaussian elimination.

BAND: This subroutine solves the coefficient matrix using BAND algorithm.

PRODCTN: This subroutine calculates the molar steam injection rates, total hydrocarbon and water production rates, as well as the individual hydrocarbon component production rates. The routine also calculates the enthalpy injection and production rates and well productivity index.

MTLHIB: This subroutine computes incremental and cumulative material and energy balance errors.

HTLESS: This routine employs a one-dimensional heat conduction (diffusivity) equation to calculate the rate of heat loss to and temperature in the adjacent strata.

PRNTOUT: This subroutine prints out the pressure, temperature, phase saturations, oll and gas phase composition distributions over the whole space. It also prints out the production rates, phase and component material balance errors, energy balance errors, heat loss rates and other information.

PRNTARY: This subroutine prints out pressure, temperature and saturation arrays. Called by the subroutine PRNTOUT.

PRNTPRPI: This subroutine prints out rock and fluid properties at the initial reservoir conditions. 


\section{EUNCTIONS}

SPLNEVL: This function subroutine evaluates the cublc spline Interpolation function. 


\section{CHAPTER 6. - RESULTS AND DISCUSSION}

The main objective of this study was achieved with the development and testing of a numerical steamflood simulator on a personal computer. The model was validated by comparing the numerical simulator results with the published data. Since a complete set of data for a reservoir undergoing steamflooding is seldom available and since treatment of the phase behavior and other thermodynamic and trancport properties of the fluid differ from model-to-model, an exact comparison of results from this simulator with results of other models is impossible. Therefore, the validation of this simulator was made by investigating the behavior of the variables qualitatively.

\section{Model Validation}

Numerical model runs were conducted using two lest cases. The purpose of these runs was to determine qualitatively if the same behavior would be observed in the numerical model as in the test problems.

In the first problem, the model's temperature distribution was compared with the experimental values of Malofeev 68 for horizontal flow of steam in a water-saturated sandpack. The data used in this nun are listed in table 6.1. In figure 6.1, the model temperature profile is compared with Malofoev's experimental data and Spillette's ${ }^{69}$ predicted values. The model prediction lies below the laboratory case, indicating that the heat losses assumed in the numerical model were large. However, keeping in mind the differences between the two cases, the behavior between the numerical and physical models is qualitatively similar.

In the second problem, the simulated temperature and oil recovery data were compared with the experimental data of Willman et al. ${ }^{6}$ for a linear 1-D steamflood. Wilman et al. carried out a number of onedimensional steamflood and hot water injection studies in cores. For one set of experiments, they reported temperature distributions, and Shuttler ${ }^{17}$ presented the corresponding oil recovery from their simulator's match of the temperature and oil recovery data, employing Weinstein et al's. ${ }^{22}$ proposed set of rock, fluid, and thermal data. This data set (table 6.2) was used in this study in an attempt to simulate the experimental results.

In figure 6.2, the predicted temperature profile using the current model is compared with the publistiad results. The model underpredicted the temperature. In figure 6.3 , the simulated and experimental oil recovery are compared and show that the general character of the curves is similar, but the model failed to match the experimental recovery exactly. This can be attributed io simulator heat loss being too large and suspected rock fluid data.

Even though the simulator results failed to reproduce the experimental results, the results were qualitatively similar and deemed to yield a close enough match of the laboratory data. The observed behavioral differences can be attributed to the numerical characteristics of the simulator and the unverified property functionalities such as the relative permeabilities, capillary pressure, rock thermal conductivity, 
heat transfer coefficient, and most of the oil-phase physical and thermodynamic property relationships. These properties are suspect because they are based on empirical correlations that remained unverified and are not measured for the specific case being simulated.

TABLE 6.1 - Data for Malofeev's temperature distribution test 69

\begin{tabular}{|c|c|}
\hline 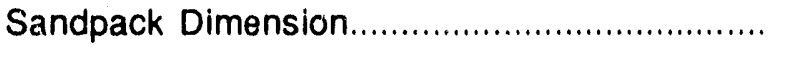 & 1 in. high $\times 9$ in. wide $\times 28$ in. long \\
\hline 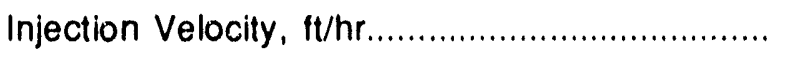 & 4.14 \\
\hline \multicolumn{2}{|l|}{ SANDPACK PROPERTIES } \\
\hline Porosity, \% & 40 \\
\hline 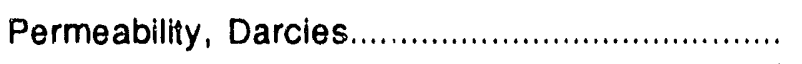 & 15 \\
\hline Heat capacity of sandpack, BTU/ft3 ${ }^{\circ} \mathrm{F} \ldots \ldots \ldots \ldots \ldots$ & 42.45 \\
\hline Heat capacity of overburden, BTU $/ \pi t 3^{\circ} \mathrm{F} \ldots \ldots \ldots \ldots . . . .$. & 36.3 \\
\hline Heat capacity of water, BTU/tt3 ${ }^{\circ} \mathrm{F} \ldots \ldots \ldots \ldots \ldots \ldots$ & 62.4 \\
\hline Thermal conductivity of sand, BTU/hr $\mathrm{ft}{ }^{\circ} \mathrm{F} \ldots \ldots \ldots \ldots$ & 1.4 \\
\hline Thermal conductivity of overburden, BTU/hr $\mathrm{ft}^{\circ} \mathrm{F} \ldots$ & 1.4 \\
\hline
\end{tabular}

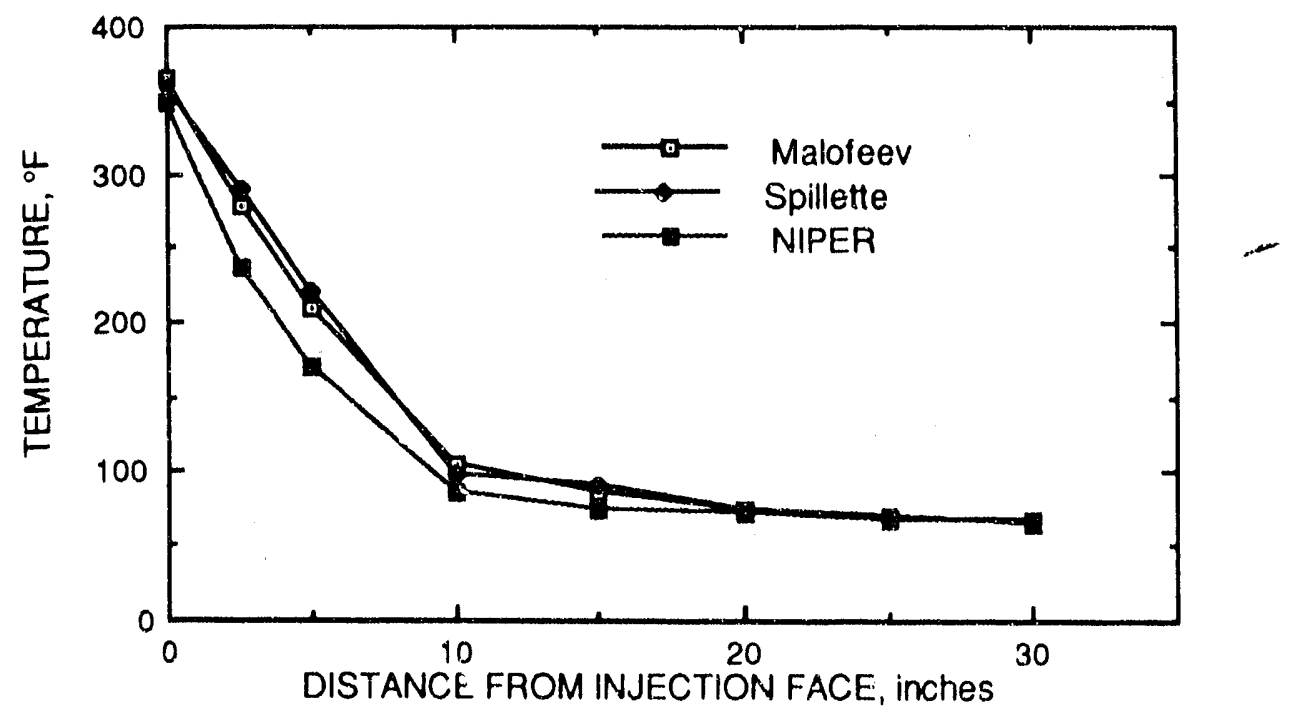

FIGURE 6.1. - Temperature distribution after 1 hour of steam injection. 
TABLE 6.2 - Data for Willman's steamflood run 17,22

Core length, $\mathrm{ft}$

3.0

Core diameter, ft

0.5

Porosity, \%

Permeability, mo.

26.2

Thickness of steel casing, ft.

856.0

Thickness of insulation, $\mathrm{ft}$

0.25

Grid blocks in $\mathrm{x}$-direction

10

Heat capacity of core, BTU/cu ft - ${ }^{\circ} \mathrm{F}$

26.0

Heat capacity of overburden, BTU/CU At - ${ }^{\circ} \mathrm{F}$

Thermal conductivity of core, BTU/ft D - ${ }^{\circ} \mathrm{F}$

Thermal conductivity of overburden, BTU/ft D $-^{\circ} \mathrm{F} \ldots \ldots \ldots$

Initial temperature, ${ }^{\circ} \mathrm{F}$

Initial water saturation, fraction.

Initial gas saturation, fraction.

Initial oil density, $\mathrm{lbm} / \mathrm{cu} \mathrm{ft}$

Initial oil viscosity, $\mathrm{CP}$.

Injection temperature, ${ }^{\circ} \mathrm{F}$

14.84

Injection pressure, psia.

Production Pressure, psia

2100.0

260.0

80.0

0.26

0.0

53.3

22.5

330.0

103.0

63.0

OIL VISCOSITY - TEMPERATURE DATA

Temperature ${ }^{\circ} \mathrm{F}$

50

150

250

350
Viscosity.cP

48.0

6.2

2.0

0.9

RELATIVE PERMEABILITY AND CAPILLARY PRESSURE DATA

\begin{tabular}{|c|c|c|c|c|c|c|c|}
\hline$\hat{s}_{x y}$ & $k_{w}$ & $\mathrm{kr}_{\text {ow }}$ & Dew & $\mathrm{S}_{\Omega}$ & $\mathrm{k}_{\mathrm{g}}$ & $\mathrm{kr}_{2 \mathrm{~g}}$ & 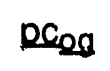 \\
\hline 0.26 & 0 & 0.7 & 2.2 & 0.3 & 0.175 & 0 & \\
\hline .3 & 0.001 & 0.475 & 1.0 & 0.4 & 0.105 & 0.01 & 0.2 \\
\hline .4 & 0.015 & 0.195 & 0.7 & 0.5 & 0.05 & 0.04 & 0.2 \\
\hline 0.5 & 0.050 & 0.122 & 0.52 & 0.6 & 0.01 & 0.125 & 0.1 \\
\hline 0.6 & 0.115 & 0.075 & 0.37 & 0.7 & 0.001 & 0.380 & 0.1 \\
\hline 0.7 & 0.205 & 0.0 & 0.23 & 0.73 & 0.0 & 0.700 & 0. \\
\hline
\end{tabular}

1 Low valise for insulation.

2 High value reflects presence of metal cylinder. 


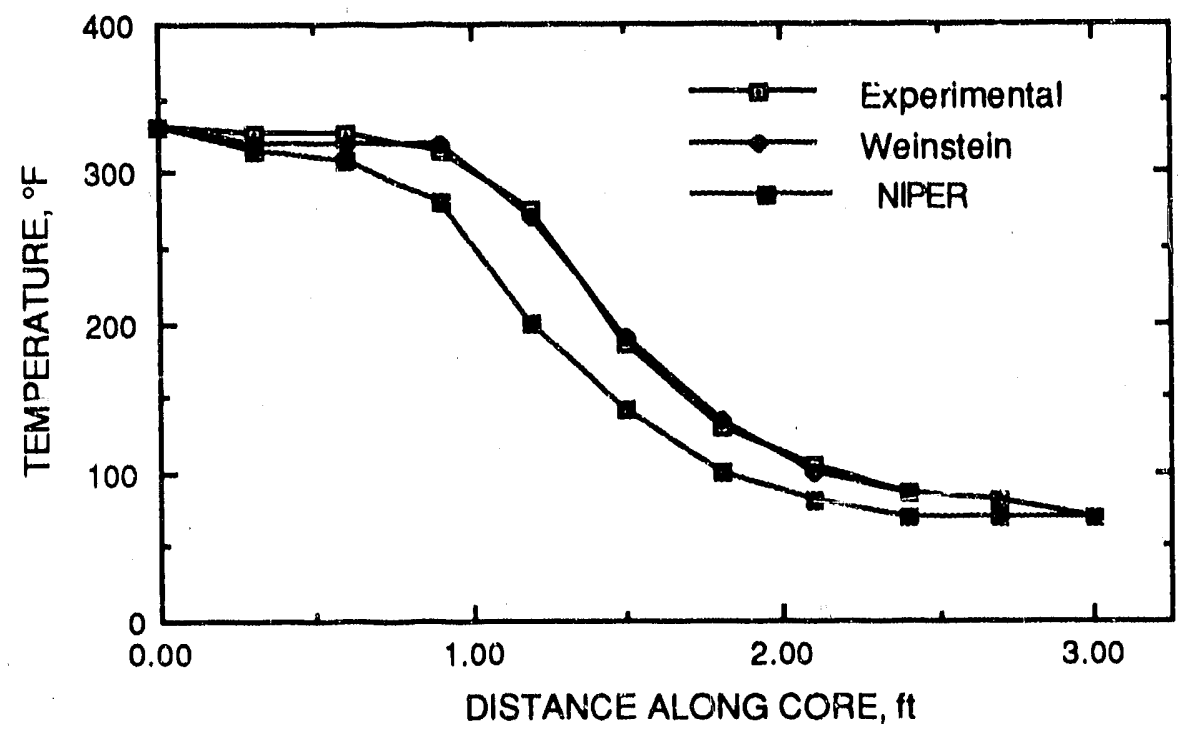

FIGURE 6.2. - Comparison of simulated and experimental temperature profiles for laboratory model after 2.5 hours of steam injection.

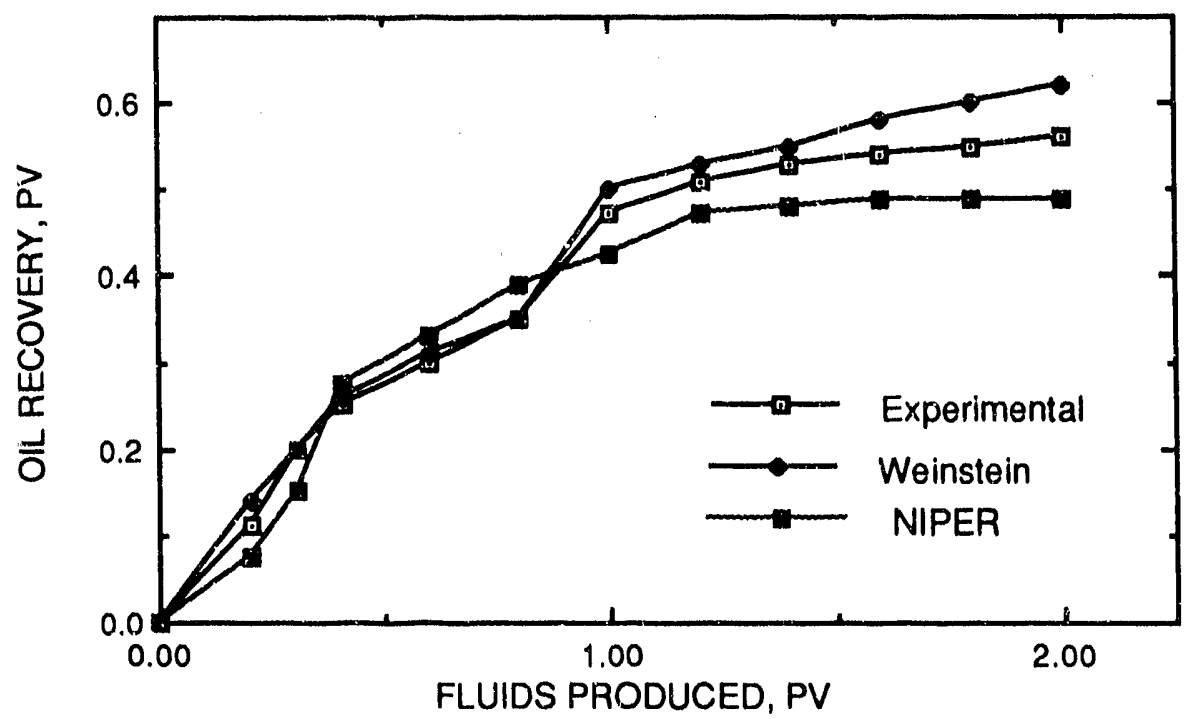

FIGURE 6.3. - Calculated and experimental oil recovery curves for laboratory experiments 
The complex interactions among the property functionalities and the assumptions made to simplify the mathematics of the model make it difficult to assess the specific causes for deviations between model and experimental results. The functional dependency of interblock flow terms and the property functionalities on dependent variables render exact agreement between simulation and experimental results unlikely. Even if the modeler succeeds in matching the simulation and experimental data by manipulating certain properties, one cannot conclude with certainty that this modified property is an accurate description of the involved property and is globally applicable. Under a different set of conditions such a modification may produce incorrect results when applied to simulating experiments.

With the above in mind, it is concluded that the ability of the simulator to predict qualitatively the performance trends is an indication of its validity. Next, sensitivity studies were made to check the effects of various parameters on steamflood performance.

\section{Sensitivity Studies}

Sensitivity studies were conducted with respect to rock and fluid properties, process variables, and time-step size. The selected parameters are:

(a) time-step size

(b) reservoir parameter sensitivities:

(i) porosity

(ii) absolute permeability

(iii) initial oil and irreducible water saturations

(iv) rock heat capacity

(v) relative permeability

(c) Fluid property sensitivities:

(i) oil viscosity

(ii) oil volatility

(d) Process sensitivities:

(i) steam quality

(ii) steam injection rate

(iii) back pressure

To minimize computational efforts, all sensitivity runs were conducted in one-dimensional mode with 17 grid blocks and two hydrocarbon components. Sensitivity of process and physical property variables were evaluated by plotting cumulative oil recovery against pore volume steam (cold water equivalent) injected. The effect of a parameter was observed by changing the value of that parameter while holding all other parameters constant. The time-step sensitivity studies were conducted by specifying a constant time-step size. During the time-step sensitivity run, the automatic time-step control feature was turned off. Time-step sensitivity was evaluated by plotting the oil and water saturation at grid block 9 as a function of 
time. The sensitivity of the solution to time-step size was evaluated by plotting the absolute oil material balance error as a function of time.

A data set was developed to conduct numerical model test runs and to determine process, parameter, and time-step sensitivities. The data set was structured to roughly represent the conditions and properties of the porous media used in a typical laboratory test. The data set allowed for steam formation and condensation. The light oil component was fairly volatile, and the heavy oll component was treated as a dead oil. The initial phase composition is shown in table 6.3. Table 6.4 shows the reservoir data used in the sensitivity study. Porosity absolute permeability, fluid saturations, and initial pressure and temperalure are similar to those of the laboratory tests.

Oil component and water properties are shown in table 6.5. Oil viscosity data are presented in table 6.6. Light oil equilibrium K-values are shown in table 6.7 as a function of pressure and temperature.

Capillary pressure was set to zero and the relative permeabilities were computed using the following simple formula,

$$
\begin{aligned}
& k_{r w}=k_{r w_{r o}}\left(\frac{S_{w}-S_{w_{i}}}{1-S_{w_{i}}}\right)^{N_{k r w}} \\
& k_{r o}=k_{r o_{i w}}\left(\frac{S_{o}-S_{o_{w}}}{1-S_{o_{w}}}\right)^{N_{k r o w}} \\
& k_{r g}=k_{r g r o}\left(\frac{S_{g}-S_{g_{c}}}{1-S_{g_{c}}}\right)^{N_{k r g}}
\end{aligned}
$$

No temperature dependence of relative permeability and end points were included.

A one-dimensional grid of 17 blocks was chosen. The grid block dimensions are shown in table 6.8 and illustrated in figure 6.4. Program convergence tolerances are shown in table 6.9.

TABLE 6.3 - Initial phase composition (mole fraction)

\begin{tabular}{lccc}
\hline Component & $\begin{array}{c}\text { Aqueous } \\
\text { phase, }\end{array}$ & $\begin{array}{c}\text { Oleic } \\
\text { phase, }\end{array}$ & $\begin{array}{c}\text { Vapor } \\
\text { phase, }\end{array}$ \\
\hline 1. Water & 1.0 & 0.0 & 0.0 \\
2. Light oil & 0.0 & 0.35 & 0.0 \\
3. Heavy oil & 0.0 & 0.65 & 0.0 \\
\hline
\end{tabular}


TABLE 6.4 - Process and reservoir data (base case)

Number of blocks in $x$-direction.

17

Number of blocks in z-direction.

1

$x$-direction permeability, Darcy

6.0

z-direction permeability, Darcy

Porosity,

Initial resenoir pressure, psia

Initial reservoir temperature, ${ }^{\circ} \mathrm{F}$

Initial oil saturation, \% PV

Initial water saturation, \% PV

Initial gas saturation, \% PV

Connate water saturation, \% PV

Residual oil saturation, \% PV

Critical gas saturation, \% PV.

Injected steam pressure, psia

Injected steam quality.

Steam injection rate, $\mathrm{cm}^{3} / \mathrm{hr}$

(Cold water equivalent)

Backpressure on the model, psia

Oll gravity, ${ }^{\circ} \mathrm{API}$

RESERVOIR (SANDPACK) PROPERTIES

Compressibility, $\mathrm{psi}^{-1}$

Specitic heat, BTU//bm

0.000005

0.2

Dry rock density, $\mathrm{lbm} / \mathrm{ft}^{3}$

162.0

Thermal conductivity, BTU/ft - day - ${ }^{\circ} \mathrm{F}$

18.5

\section{OVERBURDEN (INSULTATION) PROPERTIES}

Insulation thickness, in

Thermal conductivity, BTU/tt - day ....

Heat capacity, BTU/ft ${ }^{3}$ - ${ }^{\circ} \mathrm{F}$.

RELATIVE PERMEABILITY DATA

$k_{r w_{r o}}=k_{\text {roiw }}=k_{\text {rgro }}$

$N_{\text {krw }}=N_{\text {krow }}=N_{\text {krg }}$

1 High value reflects presence of metal wall.

2 Low value for insulation. 
TABLE 6.5 - Oll and water properties

\section{OIL COMPONENT PROPERTIES}

\begin{tabular}{|c|c|c|}
\hline Preperties & Liaht & Heavy \\
\hline 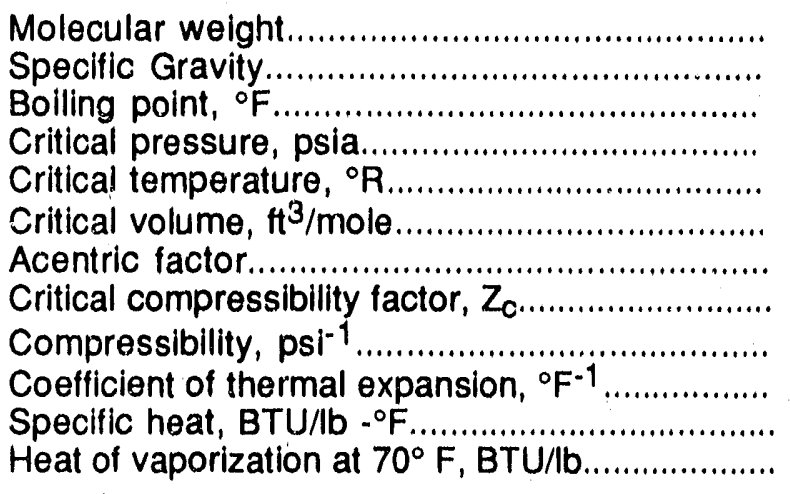 & $\begin{array}{l}79.0 \\
0.75 \\
194.0 \\
488.6 \\
845.0 \\
4.86 \\
0.25 \\
0.27 \\
2.0 \times 10^{-5} \\
0.0 \\
0.41 \\
150.6\end{array}$ & $\begin{array}{c}235.0 \\
0.806 \\
566.0 \\
198.0 \\
1,280.0 \\
3.44 \\
0.24 \\
0.25 \\
1.5 \times 10^{-5} \\
34.0 \times 10^{-5} \\
0.43 \\
93.7\end{array}$ \\
\hline \multicolumn{3}{|c|}{ WATER PROPERTIES } \\
\hline $\begin{array}{l}\text { Water compressibility, psi-1 } \\
\text { Coefficient of thermal expansion, }{ }^{\circ} \mathrm{F}^{-1}\end{array}$ & $\begin{array}{l}3.0 \times 10^{-6} \\
4.9 \times 10^{-4}\end{array}$ & \\
\hline
\end{tabular}

TABLE 6.6 - Oil viscosity data

\begin{tabular}{cc}
\hline Temperaiure $^{\circ} \mathrm{F}$ & Viscosity.cP \\
75 & 6.9 \\
100 & 5.1 \\
200 & 2.1 \\
300 & 0.7 \\
400 & 0.46 \\
\hline
\end{tabular}

TABLE 6.7 - Light end K-value table

\begin{tabular}{rrrrrrrrrrrrr}
\hline & \multicolumn{10}{c}{ Temperature, ${ }^{\circ} \mathrm{F}$} \\
\hline Pressure, psi & 50.0 & 100.0 & 150.0 & 200.0 & 250.0 & 300.0 & 350.0 & 400.0 & 450.0 & 500.0 \\
15.00 & .6711 & 1.2343 & 2.0543 & 3.1652 & 4.5887 & 6.3352 & 8.4050 & 10.7904 & 13.4777 & 16.4487 \\
100.00 & .1112 & .2024 & .3340 & .5110 & .7362 & 1.0109 & 1.3349 & 1.7066 & 2.1238 & 2.5833 \\
200.00 & .0629 & .1131 & .1847 & .2801 & .4005 & .5464 & .7174 & .9125 & 1.1304 & 1.3694 \\
300.00 & .0478 & .0848 & .1371 & .2060 & .2922 & .3959 & .5167 & .6538 & .8061 & .9725 \\
400.00 & .0411 & .0721 & .1152 & .1714 & .2412 & .3246 & .4210 & .5297 & .6500 & .7807 \\
500.00 & .0381 & .0658 & .1039 & .1531 & .2136 & .2853 & .3677 & .4601 & .5617 & .6717 \\
600.00 & .0370 & .0629 & .0982 & .1433 & .1982 & .2628 & .3364 & .4185 & .5082 & .6048 \\
700.00 & .0372 & .0624 & .0961 & .1388 & .1903 & .2503 & .3182 & .3934 & .4752 & .5628 \\
900.00 & .0407 & .0662 & .0994 & .1404 & .1889 & .2443 & .3062 & .3738 & .4465 & .5234 \\
\hline
\end{tabular}


TABLE 6.8 - Grid block dimensions

\begin{tabular}{cccc}
\hline Block & $\begin{array}{c}\text { Dx, } \\
\text { inches }\end{array}$ & $\begin{array}{c}\text { Cumulative } \\
\text { distance, } \\
\text { inches }\end{array}$ & $\begin{array}{c}\text { Block } \\
\text { centers, } \\
\text { inches }\end{array}$ \\
\hline & 1.5 & 1.5 & 0.75 \\
2 & 3.0 & 4.5 & 3.0 \\
3 & 3.0 & 7.5 & 6.0 \\
4 & 3.0 & 10.5 & 9.0 \\
5 & 3.0 & 13.5 & 12.0 \\
6 & 3.0 & 16.5 & 15.0 \\
7 & 3.0 & 19.5 & 18.0 \\
8 & 3.0 & 22.5 & 21.0 \\
9 & 3.0 & 25.5 & 24.0 \\
10 & 3.0 & 31.5 & 30.0 \\
11 & 3.0 & 34.5 & 33.0 \\
12 & 3.0 & 37.5 & 36.0 \\
13 & 3.0 & 40.5 & 39.0 \\
14 & 3.0 & 43.5 & 42.0 \\
15 & 3.0 & 46.5 & 47.25 \\
16 & 3.0 & 48.0 & \\
17 & 1.5 & & \\
& 38 & & \\
\hline Total & 3.0 & & \\
\hline
\end{tabular}

$D z=3.0$ inches .

Thickness $(h)=2.0$ inches.

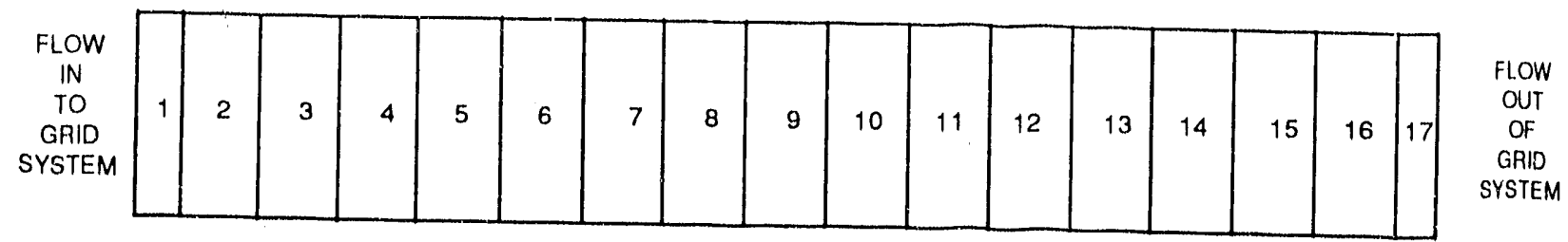

FIGURE 6.4 - One-dimensional grid system. 
TABLE 6.9 - Program control parameters

\begin{tabular}{|c|c|}
\hline 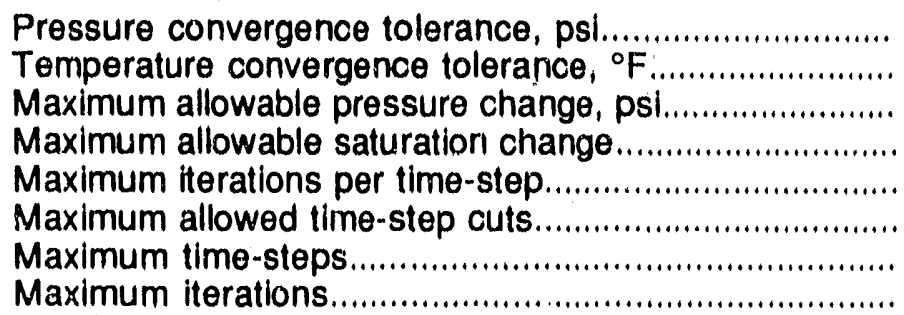 & $\begin{array}{l}0.1 \\
0.01 \\
50 \\
0.01 \\
8 \\
4 \\
250 \\
1,000\end{array}$ \\
\hline
\end{tabular}

\section{Sensitivity Runs}

\section{A. Beservolr Parameter Sensitlvities}

Prior to conducting sensitivity runs, a base case run was conducted using the data presented in tables 6.3 through 6.7. Next, changes were made to porosity, absolute permeability, initial oll saturation, irreducible water saturation, rock heat capacity and relative permeability exponents. Table 6.10 documents the changes made to the base case to identify the effects of changes in reservoir parameters. Sensitivity runs were then made and the oil production response to changes calculated.

\section{Poreslty}

The porosity was varied from 0.21 to 0.42 (base case). The obtained results are compared in figure 6.5. As can be seen from this plot, a reduction in porosity significantly reduced the oil production because of reduced oil-in-place. Further, a lower porosity reservoir has a lower recovery efficiency because a larger fraction of the injected energy is used for heating the rock matrix inside the reservoir.

\section{Absolute Permeabllity}

The absolute permeability was varied from 3.0 to 12 Darcies. The obtained results for two cases are compared with the base case in figure 6.6. It was observed that for the range of permeability investigated, absolute permeability has only minor effects on oil production rate and no effect on ultimate oil recovery. However, in the laboratory oil production increased significantly with an increase in permeability. 70

\section{Bock Heat Capacity}

Rock heat capacity had only minor effect on oil preduction rate and ulitmate recovery, as can be seen from figure 6.7. Raising the heat capacity of the rock slows the heat frontal advance, steepens the temperature gradients and slows the oil production slightly, 
TABLE 6.10 - Data for reservoir parameter sensitivity runs

\begin{tabular}{|c|c|c|c|c|c|}
\hline $\begin{array}{l}\text { Sensitivity } \\
\text { Case }\end{array}$ & \multicolumn{2}{|c|}{ Data } & \multicolumn{3}{|c|}{ Notes } \\
\hline \multicolumn{6}{|c|}{ POROSITY SENSITIVITY } \\
\hline $\begin{array}{l}1 \\
2 \\
3\end{array}$ & \multicolumn{2}{|c|}{$\begin{array}{l}0.42 \\
0.21 \\
0.315\end{array}$} & & \multicolumn{2}{|c|}{$\begin{array}{l}\text { Base case } \\
0.5 \text { times base } \\
0.75 \text { times base }\end{array}$} \\
\hline \multicolumn{6}{|c|}{ ABSOLUTE PERMEABILITY SENSITIVITY } \\
\hline \multirow[t]{2}{*}{$\begin{array}{l}1 \\
2 \\
3\end{array}$} & \multicolumn{2}{|c|}{$\begin{array}{r}\text { 6.0 Darcies } \\
\text { 3.0 Darcies } \\
\text { 12.0 Darcies }\end{array}$} & & \multicolumn{2}{|c|}{$\begin{array}{l}\text { Base case } \\
0.5 \text { times base } \\
2.0 \text { times base }\end{array}$} \\
\hline & \multicolumn{4}{|c|}{ ROCK HEAT CAPACITY SENSITIVITY } & \\
\hline \multirow[t]{2}{*}{$\begin{array}{l}1 \\
2 \\
3\end{array}$} & \multicolumn{3}{|c|}{$\begin{array}{l}32.4 \mathrm{BTU} / \mathrm{cu} \mathrm{f}^{\circ} \circ \mathrm{F} \\
16.2 \mathrm{BTU} / \mathrm{cu} \mathrm{f}^{\circ} \mathrm{F} \\
64.8 \mathrm{BTU} / \mathrm{cu} \mathrm{f}^{\circ} \mathrm{F}\end{array}$} & \multicolumn{2}{|c|}{$\begin{array}{l}\text { Base case } \\
0.5 \text { times base } \\
2.0 \text { times base }\end{array}$} \\
\hline & \multicolumn{4}{|c|}{ INITIAL OIL SATURATION SENSITIVITY } & \\
\hline $\begin{array}{l}1 \\
2 \\
3\end{array}$ & \multicolumn{2}{|c|}{$\begin{array}{l}0.8 \\
0.6 \\
0.4\end{array}$} & & \multicolumn{2}{|c|}{$\begin{array}{l}\text { Base case } \\
0.75 \text { times base } \\
0.5 \text { times base }\end{array}$} \\
\hline \multicolumn{6}{|c|}{ IRREDUCIBLE WATER SATURATION SENSITIVITY } \\
\hline $\begin{array}{l}1 \\
2 \\
3\end{array}$ & \multicolumn{2}{|c|}{$\begin{array}{l}0.15 \\
0.075 \\
0.1125\end{array}$} & & \multicolumn{2}{|c|}{$\begin{array}{l}\text { Base case } \\
0.5 \text { times base } \\
0.75 \text { times base }\end{array}$} \\
\hline \multicolumn{6}{|c|}{ RELATIVE PERMEABILITY SENSITIVITY } \\
\hline Parameter & Base & Case 1 & Case? & Case 3 & Netes \\
\hline$N_{k r w}$ & 2.0 & 3.0 & 4.0 & 3.0 & $\begin{array}{l}\text { water phase } \\
\text { exponent }\end{array}$ \\
\hline Nkrow & 2.0 & 3.0 & 4.0 & 2.0 & $\begin{array}{l}\text { oil phase } \\
\text { exponent }\end{array}$ \\
\hline Nkrg & 2.0 & 3.0 & 4.0 & 4.0 & $\begin{array}{l}\text { gas phase } \\
\text { exponent }\end{array}$ \\
\hline$S_{g_{c}}$ & 0.01 & 0.01 & 0.01 & 0.06 & $\begin{array}{l}\text { critical gas } \\
\text { saturation }\end{array}$ \\
\hline
\end{tabular}




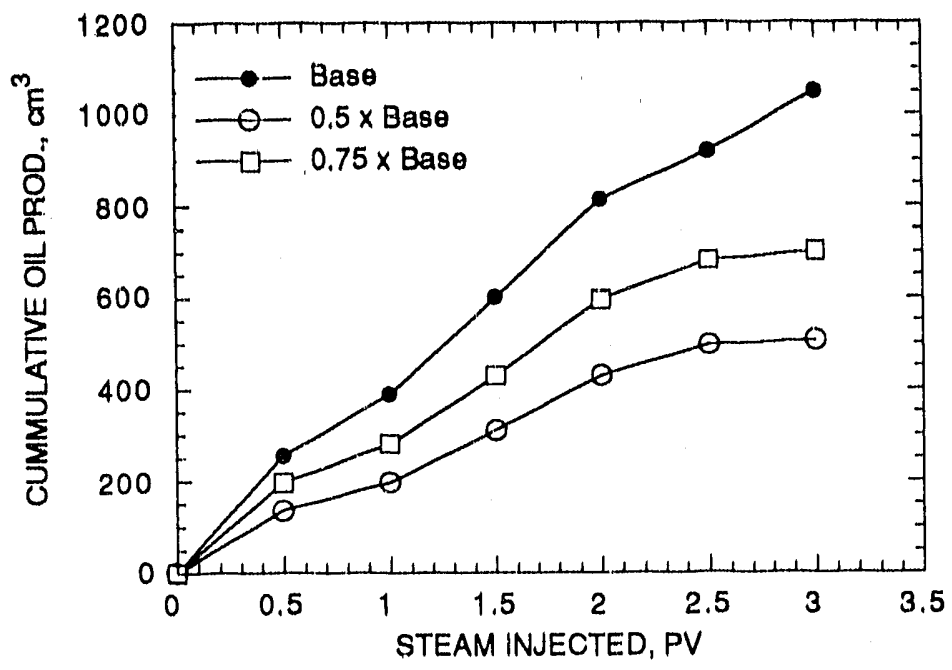

FIGURE 6.5 - Cumulative oll production histories - porosity sensitivity.

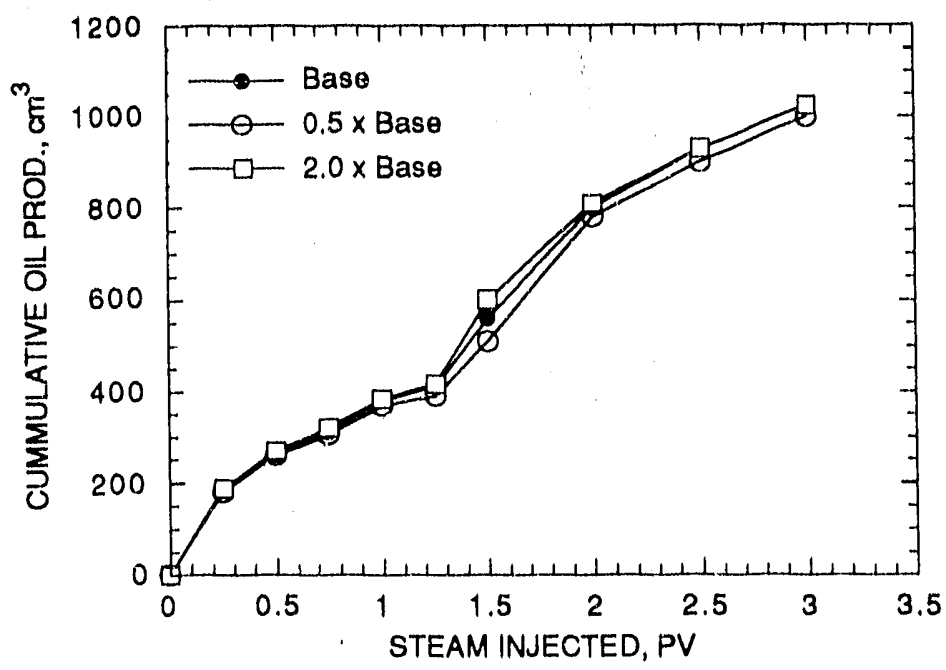

FIGURE 6.6 - Cumulative oil production histories - absolute permeability sensitivity. 


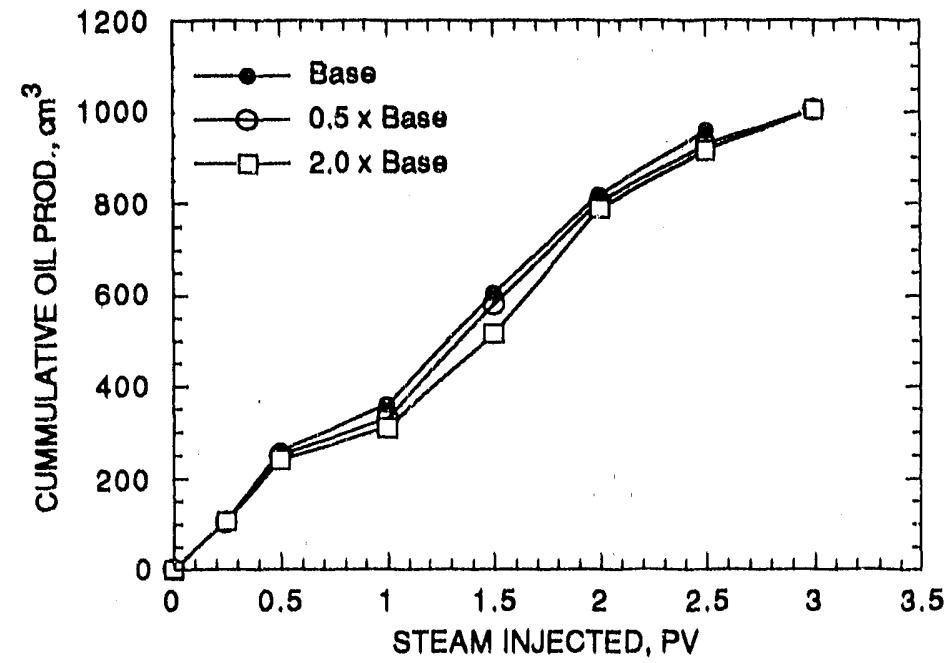

FIGURE 6.7 - Cumulative oil production histories - rock heat capacity sensitivity.

\section{Inltlal Oll and Irreduclble Water Saturation}

Oil production response to changes in initial oll saturation is depicted in figure 6.8. The effect of changes in irreducible water saturation on oil production is shown in figure 6.9. Initial oil saturation is a major parameter influencing the oll recovery. As would be expecied, reduction in initial oll saturation lowered the ultimate recovery because of the reduced oil-in-place, but the general character of the process remained the same. Irreducible water saturation has a significant effect on the initial production rate. As can be seen from figure 6.9, reducing the irreducible water saturation decreases the initial production rate, but does not affect the ultimate recovery. This is because a decrease in the irreducible water saturation results in increased initial water mobility and a reduction in initial oll mobility.

\section{Relative Permeabllity Modification}

Four runs were conducted to evaluate the effect of relative permeability on oll recovery. The relative permeability curves were altered by modifying the exponents in the relative permeability curves equations 6.1 to 6.3. In the base case run, all of the exponents were set equal to 2.0 . In the second run, an exponent of 3.0 was used for all cases, and in the third run, all of the exponents were changed to 4.0 . In the fourth run, water and gas phase exponents were increased while leaving the oil phase exponeni at 2.0. For this run, the critical gas saturation was also increased to 0.06 . 


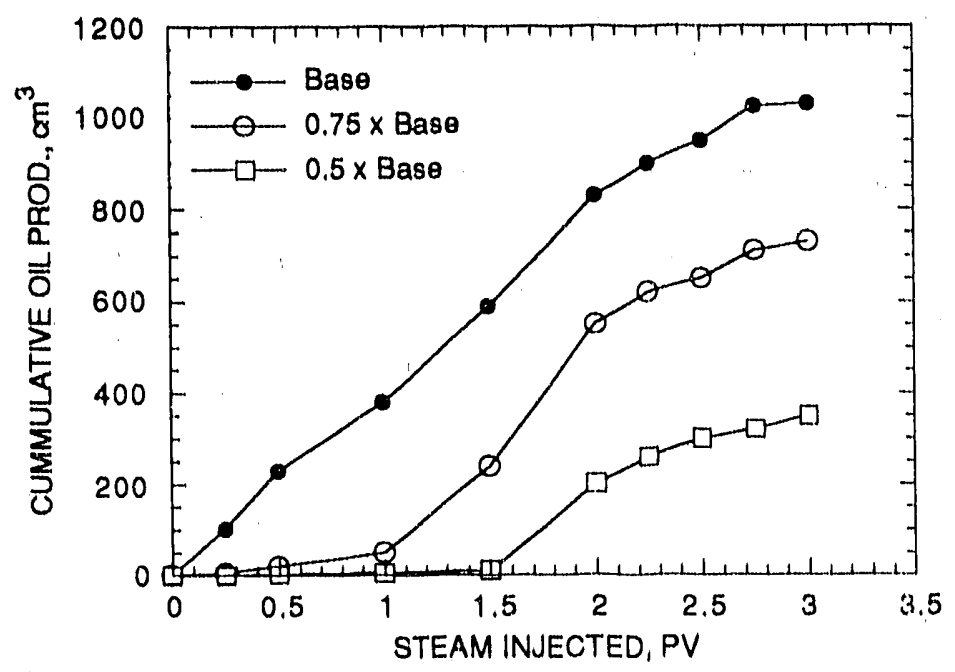

FIGURE 6.8 - Cumulative oil production histories - initial oll saturation sensitivity.

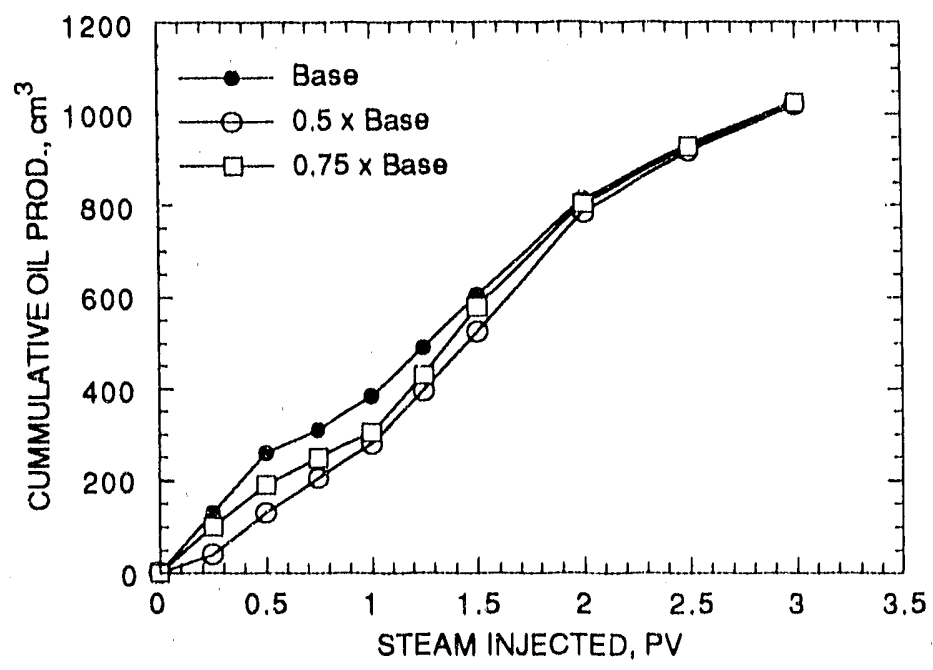

FIGURE 6.9 - Cumulative oil production - irreducible water saturation sensitivity. 
As shown in figure 6.10, the initial oil production increased when all of the exponents increased. When the exponents of equations 6.1 to 6.3 were increased by the same amount, a much larger increase in oil phase mobility was obsarved compared to water and gas mobilities. As a result, the oil phase flux was larger early in the simulation run. Increasing the water and gas phase exponents and holding the oleic phase exponent constant resulted in an increase in both oil production rate and total recovery. From figure 5.10, it is evident that increasing critical gas saturation significantly impacts oil recovery (case 3 ).

\section{B. Fluld Property Sensitivitles}

Table 6.11 summarizes the changes made to the base case run data for the fluid property sensitivity runs.

\section{Viscosity}

Oil viscosity is a significant parameter influencing the oil production rate and ultimate recovery. Figure 6.11 show's that the calculated oil recovery by steamdrive increases with the decrease in initial oil viscosity. The viscosity reduction for a given increase in temperature is higher for the high viscosity oil. towever, the viscosity values are higher for the more viscous oil. Moreover, viscous oil requires higher pressure drop to flow. Consequently, the temperatures and heat losses are higher resulting in lower recoveries. Thus, steamdrive leads to higher recoveries for low viscosity oils.

\section{Oll Volatility}

The effect of oil volatility on steamflood perfo mance is recorded in figure 6.12. The process is highly sensitive to this parameter in terms of both oil production rate and ultimate oil recovery. As the oil becomes more volatile, it responds more quickly to steam injection and rasults in higher oil recovery. Steam distillation is responsible for this effect.

In this study, oil viscosity and distillation effects ha been considered separately. However, it is recognized that more volatile oils tend to have lower viscosities. Thus, combined effect of oil viscosity and distillation were studied. It was found that the oil recoveries calculated for steamdrive for the less viscous and more volatile oil are higher than : ithe more viscous and less volatile oil. Increase in recoveries are up to $20 \%$ of the initial oil-in-place. This difference in recovery decreases as the volume of steam injectf. $I$ increases. This behavior can be explained by the difference in effective mobility. hecovery at breakthrough is considerably higher for the less viscous oil. However, because of an increase in temperature around the production well after breakthrough, more viscous oil is produced after breakthrough. 


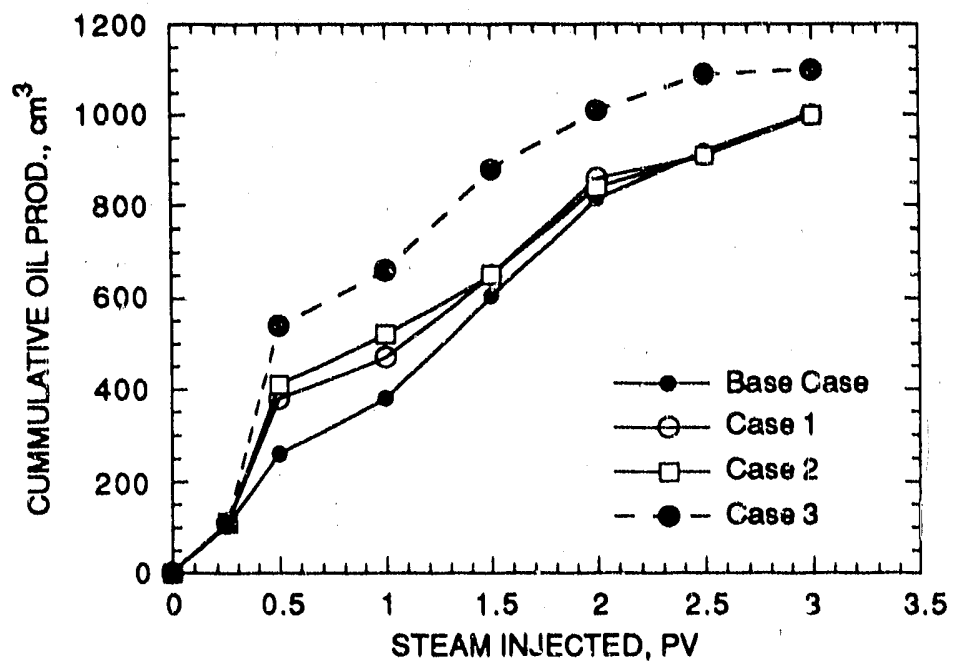

FIGURE 6.10 - Cumulative oil production histories - relative permeability sensitivity.

TABLE 6.11 - Data for fluid properties sensitivity runs

\begin{tabular}{|c|c|c|}
\hline \multicolumn{3}{|c|}{ OIL VISCOSITY SENSITIVITY } \\
\hline Case & Data & Notes \\
\hline $\begin{array}{l}1 \\
2 \\
3 \\
4\end{array}$ & $\begin{array}{l}\{\text { See note } \\
\{\text { below }\end{array}$ & $\begin{array}{l}\text { Base case } \\
0.03 \times A e^{B / T} \\
0.3 \times A e^{B} / T \\
3.0 \times A e^{B / T}\end{array}$ \\
\hline \multicolumn{3}{|c|}{ OIL VOLATILITY SENSITIVITY } \\
\hline $\begin{array}{l}1 \\
2 \\
3\end{array}$ & $\begin{array}{l}35 \text { wole percent light end } \\
50 \text { mole percent light end } \\
20 \text { mole percent light end }\end{array}$ & $\begin{array}{l}\text { Base case } \\
\text { Case } 1 \\
\text { Case } 2\end{array}$ \\
\hline
\end{tabular}

NOTE: The base case data (table 6.6) was fitted to an exponential function of the form $A e^{B / T}$. Data for al! sther cases were obtained by modifying $A$. 


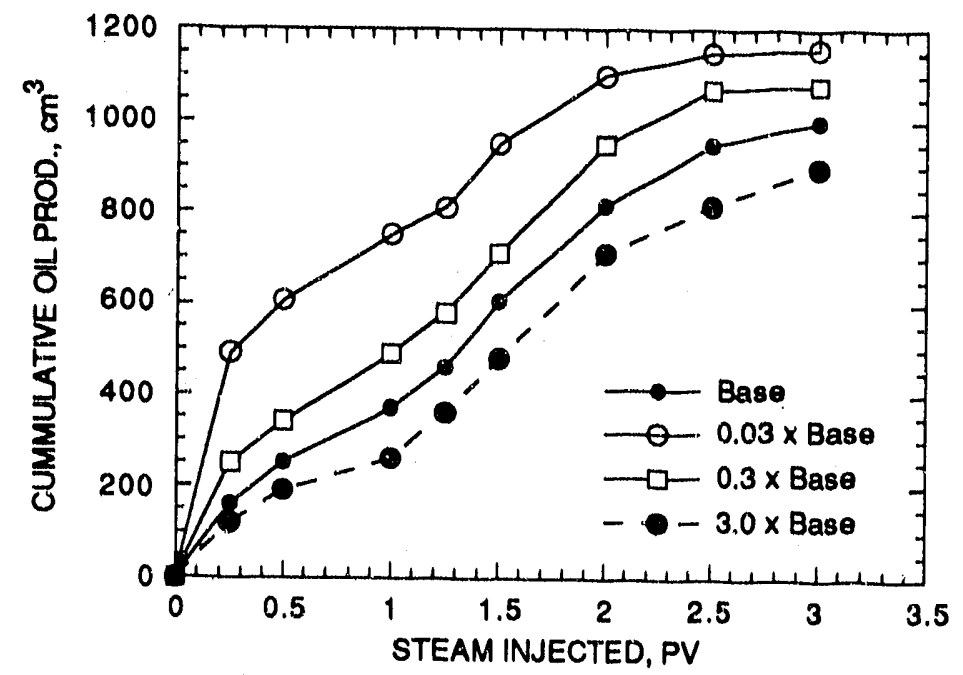

FIGURE 6.11 - Cumulative oil production histories - oil viscosity sensitivity.

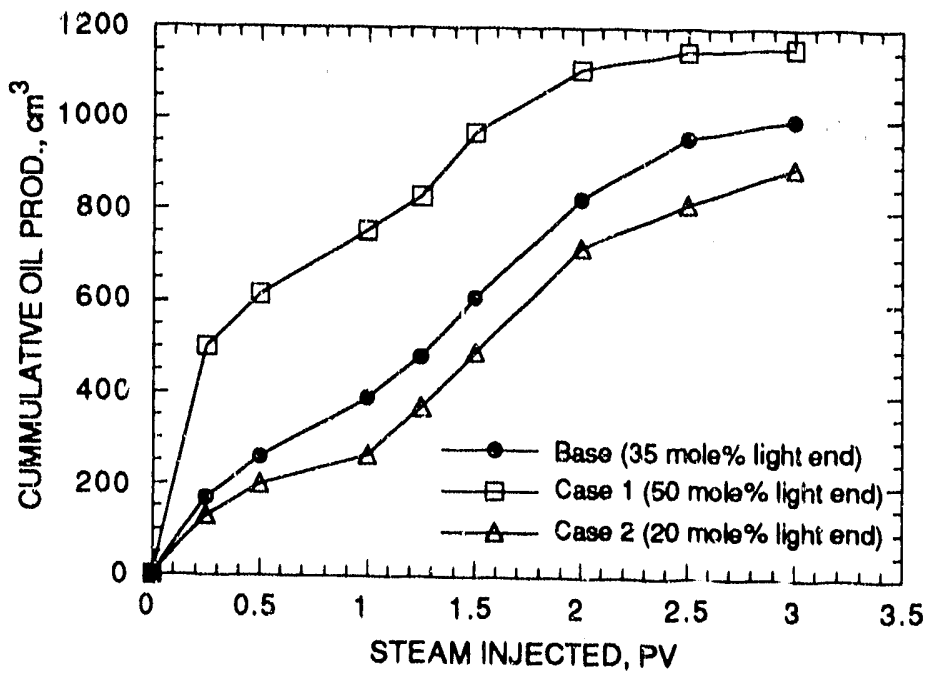

FIGURE 6.12 - Cumulative oil production histories - oil volatility sensitivity. 
As the volatility of the oil increases, the effect of viscosity diminishes. Thus, for light oils, volatility seems to play a more important role in oil recovery than oil viscosity. It must be emphasized that consideration of simultaneous changes in oil viscosity and oil volatility is more realistic than individual changes in these two parameters.

Analysis of the simulation results for the distillable component (light ends) indicated that the recovery of distillable component is much higher for the less viscous and more volatile oil. This value is higher than the increase in total oil recovery. The composition of the remaining oil calculated for the injection block clearly indicated that the distillable component in the steam zone reduces to a very low value. However, for the least-volatile oil the mole fraction of the distillable component in the reservoir has reduced only slightly. This result indicates that in light oil steamflood distillable components account for a major portion of the extra oil recovery by steam injection. These results are in agreement with experimental trends.

Further analysis of the simulation results indicated that the component production history of the most volatile system (case 1) and the least volatile system (case 2) is quite different. After injection of 1.5 PV steam (cold water equivalent), the most volatile crude shows a recovery twice as large as the least volatile crude. On the other hand, the final recovery of less volatile component was reduced by $100 \%$ for a decrease of $30 \%$ in the mole fraction of light end.

The calculated results can be explained on the basis of the effect of composition on the phase saturations. Higher mole fractions of the lighter component resulted in higher gas saturations and lower oil saturations. Consequently, gas flow rates and recovery of the most volatile component are higher. Production of the less volatile component decreases, since the oil production rate is reduced.

\section{Process Sensitivities}

Table 6.12 summarizes the changes made to the base case run data for the process sensitivity runs.

\section{Steam Iniectlon Rate}

The dependency of oil recovery on steam injection rate was investigated. Simulations were conducted for steam injection rates of $500,1,000$ (base run) and $1,500 \mathrm{~cm}^{3} / \mathrm{hr}$ (cold water equivalent) to investigate this effect. The results are shown in figure 6.13. It is observed that oil recovery aiter injecting 2 pore volumes of steam at an injection rate of $1,000 \mathrm{~cm}^{3} / \mathrm{hr}$ is more than twice compared to an injection rate of $500 \mathrm{~cm}^{3} / \mathrm{hr}$. However, recovery for an injection rate of $1,500 \mathrm{~cm}^{3} / \mathrm{hr}$ is only slightly above that obtained for the base run. The results are a consequence of a combined effect of flooding time arid reservoir pressure. At high injection rate, the time required to flood the reservoir is smaller; howevar, the reservoir pressure and consequently the temperature and iristantaneous heat losses are higher. The net result is an increase in heat losses and reduction in oil recovery. 
TABLE 6.12 - Data for process sensitivity runs

\begin{tabular}{lrl} 
& \multicolumn{2}{c}{ STEAM INJECTION RATE SENSITIVITY } \\
Case & Data & Notes \\
1 & & \\
2 & $1,000 \mathrm{~cm}^{3} / \mathrm{hr}$ & Base case \\
3 & $500 \mathrm{~cm}^{3} / \mathrm{hr}$ & 0.5 times base \\
& $1,500 \mathrm{~cm}^{3} / \mathrm{hr}$ & 1.5 times base \\
& STEAM QUALITY SENSITIVITY & \\
1 & & \\
2 & $80 \%$ quality steam & Base case \\
3 & $0 \%$ quality & Hot water \\
4 & $20 \%$ quality & - \\
6 & $50 \%$ quality & - \\
& $90 \%$ quality & Dry saturated steam \\
& $100 \%$ quality & \\
1 & BACKPRESSURE SENSITIVITY & \\
3 & 240.0 psia & Base case \\
& 480.0 psia & 2.0 times base \\
& 120.0 psia & 0.5 times base \\
\hline
\end{tabular}

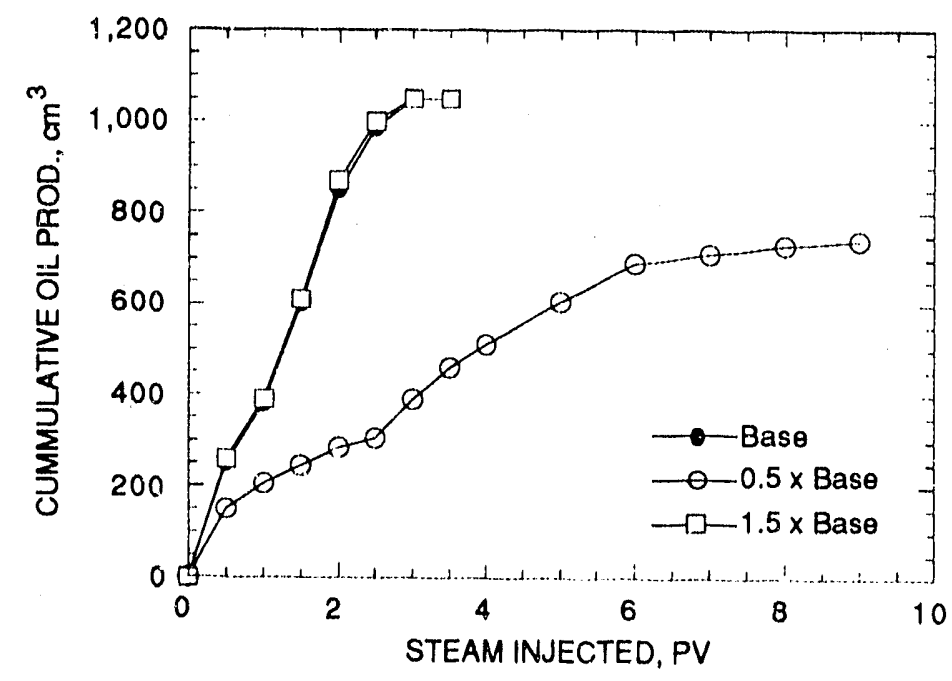

FIGURE 6.13 - Cumulative oil production histories - steam injection rate serısitivity. 


\section{Sieam Quallity}

The sensitivity of oil recovery to steam quality was investigated by varying the quality from 0.0 (hot water) to 1.0 (dry saturated steam). This results are compared in figure 6.14. Oll production rate and recovery are directly affected by thustertam quality. This is solely due to the rate of heating. Higher steam quality corresponds to larger enthalpy vesulting in higher steamfront velocity and rapid oil production. With the lower quality steam, the rate of enthalpy injection was lower and consequently the recovery was lower.

The predicted behavior is mainly explained as a consequence of the nonlinear increase in temperature with the volume of steam injected. Also, oil viscosity and steam distillation are nonlinear function of temperature. These relationships are responsible for the oil production history calculated for different quality of steam injected.

\section{Backpressure}

Figure 6.15 indicates the effect of backpressure on oil production performance. Steam throughput is much lower at the higher backpressure and consequently the production rate and recovery were lower. The effect of maintaining higher backpressure is akin to injecting steam at a lower rate. At higher backpressure steamfront advanced much more slowly, resulting in greater heat losses.

\section{IIme-Step slze Sensitivity}

Because of the IMPES nature of the formulation and explicit treatment of transmissibility (interblock flow terms) and production rates, the current version exhibits conditional stability. The stability of the simulator was evaluated by conducting time-step sensitivity studies. Four simulation runs, using a fixed time-step size of $0.01,0.1,1.0$ and 5.0 hours, was performed. Data used were those for the base run. Effect of time-step size on oil and water saturation at grid block 9 (center grid block) and oil material balance errors were studied.

Effect of time-step size on oil and water saturation changes are shown in figures 6.16 and 6.17 , respectively. The sensitivity of oil material balance error to time-step size is depicted in figure 6.18. These figures indicate that the simulator is very sensitive to time-step size and larger time-step size leads to uncontrollable oscillation in the saturation values and unacceptable material balance errors. Further, use of large time-step size resulted in saturation overshoots (negative saturation) and iruncation errors. 


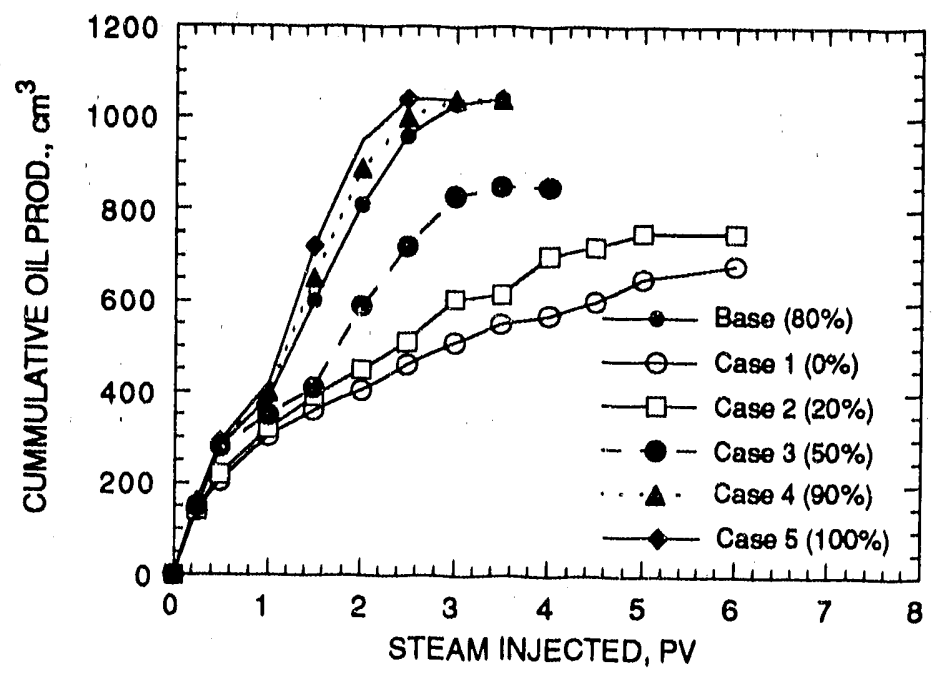

FIGURE 6.14 - Cumulative oil production histories - steam quality sensitivity.

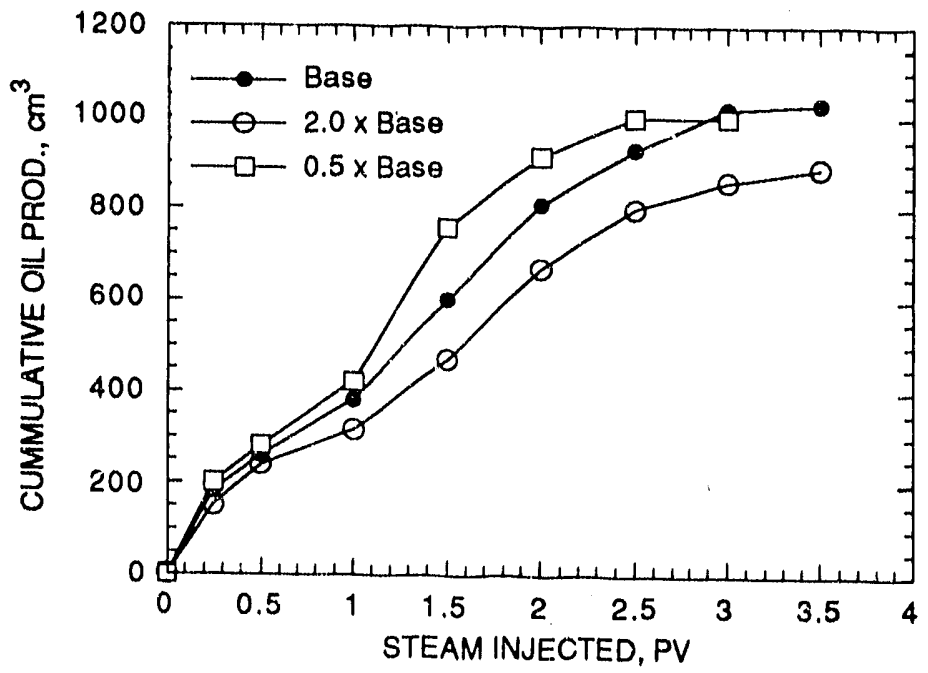

FIGURE 6.15 - Cumulative oil production histories - backpressure sensitivity. 


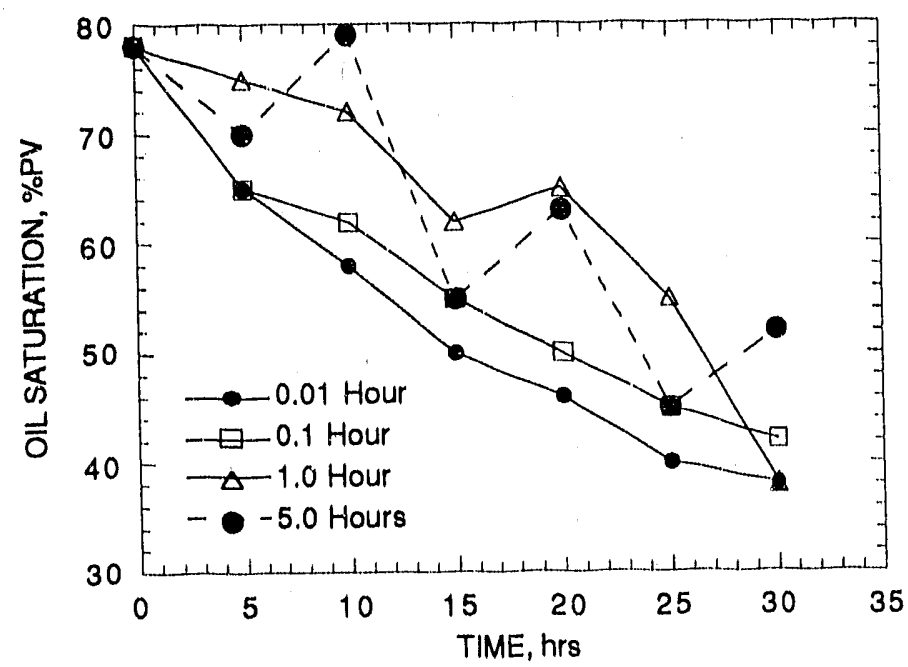

FIGURE 6.16 - Oll saturation profiles - time-step sensitivity runs.

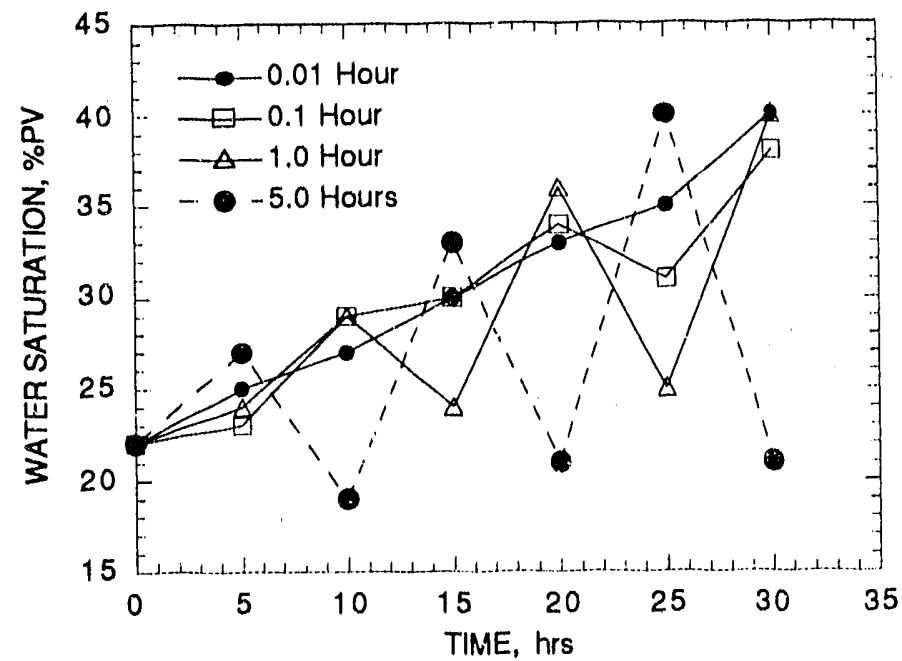

FIGURE 6.17 - Water saturation profiles - time-step sensitivity runs. 


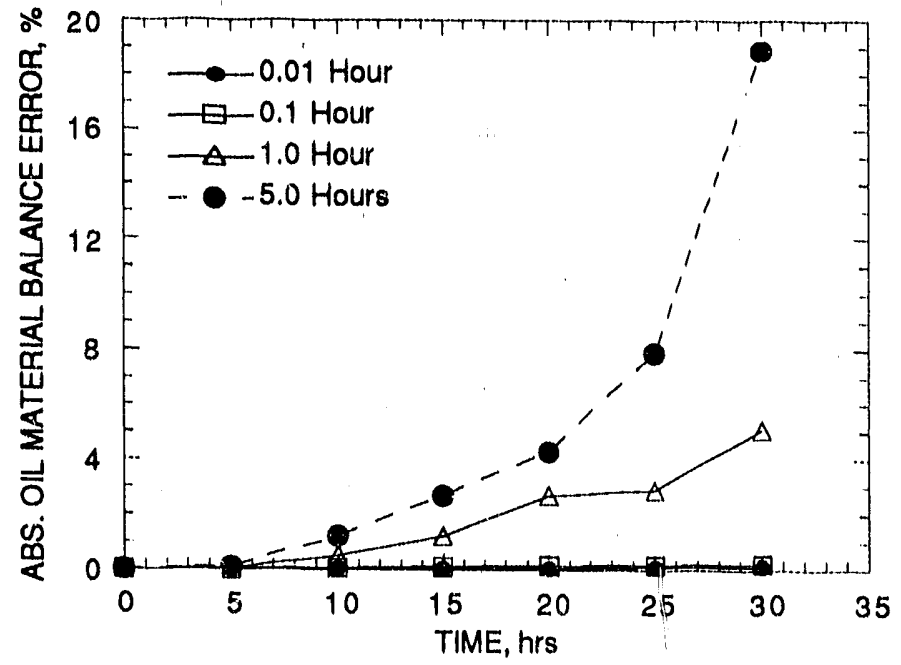

FIGURE 6.18 - Absolute oil material balance errors - time-step sensitivity runs.

These results are a consequence of evaluating relative permeabilities which depend on saturations at the beginning of each time-step. When new saturations are obtained, they are formed from 'old' reiative permeabilities. Moreover, the steamflood transmissibilities are not only a function of saturation but also of temperature and composition. This functional dependency of interblock flow terms on several dependent variables prevented its effective linearization without simplifying assumptions. The safuration overshoot and the unacceptable material balance errors are the manifestation of these assumptions. In addition, the rapid vapor phase saturation changes and steam water interaction also contributes to instability. When steam begins to accumulate in a block, vapor phase saturation changes rapidly. The rate of steam saturation changes when the steam starts to build up is about five times larger than the rate of water or oll saturation change at a time the steam does not exist in the model. This rapid saturation change results in computational difficulties, unless the maximum saturation change for a time-step is limited to a reasonable value or a very small time-step size is employed.

By taking very small time-steps, saturation oscillation was suppressed in the simulatcr and resulted in acceptable material balance errors. Since computing time depends on the time-step size, the model running time increased markedly with smaller time-steps. For example, using a fixed time-step of 0.1 hour, it took about 7 hours on a $10 \mathrm{MHz}, 286$ machine with math coprocessor to complete a ?30 time-step run. 


\section{Discusslon}

Table 6.13 summarizes the results of the numerical simulation sensitivity studies. While these sensitlvity results are by no means complete, they do provide some insight into the relative importance and effects of various parameters on the process.

The study clearly in cates the importance of heat loss, injected steam quality, and injection rate to the process. Dependence of overall recovery on oll volatility and viscosity is emphasized. Porosity and initial oll saturation which affect the amount of oll originally-in-place are also understandably important parameters. The process is very sensitive to relative permeability values.

While the reservoir and fluid property data significantly influence the simulation results, they do not affect the stability of the model. Numerical stability of the simulator depends on the type of formulation (IMPES or fully implicit) and truncation errors. Although all discrete approximations are subject to truncation errors, time-step values that are too large will result in larger truncation errors. Thus, while all simulators to a certain extent are affected by time-step size limitation, the effect is much more severe on IMPES type simulators that solves problem involving rapid saturation change or high flow rate such as the steamflood process.

As noted previously, the current version of the steamflood simulator is time-step sensitive and exhibits conditional stability. The stability of the IMPES type simulator was investigated by Todd et al. ${ }^{71}$ They concluded that the overshoot and truncation problems assoclated with these simulators can be controlled by limiting the time-step size. However, the model running time increases markedly with smaller time-steps. As pointed out by other researchers, ${ }^{26-28}$ only a fully implicit model is capable of overcoming time-step limitations, and yield stable solutions. However, this is also the most expensive method for obtaining the solution in each time-step.

TABLE 6.13 - Summary of sensitivity study

Sensitivity Case

Conclusions

Porosity

Absolute permeability

Rock heat capacity

Initial oil saturation

Irreducible water saturation

Relative permeability

Ci itical gas saturation

Oil viscosity

Oil volatility

Steam injection rate

Steam quality

Backpressure

Time-step size
Major effect due to difference in oll-in-place.

Negligible effect.

Minor effect; changes heat front advance rate.

Major effect.

Minor effect; changes initial oil production rate.

Major effect.

Minor effect, alters initial oil production rate.

Major effect on recovery.

Major effect on recovery.

Major effect; overall recovery suffers at lower injection rate.

Major effect.

Major effect; affects oil production rate and recovery.

Major effect; large time-step size affects the stability of ihe simulator. 
Coats ${ }^{26}$ compared the work requirements of the sequential (IMPES) steamflood model and fully implicit model and found that ior a three-component system, a fully impliclt steamilood simulator requires about eight times more computer time per time-step than a sequential type steamflood simulator. However, since the implicit model is much more stable, simulations can be performed using larger timesteps. The total computing time would then likely be only somewhat greater than that using a sequential model. However, Aziz ${ }^{15}$ pointed out that even with a fully implicit treatment, small time-steps are required in steamflood simulators because of the flow direction reversal. Flow reversal is the principal reason for employing direct solution technique in steamflood simulations.

Memory requirements and the complexity of the steamflood rnodel drastically increases with the use of fully implicit formulation and direct solution technique. Because of DOS's memory constraints, it is not possible to code and test a fully implicit compositional steamflood simulator on an IBM-AT type personal computer. However, efforts are being made to improve the performance of the current model. The availability of more powerful and faster personal computers and compilers that make use of DOS extenders to overcome DOS's memory limitations may permit the running of highly implicit steamflood simulators on personal computers. 


\section{CHAPTER 7 - CONCLUSIONS AND RECOMMENDATIONS}

\section{Summary}

A two-dimensional compositlonal numerical model for steamflooding was developed and tested on a personal compuler. The model is very similar to the one developed by Coats ${ }^{24}$ except for the numerical technique used. The current version solves the finite difference equations using a sequential solution technique. The model can be employed as a tool to ald in the interpretation of the laboratory results.

The model was valldated by comparing the model results with published results. The results from the model showed qualitatively similar behavior as the published results. Sensitivity studies were performed over a range of parameters to document the capability of the simulator.

\section{Conclusions}

1. Time-step sensitivity showed that due to the IMPES nature of the solution scheme, the model is highly time-step sensitive. Larger time-steps tend to destabilize the model and leads to saturation oscillation and convergence difficulties.

2. Process and reservoir parameter sensitivity studies of a typical laboratory steamflood process Indicated that the process is sensitive to the following: steam quality and injection rate, initial oll saturation, oil viscosity, oil volatility, porosity and relative permeability. Oil recovery efficiency increases with:

- an increase in steam quality

- an increase in injection rate

- an increase in oll volatility

- a decrease in initial oil viscosity

- an increase in porosity.

3. The laboratory steamfiood process was relatively insensitive to absolute permeability and rock heat capacity.

\section{Recommendations}

1. Continue the research effort to improve model performance and predictive ability.

2. Examine alternative formulation and solution schemes for implementation in the simulator. Possible examples of these schemes include the Newton-Raphson iteration scheme to solve the set of nonlinear equations at each time-step.

3. Explore the avenue for improving the stability of the model without unduly increasing its complexity. A highly implicit model improves the material balance errors and permits larger time-step size. 


\section{REFERENCES}

1. Lauwerier, H. A. The Transport of Heat in an Oll Layer Caused by the Injection of Hot Fluid. Appl. Sol. Research, v. 5, sec. 1-A, No. 2, 1955, pp. 145-150.

2. Rubinshtein, L. I. The Integral Value of Heat Losses During Hot Fluld Injection Into a Stratium. Neft Gaz, No. 9, 1959, pp. 41-48 (in Russlan)

3. Marx, J. W. and R. H. Langenheim. Reservoir Heating By Hot Fluld Injection. Trans. AIME, v. 216,1959, pp. $312-315$

4. Ramey, H. J. Discussion of Reservoir Heating By Hot Fluid Injection. Trans. AlME, v. 216, 1959, pp. 364-365.

5. Ramey, H. J. How to Calculate Heat Transmission By Hot Fluid Injection. Pet. Engr., v. 36, No. 12, November 1964, pp. 110-120.

6. Willman, B. T., V. V. Valleroy, G. W. Runberg, A. J. Cornellus and L. W. Powers. Laboratory Studies of Oil Recovery By Steam Injection. J. Pet. Tech., v. 13, July 1961, pp. 681-690.

7. Buckley, S. E. and M. C. Leverett. Mechanism of Fluid Displacement in Sands. Trans. AlME, v. 146, 1942, p. 107.

8. Hearn, C. L. Effect of Latent Heat Content of Injected Steam in a Steam Drive. J. Pet. Tech. v 21, April 1969, pp. 374-375.

9. Mandl, G. and C. W. Volek. Heat and Mass Transport in Steam Drive Processes. Soc. Pet. Engr. J., v. 9, March 1969, pp. 59-79.

10. Shutler, N. D. and T. C. Boberg. A One-Dimensional Analytical Technique for Predicting Oll Recovery By Steamflooding. Soc. Pet. Engr. J., v. 12, 1972, pp. 489-498.

11. Myhill, N. A. and G. L. Stegemeier. Steam Drive Correlation and Prediction. J. Pet. Tech., v. 30, February 1978, pp. 173-182.

12. Yortsos, Y. C. and G. R. Gavalas. Analytical Modeling of Oll Recovery by Steam Injection: Part 2 - Asymptotic and Approximate Solutions. Soc. Pet. Engr. J., V. 22, April 1982, pp. 179-190.

13. Yan Lookeren, J. Calculation Methods for Linear and Radial Steam. Flow in Oil Reservoirs. Soc. Pet. Engr. J., v. 23, June 1983, pp. 427-439,

14. Farouq Ali, S. M. and J. Ferrer. State-of-the-Art of Thermal Recovery Models. Trans. ASME, v. 103, December 1981, pp. 296-300.

15. Aziz, K. Modeling of Thermal Oll Recovery Processes. Paper pres. at the Conf. on Mathematical and Computational Methods in Seismic Exploration and Reservoir Modeling, Houston, TX, Jan. 21-24, 1985. Proceedings of Mathematical and Computational Methods in Seismic Exploration and Reservoir Modeling, Ed. by W. E. Fitzgibbon, Society for Industrial and Applied Mathematics (SIAM), Philadelphia, 1986, pp. 3-17.

16. Spillette, A. G. and R. L. Nielsen. Two-Dimensional Method for Predicting Hot Waterflood Recovery Behavior. J. Pot. Tech., v. 20, June 1968, pp. 627-638.

17. Shutler, N. D. Numerical Three-Phase Simulation of the Linear Steamflood Process. Soc. Pet. Engr. J., v. 9, June 1969, pp. 232-246. 
18. Shutler, N. D. Numerical Three-Phase Model of the Two-Dimensional Steamflood Process. Soc. Pet. Engr. J., v. 10, December 1970, pp. 405-417.

19. Abdalla, A. and K. H. Coats. Three-Phase Experimental and Numerical Simulation Study of the Sreamilood Process. Pres, at the 46th Ann. Fall Meeting of SPE of AIME, New Orleans, LA, Oct. 3-6, 1971. SPE paper 3600.

20. Vinsome, P. K. W. A Numerical Description of Hot Water and Steam Drives by the Finite Dlfference Method. Pres, at the 49th Ann. Fall Meeting of SPE of AIME, Houston, TX, Oot. 6-9, 1974. paper SPE 5248.

21. Coats, K. H., W. D. Georges, C. Chu and B. E. Marcum. Three-Dimensional Simulation of Steamflooding. Soc. Pet. Engr. J., v. 14, December 1974, pp. 573-592.

22. Weinstein, H. G., J. A. Wheeler and E. G. Woods. Numerical Model for Thermal Processes. Soc. Pet. Engr. J., v. 17, February 1977, pp. 65-78.

23. Spillette, A. G., J. G. Hillestad, and H. L. Stone. A High-Stability Sequential Solution Approach to Reservolr Simulation. Pres, at the 48th Ann. Fall Meeting of SPE of AIME, Las Vegas, NV, 1973. SPE paper 4542

24. Coats, K. H. Simulation of Steamflooding With Distillation and Solution Gas. Soc. Pet. Engr. J., v. 16, October 1976, pp. 235-247.

25. Ferrer, J. C. and S. M. Farouq All. A Threo-Phase Two-Dimensional Compositional Thermal Simulator for Steam Injection Processes. J. Canada Pet. Tech., v. 16, No. 4, January-March 1977, pp. 7890.

26. Coats, K. H. A Highly Implicit Steamflood Model. Soc. Pet Engr. J., v. 18, October 1978, pp. 369-383.

27. Abou-Kassem, J. H. Investigation of Grid Orientation in a Two-Dimensional Compositionial Three-Phase Steam Model. Ph.D. Thesis, University of Calgary, April 1981.

28. Rubin, B., and W. L. Buchanan. A General Purpose Thermal Model. Soc. Pet. Engr. J., v. 25, April 1985, pp. 204-214.

29. Potempa, T. Three-Dimensional Simulation of Steamflooding With Minimal Grid Orientation. Pres. at the Soc. Pet. Eng. California Regional Meeting, Ventura, CA, Mar. 23-25, 1983. SPE paper 11726.

30. Harding, T. G. Oll Recovery by Steam and Gas Injection. Ph.D. Thesis, U. of Alberta, Edmonton, Alberta, Canada, June 1986.

31. Ishimoto, K., G. A. Pope, and K. Sepehrnoori. An Equation-of-State Steam Simulator. In-Situ, v. 11, No. 1, 1987, pp. 1-37.

32. Dogru, A. H., A. S. Odeh, and W. R. Jines. A Field Scale, Three-Dimensional Simulator for Thermal Oll Recovery. Pres. at the 62nd Ann. Tech. Conf. and Exhibit. of the Soc. of Pet. Eng., Dallas, TX, Sept. 27-30, 1987. SPE paper 16734.

33. Kasraie, M. Simulation of Modifled Steam Injection Processes Applied to Botiom Water Reservoirs. Ph.D. Thesis, University of Aiberta, Edmonton, Alberta, Canada, August 1987. 
34. Zhai, J. Development of a Practical Steam Injection Simulator. Pres. at the Fourth UNITAR/UNDP International Conf. on Heavy Crude and Tar Sands., Edmonton, Alberta, Canada, Aug. 7 12, 1988. Proceedings of the Fourth UNITAR/UNDP International Conference on Heavy Crude and Tar Sands, Ed. by Meyer, R. F. and E. J. Wiggins. Published by Alberta Oil Sands Tech. and Research Authority, Edmonton, Alberta, v. 4, July 1989, pp. 491-494. Paper No. 145.

35. Abou-Kassem, J. H. and Farouq Ali, S. M. Practical Considerations in Developing Numerical Simulators for Thermal Recovery. Pres. at the 40th Ann. Tech. Meeting of the Pet. Soc. of CIM, Barff, Canada, May 28-31, 1989. Paper No. 89-40-53.

36. Esmail, M. N. Problems in Numerical Simulation of Heavy Oil Reservoirs. J. Can. Pet. Tech., v. 24, May-June 1985, pp. 80-82.

37. Patel, H. N., J. H. Masliyah, and J. Mathews. One-Dimensional Numerical Model for Cyclic Steam Injection in an Oil Reservoir. Oil Sands of Canada-Venezuela, CIM, Calgary, 1977, pp. 411-418.

38. Crookston, R. B., W. E. Culham, and W. H. Chen. A Numerical Simulation Model for Thermal Recovery Processes. Soc. Pet. Engr. J., v. 19, February 1979, pp. 37-58. 554.

39. Coats, K. H. In-Situ Combustion Model. Soc. Pet. Engr. J., v. 20, December 1980, pp. 533-

40. Gomaa, E. E. Correlations for Predicting Oil Recovery by Steamflood. J. Pet. Tech., v. 32, February 1980, pp. 325-332.

41. Rhee, S. W. and T. M. Doscher. A Method for Predicting Oil Recovery by Steamflooding Including the Effects of Distillation and Gravity Override. Soc. Pet. Engr. J., v. 20, August 1980, pp. 249266.

42. Jones, J. Steam Drive Model for Hand-Held Programmable Calculators. J. Pet. Tech., v. 33, September 1981, pp. 1583-1598.

43. Aydelotte, R. S. and G. A. Pope. A Simplified Predictive Model for Steam Drive Performance. J. Pet. Tech., v. 35, May 1983, pp. 991-1002.

44. Arima, E. Steamflood Predictive Model. M.S. Thesis, University of Texas, Austin, TX, 1984.

45. Farouq Ali, S. M. Graphical Determination of Oil Recovery in a Five-Spot Steamflood. Pres. at the Soc. Pet. Eng. Rocky Mountain Reg. Meeting, Casper, WY, June 8-9, 1970. SPE paper 2900.

46. Vogel, J. V. Simplified Heat Calculations for Steanfloods. J. Pet. Tech., v. 36, July 1984, pp. $1127-1136$

47. Miller, M. A. and W. K. Leung. A Simple Gravity Override Model of Steamdrive. Pres. at the 60th Ann. Tech. Conf. and Exhibit. of the Soc. of Pet. Eng. of AIME, Las Vegas, NV, September 1985. SPE paper 14241.

48. Chen, H. L. Analytical Modeling of Thermal Oil Recovery by Steam Stimulation and Steamflooding. Ph.D. Dissertation, U. of Tulsa, 1987.

49. Eoberg, T. C. Thermal Methods of Oil Recovery. John Wiley \& Sons, New York, 1988, p. 163

50. Gajdica, R. J., W. E. Brigham, and K. Aziz. A Semianalytical Thermal Model for Linear Steam Drive. Pres. at the Seventh SPE/DOE Symp. on EOR, Tulsa, OK, Apr. 22-25, 1990. SPE/DOE paper
20198 . 
51. Gajdica, R. J., W. E. Brigham, and K. Aziz. A Semianalytical Model for Linear Steam Drive. Dept. of Energy Report No. DOE/BC/14126-21, May 1990.

52. Farouq Ali, S.M. Oil Recovery by Steam Injection. Producers Publishing Company, Bradford, PA, 1970, p. 34.

53. Tikhomirov, V.M. Thermal Conductivity of Rock Samples and Its Relation to Liquid Saturatic,il, Density, and Temperature. (In Russian), Neftyanoe Khozaistvo, v. 46, No. 4, April 1968, p. 26.

54. Yao, S.C. Fluid Mechanics and Heat Transfer in Steam Injection Wells. M.S. Thesis, The University of Tulsa, 1986.

55. Herning, F. and L. Zipperer. Calculation of the Viscosity of Technical Gas Mixture From the Viscosity of Individual Components. Gas U. Wasserfach, v. 79, No. 49, 1936, p. 69.

56. Dean, D.E. and L. I. Stiel. The Viscosity of Nonpolar Gas Mixtures as Moderate and High Pressures. AlChE J. v. 11, No. 3, May 1965, pp. 526-532.

57. Tortike, W.S. and S. M. Farouq Ali. Saturated Steam Property Functional Correlations for Fully Implicit Thermal Reservoir Simulation. SPE Reservoir Eng., v. 4, No. 4, November 1989, pp. 471-474. 1984

58. Gros, P.P. Steam Soak Predictive Model. M. S. Thesis, University of Texas, Austin, TX, May

59. Standing, M. B. Volumetric and Phase Behavior of Oil Field Hydrocarbon System. SPE AIME, Dallas, TX, 1977, p. 123.

60. Takacs, G. Comparison Made for Computer Z-Factor Calculations. Oil \& Gas J., v. 74, No. 51, Dec. 20, 1976, pp. 64-66.

61. Burger, J., P. Sourieau, and M. Combarnous. Thermal Methods of Oil Recovery. Gulf Publishing Company, Houston, TX, 1985, p. 46.

62. Hadden, S.T. Heat Capacity of Hydrocarbons in the Normal Liquid Range. J. Chem. and Engr. Data, v. 15, No. 1, 1970, pp. 92-98.

63. Gambill, W. R. Determine Hat of Vaporization. Chem. Engr., v. 64, No. 12, December 1957, pp. 261-266.

64. Abou-Kassem, J.M. and K. Aziz. Handling of Phase Change in Thermal Simulation. J. Pet. Tech., v. 36, September 1985, pp. 1661-1663.

65. Stone, H. L. Estimation of Three-Phase Relative Permeability and Residual Oil Data. J. Can. Pet. Tech., v. 12, No. 6, October-December 1973, pp. 53-6i.

66. Fanchi, J.R., K. J. Harpole, and S.W. Bujnowski. BOAST: A Three-Dimensional Three-Phase Black Oil Applied Simulation Tool. v. 1, Dept. of Energy Report No. DOE/BC/10033-3, September 1982.

67. Diaz, J. Effectiveness of Hot Water Stimulation of Heavy Oil Wells - A Simulator Study. PhD Thesis. Pennsylvania State University, March 1974.

68. Malofeev, G.D. Experimental Study of Formation Heating When Injecting Hot Fluid. Neft i Gaz., v. 1 , No. 12,1958, p. 77.

69. Spillette, A.G. Heat Transfer During Hot Fluid Injection Into An Oil Reservoir. J. Can. Pet. Tech., v. 4, No. 4, October-December 1965. 
70. Sarathi, P.S., S.D. Roark, and A.R. Strycker. Light-Oil Steamflooding: A Laboratory Study. SPE Reservoir Eng., v. 5, No. 2, May 1990, pp. 177-184.

71. Todd, M.R., P.M. O'Dell, and G. J. Hirasaki. Methods for Increased Accuracy in Numerical Reservoir Simulators. Soc. Pet. Engr. J., v. 12, December 1972, pp. 515-530.

72. Higgins, R.V. and A. J. Leighton. Computer Prediction of Water Drive of Oil and Gas Mixtures Through Irregularly Bounded Porous Media - Three Phase Flow. J. Pet. Tech., v. 14, September 1962, pp. 1048-1054.

73. Lemonnier, P. Three Dimensional Numerical Simulation of Steam Injection. Paper presented at the 3rd European Symp. on Enhanced Oil Recovery, Bournemouth, U.K., Sept. 21-23, 1981. Proceedings of 3rd European Symposium or Enhanced Oil Recovery. Ed. by F.J. Fayers, Elsevier Scientific Publishing Co., Amsterdam, The Netherlands, 1981, pp. 374-394.

74. Ito, Y. A One Dimensional Computer Model for Simulating Oil Recovery by Steamflooding. M.S. Thesis, U. of Calgary, December 1976.

75. Grabowski, J.W., P.K. Vinsome, R.C. Lin, A. Behie, and B. Rubin. A Fully Implicit General Purpose Finite-Difference Thermal Model for In Situ Combustion and Steam. Pres. at the 54th Annual Fall Meeting of Society of Petroleum Engineers of AIME, Las Vegas, Nevada, Sept. 23-26, 1979. SPE paper 8396. 


\section{APPENDIX A - DERIVATION OF PARTIAL DIFFERENTIAL EQUATIONS FOR THE MATHEMATICAL MODEL}

\section{MASS BALANCE}

Let $V_{b}$ the bulk volume of an element of a reservoir having dimensions $\Delta x, \Delta z$ and $h$ as shown in figure A-1. Let $\phi$ be the porosity of the element. Considering the flow across the faces of the element, orie can express the molar flow rates of component $i$ for each phase as follows:

$X$ - direction inlet - $\left(\mathrm{Ni}_{i_{w}}+\mathrm{N}_{i_{0}}+\mathrm{Ni}_{\mathrm{g}}\right) x$

$X$ - direction oullet $-\left(\mathrm{N}_{i_{w}}+\mathrm{N}_{i_{0}}+\mathrm{Ni}_{i_{g}}\right) x+\Delta x$

$Z$ - direction inlet $-\left(N_{i_{W}}+N_{i_{0}}+N_{i_{g}}\right) z$

$z$ - direction outlet $-\left(N_{i_{w}}+N_{i_{0}}+N_{i g}\right) z+\Delta z$

Where $\mathrm{N}_{\mathrm{ij}}$ is the molar flow rate of component $\mathrm{i}$ in phase $\mathrm{j}$ in moles per unit time.

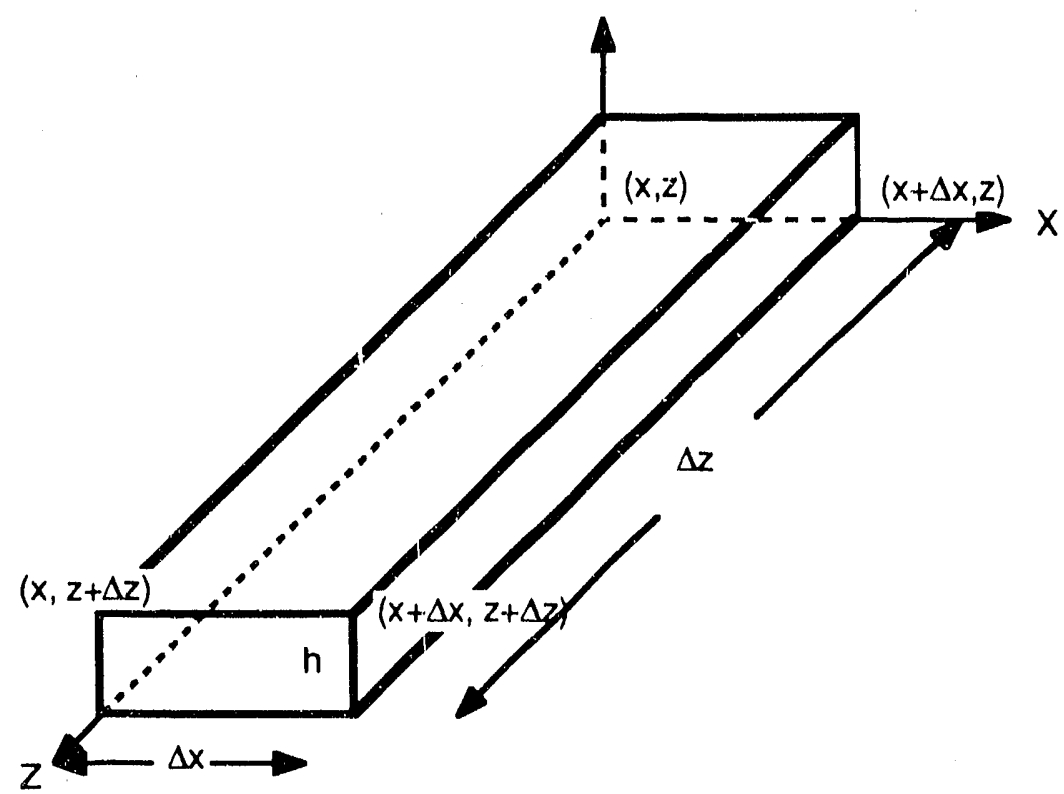

FIGURE A-1. - Volume element of the model in two-dimensions. 
Let $C_{i j}$ be the concentration of component $i$ in phase $j$ in moles per unit volume. Then the amount of component $i$ present in the element at various times is given by:

$$
\begin{array}{ll}
\text { at time } t & {\left[\phi V_{b}\left(C_{i_{W}} S_{W}+C_{i_{o}} S_{o}+C_{i_{g}} S_{g}\right)\right] t} \\
\text { at time } t+\Delta t & {\left[\phi V_{b}\left(C_{i_{W}} S_{W}+C_{i_{0}} S_{o}+C_{i_{g}} S_{g}\right)\right]+\Delta t}
\end{array}
$$

where $S_{j}$ is the fraction of phase $\mathcal{J}$ present in the element at any time.

One.can now write the molar balance of component i over a time increment $\Delta t$ as

$$
\begin{aligned}
& \text { (output - input) }+ \text { Accumulation }=0 \\
& {\left[\left(N_{i_{W}}+N_{i_{o}}+N_{i_{g}}\right) x+\Delta x-\left(N_{i_{W}}+N_{b_{b}}+N_{i_{g}}\right) x\right] \Delta t} \\
& +\left[\left(N_{i_{W}}+N_{i_{o}}+N_{i_{g}}\right) z+\Delta z-\left(N_{i_{W}}+N_{i_{o}}+N_{i_{g}}\right) z\right] \Delta t-q_{i} \Delta t \\
& +\left[\phi V_{b}\left(C_{i_{W}} S_{W}+C_{i_{0}} S_{o}+C_{i_{g}} S_{g}\right)\right] t+\Delta t- \\
& {\left[\phi V_{b}\left(C_{i_{W}} S_{W}+C_{i_{o}} S_{o}+C_{i_{g}} S_{g}\right)\right] t=0}
\end{aligned}
$$

Here $q_{i}$, the source or sink term (+ve for injection and -ve for production) is in moles/unit time.

This equation can be rewritten as

$$
\begin{aligned}
& -\frac{\left(N_{i_{w}}+N_{i_{0}}+N_{i_{g}}\right) x+\Delta x-\left(N_{i_{w}}+N_{i_{0}}+N_{i_{g}}\right) x}{\Delta x} \Delta x \\
& -\frac{\left(N_{i_{w}}+N_{i_{0}}+N_{i_{g}}\right) z+\Delta z-\left(N_{i_{w}}+N_{i_{0}}+N_{i_{g}}\right) z}{\Delta z} \Delta z+q_{i} \\
& =\frac{\left[\phi V_{b}\left(C_{i_{w}} S_{w}+C_{i_{0}} S_{0}+C_{i_{g}} S_{g}\right)\right] t+\Delta t-\left[\phi V_{b}\left(C_{i_{w}} S_{w}+C_{i_{0}} S_{o}+C_{i_{g}} S_{g}\right)\right] t}{\Delta t}
\end{aligned}
$$

Taking the limit as $\Delta x, \Delta z$, and $\Delta t$ approach zero, one obtains:

$$
-\frac{\partial}{\partial x}\left(N_{i_{w}}+N_{i_{0}}+N_{i_{g}}\right) \Delta x-\frac{\partial}{\partial z}\left(N_{i_{w}}+N_{i_{0}}+N_{i_{g}}\right) \Delta z+q_{i}
$$




$$
=V_{b} \frac{\partial}{\partial t}\left[\phi\left(C_{i_{w}} S_{w}+C_{i_{0}} S_{o}+C_{i_{g}} S_{g}\right)\right]
$$

Now

$$
\begin{aligned}
& N_{i_{W}}=\bar{\rho}_{W} u_{W} A \\
& N_{i_{0}}=x_{i} \bar{\rho}_{0} u_{0} A \\
& N_{i_{g}}=y_{i} \bar{\rho}_{g} u_{g} A
\end{aligned}
$$

and

$$
\begin{aligned}
& c_{i_{W}}=\overline{p_{W}} \\
& c_{i_{0}}=x_{i} \bar{p}_{0} \\
& c_{i_{g}}=y_{i} \bar{p}_{g}
\end{aligned}
$$

Where

$$
\begin{aligned}
& x_{i} \text { - mole fraction of component } i \text { in oleic phase } \\
& y_{i} \text { - mole fraction of component } i \text { in vapor phase } \\
& \bar{\rho}_{j} \text { - molar density of phase } j \text { in moles/volume } \\
& u_{j} \text { - phase velocity in length/time }
\end{aligned}
$$

A - cross sectional area normal to flow, (length) ${ }^{2}$

Substituting (A-4) and (A-5) into (A-3), one obtains:

$$
\begin{aligned}
& -\frac{\partial}{\partial x}\left(\bar{\rho}_{w} u_{w_{x}} A_{x}+x_{i} \bar{\rho}_{o} u_{o_{x}} A_{x}+y_{i} \bar{\rho}_{g} u_{g x} A_{x}\right) \Delta x \\
& -\frac{\partial}{\partial z}\left(\bar{\rho}_{w} u_{w_{z}} A_{z}+x_{i} \bar{\rho}_{o} u_{o_{z}} A_{z}+y_{i} \bar{\rho}_{g} u_{g_{z}} A_{z}\right) \Delta z+q_{i} \\
& =v_{b} \frac{\partial}{\partial t}\left[\phi\left(\bar{\rho}_{w} S_{w}+x_{i} \bar{\rho}_{o} S_{o}+y_{i} \bar{\rho}_{g} S_{g}\right)\right]
\end{aligned}
$$

The phase velocities are given by Darcy's law as follows:

$$
\begin{aligned}
& u_{w_{x}}=-\frac{k_{x} k_{r_{w}}}{\mu_{w}} \frac{\partial \Phi_{w}}{\partial x} \\
& u_{O_{x}}=-\frac{k_{x} k_{r_{0}}}{\mu_{0}} \frac{\partial \Phi_{0}}{\partial x}
\end{aligned}
$$




$$
\begin{aligned}
& u_{g x}=-\frac{k_{x} k_{r_{g}}}{\mu_{g}} \frac{\partial \Phi_{g}}{\partial x} \\
& u_{w_{z}}=-\frac{k_{z} k_{r_{w}}}{\mu_{w}} \frac{\partial \Phi_{w}}{\partial z} \\
& u_{z_{z}}=-\frac{k_{z} k_{r_{0}}}{\mu_{0}} \frac{\partial \Phi_{0}}{\partial z} \\
& u_{g_{z}}=-\frac{k_{z} k_{r_{g}}}{\mu_{g}} \frac{\partial \Phi_{g}}{\partial z}
\end{aligned}
$$

Substituting (A-7) inio (A-6) one obtains:

$$
\begin{gathered}
\frac{\partial}{\partial x}\left[\left(\frac{A_{x} k_{x} k_{r_{w}} \bar{\rho}_{w}}{\mu_{w}} \frac{\partial \Phi_{w}}{\partial x}\right)+\left(x_{i} \frac{A_{x} k_{x} k_{r_{0}} \bar{\rho}_{0}}{\mu_{0}} \frac{\partial \Phi_{0}}{\partial x}\right)+\left(y_{i} \frac{A_{x} k_{x} k_{r g} \bar{\rho}_{g}}{\mu_{g}} \frac{\partial \Phi_{g}}{\partial x}\right)\right] \Delta x+ \\
\frac{\partial}{\partial z}\left[\left(\frac{A_{z} k_{z} k_{r_{w}} \bar{\rho}_{w}}{\mu_{w}} \frac{\partial \Phi_{w}}{\partial z}\right)+\left(x_{i} \frac{A_{z} k_{z} k_{r_{0}} \bar{\rho}_{0}}{\mu_{0}} \frac{\partial \Phi_{0}}{\partial z}\right)+\left(y_{i} \frac{A_{z} k_{z} k_{r_{g}} \bar{\rho}_{g}}{\mu_{g}} \frac{\partial \Phi_{g}}{\partial z}\right)\right] \Delta z+q_{i} \\
=v_{b} \frac{\partial}{\partial t}\left[\phi\left(\rho_{w} S_{w}+x_{i} \bar{\rho}_{o} S_{o}+y_{i} \bar{\rho}_{g} S_{g}\right)\right]
\end{gathered}
$$

Using the del operator equation A-8 can be written for oil, water, and vapor phases in shorthand notation as:

$$
\begin{aligned}
& \nabla\left(\frac{A k k_{r_{w}} \bar{\rho}_{w}}{\mu_{w}} \nabla \Phi_{w}\right) \cdot \Delta+q_{w}=V_{b} \frac{\partial}{\partial t}\left(\Phi \bar{\rho}_{w} S_{w}\right) \\
& \nabla\left(x_{i} \frac{A k k_{r_{0}} \bar{\rho}_{0}}{\mu_{0}} \nabla \Phi_{0}\right) \cdot \Delta+q_{o}=V_{b} \frac{\partial}{\partial t}\left(\Phi x_{i} \bar{\rho}_{o} S_{0}\right) \\
& \nabla\left(y_{i} \frac{A k k_{r_{0}} \bar{\rho}_{g}}{\mu_{g}} \nabla \Phi_{g}\right) \cdot \Delta+q_{g}=V_{b} \frac{\partial}{\partial t}\left(\Phi y_{i} \bar{\rho}_{g} S_{g}\right)
\end{aligned}
$$

\section{ENERGY BALANCE}

Heat transport in the system occurs by both conduction and convection. Heat loss occurs by conduction. Heat also is carried into the system by injected steam and carried out of the system by produced fluids.

Let $q_{c o n d}=$ rate of heat conduction 
$q_{\text {conv }}=$ rate of heat convection

$\mathrm{qL} \quad=$ rate of heat loss (-ve for loss) (units: energy/time)

$\mathrm{q}_{\mathrm{p}} \mathrm{H}_{\mathrm{p}}=$ heat gained or lost due to production or injection of phase $\mathrm{p}$

(+ve if injected; -ve if produced) (Units: energ $y /$ time)

$U_{p} \quad=\quad$ internal energy of phase $p$ (units: energy/mole).

Energy entering into the element at face $x$ due to conduction

$$
=\left(q_{\text {cond }}\right) x=\left(-\lambda A_{x} \frac{\partial T}{\partial x}\right) x
$$

Energy leaving the element at face $x+\Delta x$ due to conduction

$$
=\left(q_{\text {cond }}\right) x+\Delta x=\left(-\lambda A_{x} \frac{\partial T}{\partial x}\right) x+\Delta x
$$

Energy entering into the element at face $z$ due to conduction

$$
=\left(q_{\text {cond }}\right) z=\left(-\lambda A_{z} \frac{\partial T}{\partial z}\right) z
$$

Energy leaving the element at face $z+\Delta z$ due to conduction

$$
=\left(q_{\text {cond }}\right) z+\Delta z=\left(-\lambda A_{z} \frac{\partial T}{\partial z}\right) z+\Delta z
$$

Net heat transferred by conduction over a time interval $\Delta t$

$$
=-\left[\left(\lambda A_{x} \frac{\partial T}{\partial x}\left|x+\Delta x-\lambda A_{x} \frac{\partial T}{\partial x}\right| x\right)+\left(\lambda A_{z} \frac{\partial T}{\partial z}\left|z+\Delta z-\lambda A_{z} \frac{\partial T}{\partial z}\right| z\right)\right] \Delta t
$$

Here $\lambda$ is thermal conductivity (Units = Energy per unit length per unit time per unit rise in temperature).

Energy entering into the element at face $x$ due to convection

$=\left(q_{c o n v}\right)_{x}=A_{x}\left(\bar{p}_{w} H_{w} u_{w}+\bar{p}_{0} H_{0} u_{o}+\bar{\rho}_{g} H_{g} u_{g}\right)_{x}$ 
Energy leaving the element at face $x+\Delta x$ due to convection

$=\left(q_{c o n v}\right)_{x+\Delta x}=A_{x}\left(\bar{\rho}_{w} H_{w} u_{w}+\bar{\rho}_{0} H_{0} u_{0}+\bar{\rho}_{g} H_{g} u_{g}\right)_{x+\Delta x}$

Energy entering into the element at face $z$ due to convection

$=\left(q_{\text {conv }}\right)_{z}=A_{z}\left(\bar{\rho}_{y, j} H_{w} u_{w}+\bar{\rho}_{0} H_{0} u_{0}+\bar{\rho}_{g} H_{g} u_{g}\right)_{z}$

Energy leaving the element at face $z+\Delta ?$ due to convection

$=\left(q_{\text {conv }}\right)_{z+\Delta z}=A_{z}\left(\bar{\rho}_{w} H_{w} u_{w}+\bar{\rho}_{0} H_{0} u_{0}+\bar{\rho}_{g} H_{g} u_{g}\right)_{z+\Delta z}$

Net heat transferred by convection over a time interval $\Delta t$

$=A_{x}\left[\left(\bar{\rho}_{w} H_{w} u_{w}+\bar{\rho}_{0} H_{0} u_{0}+\left.\bar{\rho}_{g} H_{g} u_{g}\right|_{x+\Delta x}-\right.\right.$

$$
\begin{aligned}
& \left.\left.\bar{\rho}_{w} H_{w} u_{w}+\bar{\rho}_{0} H_{0} u_{0}+\bar{\rho}_{g} H_{g} u_{g} \mid x\right)\right] \Delta t \\
& +A_{z}\left[\left(\bar{\rho}_{w} H_{w} u_{w}+\bar{\rho}_{0} H_{0} u_{0}+\left.\bar{\rho}_{g} H_{g} u_{g}\right|_{z+\Delta z}-\right.\right. \\
& \left.\left.\bar{\rho}_{w} H_{w} u_{w}+\bar{\rho}_{0} H_{0} u_{0}+\bar{\rho}_{g} H_{g} u_{g} \mid z\right)\right] \Delta t
\end{aligned}
$$

The energy accumulated in the elerient at time $t:$

$$
=\left[V_{b}(1-\phi) \rho_{R} U_{R}+\phi V_{b}\left(S_{W} \bar{\rho}_{W} U_{W}+S_{O} \bar{\rho}_{O} U_{o}+S_{g} \bar{\rho}_{g} U_{g}\right)\right]_{t}
$$

The energy accumulated in the element at time $t+\Delta t$

$$
=\left[V_{b}(1-\phi) \rho_{R} U_{R}+\phi V_{b}\left(S_{W} \bar{\rho}_{W} U_{W}+S_{O} \bar{\rho}_{O} U_{O}+S_{g} \bar{\rho}_{g} U_{g}\right)\right]_{i+\Delta t}
$$

Net accumulation of energy

$$
\begin{aligned}
& =\left[V_{b}(1-\phi) \rho_{R} U_{R}+\phi V_{b}\left(S_{W} \bar{\rho}_{W} U_{W}+S_{0} \bar{\rho}_{o} U_{0}+S_{g} \bar{\rho}_{g} U_{g}\right)\right]_{t+\Delta t} \\
& -\left[V_{b}(1-\phi) \rho R U_{R}+\phi V_{b}\left(S_{W} \bar{\rho}_{W} U_{W}+S_{O} \bar{\rho}_{0} U_{O}+S_{g} \bar{\rho}_{g} U_{g}\right)\right] t
\end{aligned}
$$


Net heat carried out by the produced fluids over the time interval st is given by:

$$
\left(q_{w} H_{w}+q_{0} H_{0}+q_{g} H_{g}\right) \Delta t
$$

Heat loss to the surroundings over the time interval $\Delta t$

$$
=q_{L} \Delta t
$$

Applying the principle of conservation of energy to the elemental volume over a time interval $\Delta t$, we have

Net heat transferred by conduction + net heat transferred by convection +

net heat accumulated - heat carried out by produced fluids - heat loss to the surroundings $=0$

Substituting equations A-10 through A-14 into A-15, we have

$$
\begin{aligned}
& -\left[\left(\left.\lambda A_{x} \frac{\partial T}{\partial x}\right|_{x+\Delta x}-\left.\lambda A_{x} \frac{\partial T}{\partial x}\right|_{x}\right)+\left(\left.\lambda A_{z} \frac{\partial T}{\partial z}\right|_{z+\Delta z}-\left.\lambda A_{z} \frac{\partial T}{\partial z}\right|_{z}\right)\right] \Delta t \\
& +A_{x} \cdot\left[\left(\bar{\rho}_{w} H_{w} u_{w}+\bar{\rho}_{0} H_{0} u_{0}+\left.\bar{\rho}_{g} H_{g} u_{g}\right|_{x+\Delta x}-\right.\right. \\
& \left.\left.\bar{\rho}_{w} H_{w} u_{w}+\bar{p}_{0} H_{0} u_{0}+\bar{\rho}_{g} H_{g} u_{g} \mid x\right)\right] . \Delta t \\
& +A_{z} \cdot l\left(\bar{\rho}_{w} H_{w} u_{w}+\bar{\rho}_{o} H_{0} u_{0}+\left.\bar{\rho}_{g} H_{g} u_{g}\right|_{z+\Delta z}-\right. \\
& \left.\left.\bar{\rho}_{w} H_{w} u_{w}+\bar{\rho}_{0} H_{0} u_{0}+\bar{\rho}_{g} H_{g} u_{g} \mid z\right)\right] . \Delta t \\
& +\left[V_{b}(1-\phi) \rho_{R} U_{R}+\phi V_{b}\left(S_{W} \bar{\rho}_{W} U_{W}+S_{o} \bar{\rho}_{0} U_{o}+S_{g} \bar{\rho}_{g} U_{g}\right)\right]_{t+\Delta t} \\
& -\left[V_{b}(1-\phi) \rho_{R} U_{R}+\phi V_{b}\left(S_{w} \bar{\rho}_{w} U_{w}+S_{o} \bar{\rho}_{o} U_{o}+S_{g} \bar{\rho}_{g} U_{g}\right)\right]_{t} \\
& -\left(q_{w} H_{w}+q_{0} H_{0}+q_{g} H_{g}\right) \cdot \Delta t-q_{L}=0
\end{aligned}
$$

Rearrangement of equation A-16 yields:

$$
\begin{aligned}
& \frac{\left(\left.\lambda A_{x} \frac{\partial T}{\partial x}\right|_{x+\Delta x}-\lambda A_{x} \frac{\partial T}{\partial x} \mid x\right)}{\Delta x} \cdot \Delta x+\frac{\left(\left.\lambda A_{z} \frac{\partial T}{\partial z}\right|_{z+\Delta z}-\left.\lambda A_{z} \frac{\partial T}{\partial z}\right|_{z}\right)}{\Delta z} \cdot \Delta z \\
& -\left[\bar{\rho}_{w} H_{w} u_{w} A_{x}+\bar{\rho}_{o} H_{0} u_{0} A_{x}+\left.\bar{\rho}_{g} H_{g} u_{g} A_{x}\right|_{x+\Delta x}\right. \\
& \left.-\bar{\rho}_{w} H_{w} u_{w} A_{x}+\bar{\rho}_{o} H_{0} u_{0} A_{x}+\left.\bar{\rho}_{g} H_{g} u_{g} A_{x}\right|_{x}\right] \frac{\Delta x}{\Delta x}
\end{aligned}
$$




$$
\begin{aligned}
- & {\left[\bar{\rho}_{w} H_{w} u_{w} A_{z}+\bar{\rho}_{o} H_{0} u_{0} A_{z}+\left.\bar{\rho}_{g} H_{g} u_{g} A_{z}\right|_{z+\Delta z}\right.} \\
- & \left.\bar{\rho}_{w} H_{w} u_{w} A_{z}+\bar{\rho}_{o} H_{0} u_{0} A_{z}+\left.\bar{\rho}_{g} H_{g} u_{g} A_{z}\right|_{z}\right] \frac{\Delta z}{\Delta z} \\
+ & \left(q_{w} H_{w}+\phi_{o} H_{o}+q_{g} H_{g}\right)+q_{L} \\
= & {\left[V_{b}(1-\phi) \rho_{R} U_{R}+\phi V_{b}\left(S_{w} \bar{\rho}_{w} U_{w}+S_{o} \bar{\rho}_{o} U_{o}+S_{g} \bar{\rho}_{g} U_{g}\right)\right]_{t+\Delta t} } \\
& -\left[V_{b}(1-\phi) \rho R U_{R}+\phi V_{b}\left(S_{w} \bar{\rho}_{w} U_{w}+S_{o} \bar{\rho}_{o} U+S_{g} \bar{\rho}_{g} U_{g}\right)\right]_{t / \Delta t}
\end{aligned}
$$

Taking the limits as $\Delta x, \Delta z$, and $\Delta t$ approach zero, one obtains:

$$
\begin{aligned}
& \frac{\partial}{\partial x}\left(\lambda A_{x} \frac{\partial T}{\partial x}\right) \Delta x+\frac{\partial}{\partial z}\left(\lambda A_{z} \frac{\partial T}{\partial z}\right) \Delta z-\frac{\partial}{\partial x}\left(\bar{\rho}_{W} H_{W} u_{W} A_{x}+\bar{\rho}_{o} H_{0} u_{o} A_{x}+\bar{\rho}_{g} H_{g} u_{g} A_{x}\right) . \Delta x- \\
& \frac{\partial}{\partial z}\left(\bar{\rho}_{w} H_{w} u_{w} A_{z}+\bar{\rho}_{0} H_{0} u_{0} A_{z}+\bar{\rho}_{g} H_{g} u_{g} A_{z}\right) \cdots+\left(q_{w} H_{w}+q_{0} H_{0}+q_{g} H_{g}\right)+q_{L} \\
& =V_{b} \frac{\partial}{\partial t}\left[(1-\phi) \rho_{R} U_{R}+\phi\left(S_{W} \bar{\rho}_{W} U_{W}+S_{o} \bar{\rho}_{o} U_{0}+S_{g} \bar{\rho}_{g} U_{g}\right)\right]
\end{aligned}
$$

Substituting equations A-7 for the phase velocities in A-18, one obteins:

$$
\begin{aligned}
& \frac{\partial}{\partial x}\left(\lambda A_{x} \frac{\partial T}{\partial x}\right) \Delta x+\frac{\partial}{\partial z}\left(\lambda A_{z} \frac{\partial T}{\partial z}\right) \Delta z+ \\
& \frac{\partial}{\partial x}\left(\frac{A_{x} k_{x} k_{r_{w}} \bar{\rho}_{w} H_{w}}{\mu_{w}} \frac{\partial \Phi_{w}}{\partial x}+\frac{A_{x} k_{x} k_{r_{0}} \bar{\rho}_{0} H_{0}}{\mu_{0}} \frac{\partial \Phi_{0}}{\partial x}+\right. \\
& \left.\frac{A_{x} k_{x} k_{r g} \bar{\rho}_{g} H_{g}}{\mu_{g}} \frac{\partial \Phi_{g}}{\partial x}\right) \cdot \Delta x+\frac{\partial}{\partial z}\left(\frac{A_{z} k_{z} k_{r_{w}} \bar{\rho}_{w} H_{w}}{\mu_{w}} \frac{\partial \Phi_{w}}{\partial x}+\right.
\end{aligned}
$$

$$
\begin{aligned}
& \left.\frac{A_{z} k_{z} k_{r_{0}} \bar{\rho}_{0} H_{0}}{\mu_{0}} \frac{\partial \Phi_{0}}{\partial z}+\frac{A_{z} k_{z} k_{r g} \bar{\rho}_{g}+H_{g}}{\mu_{g}}-\frac{\partial g g}{\partial z}\right) \cdot \Delta z \\
& +\left(q_{w} H_{w}+q_{0} H_{0}+q_{g} H_{g}\right)+q_{L} \\
& =V_{b} \frac{\partial}{\partial t}\left[(1-\phi) \rho R\left(U_{R}+\phi\left(S_{w} \bar{\rho}_{w} U_{w}+S_{O} \bar{\rho}_{0} U_{0}+S_{g} \bar{\rho}_{g} U_{g}\right)\right]\right.
\end{aligned}
$$

Using the del operator, equation A-19 can be written as 
$\nabla(A \lambda \nabla T) \cdot \Delta+\nabla\left(\frac{A k k_{r_{w}} \bar{\rho}_{w} \bar{h}_{w}}{\mu_{w}} \nabla \Phi_{w}+\frac{A k k_{r_{0}} \bar{\rho}_{0} h_{0}}{\mu_{0}} \nabla \Phi_{0}\right.$

$\left.+\frac{A k k_{r_{g}} \bar{\rho}_{g} H_{g}}{\mu_{g}} \nabla \Phi_{g}\right) \cdot \Delta+\left(q_{w} H_{w}+q_{0} H_{0}+q_{g} H_{g}\right)+q_{L}$

$(A-20)$

$=V_{b} \frac{\partial}{\partial t}\left[(1-\phi) \rho R U_{R}+\phi\left(S_{w} \bar{\rho}_{W} U_{W}+S_{0} \bar{\rho}_{0} U_{0}+S_{g} \bar{\rho}_{g} U_{g}\right)\right]$

102 


\section{APPENDIX B - FINITE DIFFERENCE FORM OF THE MODEL}

The differential equations describing the steam injection process are presented in appendix $A$ for oil, gas, and water. Since the model treats oil as a three-component mixture which is permitted to be distributed among oil and gas phases, it is more appropriate to express the molar balances in terms of individual component rather than phases. Also, since water is allowed to exist in both liquid and vapor phases, a single water molar balance is warranted. The modified forms of molar and energy balance equations are as follows:

\section{Molar Balances on Hydrocarbon Components}

$\frac{\partial}{\partial x}\left(x_{i} \frac{A_{x} k_{x} k_{r o} \bar{\rho}_{0}}{\mu o} \frac{\partial \Phi_{0}}{\partial x}+y_{i} \frac{A_{x} k_{x} k_{r g} \ddot{\rho}_{g}}{\mu g} \frac{\partial \Phi_{g}}{\partial x}\right)+$

$\frac{\partial}{\partial z}\left(x_{i} \frac{A_{z} k_{z} k_{r o} \bar{\rho}_{\Omega}}{\mu 0} \frac{\partial \Phi_{0}}{\partial z}+y_{i} \frac{A_{z} k_{z} k_{r g} \bar{\rho}_{g}}{\mu g} \frac{\partial \Phi_{g}}{\partial z}\right)+q_{0} x_{i} \bar{\rho}_{0}$

$+q_{g} y_{i} \bar{\rho}_{g}=V_{b} \frac{\partial}{\partial t}\left[\phi\left(x_{i} \bar{\rho}_{0} s_{o}+y_{i} \bar{\rho}_{g} s_{g}\right)\right]_{i=1,2,3}$

\section{Molar Balance on Water.}

$\frac{\partial}{\partial x}\left(\bar{\rho}_{w} \frac{k_{x} k_{r w}}{\mu w} A_{x} \frac{\partial \Phi_{w}}{\partial x}+y_{s} \bar{\rho}_{g} \frac{k_{x} k_{r g}}{\mu g} A_{x} \frac{\partial \Phi_{g}}{\partial x}\right)+$

$\frac{\partial}{\partial z}\left(\bar{\rho}_{w} \frac{k_{z} k_{r w}}{\mu w} A_{z} \frac{\partial \Phi_{w}}{\partial z}+y_{s} \bar{\rho}_{g} \frac{k_{z} k_{r g}}{\mu g} A_{z} \frac{\partial \Phi_{g}}{\partial z}\right)+q_{w} \bar{\rho}_{w}=V_{b} \frac{\partial}{\partial t}\left[\phi\left(\bar{\rho}_{w} S_{w}+y_{s} \bar{\rho}_{g} S_{g}\right)\right]$

\section{Energy Balance}

$\frac{\partial}{\partial x}\left(\lambda A_{x} \frac{\partial T}{\partial x}\right) \Delta x+\frac{\partial}{\partial z}\left(\lambda A_{z} \frac{\partial T}{\partial z}\right) \Delta z+\frac{\partial}{\partial x}\left(\frac{A_{x} k_{x} k_{r w} \bar{\rho}_{w} H_{w}}{\mu w} \frac{\partial \Phi_{w}}{\partial x}+\frac{A_{x} k_{x} k_{r o} \bar{\rho}_{0} H_{0}}{\mu 0} \frac{\partial \Phi_{0}}{\partial x}+\right.$

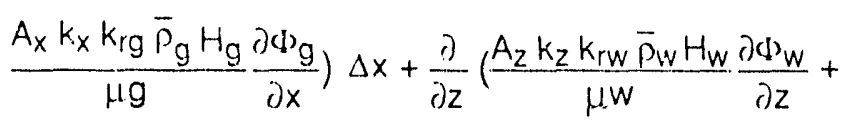

$\left.\frac{A_{z} k_{z} k_{r o} \bar{\rho}_{0} H_{0}}{\mu 0} \frac{\partial \omega_{0}}{\partial z}+\frac{A_{z} k_{z} k_{r g} \bar{\rho}_{g} H_{g}}{\mu g} \frac{\partial(l) g}{\partial z}\right) \Delta z+q L$

$+\left(q_{w} H_{w}+q_{0} H_{0}+q_{g} H_{g}\right)=V_{b} \frac{\partial}{\partial t}\left[(1-\phi) \rho R U_{R}+\phi\left(S_{w} \bar{\rho}_{w} U_{w}+S_{0} \bar{\rho}_{0} \bar{U}_{0}+S_{g} \bar{\rho}_{g} \bar{U}_{g}\right)\right]$

Since the above expressions are highly nonlinear, an analytical solution to the problem is unlikely. Accordingly, a finite difference approach has been used to obtain approximate solutions to these eciJatio.ns. The finite difference process reduces the partial differential equation to an algebraic equation. 
In this appendix, the finite difference procedure is formulated. Details of the finite difference expansion will be presented in the next appendix.

\section{Finite Difference Representation}

The partial derivatives in equations B1-B5 are approximated by means of finite difference quotients, which are developed from truncated Taylor's series expansion of the independent variables about the geometric parameters. For example, if a function $P(x)$ and all of its derivatives exist at the point $x_{0}$, then by Taylor's series

$$
P\left(x_{i}\right)=P\left(x_{0}\right)+\left.\Delta x \frac{d P}{d x}\right|_{x_{0}}+\left.\frac{\Delta x^{2}}{2 !} \frac{d^{2} P}{d x_{2}}\right|_{x_{0}}+
$$

If we neglect all but the first two terms on the right-hand side:

$$
\left.\frac{d P}{d x}\right|_{x_{0}} \cong \frac{P\left(x_{i}\right)-P\left(x_{0}\right)}{\Delta x}
$$

Equation $B-7$ is an approximation to the derivative $\frac{d P}{d x}$ which can then be substituted into the differential equation.

Also, note that converting derivatives of independent variables to finite difference form requires discrete values of $x_{1}, x_{2}, x_{3}, \ldots x_{n}, z_{1}, z_{2}, z_{3} \ldots z_{n}$. To accomplish this, the reservoir is replaced by a system of blocks. Each block has a set of suitably averaged independent variables. A typical two-dimensional grid is shown in figure B-1. The particular type of grid system used in this study was a block centered grid system, which assumes each spatial point to be at the center of a block or cell of dimension $\Delta x$ and $\Delta z$ Thus, the boundary of the reservoir occurs at the edge of the cell, or rather at points equidistant from the grid points. The temporal points also form a grid in the time domain, in this case of size increments, $\Delta t$

Hence the network of points can be defined as

$$
\begin{array}{ll}
x_{i}=i \Delta x & i=1,2,1 \\
z_{j}=j \Delta z & j=1,2, J \\
t_{n}=n \Delta t & n=0,1,2 \ldots \quad N
\end{array}
$$




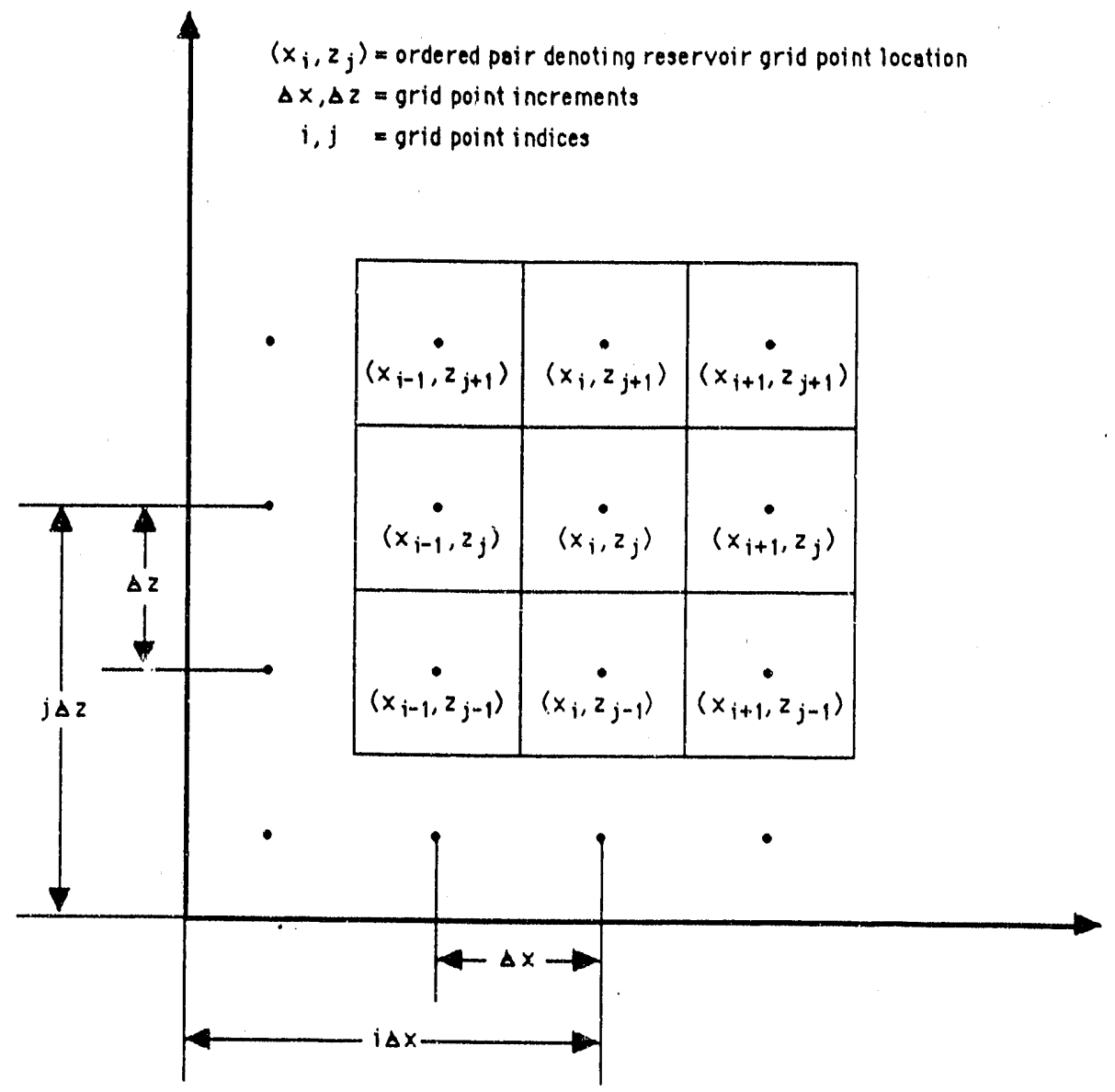

FIGURE B.1 - Diagramatic representation of a block centered grid system.

Using a centered difference approximation to represent the spatial derivative of volumetric velocity about the block, $i, j$ results in

$$
\begin{aligned}
& \frac{\partial}{\partial x}\left(x_{i} \bar{\rho}_{0} \frac{A_{x} k_{x} k_{r o}}{\mu o} \frac{\partial \Phi_{0}}{\partial x}\right)_{i, j} \\
& \cong \frac{\left(\frac{A_{x} k_{x} k_{r o}}{\mu o} \cdot x_{i} \frac{\bar{\rho}_{0} \partial \Phi_{0}}{\partial x}\right)_{i+1 / 2, j}-\left(\frac{A_{x} k_{x} k_{r o}}{\mu o} x_{i} \bar{\rho}_{0} \frac{\partial \Phi_{0}}{\partial x}\right)_{i-1 / 2, j}}{\Delta x_{i, j}}
\end{aligned}
$$

The spatial derivative of potential is also expressed as a central difference, so that

$$
\left(\frac{\partial \Phi_{0}}{\partial x}\right)_{i+1 / 2, j}=\frac{\left(\Phi_{0}\right)_{i+1, j}-\left(\Phi_{0}\right)_{i, j}}{\Delta x_{i+1 / 2, j}} \text { and }\left(\frac{\partial \Phi_{0}}{\partial x}\right)_{i-1 / 2, j}=\frac{\left(\Phi_{0}\right)_{i, j}^{-\left(\Phi_{0}\right)} i-1, j}{\Delta x_{i-1 / 2, j}}
$$


combining these expressions,

$\frac{\partial}{\partial x}\left(\frac{A_{x} k_{x} k_{10}}{\mu 0} x_{i} \bar{\rho}_{0} \frac{\partial\left(D_{0}\right.}{\partial x}\right)_{i, j}$

$\cong\left\{\left(\frac{A_{x} k_{x} k_{r o}}{\mu 0} \frac{x_{i} \bar{p}_{0}}{\Delta x}\right)_{i+1 / 2, j}\left(\Phi_{O_{i+1, j}}-\Phi_{O_{i, j}}\right)-\left(\frac{A_{x} k_{x} k_{r o}}{\mu 0} \frac{x_{i} \bar{\rho}_{0}}{\Delta x}\right)_{i-1 / 2, j}\left(\Phi_{O_{i}}-\Phi_{0 i-1, j}\right)\right) / \Delta x i_{i, j}$

Similarly

$\frac{\partial}{\partial x}\left(\frac{A_{x} k_{x} k_{r g}}{\mu g} y_{i} \bar{\rho}_{g} \frac{\partial \Phi g}{\partial x}\right)_{i, j}$

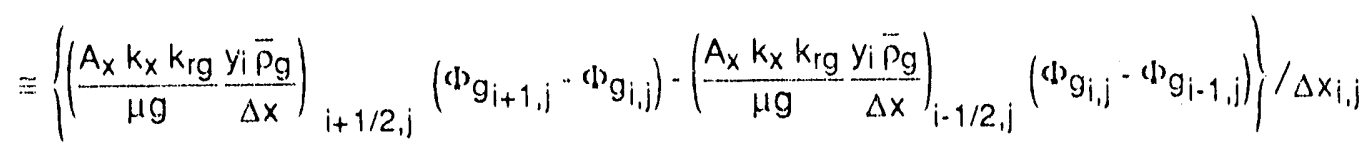

$\frac{\partial}{\partial z}\left(\frac{A_{z} k_{z} k_{10}}{\mu 0} \cdot x_{i} \bar{p}_{0} \frac{\partial\left(D_{0}\right.}{\partial z}\right)_{i, j}$

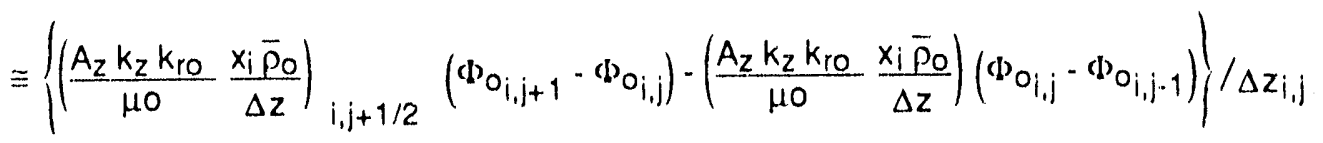

$\frac{\partial}{\partial z}\left(\frac{A_{z} k_{z} k_{r g}}{\mu g} y_{i} \overline{p g} \frac{\partial \omega_{g} g}{\partial z}\right)_{i, j}$

$\cong\left(\frac{A_{z} k_{z} k_{r g}}{\mu g} \frac{y_{i} \bar{\rho}_{g}}{\Delta z}\right)_{i, j+1 / 2}\left(\Phi_{g_{i, j+1}}-()_{g_{i, j}}\right)-\left(\frac{A_{z} k_{z} k_{r g}}{\mu g} \frac{y_{i} \bar{\rho}_{g}}{\Delta z}\right)\left(\Phi g_{i, j}-\left(\omega_{g_{i, j}-1}\right)\right\} / \Delta z_{i, j}$

The subscripts of the type $i+1 / 2$ in the above equations refer to average properties between adjacent grid blocks.

Combining equations B-11 through B-14, we have

$\frac{\partial}{\partial x}\left(x_{i} \bar{p}_{0} \frac{A_{x} k_{x} k_{r o}}{\mu 0} \frac{\partial\left(b_{0}\right.}{\partial x}+y_{i} \bar{\rho}_{g} \frac{A_{x} k_{x} k_{r g}}{\mu g} \frac{\partial g b_{g}}{\partial x}\right)+$ 


$$
\begin{aligned}
& \frac{\partial}{\partial z}\left(x_{i} \bar{\rho}_{0} \frac{A_{z} k_{z} k_{r_{0}}}{\mu 0} \frac{\partial \Phi_{0}}{\partial z}+y_{i} \bar{\rho}_{g} \frac{A_{z} k_{x} k_{r g}}{\mu g} \frac{\partial \Phi_{g}}{\partial z}\right) \\
& \cong\left\{\left(\frac{A_{x} k_{x} k_{r o}}{\mu 0} \frac{x_{i} \bar{\rho}_{0}}{\Delta x}\right)_{i+1 / 2, j}\left(\Phi_{O_{i+1, j}}-\Phi_{O_{i, j}}\right)-\left(\frac{A_{x} k_{x} k_{r o}}{\mu 0} \frac{x_{i} \bar{\rho}_{0}}{\Delta x}\right)_{i-1 / 2, j}\left(\Phi_{O_{i, j}}-\Phi_{O_{i-1, j}}\right)\right\} / \Delta x_{i, j} \\
& \left\{+\left\{\frac{A_{z} k_{z} k_{r o}}{\mu 0} \frac{x_{i} \bar{p}_{0}}{\Delta z}\right\}_{i, j+1 / 2}\left(\Phi_{O_{i, j+1}}-\Phi_{0, i, j}\right)-\left(\frac{A_{z} k_{z} k_{r o}}{\mu 0} \frac{x_{i} \bar{p}_{0}}{\Delta z}\right)_{i, j-1 / 2}\left(\Phi_{0 i, j}-\Phi_{0 i, j-1}\right)\right\} / \Delta z_{i, j} \\
& +\left\{\left(\frac{A_{z} k_{z} k_{r g}}{\mu g} \frac{y_{i} \bar{\rho}_{g}}{\Delta x}\right)_{i+1 / 2, j}\left(\Phi_{g_{i+1, j}}-\Phi g_{i, j}\right)-\left(\frac{A_{z} k_{z} k_{r g}}{\mu g} \frac{y_{i} \bar{\rho}_{g}}{\Delta x}\right)_{i-1 / 2, j}\left(\Phi g_{i, j}-()_{g_{i-1, j}}\right)\right\} / \Delta x_{i, j} \\
& +\left\{\left(\frac{A_{z} k_{z} k_{r g}}{\mu g} \frac{y_{i} \bar{\rho}_{g}}{\Delta z}\right)_{i, j+1 / 2}\left(\Phi_{g_{i, j+1}}-\Phi_{g_{i, j}}\right)-\left(\frac{A_{z} k_{z} k_{r g}}{\mu g} \frac{y_{i} \bar{\rho}_{g}}{\Delta z}\right)_{i, j-1 / 2}\left(\Phi g_{i, j}-\Phi g_{i, j-1}\right)\right\} / \Delta z_{i, j}
\end{aligned}
$$

Equation B-15 may be more concisely stated using difference operator notation as

$$
\begin{aligned}
& \frac{\partial}{\partial x}\left(x_{i} \bar{\rho}_{0} \frac{A_{x} k_{x} k_{r o}}{\mu 0} \frac{\partial \Phi_{0}}{\partial x}+y_{i} \bar{\rho}_{g} \frac{A_{x} k_{x} k_{r g}}{\mu g} \frac{\partial \Phi_{g}}{\partial x}\right)+ \\
& \frac{\partial}{\partial z}\left(x_{i} \bar{\rho}_{0} \frac{A_{z} k_{z} k_{r o}}{\mu 0} \frac{\partial \Phi_{0}}{\partial z}+y_{i} \bar{\rho}_{g} \frac{A_{z} k_{z} k_{r g}}{\mu g} \frac{\partial \Phi_{g}}{\partial z}\right) \\
& \cong \Delta\left(\frac{A_{k} k_{r o} \bar{\rho}_{0}}{\mu 0} x_{i} \Delta \Phi_{0}\right)+\Delta\left(\frac{A_{k} k_{r g}-\bar{\rho}_{g}}{\mu g} y_{i} \Delta \Phi_{g}\right)
\end{aligned}
$$

where

$$
\Delta\left(\frac{A_{k} k_{r o} \bar{\rho}_{0}}{\mu_{0}} x_{i} \Delta \Phi_{0}\right)=\Delta x\left(\frac{A_{k} k_{x} k_{r o} \bar{\rho}_{0}}{\mu_{g} \Delta x} x_{i} \Delta x(D \circ) / \Delta x_{i, j}+\Delta z\left(\frac{A_{z} k_{z} k_{r o} \bar{\rho}_{0}}{\mu_{0} \Delta z} x_{i} \Delta z\left(\Phi_{0}\right) / \Delta z_{i, j}\right.\right.
$$

and

$$
\begin{aligned}
& \Delta x\left(\frac{A_{k} k_{x} k_{r o} \bar{P}_{0}}{\mu_{g} \Delta x} x_{i} \Delta x(\Phi)=\left(\frac{A_{k} k_{r o} \bar{P}_{0} x_{i}}{\mu_{0} \Delta x}\right)_{i+1 / 2, j}\left(\Phi_{O_{i+1, j}}-\Phi_{O_{i, j}}\right)\right. \\
& \left(\frac{A_{k} k_{r o} \bar{\rho}_{O} x_{i}}{\mu_{0} \Delta x}\right)_{i-1 / 2, j}\left(\Phi_{O_{i, j}}-\Phi_{O i-1, j}\right)
\end{aligned}
$$

107 
The finite difference approximation to the right side of equation B-1 is written as

$$
\begin{aligned}
& V_{b} \frac{\partial}{\partial t}\left[\phi\left(x_{i} \bar{\rho}_{o} S_{o}+y_{i} \bar{\rho}_{g} S_{g}\right)\right] \cong V_{b}\left[\left\{\left(\phi x_{i} \bar{\rho}_{o} S_{o}\right)^{n+1}-\left(\phi x_{i} \bar{\rho}_{o} S_{0}\right)^{n}\right\}\right. \\
& +\left\{\left(\phi y_{i} \bar{\rho}_{g} S_{g}\right)^{n+1}-\left(\phi y_{i} \bar{\rho}_{g} s_{g}\right)^{n} \text { ij } / \Delta l\right.
\end{aligned}
$$

or in shorthand notation

$$
V_{b} \frac{\partial}{\partial t}\left[\phi\left(x_{i} \bar{\rho}_{o} S_{o}+y_{i} \bar{p}_{o} S_{g}\right)\right] \cong \frac{V_{b}}{\Delta t} \delta\left[\phi\left(x_{i} \bar{p}_{o} S_{o}+y_{i} \bar{p}_{0} S_{g}\right)\right]
$$

where $\delta x=x^{n+1}-x^{n}, x$ is any quantity.

Expressions for water molar balance and energy balance are developed in analogous fashion and are given by:

\section{Water Molar Balance}

$$
\begin{gathered}
\Delta\left(\frac{A k k_{r w} \bar{P}_{w}}{\mu w} \Delta \Phi_{w}\right)+\Delta\left(\frac{A k k_{r g} \overline{\rho g}_{g} y_{s}}{\mu g} \Delta \downarrow g\right) \\
\frac{V_{b}}{\Delta t} \delta\left[\phi\left(\bar{\rho}_{w} S_{w}+y_{s} \bar{\rho}_{g} S_{g}\right)\right]
\end{gathered}
$$

\section{Energy Balance}

$$
\begin{aligned}
& \Delta(\lambda A \Delta T)+\left(\frac{A k k_{r w} \bar{\rho}_{W}}{\mu w} H_{w} \Delta \Phi_{W}\right)+\Delta\left(\frac{A k k_{r o} \bar{\rho}_{0}}{\mu 0} H_{0} \Delta \Phi_{O}\right) \\
& +\Delta\left(\frac{A k k_{r g} \bar{\rho}_{g}}{\mu g} H_{g} \Delta \Phi_{g}\right)+\left(q_{w} H_{w}+q_{0} H_{0}+q_{g} H_{g}\right)+q_{L} \\
& =\frac{V_{b}}{\Delta t} \delta\left[(1-\phi) \rho R U_{R}+\phi\left(S_{w} \bar{\rho}_{W} U_{w}+S_{0} x_{i} \bar{\rho}_{O} U_{O}+S_{g} y_{i} \bar{\rho}_{g} U_{g}\right)\right]
\end{aligned}
$$




\section{Iransmissibility and Transconductivity}

Transmissibility $\left(\tau_{x}\right)$ and transconductivity $\left(\tau_{c}\right)$ are interblock properties and are defined as

$$
\begin{aligned}
& \left(\tau_{x_{0}}\right)_{i-1 / 2, j} \equiv\left(\frac{k_{x} k_{r o} \bar{\rho}_{0}}{\mu 0} \frac{A_{x}}{\Delta x}\right)_{i-1 / 2, j} \\
& \left(\tau_{c_{x}}\right)_{i-1 / 2, j} \equiv \lambda\left(\frac{A_{x}}{\Delta x}\right)_{i-1 / 2, j}
\end{aligned}
$$

The transmissibility term may be thought of as a measure of the ability of a given phase to be transmitted between adjacent grid blocks under the influence of a unit pressure drop. In the present study, transmissibility units are in mole per unit time per psi pressure drop. Since transmissibility is an interblock flow property, its value must realistically reflect the actual average molar flow from one block to the next during a given time step. This average is formulated by partitioning the transmissibility expression into two terms and obtaining a workable average value for each group. The first group is the term $\left(A_{x} k_{x} / \Delta x\right)_{i-1 / 2, j}$ and the second the molar mobility coefficient term, $\left(\frac{k_{10}}{\mu_{0}}\right)_{i-1 / 2, j}$.

The first group is computed as a mean harmonic average between grid block centers.

$$
\left(A_{x} k_{x} / \Delta x\right)_{i-1 / 2, j}=\frac{2 A_{i-1, j} A_{i j} k_{i-1, j} k_{i, j}}{A_{i-1, j} k_{i-1, j} \Delta_{x_{i, j}}+A_{i, j} k_{i, j} \Delta_{x-1, j}}
$$

The second term, the molar mobility coefficient, presents a more difficult problem, since each of these parameters vary with pressure, temperature, saturation and composition of the system. A simple weighting procedure is used to determine the average value. For instance,

$$
\left(\frac{k_{r o} \bar{P}_{0}}{\mu O}\right)_{i-1 / 2, j}=W\left(\frac{k_{r o} \bar{P}_{0}}{\mu 0}\right)_{i-1, j}+(1-W)\left(\frac{k_{r o} \bar{P}_{0}}{\mu()}\right)_{i, j}
$$

Where $W$ is a weighting factor. The value chosen for $W$ will affect the stability and accuracy of the numerical process. In the present study an upstream weighting is used exclusively. That is $W=1.0$ when $\Phi_{j-1}$ is greater than $\Phi_{i}$ and $W=0.0$ when $\Phi_{i-1}$ is less than $\Phi_{j}$.

Combining the two average expressions, a final expression is obtained which defines the transmissibility. Thus, 


$$
\left(\tau_{x_{0}}\right)_{i-1 / 2, j} \equiv\left(\frac{2 A_{i-1, j} A_{i j} k_{i-1, j} k_{i j}}{A_{i-1, j} k_{i-1, j} \Delta x_{i, j}+A_{i, j} k_{i, j} \Delta x_{i-1, j}}\right)\left[W\left(\frac{K_{r o} \bar{\rho}_{0}}{\mu_{0}}\right)_{i-1, j}+(1-W)\left(\frac{K_{r o} \bar{\rho}_{0}}{\mu_{0}}\right)_{i, j}\right]
$$

where $\quad W=1.0$ for $\Phi_{\mid-1, j}>\Phi_{1, j}$

$$
W=0.0 \text { for } \Phi_{i, j}>\Phi_{i-1, j}
$$

Similarly, the transconductivity term can be defined as the ability of heat to be transmitted between adjacent blocks by conduction under the influence of a unit change in temperature. The units of transconductivity are in BTU per unit time per degree Fahrenhelt change in temperature. Like transmissibility term, the transconductivity expression is partitioned into two terms and an average value is obtained for each group. The first group is the term $\left(A_{x} / \Delta x\right)_{i-1 / 2, j}$ and the second the thermal conductivity $(\lambda) i-1 / 2, j$.

The first group is computed as a mean harmonic average between grid block centers.

$$
\left(A_{x} / \Delta x\right)_{i-1 / 2, j}=\frac{2 A_{i-1, j} A_{i, j}}{A_{i-1, j} \Delta x_{i, j}+A_{i, j} \Delta x_{i-1, j}}
$$

The thermal conductivity is averaged using a simple weighting procedure. For instance,

$$
(\lambda)_{i-1 / 2, j}=W(\lambda)_{i-1, j}+(1-W)(\lambda)_{i, j}
$$

Where $W$ is a weighting factor. In the present study, an upstream weighting is used exclusively. That is $W=1.0$ when $T_{i-1}$ is greater than $T_{i}$ and $W-0.0$ when $T_{i-1}$ is less than $T_{i}$.

Combining the two average expressions, a final expression is obtained which defines the transconductivity. Thus,

$$
\left.\left(\tau_{c}\right)_{i-1 / 2, j}=\left(\frac{2 A_{i-1, j} A_{i, j}}{A_{i-1, j} \Delta x_{i, j}+A_{i, j} \Delta x_{i-1, j}}\right)[W \mid \lambda)_{i-1, j}+(1-W)(\lambda)_{i, j}\right]
$$

$$
\text { where } \begin{aligned}
W & =1.0 \text { if } \quad(T)_{i-1, j}>(T)_{i, j} \\
& =0 \text { if } \quad(T)_{i-1, j}<(T)_{i, j}
\end{aligned}
$$

Utilizing these definitions, the partial differential equations describing the steam injection process (equations B-1 through B-5) can be expressed in finite difference form as follows: 


\section{Molar Balance on Hydrocarbon Compounds}

$\Delta\left[\tau_{0} x_{i} \Delta \Phi_{0}+\tau_{g} x_{i} \Delta \Phi_{g}\right]+q_{0} x_{i} \bar{p}_{0}+q_{g} y_{i} \bar{\rho}_{g}=$

$$
\frac{V_{b}}{\Delta t} \delta\left[\phi\left(x_{i} \bar{\rho}_{o} s_{o}+y_{i} \bar{\rho}_{g} s_{g}\right)_{l=1,2,3}\right]
$$

\section{Molar Balance on Water}

$\Delta\left[\tau_{w} \Delta \Phi_{W}+\tau_{g} y_{s} \Delta \Phi_{g}\right]+q_{w} \bar{\rho}_{W}+q_{g} y_{s} \bar{\rho}_{g}=\frac{V_{b}}{\Delta t} \delta\left[\phi\left(\bar{\rho}_{W} S_{W}+y_{s} \bar{\rho}_{g} S_{g}\right)\right]$

\section{Eneray Balance}

$$
\begin{aligned}
& \Delta\left(\tau_{H} \Delta \Phi_{O}\right)+\Delta\left(\tau_{c} \Delta T\right)-q L+q_{H}= \\
& \frac{V_{b}}{\Delta t} \delta\left[\phi\left(\bar{\rho}_{W} S_{W} U_{W}+\bar{\rho}_{O} S_{O} U_{O}+\bar{\rho}_{g} S_{g} U_{g}\right)+(1-\phi) \rho_{r} U_{r}\right]
\end{aligned}
$$

In equation B-33, the capillary pressures have been neglected. In equation B-35, $\tau_{H}$ and $\tau_{c}$ are defined as follows:

$$
\begin{aligned}
& \tau_{H}=\tau_{w} H_{w}+\tau_{0} H_{0}+\tau_{g} H_{g} \\
& \tau_{C}=\frac{\lambda A}{L}
\end{aligned}
$$

The phase potentials $\Phi_{0}, \Phi_{W}$ and $\Phi_{g}$ by their definitions are

$$
\begin{aligned}
& \Phi_{0}=p_{0}-\gamma_{0} D \\
& \Phi_{W}=p_{W}-\gamma_{W} D \\
& \Phi_{g}=p_{g}-\gamma_{g} D
\end{aligned}
$$

In equations B-38 through B-40, $\gamma$ is the specific weight, and $D$ is the depth measured vertically downward. 
Utilizing these definitions, the partial differential equations describing the steam Injection process (equations B-1 through B-5) can be expressed in finite difference form as follows:

\section{Hydrocarbon Components Molar Balance}

$$
\begin{gathered}
\Delta\left[\tau_{0} x_{i}\left(\Delta p_{o}-\gamma_{0} \Delta D\right)+\tau_{g} y_{1}\left(\Delta p_{g}-\gamma_{g} \Delta D\right)\right]+q_{o} x_{i} \bar{\rho}_{o}+q_{g} y_{i} \bar{p}_{g} \\
\left.\frac{v_{b}}{\Delta t} \delta\left[\phi\left(x_{i} \bar{\rho}_{o} s_{o}+y_{i} \bar{\rho}_{g} s_{g}\right)\right]\right]_{i=1,2,3}
\end{gathered}
$$

\section{Water Molar $F$ ance}

$$
\begin{aligned}
& \Delta\left[\tau_{w}\left(\Delta p_{w}-\gamma_{w} \Delta D\right)+\tau_{g} y_{s}\left(\Delta p_{g}-\gamma_{g} \Delta D\right)\right]+q_{w} \bar{\rho}_{w}+q_{g} y_{s} \bar{\rho}_{g} \\
& \frac{v_{b}}{\Delta t} \delta\left[\phi\left(\bar{\rho}_{w} s_{w}+y_{s} \bar{\rho}_{g} s_{g}\right)\right]
\end{aligned}
$$

\section{Energy Balance}

By definition

$$
U_{R}=H_{R}+\frac{P}{J \rho R}
$$

and

$$
H_{R}=\left(C_{p}\right)_{R}^{T}
$$

$\left(C_{p}\right)_{R}=$ rock specific heat

In steam injection process the term $\frac{P}{J_{\rho R}}$ is negligibly small and can be neglected. Hence combining equations $B-45$ and $B-46$ we have

$$
U_{R}=\left(C_{p}\right)_{R}^{\top}
$$

Furthermore, in the energy balance expression, the gradient term $\gamma D$ in the potential is neglected and hence 


$$
\Phi_{0} \cong P_{0}
$$

Substituting B-47 and B-48 in B-35 we have

$$
\begin{aligned}
& \Delta\left(\tau_{H} \Delta P_{0}\right)+\Delta\left(\tau_{c} \Delta T\right)-q_{L}+q_{H} \\
& \quad=\frac{V_{b}}{\Delta t} \delta\left[\phi\left(\bar{\rho}_{W} S_{W} U_{W}+\bar{p}_{O} S_{O} U_{o}+\bar{\rho}_{g} S_{g} U_{g}\right)+(1-\phi)\left(\rho C_{p}\right)_{R}^{T} T\right]
\end{aligned}
$$

here $\mathrm{qH}=$ enthalpy production rate

$$
q_{w} \bar{\rho}_{w} H_{w}+q_{o} \bar{\rho}_{o} H_{o}+q_{g} \bar{\rho}_{g} H_{g}
$$




\section{APPENDIX C - FINITE DIFFERENCE EXPANSION}

In this appendix, the expansion of the finite difference equations developed In appendix $B$ is detalled.

\section{Bight-Hand Side (Accumulation Terms) Expansion}

The accumulation terms in the finlte difference form of molar and energy balance equations are expanded in terms of the time differences $\delta x_{1}, \delta x_{2}, \delta x_{3}, \delta S_{g}, \delta S_{W}, \delta T$, $\delta p$. Here ' $\delta$ ' is the time difference operator.

The expansion of the accumulation terms in the difference equations is critlcal. For a given varlable $x$ the Identity

$$
\delta x \equiv x^{N+1}-x^{N}
$$

where ' $N$ ' denotes the time level must be strlctly preserved otherwise molar and heat balances will not check.

Before carrying out the actual finite difference expansions, it is important to explain how some parameters are treated by the model.

\section{Porosity}

It is defined by:

$$
\phi=\phi \operatorname{int}\left(1+C_{R}\left(p-p_{i n t}\right)\right)
$$

Where $\phi$ int is porosity at initial pressure pint and

$$
\mathrm{C}_{\mathrm{R}}=\text { rock compressibility }
$$

$$
\begin{aligned}
\delta \phi=\phi^{n+1} & -\phi^{n} \\
& =\left[\phi_{\text {int }}\left(1+C_{R}\left(p-p_{\text {int }}\right)\right\}\right]^{n+1} \cdot\left[\phi \text { int }\left\{1+C_{R}\left(p-p_{\text {int }}\right)\right)\right]^{n} \\
& =\phi_{\text {int }}+\phi_{\text {int }} C_{R} p^{n+1}-\phi_{\text {int }} C_{R} p_{\text {int }}-\phi \text { int }-\phi_{\text {int }} C_{R} p^{n}+\phi_{\text {int }} C_{R} p_{\text {int }} . \\
& =\phi_{\text {int }} C_{R}\left(p^{n+1}-p^{n}\right) \\
& =\phi_{\text {int }} C_{R} \delta p \\
\therefore \delta \phi=\phi_{\text {int }} & C_{R} \delta p
\end{aligned}
$$




\section{Q11 Density}

Oil phase molar density is a nonlinear function of pressure, temperature, and composition and is defined by

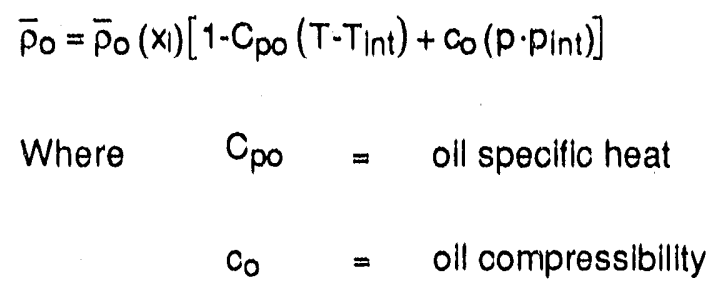

Expanding equation C-4 by Taylor series and neglecting higher order terms, we have

$$
\begin{aligned}
& \bar{\rho}_{0}^{n+1} \cong \bar{\rho}_{0}+\frac{\partial \bar{\rho}_{0}^{-1}}{\partial p}\left(p^{n+1}-p^{\prime}\right)+\frac{\partial \rho_{0}^{-1}}{\partial T}\left(T^{n+1}-T^{\prime}\right)+\frac{\partial \bar{\rho}_{0}^{-1}}{\partial x_{1}}\left(\left.x\right|^{n+1} \cdot x \mid\right) \\
& \text { Where } \begin{aligned}
n+1 & =\text { new time level } \\
1 \quad & \text { iteration step } \\
n \quad & =\text { old time level }
\end{aligned}
\end{aligned}
$$

or

$$
\begin{aligned}
\bar{\rho}_{0}^{n+1}-\bar{\rho}_{0}^{n} \cong & \bar{\rho}_{0}^{-}-\bar{\rho}_{0}^{n}+\left(\frac{\partial \bar{\rho}_{o}}{\partial p}\right)^{\prime}\left(p^{n+1}-p^{\prime}+p^{n}-p^{n}\right)+\left(\frac{\partial \bar{\rho}_{0}}{\partial T}\right)^{\prime}\left(T^{n+1}-T^{\prime}+T^{n}-T^{n}\right) \\
& +\left(\frac{\partial \bar{\rho}_{0}}{\partial x_{i}}\right)^{\prime}\left(x p^{p+1}-x_{1}+x_{1}^{n}-x_{1}^{n}\right)
\end{aligned}
$$

Now by definition

$$
\begin{aligned}
& \bar{\rho}_{0}^{n+1} \cdot \bar{\rho}_{0}^{n}=\delta \bar{\rho}_{0} \\
& p^{n+1} \cdot p^{n}=\delta p \\
& T^{n+1} \cdot T^{n}=\delta T \\
& x_{1}^{n+1} \cdot x_{1}^{n}=\delta x_{1}
\end{aligned}
$$


Hence

$$
\begin{aligned}
\delta \bar{\rho}_{0} \cong \bar{\rho}_{0}^{-1} & -\bar{\rho}_{0}^{n}+\left(\frac{\partial \bar{\rho}_{0}}{\partial p}\right)^{\prime} \delta p+\left(\frac{\partial \bar{\rho}_{0}}{\partial T}\right)^{\prime} \delta T+\left(\frac{\partial \bar{\rho}_{0}}{\partial x_{i}}\right) \delta x_{1} \\
& -\left(\frac{\partial \bar{\rho}_{0}}{\partial p}\right)^{\prime}\left(p^{\prime}-p^{n}\right)-\left(\frac{\partial \bar{\rho}_{0}}{\partial T}\right)^{\prime}\left(r^{\prime}-T^{n}\right)-\left(\frac{\partial \bar{\rho}_{0}}{\partial x_{1}}\right)^{\prime}\left(x_{1}-x_{1}^{n}\right)
\end{aligned}
$$

In equation $\mathrm{C}-11$, we notice that as we reach convergence, l.e., I is $n+1$ (within the allowed tolerance), the last six terms cancel out, and we immediately get:

$$
\delta \bar{\rho}_{0}=\bar{\rho}_{0}^{1}-\bar{\rho}_{0}^{n}
$$

which of course, should hold true.

\section{Gas Density}

Assuming gas-phase molar density to be a nonlinear function of pressure and temperature only, we can obtain $\delta \bar{\rho}_{g}$ similar to oil density. The term $\delta \bar{\rho}_{\mathrm{g}}$ is given by

$$
\delta \bar{\rho}_{g} \cong \bar{\rho}_{g}^{-1}-\bar{\rho}_{g}^{n}+\left(\frac{\partial \bar{\rho}_{g}}{\partial p}\right)^{\prime} \ddot{p}+\left(\frac{\partial \bar{\rho}_{g}}{\partial T}\right)^{\prime} \delta T-\left(\frac{\partial \bar{\rho}_{g}}{\partial p}\right)^{\prime}\left(p^{\prime}-p^{n}\right)-\left(\frac{\partial \bar{\rho}_{g}}{\partial T}\right)^{\prime}\left(T^{\prime}-T^{n}\right)
$$

\section{Water Density}

Water-phase molar density is a nonlinear function of pressure and temperature and is defined as

$$
\bar{\rho}_{W}=\bar{\rho}_{W}(T)\left[1+c_{W}\left(p-p_{s a t}\right)\right]
$$

Similar to the oil density expression, $\delta \bar{\rho}_{\mathrm{w}}$ is given by

$$
\delta \bar{\rho}_{W} \cong \bar{\rho}_{W}^{-1}-\bar{\rho}_{W}^{n}+\left(\frac{\partial \bar{\rho}_{W}}{\partial p}\right)^{\prime} \delta p+\left(\frac{\partial \bar{\rho}_{W}}{\partial T}\right)^{\prime} \delta T-\left(\frac{\partial \bar{\rho}_{W}}{\partial p}\right)^{\prime}\left(p^{\prime}-p^{n}\right)-\left(\frac{\partial \bar{\rho}_{W}}{\partial T}\right)^{\prime}\left(T^{\prime}-T^{n}\right)
$$

\section{Equilibrium Constant}

The vapor-liquid equilibrium constant of a component $i$ is a nonlinear function of pressure and temperature, l.e.

$$
K_{i}=K_{i}(T, p)
$$


By Taylor series expansion

$$
\begin{aligned}
& \left(K_{i}\right)^{n+1} \cong K_{i}^{\prime}+\left(\frac{\partial K_{i}}{\partial p}\right)^{\prime}\left(p^{n+1}-p^{\prime}\right)+\left(\frac{\partial K_{i}}{\partial T}\right)^{\prime}\left(T^{n+1}-T^{\prime}\right) \\
& K_{i}^{n+1}-K_{i}^{n}=K_{i}^{\prime}-K_{i}^{n}+\left(\frac{\partial K_{i}}{\partial p}\right)^{\prime}\left(p^{n+1}-p^{\prime}+p^{n}-p^{n}\right)+\left(\frac{\partial K_{i}}{\partial T}\right)^{\prime}\left(T^{n+1}-T^{\prime}+T^{n}-T^{n}\right) \\
& \delta K_{i}=K_{i}^{\prime}-K_{i}^{n}+\left(\frac{\partial K_{i}}{\partial p}\right)^{\prime} \delta p+\left(\frac{\partial K_{i}}{\partial T}\right)^{\prime} \delta T-\left(\frac{\partial K_{i}}{\partial P}\right)^{\prime}\left(p^{\prime}-p^{n}\right)-\left(\frac{\partial K_{i}}{\partial T}\right)^{\prime}\left(T^{\prime}-T^{n}\right)
\end{aligned}
$$

\section{Vapor-Phase Mole Fraction}

The mole fraction of the hydrocarbon component $i$ in the vapor-phase is given by

$$
y_{i}=K_{i} x_{i}
$$

Where $\quad x_{i}=$ mole fraction of the component $i$ in the oleic-phase

$$
K_{i}=\text { vapor.liquid equilibrium constant for component } i \text { at a given } p \text { and } T
$$

$$
\begin{aligned}
y_{i}^{n+1}-y_{i}^{n} & =\left(K_{i} x_{i}\right)^{n+1}-\left(K_{i} x_{i}\right)^{n} \\
& =K_{i}^{n+1} x_{i}^{n+1}-K_{i}^{n} x_{i}^{n}+K_{i}^{n+1} x_{i}^{n}-K_{i}^{n+1} x_{i}^{n} \\
& =K_{i}^{n+1}\left(x_{i}^{n+1}-x_{i}^{n}\right)+x_{i}^{n}\left(K_{i}^{n+i}-K_{i}^{n}\right) \\
& =K_{i}^{n+1} \delta x_{i}+x_{i}^{n} \delta K_{i}
\end{aligned}
$$

Hence

$$
y_{i}^{n+1}-y_{i}^{r_{i}}=\delta y_{i}:=K_{i}^{n+1} \delta x_{i}+x_{i}^{n} \delta K_{i}
$$

\section{Liquid-Phase Saturation Constraint}

$$
\begin{aligned}
& S_{0}+S_{w}+S_{g}=1 \\
& \text { or }\left(S_{0}+S_{w}+S_{g}\right)^{n+1}-\left(S_{0}+S_{w}+S_{g}\right)^{n}=0 \\
& \text { i.e. }\left(S_{0}^{n+1}-S_{0}^{n}\right)+\left(S_{w}^{n+1}-S_{w}^{n}\right)+\left(S_{g}^{n+1}-S_{g}^{n}\right)=0 \\
& \text { i.e. } \delta S_{0}+\delta S_{w}+\delta S_{g}=0 \\
& \text { Hence } \quad \delta S_{0}=-\delta S_{w}-\delta S_{g}
\end{aligned}
$$




\section{Capillary Pressure}

Capillary pressure of a phase is a function of the phase saturation $S_{i}, i=g, w$

i.e. $\quad p c_{o_{g}}=p c_{O_{g}}\left(S_{g}\right)$

and $\quad p c_{o_{W}}=p c_{o_{W}}\left(S_{W}\right)$

By Taylor series expansion

$$
\begin{aligned}
& \left(p c_{o_{g}}\right)^{n+1} \cong\left(p c_{o_{g}}\right)^{n}+\left(\frac{\partial p c_{o_{g}}}{\partial s_{g}}\right)^{n}\left(s_{g}^{n+1}-s_{g}^{n}\right) \\
& \text { and }\left(p c_{o_{W}}\right)^{n+1} \cong\left(p c_{o_{W}}\right)^{n}+\left(\frac{\partial p c_{o_{W}}}{\partial s_{W}}\right)^{n}\left(s_{W}^{n+1}-s_{W}^{n}\right)
\end{aligned}
$$

or

$$
\left(p c_{o_{g}}\right)^{n+1}-\left(p c_{\sigma_{g}}\right)^{n}=\delta p c_{\sigma_{g}} \cong\left(\frac{\partial p c_{o_{g}}}{\partial S_{g}}\right)^{n} \delta S_{g}
$$

and

$$
\left(p c_{o_{W}}\right)^{n+1} \cdot\left(p c_{o_{W}}\right)^{n}=\delta p c_{o_{W}} \cong\left(\frac{\partial p c_{o_{W}}}{\partial S_{W}}\right)^{n} \delta S_{W}
$$

\section{Expansion of Accumulation Terms in Hydrocarbon Molar Balance Equation}

The accumulation terms of the molar balance for component i are expanded as follows:

$$
\begin{aligned}
& \delta\left(\phi S_{\circ} \bar{\rho}_{o} x_{i}+\phi S_{g} \bar{\rho}_{g} y_{i}\right)=\delta\left(\phi S_{o} \bar{\rho}_{o} x_{i}\right)+\delta\left(\phi S_{g} \bar{\rho}_{g} y_{i}\right) \\
& \delta\left(\phi S_{\circ} \bar{\rho}_{\circ} x_{i}\right)=\phi^{n+1} \delta\left(S_{0} \bar{\rho}_{\circ} x_{i}\right)+\left(S_{\circ} \bar{\rho}_{\circ} x_{i}\right)^{n} \delta \phi \\
& \delta\left(S_{0} \bar{\rho}_{0} x_{i}\right)=x_{1}^{n+1} \delta\left(S_{0} \bar{\rho}_{0}\right)+\left(S_{0} \bar{\rho}_{0}\right)^{n} \delta x_{i} \\
& \delta\left(S_{0} \bar{\rho}_{0}\right)=S_{0}^{n+1} \delta \bar{\rho}_{0}+\bar{\rho}_{0}^{n} \delta S_{0}
\end{aligned}
$$

Substituting equations $\mathrm{C}-34$ and $\mathrm{C}-35$ in equation $\mathrm{C}-33$ gives

$$
\delta\left(\phi S_{0} \bar{\rho}_{0} x_{i}\right)=\phi^{n+1}\left[x_{i}^{n+1}\left\{S_{0}^{n+1} \delta \bar{\rho}_{0}+\bar{\rho}_{0}^{n} \delta S_{0}\right\}+\left(S_{0} \bar{\rho}_{0}\right)^{n} \delta x_{i}\right]+\left(S_{0} \bar{\rho}_{0} x_{i}\right)^{n} \delta \phi
$$

Substituting values of $\delta \phi, \delta \bar{\rho}_{0}$ and $\delta S_{0}$ from equations $C-3, C_{-}-11$, and $C-26$ into equation $C-36$, we have

$$
\delta\left(\phi S_{0} \bar{\rho}_{0} x_{i}\right)=\left(\phi S_{0} x_{i}\right)^{n+1}\left\{\mid \bar{p}_{0}^{-}-\bar{\rho}_{0}^{n}\right\}+\left(\frac{\partial \bar{\rho}_{0}}{\partial p}\right)_{T, x}^{l} \delta p+\left(\frac{\partial \bar{p}_{0}}{\partial T}\right)_{p, x}^{l} \delta T
$$




$$
\begin{aligned}
& +\left(\frac{\partial \bar{\rho}_{0}}{\partial x_{i}}\right)_{j, p, T}^{1} \delta x_{i}-\left(\frac{\partial \bar{\rho}_{0}}{\partial p}\right)_{T, x}^{l}\left(p^{\prime}-p^{n}\right)-\left(\frac{\partial \bar{\rho}_{0}}{\partial T}\right)_{p, x}^{1}\left(T^{\prime}-T^{n}\right) \\
& \left.+\left(\frac{\partial \bar{\rho}_{0}}{\partial x_{i}}\right)_{j, p, T}^{1}\left(x_{i}-x_{i}^{n}\right)\right] \\
& +\left(\phi x_{i}\right)^{n+1} \bar{\rho}_{o}^{n}\left(-\delta S_{g}-\delta S_{W}\right)+\phi^{n+1}\left(S_{o} \bar{\rho}_{o}\right)^{n} \delta x_{i}+\left(S_{O} \bar{\rho}_{O} x_{i}\right)^{n}\left(\phi_{\text {int }} C_{R} \delta p\right)
\end{aligned}
$$

On rearrangement, equation $\mathrm{C}-37$ becomes

$$
\begin{aligned}
& \delta\left(\phi S_{O} \bar{\rho}_{O} x_{i}\right)=\left[\left(\phi S_{O} x_{i}\right)^{n+1}\left(\frac{\partial \bar{\rho}_{0}}{\partial x_{i}}\right)_{j, p, T}^{1}+\phi^{n+1}\left(S_{0} \bar{\rho}_{0}\right)^{n}\right] \delta x_{i} \\
& \cdot\left(\phi x_{i}\right)^{n+1} \bar{\rho}_{o}^{n} \delta S_{g}-\left(\phi x_{i}\right)^{n+1} \bar{\rho}_{0}^{n} \delta S_{w} \\
& +\left(\phi S_{0} x_{i}\right)^{n+1}\left(\frac{\partial \bar{\rho}_{0}}{\partial T}\right)_{p, x}^{l} \delta T+\left[\left(\phi S_{0} x_{i}\right)^{n+1}\left(\frac{\partial \bar{\rho}_{0}}{\partial p}\right)_{T, x}^{l}+\left(S_{0} \bar{\rho}_{0} x_{i}\right)^{n} \phi i n t C_{R}\right] \delta p \\
& +\left(\phi S_{0} x_{i}\right)^{n+1}\left(\vec{\rho}_{0}^{-}-\bar{\rho}_{0}^{n}\right)-\left(\frac{\partial \bar{\rho}_{0}}{\partial p}\right)_{T, x}^{l}\left(p^{l}-p^{n}\right) \cdot\left(\frac{\partial \bar{\rho}_{0}}{\partial T}\right)_{p, x}^{\prime}\left(T^{\prime}-T^{n}\right) \\
& -\left(\frac{\partial \bar{\rho}_{o}}{\partial x_{i}}\right)_{j, p, T}^{1}\left(x_{i}-x_{i}^{n}\right)
\end{aligned}
$$

Expansion of $\delta\left(\phi S_{g} \bar{\rho}_{g} y_{i}\right)$ gives

$$
\begin{aligned}
& \delta\left(\phi S_{g} \bar{\rho}_{g} y_{i}\right)=\phi^{n+1} \delta\left(S_{g} \bar{\rho}_{g} y_{i}\right)+\left(S_{g} \bar{\rho}_{g} y_{i}\right)^{n} \delta \phi \\
& \delta\left(S_{g} \bar{\rho}_{g} y_{i}\right)=y_{i}^{n+1} \delta\left(S_{g} \bar{\rho}_{g}\right)+\left(S_{g} \bar{\rho}_{g}\right)^{n} \delta y_{i} \\
& \text { and } \delta\left(S_{g} \bar{\rho}_{g}\right)=S_{g}^{n+1} \delta \bar{\rho}_{g}+\bar{\rho}_{g}^{n} \delta S_{g}
\end{aligned}
$$

Hence

$$
\delta\left(\phi S_{g} \bar{\rho}_{g} y_{i}\right)=\phi^{n+1}\left[y_{i}^{n+1}\left\{S_{g}^{n+1} \delta \bar{\rho}_{g}+\bar{\rho}_{g}^{n} \delta S_{g}\right\}+\left(S_{g} \bar{\rho}_{g}\right) \delta y_{i}\right]+\left(S_{g} \bar{\rho}_{g} y_{i}\right)^{n} \delta \phi
$$

Substituting equations $\mathrm{C}-12, \mathrm{C}-18, \mathrm{C}-19$, and $\mathrm{C}-22$ in equation $\mathrm{C}-42$ gives

$$
\begin{aligned}
\delta\left(\phi S_{g} \bar{\rho}_{g} y_{i}\right) & =\phi^{n+1}\left[K _ { i } ^ { n + 1 } x _ { i } ^ { n + 1 } \left\{S _ { g } ^ { n + 1 } \left\{\left(\bar{\rho}_{g}^{-}-\bar{\rho}_{g}^{n}\right)+\left(\frac{\partial \bar{\rho}_{g}}{\partial p}\right)_{T}^{l} \delta p+\left(\frac{\partial \bar{\rho}_{g}}{\partial T}\right)_{p}^{l} \delta T\right.\right.\right. \\
& \left.\left.-\left(\frac{\partial \bar{\rho}_{g}}{\partial p}\right)_{T}^{l}\left(\bar{p}^{-1}-\bar{p}^{n}\right) \cdot\left(\frac{\partial \bar{\rho}_{g}}{\partial T}\right)_{p}^{l}\left(T-T^{n}\right)\right\}+\bar{\rho}_{g}^{n} \delta S_{g}\right\}
\end{aligned}
$$




$$
\begin{aligned}
& +\left(S_{g} \bar{\rho}_{g}\right)^{n}\left\{K_{i}^{n+1} \delta x_{i}+x_{i}^{n}\left\{\left(K_{i} !-K_{i}^{n}\right)+\left(\frac{\partial K_{i}}{\partial p}\right)_{T}^{l} \delta p+\left(\frac{\partial K_{i}}{\partial T}\right)_{p}^{1} \delta T\right.\right. \\
& \left.\left.\left.-\left(\frac{\partial K_{i}}{\partial p}\right)_{T}^{\prime}\left(p^{\prime}-p^{n}\right)-\left(\frac{\partial K_{i}}{\partial T}\right)_{p}^{\prime}\left(T^{\prime}-T^{n}\right)\right\}\right\}\right] \\
& +\left(S_{g} \bar{\rho}_{g} y_{i}\right)^{n} \phi_{i n t} C_{R} \delta p
\end{aligned}
$$

Rearranging equation $\mathrm{C}-43$ gives

$$
\begin{aligned}
\delta\left(\phi S_{g} \bar{\rho}_{g} y_{i}\right) & =\left(\phi K_{i}\right)^{n+1}\left(S_{g} \bar{\rho}_{g}\right)^{n} \delta x_{i}+\left(\phi y_{i}\right)^{n+1} \bar{\rho}_{g}^{n} \delta S_{g} \\
& +\left[\left(\phi S_{g} y_{i}\right)^{n+1}\left(\frac{\partial \bar{\rho}_{g}}{\partial T}\right)_{p}^{1}+\phi^{n+1}\left(S_{g} \bar{\rho}_{g} x_{i}\right)^{n}\left(\frac{\partial K_{i}}{\partial T}\right)_{p}\right]^{\prime} \delta T \\
+ & {\left[\left(\phi S_{g} y_{i}\right)^{n+1}\left(\frac{\partial \bar{\rho}_{g}}{\partial p}\right)_{T}^{l}+\phi^{n+1}\left(S_{g} \bar{\rho}_{g} x_{i}\right)^{n}\left(\frac{\partial K_{i}}{\partial p}\right)_{T}^{l}+\left(S_{g} \bar{\rho}_{g} y_{i}\right)^{n} \phi_{i n t} C_{R}\right] \delta p } \\
+ & \left(\phi S_{g} y_{i}\right)^{n+1}\left(\bar{\rho}_{g} \cdot \bar{\rho}_{g}^{n}\right)+\phi^{n+1}\left(S_{g} \bar{\rho}_{g} x_{i}\right)^{n}\left(K_{i} \cdot K_{i}^{n}\right) \\
& -\left[\left(\phi S_{g} y_{i}\right)^{n+1}\left(\frac{\partial \bar{\rho}_{g}}{\partial p}\right)_{T}^{1}+\phi^{n+1}\left(S_{g} \bar{\rho}_{g} x_{i}\right)^{n}\left(\frac{\partial K_{i}}{\partial p}\right)_{T}^{\prime}\right]\left(p^{\prime}-p^{n}\right) \\
& -\left[\left(\phi S_{g} y_{i}\right)^{n+1}\left(\frac{\partial \bar{\rho}_{g}}{\partial T}\right)_{p}^{1}+\phi^{n+1}\left(S_{g} \bar{\rho}_{g} x_{i}\right)^{n}\left(\frac{\partial K_{i}}{\partial T}\right)_{p}^{\prime}\right]\left(T^{\prime}-T^{n}\right)
\end{aligned}
$$

Combining equations C.38 and C-44 and regrouping similar terms together, results are

$$
\begin{aligned}
& \delta\left(\phi S_{O} \bar{\rho}_{o} x_{i}+\phi S_{g} \bar{\rho}_{g} y_{i}\right)=\left[\left(\phi S_{O} x_{i}\right)^{n+1}\left(\frac{\partial \bar{\rho}_{o}}{\partial x_{i}}\right)_{j, p_{,}, T}^{l}+\phi^{n+1}\left(S_{O} \bar{\rho}_{o}\right)^{n}+\left(\phi K_{i}\right)^{n+1}\left(S_{g} \bar{\rho}_{g}\right)^{n}\right] \delta x_{i} \\
& +\left[\left(\phi y_{i}\right)^{n+1} \bar{\rho}_{g}^{n}-\left(\phi x_{i}\right)^{n+1} \bar{\rho}_{0}^{n}\right] \delta S_{g}-\left(\phi x_{i}\right)^{n+1} \bar{\rho}_{0}^{n} \delta S_{w} \\
& +\left[\left(\phi S_{o} x_{i}\right)^{n+1}\left(\frac{\partial \bar{\rho}_{o}}{\partial T}\right)_{p, x}^{l}+\left(\phi S_{g} y_{i}\right)^{n+1}\left(\frac{\partial \vec{\rho}_{g}}{\partial T}\right)_{p}^{l}+\phi^{n+1}\left(S_{g} \vec{\rho}_{g} x_{i}\right)^{n}\left(\frac{\partial K_{i}}{\partial T}\right)_{p}^{l}\right] \delta T \\
& +\left[\left(\phi S_{0} x_{i}\right)^{n+1}\left(\frac{\partial \vec{\rho}_{o}}{\partial p}\right)_{T, x}^{l}+\left(\phi S_{g} y_{i}\right)^{n+1}\left(\frac{\partial \bar{\rho}_{g}}{\partial p}\right)_{T}^{l}+\phi^{n+1}\left(S_{g} \bar{\rho}_{g} x_{i}\right)^{n}\left(\frac{\partial K_{i}}{\partial p}\right)_{T}^{l}\right. \\
& \left.+\left\{\left(S_{o} \bar{\rho}_{o} x_{i}\right)^{n}+\left(S_{g} \bar{\rho}_{g} y_{i}\right)^{n}\right\} \phi_{i n t} C_{R}\right] \delta p \\
& +\left(\phi S_{0} x_{i}\right)^{n+1}\left(\vec{\rho}_{0}^{\prime}-\bar{\rho}_{0}^{n}\right)+\left(\phi S_{g} y_{i}\right)^{n+1}\left(\bar{\rho}_{g}^{\prime}-\bar{\rho}_{g}^{n}\right)+\phi^{n+1}\left(S_{g} \bar{\rho}_{g} x_{i}\right)^{n}\left(K_{i}^{\prime}-K_{i}^{n}\right)
\end{aligned}
$$




$$
\begin{aligned}
& -\left[\left(\phi S_{o} x_{i}\right)^{n+1}\left(\frac{\partial \bar{\rho}_{o}}{\partial T}\right)_{p, x}^{l}+\left(\phi S_{g} y_{i}\right)^{n+1}\left(\frac{\partial \bar{\rho}_{g}}{\partial T}\right)_{p}^{l}+\phi^{n+1}\left(S_{g} \bar{\rho}_{g} x_{i}\right)^{n}\left(\frac{\partial K_{i}}{\partial T}\right)_{p}^{l}\right]\left(T^{\prime}-T^{n}\right) \\
& -\left[\left(\phi S_{o} x_{i}\right)^{n+1}\left(\frac{\partial \bar{\rho}_{o}}{\partial p}\right)_{T, x}^{l}+\left(\phi S_{g} y_{i}\right)^{n+1}\left(\frac{\partial \bar{\rho}_{g}}{\partial p}\right)_{T}^{1}+\phi^{n+1}\left(S_{g} \bar{\rho}_{g} x_{i}\right)^{n}\left(\frac{\partial K_{i}}{\partial p}\right)_{T}^{l}\right]\left(p^{\prime}-p^{n}\right) \\
& -\left(\phi S_{o} x_{i}\right)^{n+1}\left(\frac{\partial \bar{\rho}_{o}}{\partial x_{i}}\right)_{j, p, T}^{l}\left(x_{i}-x_{p}\right)
\end{aligned}
$$

Equation C-45 is then the expansion of the right-hand side of the ith hydrocarbon molar balance equation.

\section{Expansion of Accumulation Terms in Water Molar Balance Equation}

The accumulation terms in the water molar balance equations are expanded as follows:

$\delta\left(\phi S_{w} \bar{\rho}_{W}+\phi S_{g} \bar{\rho}_{g} y_{s}\right)=\delta\left(\phi S_{w} \bar{\rho}_{W}\right)+\delta\left(\phi S_{g} \bar{\rho}_{g} y_{s}\right)$

$\delta\left(\phi S_{W} \bar{\rho}_{W}\right)=\phi^{n+1} \delta\left(S_{w} \bar{\rho}_{W}\right)+\left(S_{w} \bar{\rho}_{W}\right)^{n} \delta \phi$

and $\delta\left(S_{w} \bar{\rho}_{w}\right)=S_{w}^{n+1} \delta \bar{\rho}_{w}+\bar{\rho}_{w}^{n} \delta S_{W}$

Substituting equation $\mathrm{C}-48$ in equation $\mathrm{C}-47$ gives

$$
\delta\left(\phi S_{W} \bar{\rho}_{W}\right)=\phi^{n+1}\left[S_{W}^{n+1} \delta \bar{p}_{W}+\bar{\rho}_{W}^{n} \delta S_{W}\right]+\left(S_{W} \bar{p}_{W}\right)^{n} \delta \phi
$$

Then using equations $\mathrm{C}-3$ and $\mathrm{C}-14$ in equation $\mathrm{C}-49$ gives

$$
\begin{aligned}
\delta\left(\phi S_{W} \bar{\rho}_{W}\right) & =\left(\phi S_{W}\right)^{n+1}\left(\left(\bar{\rho}_{W}^{\prime}-\bar{\rho}_{W}^{n}\right)+\left(\frac{\partial \bar{\rho}_{W}}{\partial p}\right)_{T}^{l} \delta p+\left(\frac{\partial \bar{\rho}_{W}}{\partial T}\right)_{p}^{l} \delta T\right. \\
& \left.-\left(\frac{\partial \bar{\rho}_{W}}{\partial p}\right)_{T}^{l}\left(p^{\prime}-p^{n}\right)-\left(\frac{\partial \bar{\rho}_{W}}{\partial T}\right)_{p}^{l}\left(T^{\prime}-T^{n}\right)\right]+\phi^{n+1} \bar{\rho}_{W}^{n} \delta S_{W} \\
+ & \left(S_{W} \bar{\rho}_{W}\right)^{n} \phi_{\text {int }} C_{R} \delta p
\end{aligned}
$$

Rearranging equation $\mathrm{C}-50$ gives

$$
\begin{gathered}
\delta\left(\phi S_{W} \bar{\rho}_{W}\right)=\phi^{n+1} \bar{\rho}_{W}^{n} \delta S_{W}+\left(\phi S_{W}\right)^{n+1}\left(\frac{\partial \bar{\rho}_{W}}{\partial T}\right)_{p}^{l} \delta T+\left[\left(\phi S_{W}\right)^{n+1}\left(\frac{\partial \bar{\rho}_{W}}{\partial p}\right)_{T}^{l}\right. \\
\left.+\left(S_{W} \bar{\rho}_{W}\right)^{n} \phi_{\text {int }} C_{R}\right] \delta p+\left(\phi S_{W}\right)^{n+1}\left(\bar{\rho}_{W}^{-1}-\bar{\rho}_{W}^{n}\right)
\end{gathered}
$$




$$
-\left(\phi S_{W}\right)^{n+1}\left(\frac{\partial \bar{\rho}_{W}}{\partial p}\right)_{T}^{l}\left(p^{l}-p^{n}\right)-\left(\frac{\partial \bar{\rho}_{W}}{\partial T}\right)_{p}^{l}\left(T^{\prime}-T^{n}\right)\left(\phi S_{W}\right)^{n+1}
$$

The term $\delta\left(\phi S_{g} \bar{\rho}_{g} y_{s}\right)$ in the water molar balance equation is expanded as:

$$
\begin{aligned}
& \delta\left(\phi S_{g} \bar{\rho}_{g} y_{s}\right)=\phi^{n+1} \delta\left(S_{g} \bar{\rho}_{g} y_{s}\right)+\left(S_{g} \bar{\rho}_{g} y_{s}\right)^{n} \delta \phi \\
& \delta\left(S_{g} \cdot \bar{\rho}_{g} y_{s}\right)=y_{s}^{n+1} \delta\left(S_{g} \bar{\rho}_{g}\right)+\left(S_{g} \bar{\rho}_{g}\right)^{n} \delta y_{s} \\
& \text { and } \delta\left(S_{g} \bar{\rho}_{g}\right)=S_{g}^{n+1} \delta \bar{\rho}_{g}+\bar{\rho}_{g}^{n} \delta S_{g}
\end{aligned}
$$

Then using equations $\mathrm{C}-53$ and $\mathrm{C}-54$ in equation $\mathrm{C}-52$ gives

$$
\begin{gathered}
\delta\left(\phi S_{g} \bar{\rho}_{g} y_{s}\right)=\phi^{n+1}\left[y_{s}^{n+1}\left\{S_{g}^{n+1} \delta \bar{\rho}_{g}+\bar{\rho}_{g}^{n} \delta S_{g}\right\}+\left(S_{g} \bar{\rho}_{g}\right)^{n} \delta y_{s}\right]+ \\
\left(S_{g} \bar{\rho}_{g} y_{s}\right)^{n} \delta \phi
\end{gathered}
$$

Since water is considered a single component system, the mole fraction of steam in the vapor phase, $y_{s}$, is equal to $K 4$, the equilibrium $K$ value for steam. Then,

$$
\delta y_{s}=\delta K_{4}
$$

However, from equation $\mathrm{C}-18$, we have

$$
\delta K_{4}=\left(K_{4}^{\prime}-K_{4}^{n}\right)+\left(\frac{\partial K_{4}}{\partial p}\right)_{T}^{l} \delta p+\left(\frac{\partial K_{4}}{\partial T}\right)_{p}^{l} \delta T-\left(\frac{\partial K_{4}}{\partial p}\right)_{T}^{l}\left(p^{\prime}-p^{n}\right)-\left(\frac{\partial K_{4}}{\partial T}\right)_{p}^{l}\left(T^{-}-T^{n}\right)
$$

Substituting equations $\mathrm{C}-3, \mathrm{C}-12$, and $\mathrm{C}-57$ in equation $\mathrm{C}-55$ gives

$$
\begin{aligned}
\delta\left(\phi S_{g} \bar{\rho}_{g} y_{s}\right)= & \phi^{n+1}\left\{y _ { s } ^ { n + 1 } \left\{S _ { g } ^ { n + 1 } \left(\left(\bar{\rho}_{g}^{-}-\bar{\rho}_{g}^{n}\right)+\left(\frac{\partial \bar{\rho}_{g}}{\partial p}\right)_{T}^{l} \delta p+\left(\frac{\partial \bar{\rho}_{g}}{\partial T}\right)^{\prime} \delta T\right.\right.\right. \\
& \left.\left.-\left(\frac{\partial \bar{\rho}_{g}}{\partial p}\right)_{T}^{l}\left(p^{\prime}-p^{n}\right)-\left(\frac{\partial \bar{\rho}_{g}}{\partial T}\right)_{p}^{l}\left(T^{\prime}-T^{n}\right)\right\}+\bar{p}_{g}^{n} \delta S_{g}\right\} \\
& +\left(S_{g} \bar{\rho}_{g}\right)^{n}\left\{\left(K_{4}^{\prime}-K_{4}^{n}\right)+\left(\frac{\partial K_{4}}{\partial p}\right)_{T}^{l} \delta p+\left(\frac{\partial K_{4}}{\partial T}\right)_{p}^{l} \delta T-\left(\frac{\partial K_{4}}{\partial p}\right)_{T}^{l}\left(p^{\prime}-p^{n}\right)\right. \\
& \left.\left.-\left(\frac{\partial K_{4}}{\partial T}\right)_{p}^{l}\left(T^{\prime}-T^{n}\right)\right\}\right]+\left(S_{g} \bar{\rho}_{g} y_{s}\right)^{n} \phi_{\text {int }} C_{R} \delta p
\end{aligned}
$$


Grouping like terms together yields

$$
\begin{aligned}
& \delta\left(\phi S_{g} \bar{\rho}_{g} y_{s}\right)=\left(\phi y_{s}\right)^{n+1} \bar{\rho}_{g}^{n} \delta S_{g}+\left[\left(\phi S_{g} y_{s}\right)^{n+1}\left(\frac{\partial \bar{\rho}_{g}}{\partial T}\right)_{p}^{l}+\phi^{n+1}\left(S_{g} \bar{\rho}_{g}\right)^{n}\left(\frac{\partial K_{4}}{\partial T}\right)_{p}^{l}\right] \delta T \\
& +\left[\left(\phi S_{g} y_{s}\right)^{n+1}\left(\frac{\partial \bar{\rho}_{g}}{\partial p}\right)_{T}^{l}+\phi^{n+1}\left(S_{g} \bar{\rho}_{g}\right)^{n}\left(\frac{\partial K_{4}}{\partial p}\right)_{T}^{l}+\left(S_{g} \bar{\rho}_{g} y_{s}\right)^{n} \phi_{i n t} C_{R}\right] \delta p \\
& +\left(\phi S_{g} y_{s}\right)^{n+1}\left(\bar{\rho}_{g}^{-}-\bar{\rho}_{g}^{n}\right)+\phi^{n+1}\left(S_{g} \bar{\rho}_{g}\right)^{n}\left(k_{4}^{l}-k_{4}^{n}\right) \\
& -\left[\left(\phi S_{g} y_{s}\right)^{n+1}\left(\frac{\partial \bar{\rho}_{g}}{\partial T}\right)_{p}^{l}+\phi^{n+1}\left(S_{g} \bar{\rho}_{g}\right)^{n}\left(\frac{\partial K_{4}}{\partial T}\right)_{p}^{l}\right]\left(T^{\prime}-T^{n}\right) \\
& -\left[\left(\phi S_{g} y_{s}\right)^{n+1}\left(\frac{\partial \bar{\rho}_{g}}{\partial p}\right)_{T}^{l}+\phi^{n+1}\left(S_{g} \bar{\rho}_{g}\right)^{n}\left(\frac{\partial K_{4}}{\partial p}\right)_{T}^{l}\right]\left(p^{\prime}-p^{n}\right)
\end{aligned}
$$

By combining equations C-51 and C-59, the complete accumulation terms for water molar balance equation is obtained. Thus,

$$
\begin{aligned}
& \delta\left[\phi\left(S_{w} \bar{\rho}_{W}+S_{g} \bar{\rho}_{g} y_{s}\right)\right]=\left(\phi y_{s}\right)^{n+1} \bar{\rho}_{g}^{n} \delta S_{g}+\phi^{n+1} \bar{\rho}_{W}^{n} \delta S_{W} \\
& +\left[\left(\phi S_{W}\right)^{n+1}\left(\frac{\partial \bar{\rho}_{W}}{\partial T}\right)_{p}^{l}+\left(\phi S_{g} y_{s}\right)^{n+1}\left(\frac{\partial \bar{\rho}_{g}}{\partial T}\right)_{p}^{l}+\phi^{n+1}\left(S_{g} \bar{\rho}_{g}\right)^{n}\left(\frac{\partial K_{4}}{\partial T}\right)_{p}^{l}\right] \delta T \\
& +\left[\left(\phi S_{W}\right)^{n+1}\left(\frac{\partial \bar{\rho}_{W}}{\partial p}\right)_{T}^{l}+\left(\phi S_{g} y_{s}\right)^{n+1}\left(\frac{\partial \bar{\rho}_{g}}{\partial p}\right)_{T}^{l}+\phi^{n+1}\left(S_{g} \bar{\rho}_{g}\right)^{n}\left(\frac{\partial K_{4}}{\partial p}\right)_{T}^{l}\right. \\
& \left.+\left\{\left(S_{w} \bar{\rho}_{w}\right)^{n}+\left(S_{g} \bar{\rho}_{g} y_{s}\right)^{n}\right\} \phi_{\text {int }} C_{R}\right] \delta p \\
& +\left(\phi S_{W}\right)^{n+1}\left(\bar{\rho}_{W}-\bar{\rho}_{W}^{n}\right)+\left(\phi S_{g} y_{s}\right)^{n+1}\left(\bar{\rho}_{g}^{-}-\bar{\rho}_{g}^{n}\right)+\phi^{n+1}\left(S_{g} \bar{\rho}_{g}\right)^{n}\left(K_{4}^{1}-K_{4}^{n}\right) \\
& -\left[\left(\phi S_{w}\right)^{n+1}\left(\frac{\partial \bar{\rho}_{w}}{\partial T}\right)_{p}^{l}+\left(\phi S_{g} \gamma_{S}\right)^{n+1}\left(\frac{\partial \bar{\rho}_{g}}{\partial T}\right)_{p}^{l}+\phi^{n+1}\left(S_{g} \bar{\rho}_{g}\right)^{n}\left(\frac{\partial K_{4}}{\partial T}\right)_{p}^{l}\right]\left(T^{\prime}-T^{n}\right) \\
& -\left[\left(\phi S_{W}\right)^{n+1}\left(\frac{\partial \bar{\rho}_{W}}{\partial p}\right)_{T}^{l}+\left(\phi S_{g} y_{S}\right)^{n+1}\left(\frac{\partial \bar{\rho}_{g}}{\partial p}\right)_{T}^{l}+\phi^{n+1}\left(S_{g} \bar{\rho}_{g}\right)^{n}\left(\frac{\partial K_{4}}{\partial p}\right)_{T}^{l}\right]\left(p^{l}-p^{n}\right)
\end{aligned}
$$

\section{Expansioin of Accumulation Terms in Eneray Balance Equation}

The accumulation terms in ihe energy balance equation can be expanded as follows:

$$
\delta\left[\phi\left\{S_{w} \bar{\rho}_{w} U_{w}+S_{g} \bar{\rho}_{g} y_{s} U_{s}+\sum_{i=1}^{3}\left(S_{o} \bar{\rho}_{o}+S_{g} \bar{\rho}_{g} y_{i}\right) U_{i}\right\}+(1-\phi)\left(\rho C_{p}\right)_{R} T\right]
$$




$$
\begin{aligned}
& =\delta\left(\phi S_{W} \bar{\rho}_{W} U_{W}\right)+\delta\left(\phi S_{g} \bar{\rho}_{g} y_{s} U_{s}\right)+\delta\left(\sum_{i=1}^{3} \phi S_{0} \bar{\rho}_{O} x_{i} U_{i}\right) \\
& \quad+\delta\left(\sum_{i=1}^{3} \phi S_{g} \bar{\rho}_{g} y_{i} U_{i}\right)+\delta\left[(1-\phi)\left(\rho C_{p}\right)_{R} T\right]
\end{aligned}
$$

The accumulation terms for the water phase in the energy balance equation are given by

$$
\delta\left(\phi S_{W} \bar{\rho}_{W} U_{W}\right)
$$

The water accumulation terms can be expanded as follows:

$$
\begin{aligned}
& \delta\left(\phi S_{W} \bar{\rho}_{W} U_{W}\right)=\left(\phi S_{W} \bar{\rho}_{W}\right)^{n+1} \delta U_{W}+U_{W}^{n} \delta\left(\phi S_{W} \bar{\rho}_{W}\right) \\
& \delta\left(\phi S_{W} \bar{\rho}_{W}\right)=\phi^{n+1} \delta\left(S_{W} \bar{\rho}_{W}\right)+\left(S_{W} \bar{\rho}_{W}\right)^{n} \delta \phi \\
& \delta\left(S_{W} \bar{\rho}_{W}\right)=S_{W}^{n+1} \delta \bar{\rho}_{W}+\bar{\rho}_{W}^{n} \delta S_{W}
\end{aligned}
$$

Hence

$\delta\left(\phi S_{W} \bar{\rho}_{W} U_{W}\right)=\left(\phi S_{W} \bar{\rho}_{W}\right)^{n+1} \delta U_{W}+\left(\phi S_{W}\right)^{n+1} U_{W}^{n} \delta_{p_{W}}+\phi^{n+1}\left(\bar{\rho}_{W} U_{W}\right)^{n} \delta S_{W}+\left(S_{W} \bar{\rho}_{W} U_{W}\right)^{n} \delta \phi$

The water internal energy Uw is a single valued function of temperature. Hence

$$
\delta U_{W}=U_{W}^{\prime}-U_{W}^{n}+\left(\frac{d U_{W}}{d T}\right)^{\prime} \delta T \cdot\left(\frac{d U_{W}}{d T}\right)^{\prime}\left(r^{\prime}-T^{n}\right)
$$

Substituting equations C-3, C-14, and C-65 in equation C-64 gives

$$
\begin{aligned}
\delta\left(\phi S_{W} \bar{\rho}_{W} U_{W}\right) & =\left(\phi S_{W} \bar{\rho}_{W}\right)^{n+1}\left[\left(U_{W}^{\prime}-U_{W}^{n}\right)+\left(\frac{d U_{W}}{d T}\right)^{\prime} \delta T-\left(\frac{d U_{W}}{d T}\right)^{\prime}\left(T^{\prime}-T^{n}\right)\right] \\
+ & \left(\phi S_{W}\right)^{n+1} U_{W}^{n}\left[\left(\bar{\rho}_{W}^{-1}-\bar{\rho}_{W}^{n}\right)+\left(\frac{\partial \bar{\rho}_{W}}{\partial p}\right)^{\prime} \delta p+\left(\frac{\partial \bar{\rho}_{W}}{\partial T}\right)^{\prime} \delta T\right. \\
& -\left(\frac{\partial \bar{\rho}_{W}}{\partial p}\right)^{\prime}\left(p^{\prime}-p^{n}\right)-\left(\frac{\partial \bar{\rho}_{W}}{\partial T}\right)^{\prime}\left(T^{\prime}-T^{n}\right) . \\
+ & \phi^{n+1}\left(\bar{\rho}_{W} U_{W}\right)^{n} \delta S_{W}+\left(S_{W} \bar{\rho}_{W} U_{W}\right)^{n} \phi_{\text {int }} C_{R} \delta p
\end{aligned}
$$

Rearranging equation C-66, we have

$$
\delta\left(\phi S_{W} \bar{\rho}_{W} U_{W}\right)=\phi^{n+1}\left(\bar{\rho}_{W} U_{W}\right)^{n} \delta S_{W}+\mid\left(\phi S_{W} \bar{\rho}_{W}\right)^{n+1}\left(\frac{d U_{W}}{d T}\right)
$$




$$
\begin{gathered}
\left.+\left(\phi S_{W}\right)^{n+1} U_{W}^{n}\left(\frac{\partial \bar{\rho}_{W}}{\partial T}\right)\right] \delta T \\
+\left[\left(\phi S_{W}\right)^{n+1} U_{W}^{n}\left(\frac{\partial \bar{\rho}_{W}}{\partial p}\right)+\left(S_{W} \bar{\rho}_{W} U_{W}\right)^{n} \phi_{i n t} C_{R}\right] \delta p \\
+\left(\phi S_{W} \bar{\rho}_{W}\right)^{n+1}\left(U_{W}^{\prime}-U_{W}^{n}\right)+\left(\phi S_{W}\right)^{n+1} U_{W}^{n}\left(\bar{\rho}_{W}^{-1}-\bar{\rho}_{W}^{n}\right) \cdot\left[\left(\phi S_{W} \bar{\rho}_{W}\right)^{n+1}\left(\frac{d U_{W}}{d T}\right)^{\prime}+\left(\phi S_{W^{\prime}}\right)^{n+1} U_{W}^{n}\left(\frac{\partial \bar{\rho}_{W}}{\partial T}\right)_{p}^{\prime}\right] \\
\left(T^{\prime}-T^{n}\right)-\left(\phi S_{W}\right)^{n+1} U_{W}^{n}\left(\frac{\partial \bar{\rho}_{W}}{\partial p}\right)_{T}^{\prime}\left(p^{\prime}-p^{n}\right)
\end{gathered}
$$

The accumulation terms for thit steam in the energy balance equation are represented by

$\delta\left(\phi S_{g} \bar{\rho}_{g} y_{s} U_{s}\right)$

The expansion of steam accumulation terms yieids

$$
\begin{aligned}
& \delta\left(\phi S_{g} \bar{\rho}_{g} y_{s} U_{s}\right)=\left(\phi S_{g} \bar{\rho}_{g} y_{s}\right)^{n+1} \delta U_{s}+U_{s}^{n} \delta\left(\phi S_{g} \bar{\rho}_{g} y_{s}\right) \\
& \delta\left(\phi S_{g} \bar{\rho}_{g} y_{s}\right)=\phi^{n+1} \delta\left(S_{g} \bar{\rho}_{g} y_{s}\right)+\left(S_{g} \bar{\rho}_{g} y_{s}\right)^{n} \delta \phi \\
& \delta\left(S_{g} \bar{\rho}_{g} y_{s}\right)=y_{s}^{n+1} \delta\left(S_{g} \bar{\rho}_{g}\right)+\left(S_{g} \bar{\rho}_{g}\right)^{n} \delta y_{s} \\
& \delta\left(S_{g} \bar{\rho}_{g}\right)=S_{g}^{n+1} \delta \bar{\rho}_{g}+\bar{\rho}_{g}^{n} \delta S_{g}
\end{aligned}
$$

Hence

$$
\begin{aligned}
\delta\left(\phi S_{g} \bar{\rho}_{g} y_{s} U_{s}\right) & =\left(\phi S_{g} \bar{\rho}_{g} y_{s}\right)^{n+1} \delta U_{s}+\left(\phi S_{g} y_{s}\right)^{n+1} U_{s}^{n} \delta \bar{\rho}_{g} \\
& +\left(\phi y_{s}\right)^{n+1}\left(\bar{\rho}_{g} U_{s}\right)^{n} \delta S_{g}+\phi^{n+1}\left(S_{g} \bar{\rho}_{g} U_{s}\right)^{n} \delta y_{s} \\
& +\left(S_{g} \bar{\rho}_{g} y_{s} U_{s}\right)^{n} \delta \phi
\end{aligned}
$$

The steam internal energy $U_{s}$ is a single valued function of temperature. Hence

$$
\delta U_{S}=U_{S}^{\prime}-U_{S}^{n}+\left(\frac{d U_{S}}{d T}\right)^{\prime} \delta T \cdot\left(\frac{d U_{S}}{d T}\right)^{\prime}\left(T^{\prime}-T^{n}\right)
$$

Substituting equations $C-3, C-12, C-57$, and $C-71$ in equation $C-70$ and rearranging, we have $\delta\left(\phi S_{g} \bar{\rho}_{g} y_{s} U_{s}\right)=\left(\phi y_{s}\right)^{n+1}\left(\bar{\rho}_{g} U_{s}\right)^{n} \delta S_{g}+\left[\left(\phi S_{g} \bar{\rho}_{g} y_{s}\right)^{n+1}\left(\frac{d U_{s}}{d T}\right)^{\prime}+\left(\phi S_{g} y_{s}\right)^{n+1} U_{s}^{n}\left(\frac{\partial \bar{\rho}_{g}}{\partial T}\right)^{l}\right.$ 


$$
\begin{gathered}
\left.+\phi^{n+1}\left(S_{g} \bar{\rho}_{g} U_{s}\right)^{n}\left(\frac{\partial K_{4}}{\partial T}\right)^{\prime}\right] \delta T \\
+\left[\left(\phi S_{g} y_{s}\right)^{n+1} U_{g}^{n}\left(\frac{\partial \bar{\rho}_{g}}{\partial p}\right)^{\prime}+\phi^{n+1}\left(S_{g} \bar{\rho}_{g} U_{s}\right)^{n}\left(\frac{\partial K_{4}}{\partial p}\right)_{T}^{\prime}+\left(S_{g} \bar{\rho}_{g} y_{s} U_{s}\right)^{n}\right. \\
\left.\phi_{\text {Int }} C_{R}\right] \delta p \\
+\left(\phi S_{g} \bar{\rho}_{g} y_{s}\right)^{n+1}\left(U_{s}^{l}-U_{s}^{n}\right)+\left(\phi S_{g} y_{s}\right)^{n+1} U_{s}^{n}\left(\bar{\rho}_{g}-\bar{\rho}_{g}^{n}\right)+\phi^{n+1}\left(S_{g} \bar{\rho}_{g} U_{s}\right)^{n}\left(K_{4}^{\prime}-K_{4}^{n}\right) \\
-\left[\left(\phi S_{g} \bar{\rho}_{g} y_{s}\right)^{n+1}\left(\frac{d U_{s}}{d T}\right)^{\prime}+\left(\phi S_{g} y_{s}\right)^{n+1} U_{s}^{n}\left(\frac{\partial \bar{\rho}_{g}}{\partial T}\right)^{\prime}+\phi^{n+1}\left(S_{g} \bar{\rho}_{g} U_{s}\right)^{n}\left(\frac{\partial K_{4}}{\partial T}\right)_{p}^{\prime}\right]\left(T^{l}-T^{n}\right) \\
-\left[\left(\phi S_{g} y_{s}\right)^{n+1} U_{s}^{n}\left(\frac{\partial \bar{\rho}_{g}}{\partial p}\right)^{\prime}+\phi^{n+1}\left(S_{g} \bar{\rho}_{s} U_{s}\right)^{n}\left(\frac{\partial K_{4}}{\partial p}\right)^{\prime}\right]\left(p^{\prime}-p^{n}\right)
\end{gathered}
$$

The oleic phase accumulation terms in the energy balance equation are represented by

$$
\delta\left(\sum_{i=1}^{3} \phi S_{0} \bar{\rho}_{0} x_{i} U_{i}\right)
$$

The oleic phase accumulation terms can be expanded as follows:

$$
\begin{aligned}
& \delta\left(\sum_{i=1}^{3} \phi S_{\circ} \bar{\rho}_{\circ} x_{i} U_{i}\right)=\delta\left(\phi S_{\circ} \bar{\rho}_{\circ} \sum_{i=1}^{3} x_{i} U_{i}\right)=\delta\left(\phi S_{\circ} \bar{\rho}_{\circ} U_{0}\right) \\
& \delta\left(\phi S_{0} \bar{\rho}_{0} U_{0}\right)=\left(\phi S_{0} \bar{\rho}_{0}\right)^{n+1} \delta U_{0}+U_{0}^{n} \delta\left(\phi S_{0} \bar{\rho}_{0}\right) \\
& \delta\left(\phi S_{0} \bar{p}_{0}\right)=\phi^{n+1} \delta\left(S_{0} \bar{p}_{0}\right)+\left(S_{0} \bar{p}_{0}\right)^{n} \delta \phi \\
& \delta\left(S_{0} \bar{\rho}_{0}\right)=S_{o}^{n+1} \delta \bar{\rho}_{0}+\bar{\rho}_{0}^{n} \delta S_{0}
\end{aligned}
$$

Hence

$$
\begin{aligned}
\delta\left(\sum_{i=1}^{3} \phi S_{0} \bar{\rho}_{0} x_{i} U_{i}\right) & =\left(\phi S_{0} \bar{\rho}_{0}\right)^{n+1} \delta U_{0}+\left(\phi S_{0}\right)^{n+1} U_{0}^{n} \delta \bar{\rho}_{0}+\phi^{n+1}\left(\bar{\rho}_{0} U_{0}\right)^{n} \delta S_{0} \\
& +\left(S_{0} \bar{\rho}_{0} U_{0}\right)^{n} \delta \phi
\end{aligned}
$$

The oleic phase internal energy is calculated as

$$
U_{0}=\sum_{i=1}^{3} x_{i} U_{i}
$$


Where

$$
U_{i}=C_{p l}\left(T-T_{r e t}\right)
$$

Hence

$$
U_{0}=\left(T-T_{r e f}\right) \sum_{l=1}^{3} x_{i} C_{p l}
$$

Here $C_{p l}$ is the speclfic heat of component $i$ and is assumed to be a constant.

$$
\text { Hence } U_{0}=U_{0}\left(x_{1}, T\right)
$$

and $\delta U_{0}=\delta\left[U_{0}\left(x_{i}, T\right)\right]=\delta\left[\sum_{i=1}^{3} U_{0}\left(x_{i}, T\right)\right]$

$$
\begin{aligned}
& =\sum_{i=1}^{3}\left(\frac{\partial U_{0}}{\partial x_{i}}\right) \delta x_{i}+\left(\frac{\partial U_{0}}{\partial T}\right) \delta T+\left(U_{0}^{l}-U_{0}^{n}\right) \\
& -\sum_{i=1}^{3}\left(\frac{\partial U_{0}}{\partial x_{i}}\right)_{1, T}\left(x_{i}-x_{i}^{n}\right) \cdot\left(\frac{\partial U_{0}}{\partial T}\right)_{x}\left(T^{l}-T^{n}\right)
\end{aligned}
$$

Substituting equations $\mathrm{C}-3, \mathrm{C}-11$, and $\mathrm{C}-80$ in equation $\mathrm{C}-74$, we have

$$
\begin{aligned}
& \delta\left(\phi S_{0} \bar{\rho}_{0} U_{0}\right)=\left(\phi S_{0} \bar{\rho}_{0}\right)^{n+1}\left[\left(U_{0}^{l}-U_{0}^{n}\right)+\sum_{i=1}^{3}\left(\frac{\partial U_{0}}{\partial x_{i}}\right)_{j, T}^{l} \delta x_{1}+\left(\frac{\partial U_{0}}{\partial T}\right)_{x}^{l} \delta T\right. \\
& \left.-\sum_{l=1}^{3}\left(\frac{\partial U_{0}}{\partial x_{i}}\right)_{j, T}^{l}\left(x_{l} \mid-x_{i}^{n}\right)-\left(\frac{\partial U_{0}}{\partial T}\right)_{x}^{l}\left(T^{l}-T^{n}\right)\right] \\
& +\left(\phi S_{0}\right)^{n+1} \cup_{0}^{n}\left(\left(\bar{\rho}_{0}^{-1}-\bar{\rho}_{0}^{n}\right)+\left(\frac{\partial \bar{\rho}_{0}}{\partial p}\right)_{T, x}^{l} \delta p+\left(\frac{\partial \bar{\rho}_{0}}{\partial T}\right)_{p, x}^{l} \delta T+\left(\frac{\partial \bar{\rho}_{0}}{\partial x_{i}}\right)_{T, p}^{l} \delta x_{1}\right. \\
& \left.-\left(\frac{\partial \bar{\rho}_{0}}{\partial p}\right)^{\prime}\left(p^{\prime}-p^{n}\right)-\left(\frac{\partial \ddot{p}_{0}}{\partial T}\right)^{\prime}\left(T^{\prime}-T^{n}\right)-\left(\frac{\partial \bar{\rho}_{0}}{\partial x_{i}}\right)^{\prime}\left(x_{1}-x^{n}\right)\right] \\
& +\phi^{n+1}\left(\bar{\rho}_{O} U_{0}\right)^{n}\left(-\delta S_{g}-\delta S_{W}\right)+\left(S_{0} \bar{\rho}_{O} U_{0}\right)^{n} \phi \operatorname{lnt} C_{R} \delta p
\end{aligned}
$$

Rearranging equation C-81, we have

$$
\delta\left(\phi S_{0} \bar{\rho}_{0} U_{0}\right)=\left[\left(\phi S_{0} \bar{\rho}_{0}\right)^{n+1} \sum_{l=1}^{3}\left(\frac{\partial U_{0}}{\partial x_{i}}\right)_{j, T}^{1}+\left(\phi S_{0}\right)^{n+1} U_{0}^{n}\left(\frac{\partial \bar{\rho}_{0}}{\partial x_{1}}\right)^{1}\right] \delta x_{1}
$$




$$
\begin{aligned}
& \text { - } \phi^{n+1}\left(\bar{\rho}_{0} U_{0}\right)^{n} \delta S_{g} \cdot \phi^{n+1}\left(\bar{\rho}_{0} U_{0}\right)^{n} \delta S_{W} \\
& +\left[\left(\phi S_{0} \vec{p}_{0}\right)^{n+1}\left(\frac{\partial U_{0}}{\partial T}\right)_{x}^{l}+\left(\phi S_{0}\right)^{n+1} U_{0}^{n}\left(\frac{\partial \vec{p}_{0}}{\partial T}\right)_{p, x}^{l}\right] \delta T \\
& +\left[\left(\phi S_{0}\right)^{n+1} \cup_{0}^{n}\left(\frac{\partial \vec{p}_{0}}{\partial p}\right)_{T, x}^{l}+\left(\phi S_{0} \bar{p}_{O} U_{0}\right)^{n} \phi_{\text {int }} C_{R}\right] \delta p \\
& +\left(\phi S_{0} \bar{\rho}_{0}\right)^{n+1}\left[\left(U_{0}^{l}-U_{0}^{n}\right) \cdot \sum_{\mid=1}^{3}\left(\frac{\partial U_{0}}{\partial x_{1}}\right)_{1, T}^{l}\left(x_{\mid}-\lambda \mid\right)\right] \\
& \left.+\left(\phi S_{0}\right)^{n} \cup_{0}^{n}\left[\left(\bar{\rho}_{0}^{-1}-\bar{\rho}_{0}^{n}\right) \cdot\left(\frac{\partial \bar{\rho}_{0}}{\partial x_{1}}\right)_{,, T}^{l}(x \mid-x)^{n}\right)\right] \\
& \cdot\left[\left(\phi S_{0} \bar{\rho}_{0}\right)^{n+1}\left(\frac{\partial U_{0}}{\partial T}\right)_{x}^{l}+\left(\phi S_{0}\right)^{n+1} \cup_{0}^{n}\left(\frac{\partial \bar{p}_{0}}{\partial T}\right)_{p, x}^{l}\right]\left(T^{l}-T^{n}\right) \\
& -\left[\left(\phi S_{0}\right)^{n+1} \cup_{0}^{n}\left(\frac{\partial \bar{p}_{0}}{\partial p}\right)_{T, x}^{\prime}\right]\left(p^{\prime}-p^{n}\right)
\end{aligned}
$$

The gas-phase accumulation terms in the energy balance equation are

$$
\begin{aligned}
& \delta \sum_{i=1}^{3} \phi S_{g} \bar{\rho}_{g} y_{i} U_{i} \\
& \quad=\delta\left(\phi S_{g} \bar{\rho}_{g} \sum_{i=1}^{3} y_{i} U_{i}\right)=\delta\left(\phi S_{g} \bar{\rho}_{g} U_{g}\right)
\end{aligned}
$$

The gas-phase accumulation terms can be expanded as follows:

$$
\begin{aligned}
& \delta\left(\phi S_{g} \bar{\rho}_{g} U_{g}\right)=\left(\phi S_{g} \bar{\rho}_{g}\right)^{n+1} \delta U_{g}+U_{g}^{n} \delta\left(\phi S_{g} \bar{\rho}_{g}\right) \\
& \delta\left(\phi S_{g} \bar{\rho}_{g}\right)=\phi^{n+1} \delta\left(S_{g} \bar{\rho}_{g}\right)+\left(S_{g} \bar{\rho}_{g}\right)^{n} \delta \phi \\
& \delta\left(S_{g} \bar{\rho}_{g}\right)=S_{g}^{n+1} \delta \bar{\rho}_{g}+\bar{\rho}_{g}^{n} \delta S_{g}
\end{aligned}
$$

Hence

$$
\begin{aligned}
\delta \sum_{i=1}^{3} \phi S_{g} \bar{\rho}_{g} y_{l} U_{i} & =\left(\phi S_{g} \bar{\rho}_{g}\right)^{n+1} \delta U_{g}+\left(\phi S_{g}\right)^{n+1} U_{g}^{n} \delta \overline{\rho g}_{g} \\
& +\phi^{n+1}\left(\bar{\rho}_{g} U_{g}\right)^{n} \delta S_{g}+\left(S_{g} \ddot{\rho}_{g} U_{g}\right)^{n} \delta \phi
\end{aligned}
$$


The vapor-phase internal energy is calculated as

$$
U_{g}=\sum_{i=1}^{3} y_{1} U_{i}=\left(T-T_{r e f}\right) \sum_{i=1}^{3} y_{l} C_{p_{i}}=U_{g}\left(y_{1}, T\right)
$$

Hence

$$
\begin{aligned}
\delta U_{g} & =\delta\left[\sum_{l=1}^{3} U_{g}\left(y_{i}, T\right)\right] \\
& \sum_{i=1}^{3}\left(\frac{\partial U_{g}}{\partial y_{i}}\right)_{l, T} \delta y_{i}+\left(\frac{\partial U_{g}}{\partial T}\right)_{y} \delta T+\left(U_{g}^{l}-U_{g}^{n}\right)-\sum_{\mid=1}^{3}\left(\frac{\partial U_{g}}{\partial y_{l}}\right)_{j}\left(y \mid-y^{\prime}\right) \cdot\left(\frac{\partial U_{g}}{\partial T}\right)\left(T^{\prime}-T^{n}\right)
\end{aligned}
$$

Substituting equations C-3, C-12, C-18, C-22, and C-88 in equation C-85, we have

$$
\begin{aligned}
& \delta\left(\phi S_{g} \bar{\rho}_{g} U_{g}\right)=\left(\phi S_{g} \bar{\rho}_{g}\right)^{n+1}\left[\left(U_{g}^{l}-U_{g}^{n}\right)+\sum_{l=1}^{3}\left(\frac{\partial U_{g}}{\partial y_{l}}\right)_{j, T} K_{l}^{n+1} \delta x_{i}\right. \\
& +\sum_{i=1}^{3} x_{i}^{n}\left(\frac{\partial U_{g}}{\partial y_{i}}\right)_{j, T}^{l}\left(\frac{\partial K_{i}}{\partial T}\right)_{p}^{l} \delta T+\sum_{i=1}^{3} x_{l}^{\Gamma}\left(\frac{\partial U_{g}}{\partial y_{i}}\right)_{j, T}^{l}\left(\frac{\partial K_{i}}{\partial p}\right)_{T}^{l} \delta p \\
& \left.+\left(\frac{\partial U_{g}}{\partial T}\right)_{y}^{l} \delta T-\sum_{i=1}^{3}\left(\frac{\partial U_{g}}{\partial y_{i}}\right)_{j}^{l}\left(y \mid-y_{i}^{n}\right)-\left(\frac{\partial U_{g}}{\partial T}\right)^{l}\left(T^{l}-T^{n}\right)\right] \\
& +\left(\phi S_{g}\right)^{n+1} U_{g} I\left(\bar{\rho}_{g}-\bar{\rho}_{g}^{n}\right)+\left(\frac{\partial \bar{\rho}_{g}}{\partial p}\right)_{T}^{l} \delta p+\left(\frac{\partial \bar{\rho}_{g}}{\partial T}\right)_{p}^{1} \delta T-\left(\frac{\partial \bar{\rho}_{g}}{\partial p}\right)^{\prime}\left(p^{\prime}-p^{n}\right) \\
& \left.\cdot\left(\frac{\partial \vec{\rho}_{g}}{\partial T}\right)^{\prime}\left(T^{\prime}-T^{n}\right)\right]+\phi^{n+1}\left(\bar{\rho}_{g} U_{g}\right)^{n} \delta S_{g} \\
& +\left(S_{g} \bar{\rho}_{g} U_{g}\right)^{n} \phi_{\text {int }} C_{R} \delta p
\end{aligned}
$$

Rearranging equation C-89, we have

$$
\begin{aligned}
& \delta\left(\phi S_{g} \bar{\rho}_{g} U_{g}\right)=\left[\left(\phi S_{g} \bar{\rho}_{g}\right)^{n+1} \sum_{i=1}^{3}\left(\frac{\partial U_{g}}{\partial y_{i}}\right)_{j, T} K_{i}^{n+1}\right] \delta x_{i}+\phi^{n+1}\left(\bar{\rho}_{g} U_{g}\right)^{n} \delta S_{g} \\
& +\left[\left(\phi S_{g} \bar{\rho}_{g}\right)^{n+1}\left\{\sum_{i=1}^{3} x^{n}\left(\frac{\partial U_{g}}{\partial y_{i}}\right)_{l, T}^{l}\left(\frac{\partial K_{i}}{\partial T}\right)_{p}^{l}+\left(\frac{\partial U_{g}}{\partial T}\right)^{l}\right\}+\left(\delta S_{g}\right)^{n+1} \cup_{g}^{n}\left(\frac{\partial \bar{\rho}_{g}}{\partial T}\right)_{p}^{l}\right] \delta T \\
& +\left[\left(\phi S_{g} \bar{\rho}_{g}\right)^{n+1}\left\{\sum_{i=1}^{3} x_{i}^{n}\left(\frac{\partial U_{g}}{\partial y_{i}}\right)_{l}^{l}\left(\frac{\partial K_{i}}{\partial p}\right)_{T}^{l}\right\}+\left(\phi S_{g}\right)^{n+1} U_{g}^{n}\left(\frac{\partial \bar{\rho}_{g}}{\partial p}\right)_{T}^{l}+\left(S_{g} \bar{\rho}_{g} U_{g}\right)^{n} \phi_{\text {int }} C_{R}\right] \delta p
\end{aligned}
$$




$$
\begin{aligned}
& +\left(\phi S_{g} \bar{\rho}_{g}\right)^{n+1}\left[\left(U_{g}^{l}-U_{g}^{n}\right) \cdot \sum_{\mid=1}^{3}\left(\frac{\partial U_{g}}{\partial y_{l}}\right)_{j}(y|-y|)\right]+\left(\phi S_{g}\right)^{n+1} U_{g}^{n}\left(\bar{\rho}_{g}^{-1}-\bar{\rho}_{g}^{n}\right) \\
& -\left[\left(\phi S_{g} \bar{\rho}_{g}\right)^{n+1}\left(\frac{\partial U_{g}}{\partial T}\right)^{\prime}+\left(\phi S_{g}\right)^{n+1} U_{g}^{n}\left(\frac{\partial \bar{\rho}_{g}}{\partial T}\right)_{p}\right]\left(T^{\prime} \cdot T^{n}\right) \\
& -\left(\phi S_{g}\right)^{r+1} U_{g}^{n}\left(\frac{\partial \bar{\rho}_{g}}{\partial p}\right)_{T}^{l}\left(p^{l}-p^{n}\right)
\end{aligned}
$$

The rock matrix term of the accumulation term in the energy balance equation is expanded as

$$
\delta\left[(1-\phi)\left(\rho C_{p}\right)_{R} T\right]=\delta\left[\left(\rho C_{p}\right)_{R} T-\phi\left(\rho C_{p}\right)_{R} T\right]
$$

Assuming rock density $(\rho)_{R}$ and rock specific heat $\left(C_{p}\right)_{R}$ as constants, we have

$$
\begin{aligned}
& \delta\left[\left(\rho C_{p}\right)_{R} T-\phi\left(\rho C_{p}\right)_{R} T\right]=\left(\rho C_{p}\right)_{R} \delta(T-\phi T) \\
& \quad=\left(\rho C_{p}\right)_{R} \delta T-\left(\rho C_{p}\right)_{R}\left[\phi^{n+1} \delta T+T^{n} \delta \phi\right]
\end{aligned}
$$

Substituting equation $\mathrm{C}-3$ in $\mathrm{C}-93$ and rearranging, we have

$\delta\left[(1-\phi)\left(\rho C_{p}\right)_{R} T\right]=\left(\rho C_{p}\right)_{R}\left(1-\phi^{n+1}\right) \delta T+T^{n} \phi_{\text {int }} C_{R}\left(\rho C_{p}\right)_{R} \delta p$

By combining equations C-67, C-72, C-82, C-90, and C-94, the complete expansion of the accumulation terms in the energy balance equation can be written as

$$
\begin{aligned}
& \left.\delta\left[\phi \mid S_{w} \bar{\rho}_{W} U_{W}+S_{g} \bar{\rho}_{g} y_{s} U_{S}+\sum_{i=1}^{3}\left(S_{o} \bar{\rho}_{o} x_{i}+S_{g} \bar{\rho}_{g} y_{i}\right) U_{i}\right\}+(1-\phi)\left(\rho C_{p}\right)_{R} T\right] \\
& =\left[\left(\phi S_{0} \bar{\rho}_{0}\right)^{n+1} \sum_{i=1}^{3}\left(\frac{\partial U_{0}}{\partial x_{i}}\right)_{j, T}^{1}+\left(\phi S_{0}\right)^{n+1} U_{0}^{n}\left(\frac{\partial \bar{\rho}_{0}}{\partial x_{i}}\right)_{j}^{l}+\left(\phi S_{g} \bar{p}_{g}\right)^{n+1} \sum_{i=1}^{3}\left(\frac{\partial U_{g}}{\partial y_{i}}\right)_{i} K_{i}^{n+1}\right] \delta x_{i} \\
& +\left[\phi^{n+1}\left(\bar{\rho}_{g} U_{g}\right)^{n}-\phi^{n+1}\left(\bar{\rho}_{o} U_{0}\right)^{n}+\left(\phi y_{s}\right)^{n+1}\left(\bar{\rho}_{g} U_{s}\right)^{n}\right] \delta S_{g} \\
& +\left[\phi^{n+1}\left(\bar{\rho}_{w} U_{w}\right)^{n} \cdot \phi^{n+1}\left(\bar{\rho}_{0} U_{0}\right)^{n}\right] \delta S_{W} \\
& +\left[\left(\phi S_{0} \bar{\rho}_{0}\right)^{n+1}\left(\frac{\partial U_{0}}{\partial T}\right)_{x}^{1}+\left(\phi S_{0}\right)^{n+1} U_{o}^{n}\left(\frac{\partial \bar{\rho}_{o}}{\partial T}\right)_{p, x}^{l}+\left(\phi S_{g} \bar{\rho}_{g}\right)^{n+1}\right. \\
& \left\{\sum_{i=1}^{3} x_{i}^{\prime \prime}\left(\frac{\partial U_{g}}{\partial y_{i}}\right)_{j, T}^{l}\left(\frac{\partial K_{i}}{\partial T}\right)_{p}^{1}+\left(\frac{\partial U_{g}}{\partial T}\right)^{\prime \prime}\right\}+\left(\phi S_{g}\right)^{n+1} \quad U_{g}^{n}\left(\frac{\partial \bar{p}_{g}}{\partial T}\right)_{p}
\end{aligned}
$$




$$
\begin{aligned}
& +\left(\phi S_{W}\right)^{n+1} U_{W}^{n}\left(\frac{\partial \bar{\rho}_{w}}{\partial T}\right)_{p}^{1}+\left(\phi S_{W} \bar{\rho}_{W}\right)^{n+1}\left(\frac{d U_{W}}{d T}\right)^{\prime}+\left(\phi S_{g} \bar{\rho}_{g} y_{s}\right)^{n+1}\left(\frac{d U_{s}}{d T}\right)^{\prime} \\
& +\left(\phi S_{g} y_{s}\right)^{n+1} U_{s}^{n}\left(\frac{\partial \bar{\rho}_{g}}{\partial T}\right)_{p}^{l}+\phi^{n+1}\left(S_{g} \bar{\rho}_{g} U_{s}\right)^{n}\left(\frac{\partial K_{4}}{\partial T}\right)_{p}^{l} \\
& +\left(\rho C_{p}\right)_{R}\left(1-\phi^{n+1}\right) \delta \delta \\
& +\left[\left(\phi S_{o}\right)^{n+1} U_{o}^{n}\left(\frac{\partial \bar{\rho}_{o}}{\partial p}\right)_{T, x}^{!}+\left(\phi S_{g} \bar{\rho}_{g}\right)^{n+1}\left\{\sum_{i=1}^{3} x_{i}^{n}\left(\frac{\partial U_{g}}{\partial y_{i}}\right)_{j}^{l}\left(\frac{\partial K_{i}}{\partial p}\right)_{T}^{l}\right\}\right. \\
& +\left(\phi S_{g}\right)^{n+1} U_{g}^{n}\left(\frac{\partial \bar{\rho}_{g}}{\partial p}\right)_{T}^{\prime}+\left(\phi S_{W}\right)^{n+1} U_{W}^{n}\left(\frac{\partial \bar{\rho}_{W}}{\partial p}\right)_{T}^{\prime} \\
& +\left(\phi S_{g} y_{s}\right)^{n+1} U_{S}^{n}\left(\frac{\partial \bar{\rho}_{g}}{\partial p}\right)_{T}^{\prime}+\phi^{n+1}\left(S_{g} \bar{\rho}_{g} U_{s}\right)^{n}\left(\frac{\partial K_{4}}{\partial p}\right)_{T}^{l} \\
& \left.+\left\{\left(S_{O} \bar{\rho}_{o} U_{O}\right)^{n}+\left(S_{g} \bar{\rho}_{g} U_{g}\right)^{n}+\left(S_{w} \bar{\rho}_{W} U_{w}\right)^{n}+\left(S_{g} \bar{\rho}_{g} y_{s} U_{S}\right)^{n}\right\} \phi_{\text {int }} C_{R}\right] \delta p \\
& +\left(\phi S_{0} \bar{\rho}_{0}\right)^{n+1}\left[\left(u_{0}^{l}-u_{0}^{n}\right)-\sum_{i=1}^{3}\left(\frac{\partial u_{0}}{\partial x_{i}}\right)_{j, T}^{l}\left(x_{i}-x_{i}^{n}\right)\right] \\
& +\left(\phi S_{0}\right)^{n+1} U_{0}^{n}\left[\left(\bar{\rho}_{0}^{-}-\bar{\rho}_{0}^{n}\right)-\left(\frac{\partial \bar{\rho}_{0}}{\partial x_{i}}\right)_{j}^{l}\left(x_{1}^{l}-x_{i}^{n}\right)\right] \\
& +\left(\phi S_{g} \bar{\rho}_{g}\right)^{n+1}\left[\left(U_{g}^{l}-U_{g}^{n}\right)-\sum_{i=1}^{3}\left(\frac{\partial U_{g}}{\partial y_{i}}\right)_{j}^{l}\left(y_{i}-y_{i}^{n}\right)\right]+\left(\phi S_{g}\right)^{n+1} U_{g}^{n}\left(\bar{\rho}_{g}^{\prime}-\bar{\rho}_{g}^{n}\right) \\
& +\left(\phi S_{w} \bar{\rho}_{w}\right)^{n+i}\left(U_{w}^{\prime}-U_{w}^{n j}\right)+\left(\phi S_{w}\right)^{n+1} U_{w}^{n}\left(\bar{\rho}_{w}^{-1}-\bar{\rho}_{w}^{n}\right) \\
& +\left(\phi S_{g} \bar{\rho}_{g} y_{s}\right)^{n+1}\left(U_{s}^{\prime}-U_{s}^{n}\right)+\left(\phi S_{g} y_{s}\right)^{n+1} U_{s}^{n}\left(\bar{\rho}_{g}^{-}-\bar{\rho}_{g}^{n}\right)+\phi^{n+1}\left(S_{g} \bar{\rho}_{g} U_{s}\right)^{n}\left(K_{4}^{\prime}-K_{4}^{n}\right) \\
& -\left[\left(\phi S_{0} \bar{\rho}_{0}\right)^{n+1}\left(\frac{\partial U_{0}}{\partial T}\right)_{x}^{l}+\left(\phi S_{0}\right)^{n+1} U_{0}^{n}\left(\frac{\partial \bar{\rho}_{0}}{\partial T}\right)_{p, x}^{l}+\left(\phi S_{g} \bar{\rho}_{g}\right)^{n+1}\left(\frac{\partial U_{g}}{\partial T}\right)^{\prime}\right. \\
& +\left(\phi S_{g}\right)^{n+1} U_{g}^{n}\left(\frac{\partial \bar{\rho}_{g}}{\partial T}\right)_{p}+\left(\phi S_{w} \bar{\rho}_{w}\right)^{n+1}\left(\frac{d U_{W}}{d T}\right)^{\prime}+\left(\phi S_{w}\right)^{n+1} U_{W}^{n}\left(\frac{\partial \bar{\rho}_{W}}{\partial T}\right)_{p}^{l} \\
& +\left(\phi S_{g} \bar{\rho}_{g} y_{s}\right)^{n+1}\left(\frac{d U_{s}}{d T}\right)^{\prime}+\left(\phi S_{g} y_{s}\right)^{n+1} U_{s}^{n}\left(\frac{\partial \bar{\rho}_{g}}{\partial T}\right)_{p}^{l}+\phi^{n+1}\left(S_{g} \bar{\rho}_{g} U_{s}\right)^{n}\left(\frac{\partial K_{4}}{\partial T} \int_{p}^{l}\right]\left(T^{\prime}-T^{n}\right) \\
& -l\left(\phi S_{0}\right)^{n+1} U_{0}^{n}\left(\frac{\partial \bar{\rho}_{0}}{\partial p}\right)_{T, x}^{1}+\left(\phi S_{g}\right)^{n+1} U_{g}^{n}\left(\frac{\partial \bar{\rho}_{g}}{\partial p}\right)_{T}^{1}+\left(\phi S_{W}\right)^{n+1} U_{W}^{n}\left(\frac{\partial \bar{\rho}_{W}}{\partial p}\right)_{T}^{l}
\end{aligned}
$$




$$
\left.+\left(\phi S_{g} y_{s}\right)^{n+1} U_{S}^{n}\left(\frac{\partial \bar{\rho}_{g}}{\partial p}\right)_{T}^{l}+\phi^{n+1}\left(S_{g} \bar{\rho}_{g} U_{S}\right)^{n}\left(\frac{\partial K_{4}}{\partial p}\right)_{T}^{l}\right]\left(p^{\prime} \cdot p^{n}\right)
$$

The composition constraints for the oil- and gas-phase are

$$
\delta x_{1}+\delta x_{2}+\delta x_{3}=0
$$

and

$$
\delta y_{1}+\delta y_{2}+\delta y_{3}+\delta y_{4}=0
$$

i.e., $\quad \sum_{i=1}^{3} \delta y_{i}+\delta y_{4}=0$

The expansion of the composition constraint for the gas molar fraclion in terms of primary variables is obtained by combining equations $\mathrm{C}-18, \mathrm{C}-22$, and C- 57 .

Thus,

$$
\begin{aligned}
\sum_{i=1}^{3} \delta y_{i}+ & \delta y_{4}=\sum_{i=1}^{3} K_{i}^{n+1} \delta x_{i} \\
& +\left[\sum_{i=1}^{3} x_{i}^{n}\left\{\left(\frac{\partial K_{i}}{\partial T}\right)_{p}^{\prime} \delta T+\left(\frac{\partial K_{i}}{\partial p}\right)_{T}^{\prime} \delta p+\left(K_{i}^{\prime}-K_{i}^{n}\right)-\left(\frac{\partial K_{i}}{\partial p}\right)^{\prime}\left(p^{\prime}-p^{n}\right)-\left(\frac{\partial K_{i}}{\partial T}\right)^{\prime}\left(T^{\prime}-T^{n}\right)\right]\right. \\
& +\left(K_{4}^{\prime}-K_{4}^{n}\right)+\left(\frac{\partial K_{4}}{\partial p}\right)_{T}^{\prime} \delta p+\left(\frac{\partial K_{4}}{\partial T}\right)_{p}^{1} \delta T-\left(\frac{\partial K_{4}}{\partial p}\right)^{\prime}\left(p^{\prime}-p^{n}\right) \\
& -\left(\frac{\partial K_{4}}{\partial T}\right)^{\prime}\left(T^{\prime}-T^{n}\right)=0
\end{aligned}
$$

Regrouping:

$$
\begin{aligned}
\sum_{i=1}^{3} \delta y_{i} & +\delta y_{4} \\
& =\sum_{i=1}^{3} K_{i}^{n+1} \delta x_{i}+\left[\sum_{i=1}^{3} x_{i}^{n}\left(\frac{\partial K_{i}}{\partial T}\right)_{p}^{1}+\left(\frac{\partial K_{4}}{\partial T}\right)^{\prime}\right] \delta T \\
& +\left[\sum_{i=1}^{3} x_{i}^{n}\left(\frac{\partial K_{i}}{\partial p}\right)_{T}^{1}+\left(\frac{\partial K_{4}}{\partial p}\right)_{T}^{1}\right] \delta p+\sum_{i=1}^{3} x_{i}^{n}\left(K_{i}^{i}-K_{i}^{n}\right)
\end{aligned}
$$




$$
\begin{aligned}
& +\left(K_{4}^{l}-K_{4}^{n}\right)-\left[\sum_{i=1}^{3} x_{i}^{n}\left(\frac{\partial K_{i}}{\partial T}\right)^{\prime}+\left(\frac{\partial K_{4}}{\partial T}\right)^{\prime}\right]\left(T^{\prime}-T^{n}\right) \\
& -\left[\sum_{i=1}^{3} x_{i}^{n}\left(\frac{\partial K_{i}}{\partial p}\right)^{\prime}+\left(\frac{\partial K_{4}}{\partial p}\right)^{\prime}\right]\left(p^{\prime}-p^{n}\right)=0
\end{aligned}
$$

\section{Left-Hand-Side (Flow Terms) Expansinn}

Here we present left-hand-side (flow term) expansion of mass and energy conservation equations. The expansions presented here are highly implicit. Later we present the form of expansion used in the current version of the model.

\section{Treatment of Hydrocarbon Flow Terms}

The left-hand-side of the hydrocarbon mass conservation equations, (eq. 3.1 to 3.3 ) includes interblock flow of component $i$. For $x$-direction flow between grid blocks $i-1, j$ and $i, j$, the flow term is

$$
\tau_{0} x_{i}\left(\Delta p_{0}-\gamma_{0} \Delta D\right)+\tau_{g} y_{i}\left(\Delta p_{g}-\gamma_{g} \Delta D\right)
$$

Here $\tau_{0}$ and $\tau_{g}$ are interblock transmissibilities and given by

$$
\begin{aligned}
& \tau_{0}=\tau_{x k_{r o}} \rho_{o} / \mu_{o} \\
& \tau_{g}=\tau_{x k_{r g}} \rho_{g} / \mu_{g}
\end{aligned}
$$

Where $\tau_{x}$ is the interblock absolute transmissibility $(k A l)_{i-1 / 2, j}$

As pointed out by Coats, ${ }^{26}$ the PVT terms in the interblock transmissibility, $\rho_{0} / \mu_{0}, \rho_{g} / \mu_{g}, \gamma_{0}$ and $\gamma_{g}$ are insensitive to either implicit or explicit dating. Hence in this model these terms are expressed at time level $n$. Further, viscosities $\left(\mu_{0}, \mu_{g}\right)$ and gas-phase density $\left(\rho_{g}\right)$ are calculated as upsiream grid block values. The oleic-phase density $\left(\rho_{0}\right)$ and phase specific weights $\left(\gamma_{0}\right.$ and $\left.\gamma_{g}\right)$ are calculated as arithmetic averages of their respective adjacent grid block values.

We will first discuss in detail the oleic-phase interblock flow term expansion in equation $\mathrm{C}-101$. The change (increment) in oil flow over a time-step is:

$$
\delta\left[\tau_{0} x_{i}\left(\Delta p_{0}-\gamma_{0} \Delta D\right)\right]=\left[\tau_{0} x_{i}\left(\Delta p_{0}-\gamma_{0} \Delta D\right)\right]^{n+1}-\left[\tau_{0} x_{i}\left(\Delta p_{o}-\gamma_{o} \Delta D\right)\right]^{n}
$$

or

$$
\left[\tau_{0} x_{i}\left(\Delta p_{0}-\gamma_{0} \Delta D\right)\right]^{n+1}=\left[\tau_{0} x_{i}\left(\Delta p_{0}-\gamma_{0} \Delta D\right)\right]^{n}+\delta\left[\tau_{0} x_{i}\left(\Delta p_{0}-v_{0} \Delta D\right)\right]
$$


The increment terms in equation $\mathrm{C}-102$ are expanded as follows:

$$
\begin{aligned}
& \delta\left[\tau_{0} x_{i}\left(\Delta p_{o}-\gamma_{0} \Delta D\right)\right]=\left(\Delta p_{o}-\gamma_{0} \Delta D\right)^{n+1} \delta\left(\tau_{0} x_{i}\right)+\left(\tau_{0} x_{i}\right)^{n} \delta\left(\Delta p_{0}-\gamma_{0} \Delta D\right) \\
& \delta\left(\tau_{0} x_{i}\right)=x_{i}^{n+1} \delta \tau_{0}+\tau_{0}^{n} \delta x_{i}
\end{aligned}
$$

and $\delta\left(\Delta p_{0}-\gamma_{0} \Delta D\right)=\Delta \delta p_{0}$, since $\gamma_{0} \Delta D$ is a constant

Hence

$$
\delta\left[\tau_{0} x_{i}\left(\Delta p_{o}-\gamma_{0} \Delta D\right)\right]=\left(\Delta p_{0}-\gamma_{0} \Delta D\right)^{n+1}\left(x_{i}^{n+1} \delta \tau_{0}+\tau_{0}^{n} \delta x_{i}\right)+\tau_{0}^{n} x^{n} \Delta \delta p_{0}
$$

Substituting equation C-106 in equation C-102, we have

$$
\begin{gathered}
{\left[\tau_{0} x_{i}\left(\Delta p_{0}-\gamma_{0} \Delta D\right)\right]^{n+1}=\left[\tau_{0} x_{i}\left(\Delta p_{0}-\gamma_{0} \Delta D\right)\right]^{n}+\tau_{0}^{n} x_{i}^{n} \Delta \delta p_{0}} \\
+\left(\Delta p_{0}^{n+1}-\gamma_{0} \Delta D\right)\left(x_{i}^{n+1} \delta \tau_{0}+\tau_{0}^{n} \delta x_{i}\right)
\end{gathered}
$$

The increment in the oil transmissibility $\delta \tau_{0}$ is expanded in the following manner:

$$
\delta \tau_{0}=\delta\left[\tau_{x} k_{r o} \rho_{0} / \mu_{0}\right]
$$

Where

$$
\begin{aligned}
\tau_{x} & =\text { interblock absolute transmissibility in the } x \text {-direction from grid block } i-1, j \text { to } i, j \\
& =(k A / l) i-1 / 2, j
\end{aligned}
$$

Dating the PVT term $\rho_{0} / \mu_{0}$ explicitly, we have

$$
\delta \tau_{0}=\left(\tau_{x} \rho_{0} / \mu_{0}\right)^{n} \delta k_{r_{0}}
$$

Since $k_{r_{0}}=k_{r_{0}}\left(S_{w}, S_{g}\right)$, we have

$$
\begin{aligned}
\delta k_{r_{0}} & =k_{r_{0}}^{l}-k_{r_{0}}^{n}+\left(\frac{\partial k_{r_{0}}}{\partial S_{w}}\right)^{n} \delta S_{w}+\left(\frac{\partial k_{r_{0}}}{\partial S_{g}}\right)^{n} \delta S_{g} \cdot\left(\frac{\partial k_{r_{0}}}{\partial S_{w}}\right)^{n}\left(S_{w}^{l}-S_{w}^{n}\right) \\
& -\left(\frac{\partial k_{r_{0}}}{\partial S_{g}}\right)^{n}\left(S_{g}^{l}-S_{g}^{n}\right)
\end{aligned}
$$


Assuming the changes in saturation to be negligible from iteration to iteration within a time-step, we have

$$
\delta k_{r_{0}} \approx\left(\frac{\partial k_{r_{0}}}{\partial S_{W}}\right)^{n} \delta S_{w}+\left(\frac{\partial k_{r_{0}}}{\partial S_{g}}\right)^{n} \delta S_{g}
$$

Hence

$$
\delta \tau_{0}=\tau_{x}\left(\frac{\rho_{0}}{\mu_{0}}\right)^{n}\left[\left(\frac{\partial k_{r_{0}}}{\partial S_{w}}\right)^{n} \delta S_{w}+\left(\frac{\partial k_{r_{0}}}{\partial S_{g}}\right)^{n} \delta S_{g}\right]
$$

Substituting equation $\mathrm{C}-113$ in equation $\mathrm{C}-107$, we have

$$
\begin{aligned}
& {\left[\tau_{0} x_{i}\left(\Delta p_{0}-\gamma_{0} \Delta D\right)\right]^{n+1}=\left[\tau_{0} x_{i}\left(\Delta p_{o}-\gamma_{0} \Delta D\right)\right]^{n}+\tau \delta x_{1}^{n} \delta \Delta p_{o}} \\
& \quad+\left(\Delta p_{0}^{n+1}-\gamma_{0} \Delta D\right)\left[x_{i} \tau_{x}\left(\frac{p_{0}}{\mu_{0}}\right)^{n}\left\{\left(\frac{\partial k_{r_{0}}}{\partial S_{w}}\right)^{n} \delta S_{w}+\left(\frac{\partial k_{r_{0}}}{\partial S_{g}}\right)^{n} \delta S_{g}\right\}+\tau_{0}^{n} \delta x_{i}\right]
\end{aligned}
$$

The increment in the gas-phase flow over a time-step is:

$$
\delta\left[\tau_{g} y_{i}\left(\Delta p_{g}-\gamma_{g} \Delta D\right)\right]=\left[\tau_{y} y_{i}\left(\Delta p_{g}-\gamma_{g} \Delta D\right)\right]^{n+1}-\left[\tau_{g} y_{i}\left(\Delta p_{g}-\gamma_{g} \Delta D\right)\right]^{n}
$$

Since $p_{g}=p_{o}+p_{c g o}$, we have

$$
\left[\tau_{g} y_{i}\left(\Delta p_{o}+\Delta p_{c_{g o}}-\gamma_{g} \Delta D\right)\right]^{n+1}=\left[\tau_{g} y_{i}\left(\Delta p_{o}+\Delta p_{c_{g o}}-\gamma_{g} \Delta D\right)\right]^{n}+\delta\left[\tau_{g} y_{i}\left(\Delta p_{o}+\Delta p_{c_{g o}}-\gamma_{g} \Delta D\right)\right]
$$

$$
\delta\left[\tau_{g} y_{i}\left(\Delta p_{o}+\Delta p_{c_{g o}}-\gamma_{g} \Delta D\right)\right]=\left(\Delta p_{o}+\Delta p_{c_{g o}}-\gamma_{g} \Delta D\right)^{n+1} \delta\left(\tau_{g} y_{i}\right)+\left(\tau_{g} y_{i}\right)^{n} \delta\left(\Delta p_{o}+\Delta p_{c_{g o}}-\gamma_{g} \Delta D\right)
$$

$$
\delta\left(\Delta p_{0}+\Delta p_{c_{g o}}-\gamma_{g} \Delta D\right)=\Delta \delta p_{o}+\Delta \delta p_{c_{g o}}
$$

and $\delta\left(\tau_{g} y_{i}\right)=y_{i}^{n+1} \delta \tau_{g}+\tau g y_{i}$

Substituting equations $\mathrm{C}-118$ and $\mathrm{C}-119$ in $\mathrm{C}-117$

$$
\begin{gathered}
\delta\left[\tau_{g} y_{i}\left(\Delta p_{o}+\Delta p_{c_{g o}}-\gamma_{g} \Delta D\right)\right]=\tau g y_{i}^{n}\left(\Delta \delta p_{o}+\Delta \delta p_{c_{g o}}\right) \\
+\left(\Delta p_{o}^{n+1}+\Delta p_{c_{g o}^{n+1}}^{n+1}-\gamma_{g} \Delta D\right)\left(y_{1}^{n+1} \delta \tau_{g}+\tau g \delta y_{i}\right)
\end{gathered}
$$


Substituting equation $\mathrm{C}-120$ in equation $\mathrm{C}-116$, we have

$$
\begin{aligned}
& {\left[\tau_{g} y_{i}\left(\Delta p_{g}+\Delta p_{c_{g o}}-\gamma_{g} \Delta D\right)\right]^{n+1}=\left[\tau_{g} y_{i}\left(\Delta p_{o}+\Delta p_{c_{g o}}-\gamma_{g} \Delta D\right)\right]^{n}} \\
& \quad+\tau g y_{i}^{n}\left(\Delta \delta p_{o}+\Delta \delta p_{c_{g o}}\right)+\left(\Delta p_{o}^{n+1}+\Delta p_{c_{g o}^{n+1}}^{n+1}-\gamma_{g} \Delta D\right)\left(y p^{n+1} \delta \tau_{g}+\tau g \delta y_{i}\right)
\end{aligned}
$$

Where

$$
\begin{aligned}
& \delta \tau_{g}=\tau_{x}\left(\rho_{g} / \mu_{g}\right)^{n}\left[\left(\frac{\partial k_{r g}}{\partial S_{g}}\right) \delta S_{g}\right] \\
& \Delta \delta p_{g_{g o}}=\left(\frac{\partial p_{c_{g o}}}{\partial S_{g}}\right) \delta S_{g} \\
& \delta y_{i}=K_{i}^{n+1} \delta x_{i}+x_{i}^{n} \delta K_{i}
\end{aligned}
$$

and $\delta \mathrm{K}_{i}$ is given by equation $\mathrm{C}-18$.

Substitution of equations $\mathrm{C}-114$ and $\mathrm{C}-121$ in equation C-101 yields the following highly implicit expression for the hydrocarbon interblock flow term.

$$
\begin{aligned}
& {\left[\tau_{0} x_{i}\left(\Delta p_{o}-\gamma_{0} \Delta D\right)+\tau_{g} y_{i}\left(\Delta p_{o}-\gamma_{g} \Delta D\right)\right]^{n+1}} \\
& {\left[\tau_{o} x_{i}\left(\Delta p_{o}-\gamma_{o} \Delta D\right)\right]^{n}+\left[\tau_{g} y_{i}\left(\Delta p_{g}-\gamma_{g} \Delta D\right)\right]^{n}} \\
& +\tau \delta x_{i}^{n} \Delta \delta p_{0}+\left(\Delta p_{0}^{n+1}-\gamma_{0} \Delta D\right)\left(x_{i}^{n+1} \delta \tau_{0}+\tau_{0}^{n} \delta x_{i}\right) \\
& +\tau g y_{i}^{n}\left(\Delta \delta p_{o}+\Delta \delta p_{c_{g o}}\right)+\left(\Delta p_{o}^{n+1}+\Delta p_{c_{g o}+1}^{n+\gamma_{g}} \Delta D\right)\left(y_{i}^{n+1} \delta \tau_{g}+\tau g^{+1} \delta y_{i}\right)
\end{aligned}
$$

\section{Water Flow Term Expansion}

In a manner similar to the hydrocarbon interblock flow term expansion, a highly implicit expression for the aqueous-phase interblock flow term is developed. The final expression is given by

$$
\begin{aligned}
& {\left[\tau_{w}\left(\Delta p_{w}-\gamma_{w} \Delta D\right)+\tau_{g} y_{s}\left(\Delta p_{g}-\gamma_{g} \Delta D\right)\right]^{n+1}} \\
& =\left[\tau_{w}\left(\Delta p_{w}-\gamma_{w} \Delta D\right)\right]^{n}+\left[\tau_{g} y_{s}\left(\Delta p_{g}-\gamma_{g} \Delta D\right)\right]^{n} \\
& +\tau \tilde{w}\left(\Delta \delta p_{0}-\Delta \delta p_{c_{o w}}{ }^{\prime \prime}\right)+\left(\Delta p_{o}^{n+1}-\Delta p_{C_{O W}}^{n+1}-\gamma_{w} \Delta D\right) \delta \tau_{W} \\
& +\tau g y s\left(\Delta \delta p_{o}+\Delta \delta p_{c_{g o}}\right)+\left(\Delta p_{o}^{n+1}+\Delta p_{C_{g o}}^{n+1}-\gamma_{g} \Delta D\right)\left(y_{s}^{n+1} \delta \tau_{g}+\tau \delta \delta y_{s}\right)
\end{aligned}
$$


Where

$$
\begin{aligned}
& \delta \tau_{W}=\tau_{x}\left(\rho_{W} / \mu_{W}\right)^{n}\left[\left(\frac{\partial k_{w}}{\partial S_{W}}\right) \delta S_{W}\right] \\
& \delta p_{c_{O W}}=\left(\frac{\partial p_{c_{o w}}}{\partial S_{W}}\right) \delta S_{W} \\
& \delta y_{s}=\delta K_{4}
\end{aligned}
$$

\section{Expansion of Flow Terms in Energy Balance Equation}

The left-hand-side of the energy balance equation (eq. 3.5) include the convectlve energy flow term $\Delta\left(\tau_{H} \Delta p\right)$ and the conductive term $\Delta\left(\tau_{c} \Delta T\right)$. For $x$-direction flow between grid blocks $i-1, j$ and $l_{1}$, the convective term is

$$
\tau_{H} \Delta p=\tau_{0} H_{0}\left(\Delta p_{0}-\gamma_{0} \Delta D\right)+\tau_{g} H_{g}\left(\Delta p_{g}-\gamma_{g} \Delta D\right)+\tau_{w} H_{w}\left(\Delta p_{w}-\gamma_{w} \Delta D\right)
$$

Where

$$
H_{m}=\text { Phase enthalpy }=U_{m}+p / J \rho_{m} \quad m=0, g, w
$$

As an exainple, we will present in detail the expansion of the oleic-phase interblock convective flow term in equation C-126. Other interblock convective flow terms can be expanded in analogous manner.

The change in oil convective flow over a time-step is:

$$
\begin{aligned}
& \delta\left[\tau_{0} H_{0}\left(\Delta p_{0}-\gamma_{0} \Delta D\right)\right]=\left[\tau_{0} H_{0}\left(\Delta p_{0}-\gamma_{0} \Delta D\right)\right]^{n+1}-\left[\tau_{0} H_{0}\left(\Delta p_{0}-\gamma_{0} \Delta D\right)\right]^{n} \\
& \delta\left[\tau_{0} H_{0}\left(\Delta p_{0}-\gamma_{0} \Delta D\right)\right]=\left(\tau_{0} H_{0}\right)^{n} \delta\left(\Delta p_{0}-\gamma_{0} \Delta D\right)+\left(\Delta p_{0}-\gamma_{0} \Delta D\right)^{n+1} \delta\left(\tau_{0} H_{0}\right) \\
& \delta\left[\left(\Delta p_{0}-\gamma_{0} \Delta D\right)\right]=\Delta \delta p_{0} \\
& \delta\left(\tau_{0} H_{0}\right)=H_{0}^{n+1} \delta \tau_{0}+\tau B \delta H_{0} \\
& \delta H_{0}=\delta\left(H_{0}(T)\right)=\left(\frac{\partial H_{0}}{\partial T}\right)^{n} \delta T \\
& \left(\frac{\partial H_{0}}{\partial T}\right)=\frac{\partial}{\partial T}\left[U_{0}(T)+p / J \rho_{0}\right]=\left(\frac{\partial U_{0}}{\partial T}\right)
\end{aligned}
$$


and $\delta T$ is given by equation $\mathrm{C}-113$.

Hence

$$
\delta\left[\tau_{0} H_{0}\left(\Delta p_{0}-\gamma_{0} \Delta D\right)\right]=\tau_{0}^{n} H_{0}^{n} \Delta \delta p_{0}+\left(\Delta p_{0}^{n+1}-\gamma_{0} \Delta D\right)\left(H_{0}^{n+1} \delta \tau_{0}+\tau_{0}^{n}\left(\frac{\partial U_{0}}{\partial T}\right)^{n} \delta T\right)
$$

Suibstituting equation C-133 in equation C-128

$$
\begin{gathered}
{\left[\tau_{0} H_{0}\left(\Delta p_{0}-\gamma_{0} \Delta D\right)\right]^{n+1}=\left[\tau_{0} H_{0}\left(\Delta p_{0}-\gamma_{0} \Delta D\right)\right]^{n}+\tau_{0} H_{0}^{n} \Delta \delta p_{0}} \\
+\left(\Delta p_{0}^{n+1}-\gamma_{0} \Delta D\right)\left(H_{0}^{n+1} \delta \tau_{0}+\tau B\left(\frac{\partial U_{0}}{\partial T}\right)^{n} \delta T\right)
\end{gathered}
$$

Similarly

$$
\begin{gathered}
{\left[\tau_{g} H_{g}\left(\Delta p_{g}-\gamma_{g} \Delta D\right)\right]^{n+1}=\left[\tau_{g} H_{g}\left(\Delta p_{g}-\gamma_{g} \Delta D\right)\right]^{n}+\tau g H_{g}^{n}\left(\Delta \delta p_{o}+\Delta \delta p_{c_{g o}}\right)} \\
+\left(\Delta p_{o}^{n+1}+\Delta p_{C_{g o}^{n+1}}^{n}-\gamma_{g} \Delta D\right)\left[H_{g}^{n+1} \delta \tau_{g}+\tau g\left(\frac{\partial U_{g}}{\partial T}\right)^{n} \delta T\right]
\end{gathered}
$$

and

$$
\begin{aligned}
& {\left[\tau_{w} H_{w}\left(\Delta p_{w}-\gamma_{w} \Delta D\right)\right]^{n+1}=\left[\tau_{w} H_{w}\left(\Delta p_{w}-\gamma_{w} \Delta D\right)\right]^{n}+\tau_{w} H_{w}\left(\Delta \delta p_{o}-\Delta \delta p_{c_{o w}}\right)} \\
& +\left(\Delta p_{O}^{n+1}-\Delta p_{C W}^{n+1}-\gamma_{W} \Delta D\right)\left[H_{W}^{n+1} \delta \tau_{W}+\tau W\left(\frac{d U_{W}}{d T}\right)^{n} \delta T\right]
\end{aligned}
$$

$\delta p_{c_{g o}} \delta p_{c_{o w}} \delta \tau_{0}, \delta \tau_{g}$ and $\delta \tau_{w}$ are defined previously.

Substituting equations C-134, C-135, and C-136 in energy conservation expression, we have

$$
\begin{aligned}
& {\left[\tau_{0} H_{0}\left(\Delta p_{0}-\gamma_{0} \Delta D\right)+\tau_{g} H_{g}\left(\Delta p_{g}-\gamma_{g} \Delta D\right)+\tau_{w} H_{w}\left(\Delta p_{w}-\gamma_{w} \Delta D\right)\right]^{n+1}} \\
& =\left[\tau_{0} H_{o}\left(\Delta p_{o}-\gamma_{0} \Delta D\right)+\tau_{g} H_{g}\left(\Delta p_{g}-\gamma_{g} \Delta D\right)+\tau_{w} H_{w}\left(\Delta p_{w}-\gamma_{w} \Delta D\right)\right]^{n} \\
& +\left(\tau \delta H_{o}^{n}+\tau g H_{g}^{n}+\tau \eta_{W} H_{W}^{n}\right) \Delta \delta p_{o}+\tau g H_{g}^{n} \Delta \delta p_{c_{g o}}-\tau{ }_{W}^{n} H_{w}^{n} \Delta \delta p_{c_{o w}} \\
& +\left(\Delta p_{0}^{n+1}-\gamma_{0} \Delta D\right)\left(H_{0}^{n+1} \delta \pi_{0}+\tau_{0}\left(\frac{\partial U_{0}}{\partial T}\right)^{n} \delta T\right) \\
& +\left(\Delta p_{0}^{n+1}+\Delta p_{C_{g o}^{n}}^{n+1}-\gamma_{g} \Delta D\right)\left(H_{g}^{n+1} \delta \tau_{g}+\tau \theta\left(\frac{\partial U_{g}}{\partial T}\right)^{n} \delta T\right)
\end{aligned}
$$




$$
+\left(\Delta p_{0}^{n+1}-\Delta p_{C O W}^{n+1}-\gamma_{W} \Delta D\right)\left(H_{W}^{n+1} \delta \tau_{W}+\tau{ }_{W}^{n}\left(\frac{d U_{W}}{d T}\right) \delta T\right)
$$

The conductive heat flow between grid blocks $\mid-1, j$ and $1, j$ is implicitly dated in temperature. Thus, the conductive energy flow is expressed as

$$
\tau_{c} \Delta T=\tau_{c} \Delta T^{n+1}
$$

\section{Implementation of Finlte Dliference Expansion In the Present Model}

The faithful implementation of the above highly implicit expansion terms is not only computationally expensive, but also it drastically increases the complexity of the model and storage requirements. Because of memory limitations, it is not possible to code and test a fully implicit compositional steamflood simulator on a personal computer. Since the objective of this undertaking is to develop a tool to aid in the interpretation of laboratory results, and produce acceptable results in a reasonable amount of time, certain simplifying assumptions are made to reduce the complexity of the finite difference expansion terms.

In the current implementation the terms $\left(\bar{\rho}^{-}-\bar{\rho}^{n}\right),\left(p^{\prime}-p^{n}\right),\left(T^{\prime}-T^{n}\right)$, etc. in the accumulation terms expressions assumed to be negligibly small. This greatly simplified the equations C-45, C-60, C-95, and C-100. As shown elsewhere, this simplification did not materially affect the calculated results and the calculated and experimental results agreed reasonably well. To simplify the flow term equations (left-handside expansion terms), all terms except the pressure in the left-hand-side of the conservation equations (eq. 3.1-3.3) are held explicit at time-level $n$. This explicit treatment of flow terms reduced the time difference terms: $\delta \tau_{0}, \delta \tau_{\mathrm{g}}, \delta \tau_{w_{1}} \delta x_{1}, \delta y_{1}, \delta p_{c_{g o}} \delta p_{c_{0 w}}$ and $\delta \mathrm{T}$ in the left-hand-side expansion expressions (equations $\mathrm{C}-123, \mathrm{C}-124$, and $\mathrm{C}-137$ ) to zero. This greatly simplified the flow terms. As pointed out by Coats $^{26}$ this simplification may result in marginal stabllity for some cases.

The simplified representation of flow terms in the finite difference expressions are as follows:

\section{Hydrocarbon Flow Terms}

$$
\begin{aligned}
& \Delta\left[\tau_{o} x_{i}\left(\Delta p_{o}-\gamma_{0} \Delta D\right)+\tau_{g} y_{1}\left(\Delta p_{g}-\gamma_{g} \Delta D\right)\right]+q_{o} x_{i} \bar{\rho}_{o}+q_{g} y_{i} \bar{\rho}_{g} \\
& \approx \Delta\left(\tau_{0} x_{i} \Delta \Phi_{0}+\tau_{g} y_{i} \Delta \Phi_{g}\right)^{n}+\Delta\left(\tau \delta x_{i}^{n}+\tau g y^{n}\right) \Delta \delta p_{o} \\
& +q_{\delta}^{n} x_{i}^{n} \bar{\rho}_{o}^{n}+q g y_{i}^{n} \bar{\rho}_{g}^{n}, i=1,2,3
\end{aligned}
$$

Where

$$
\Phi_{0}=\Delta p_{0}-\gamma_{0} \Delta D
$$


and $\Phi_{g}=\Delta p_{g}-\gamma_{g} \Delta D$

\section{Water Flow Terms}

$$
\begin{aligned}
& \Delta\left[\tau_{w}\left(\Delta p_{w}-\gamma_{w} \Delta D\right)+\tau_{g} y_{s}\left(\Delta p_{g}-\gamma_{g} \Delta D\right)\right]+q_{w} \bar{\rho}_{w}+q_{g} y_{s} \bar{\rho}_{g} \\
& =\Delta\left(\tau_{w} \Phi_{w}+\tau_{g} y_{s} \Phi_{g}\right)^{n}+\Delta(\tau \bar{\tau}+\tau g y g) \Delta \delta p_{o}+q q_{w} \bar{\rho}_{w}^{n}+q_{g} y_{g} \bar{\rho}_{g}^{n}
\end{aligned}
$$

Where

$$
\Phi_{W}=\Delta p_{W}-\gamma_{w} \Delta D
$$

\section{Elow Terms in the Eneroy Conservation Equation}

$$
\begin{aligned}
& \Delta\left(\tau_{H} \Phi\right)+\Delta\left(\tau_{c} \Delta T\right)-q_{L}-q_{H} \\
& =\Delta\left(\tau_{0} H_{0} \Phi_{0}+\tau_{g} H_{g} \Phi_{g}+\tau_{W} H_{W} \Phi_{W}\right)^{n} \\
& \quad+\Delta\left(\tau B H_{0}^{n}+\tau g H_{g}^{n}+\tau D_{W} H_{W}^{n}\right) \Delta \delta p_{0}-q\left[-q \mathrm{q}_{H}+\tau_{c} \Delta T^{n+1}\right.
\end{aligned}
$$




\section{APPENDIX D - FINITE DIFFERENCE EXPANSION OF FLOW TERMS}

In this appendix, the finite difference expansion of the ' $R$ ' vectors (equations 4.7, 4.21 and 4.28) is detalled. The ' $R$ ' vectors comprised of interblock flow terms (transmissibilities) and the source/sink terms and defined as follows:

$$
\begin{gathered}
R_{1}=\Delta_{x}\left(\tau_{o_{x}} x_{1} \Delta \Phi_{0}\right)+\Delta_{x}\left(\tau_{g_{x}} y_{1} \Delta \Phi_{g}\right)+\Delta_{z}\left(\tau_{o_{z}} x_{1} \Delta \Phi_{0}\right) \\
+\Delta_{z}\left(\tau_{g_{z}} y_{1} \Delta \phi_{g}\right)+q_{0} \bar{\rho}_{o} x_{1}+q_{g} \bar{\rho}_{g} y_{1}
\end{gathered}
$$

Where

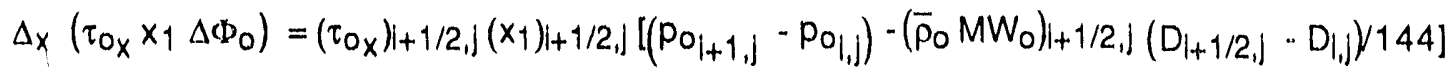

$$
\begin{aligned}
& \left.\left.\left.-\left(\tau_{12 x}\right) i-1 / 2,\right\}\left(x_{1}\right) i-1 / 2,\right\}\left[\left(P_{0, j}-P_{0 \mid-1, j}\right)-\left(\bar{p}_{0} M W_{0}\right) \mid-1 / 2,\right\}\left(D_{1, j}-D_{1-1, j}\right) / 144\right]
\end{aligned}
$$

The oleic phase interblock transmlssibility ' $\mathrm{t}$ ' in the $\mathrm{x}$-direction is:

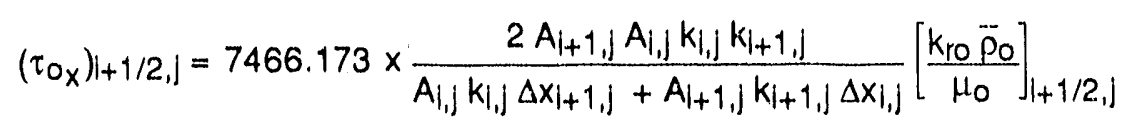

The unit of transmissibility as defined above is $\mathrm{lb}$-mole/psi-hr.

In equation D-3, the constant 7466.173 indlcates that the flow rate is expressed in $\mathrm{cm}^{3} / \mathrm{hr}$ and the absolute permeability ' $k$ ' in $m d$.

Similarly,

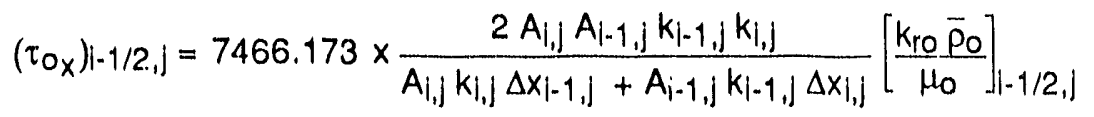

The hydrocarbon vapor interblock flow term in the $x$-direction is:

$$
\begin{aligned}
& \Delta_{x}\left(\tau_{g_{x}} y_{1} \Delta \Phi_{g}\right)=\left(\tau_{g x}\right) i_{i+1 / 2, j}\left(y_{1}\right) i_{+1 / 2, j}\left[\left(p_{o_{1+1, j}}-p_{o_{1, j}}\right)\right. \\
& \left.+\left(p c_{g_{i+1, j}}-p c_{g_{i, j}}\right)-\left(\bar{\rho}_{g} M W_{g}\right)_{i+1 / 2, j}\left(D_{i+1, j}-D_{i, j}\right) / 144\right] \\
& -\left(\tau_{g_{x}}\right)_{i-1 / 2, j}\left(y_{1}\right)_{i-1 / 2,]}\left[\left(P_{O_{1, j}}-p_{O_{\mid-1, j}}\right)+\left(p c_{g_{1, j}}-p c_{g \mid-1, j}\right)-\left(\bar{p}_{g} M W_{g}\right)_{i-1 / 2, j}\left(D_{\mid, j}-D_{\mid-1, j}\right) / 144\right]
\end{aligned}
$$

The vapor phase transmissibility ' $\mathrm{g}_{\mathrm{g}}$ ' in the $\mathrm{x}$-direction is:

$$
\left(\tau_{g}\right)_{i+1 / 2, j}=7466.173 \times \frac{2 A_{i+1, j} A_{i, j} k_{i, j} k_{i+1, j}}{A_{i, j} j k_{i, j} \Delta x_{i+1, j}+A_{l+1, j} k_{i+1, j} \Delta x_{i, j}}\left[\frac{k_{r g} \bar{\rho}_{g}}{\mu_{g}}\right]_{i+1 / 2, j}
$$


and

$$
\left(\tau_{g}\right)|-1 / 2,|=7466.173 \times \frac{2 A_{1, j} A_{\mid-1, j} k_{l, j} \mid k_{\mid-1,1},}{A_{(, j} k_{1, j} \Delta x_{\mid-1, j}+A_{\mid-1, j} k_{\mid-1, j} \Delta x_{1, j}}\left[\frac{k_{r g} \bar{\rho}_{g}}{\mu_{g}}\right]_{\mid-1 / 2, j}
$$

The plelc phase interblock flow terrn in the z-direction is:

$$
\begin{aligned}
& \Delta_{z}\left(\tau_{O_{z}} x_{1} \Delta \Phi_{0}\right)=\left(\tau_{O_{z}}\right)_{1, j+1 / 2}\left(x_{1}\right)_{1,1+1 / 2}\left[\left(P_{O_{1,1+1}}-p_{O_{1,1}}\right) *\left(\bar{\rho}_{0} M W_{0}\right)_{1,1+1 / 2}\left(D_{1,1+1}-D_{1, j}\right) / 144\right] \\
& -\left(\tau_{O_{2}}\right)|,|-1 / 2\left(x_{1}\right) I_{1, j-1 / 2}\left[\left(P_{0 \mid, j}-P_{0, j-1}\right)-\left(\bar{\rho}_{0} M W_{0}\right)_{1, j-1 / 2}\left(D_{1, j}-D_{1, j-1}\right) / 144\right]
\end{aligned}
$$

The oleic phase transmissibility in the z-direction is:

and

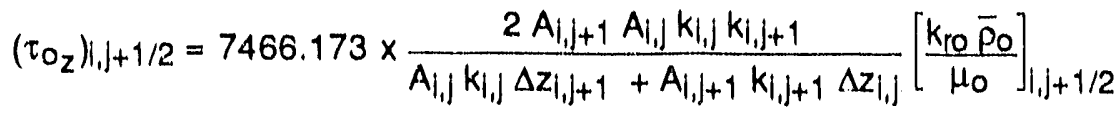

$$
\begin{aligned}
& \left(\tau_{0_{2}}\right)_{1, j-1 / 2}=7466.173 \times \frac{2 A_{1, j-1} A_{i, j} k_{1, j} k_{1, j-1}}{A_{1, j} k_{1, j} \Delta z_{1, j-1}+A_{i, j-1} k_{i, j-1} \Delta z_{1, j}}\left[\frac{k_{10} \vec{p}_{0}}{\mu_{0}}\right]_{l_{1, j-1 / 2}}
\end{aligned}
$$

The hydrocarbon vapor interblock flow term in the z-direction is:

$$
\begin{aligned}
& \Delta_{z}\left(\tau_{g_{z}} y_{1} \Delta \Phi_{g}\right)=\left(\tau _ { g _ { z } } h _ { 1 , + 1 / 2 } ( y _ { 1 } ) _ { 1 , 1 + 1 / 2 } \left[\left(p_{o_{1,1+1}}-p_{o_{1,1}}\right)\right.\right. \\
& \left.+\left(p c_{g_{1, j+1}}-p c_{g_{1,1}}\right)-\left(\bar{\rho}_{g} M W_{g}\right)_{1, j+1 / 2}\left(D_{1, j+1}-D_{1, j}\right) / 144\right] \\
& -\left(\tau_{g_{z}}\right)_{1, j-1 / 2}\left(y_{1}\right)_{1, j-1 / 2}\left(\left(p_{o_{1, j}}-p_{o_{i, j-1}}\right)+\left(p c_{g_{1, j}}-p c_{g_{i, j-1}}\right)-\left(\bar{p}_{g} M W_{g}\right)_{1, j-1 / 2}\left(D_{l, j}-D_{[, j-1}\right) / 144\right]
\end{aligned}
$$

The vapor phase transmissibility ' $\tau{ }^{\prime}$ ' in the $z$-direction is:

$$
\left(\tau_{g_{z}}\right)_{1, j+1 / 2}=7466.173 \times \frac{2 A_{i, j+1} A_{i, j} k_{i, j} k_{i, j+1}}{A_{i, j} k_{i, j} \Delta z_{i, j+1}+A_{i, j+1}}\left[\frac{k_{r g} \bar{\rho}_{g}}{\mu_{g}}\right]_{l_{1, j+1 / 2}}
$$

and

$$
\left(\tau_{g z}\right)_{i, j-1 / 2}=7466.173 \times \frac{2 A_{i, j} A_{i, j-1} k_{i, j} k_{1, j-1}}{A_{i, j} k_{1, j} \Delta z_{1, j-1}+A_{(, j-1} k_{i, j-1} \Delta z_{i, j}}\left[\frac{k_{r g} \bar{\rho}_{g}}{\mu_{g}}\right]_{1, j-1 / 2}
$$

Vectors $R_{2}$ and $R_{3}$ are defined similarly. For ' $R_{2}^{\prime}$, replace $x_{1}$ and $y_{1}$ in equations $D-1, D-2, D-5$ and $D-8$ by $x_{2}$ and $y_{2}$. For ' $R{ }^{\prime}$, replace $x_{1}$ and $y_{1}$ in the above equations by $x_{3}$ and $y_{3}$. 
The interblock flow term vector ' $R$ ' 4 for the aqueous phase is defined as follows:

$$
\begin{aligned}
R_{4}=\Delta_{x} & \left(\tau_{w} \Delta \Phi_{W}\right)+\Delta_{x}\left(\tau_{g x} y_{4} \Delta \Phi_{g}\right)+\Delta_{z}\left(\tau_{w} \Delta \Phi_{W}\right)+\Delta_{z}\left(\tau_{g_{x}} y_{4} \Delta \Phi_{g}\right) \\
& +q_{w} \bar{\rho}_{w}+q_{g} \bar{\rho}_{g} y_{s}
\end{aligned}
$$

Where

$$
\begin{aligned}
& \Delta_{x}\left(\tau_{w} \Delta \Phi_{W}\right)=\left(\tau_{w}\right)_{1, j+1 / 2}\left[\left(p_{o_{1+1, j}}-p_{o_{1, j}}\right)-\left(p c_{w_{1+1, j}}-p c_{w_{1, j}}\right)\right. \\
& \left.-\left(\bar{\rho}_{W} M W_{W}\right)_{1+1 / 2, j}\left(D_{1+1, j}-D_{1, j}\right) / 144\right]
\end{aligned}
$$

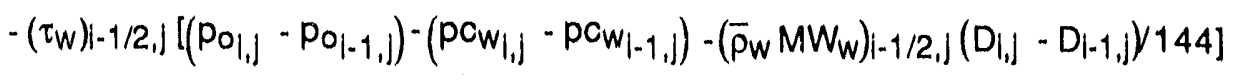

The aqueous phase interblock transmissibility ' $\tau_{w}$ ' in the x-direction is:

$$
\left(\tau_{W}\right)_{i+1 / 2, j}=7466.173 \times \frac{2 A_{1+1, j} A_{i, j} k_{i, j} k_{i+1, j}}{A_{1, j} k_{i, j} \Delta x_{i+1, j}+A_{i+1, j} k_{i+1, j} \Delta x_{1, j}}\left[\frac{k_{m w} \bar{P}_{W}}{\mu_{W}}\right]_{i+1 / 2, j}
$$

and

$$
\left(\tau_{w}\right)_{i-1 / 2, j}=7466.173 \times \frac{2 A_{1, j} A_{\mid-1, j} k_{i, j} k_{\mid-1, j}}{\left.A_{i, j} k_{i, j} \Delta x_{i-1, j}+A_{(-1, j} k_{i-1, j} \Delta x_{1, j}\right]}\left[\frac{k_{w w} \bar{\rho}_{w}}{\mu_{W}}\right]_{\mid-1 / 2, j}
$$

The steam interblock flow term in the x-direction is:

$$
\begin{aligned}
& \Delta_{x}\left(\tau_{g_{x}} y_{s} \Delta \Phi_{g}\right)=\left(\tau_{g_{x}}\right)_{+1 / 2, j}\left(y_{s}\right)_{++1 / 2, j}\left[\left(p_{o_{\mid+1, j}}-p_{o_{1, j}}\right)+\left(p c_{g_{\mid+1, j}}-p c_{g_{1, j}}\right)\right. \\
& \left.-\left(\bar{\rho}_{g} M W_{g}\right)_{1+1 / 2, j}\left(D_{1+1, j}-D_{1, j}\right) / 144\right]-\left(\tau_{g x}\right)\left|-1 / 2, j\left(y_{s}\right)\right|-1 / 2, j \\
& {\left[\left(P_{O_{1, j}}-P_{O_{1-1, j}}\right)+\left(P_{c g_{1, j}}-P_{c g_{i-1, j}}\right)-\left(\bar{\rho}_{g} M W_{g}\right)_{-1 / 2, j}\left(D_{1, j}-D_{1-1, j}\right) / 144\right]}
\end{aligned}
$$

The aqueous phase interblock flow term in the z-direction is:

$$
\begin{aligned}
& \Delta_{z}\left(\tau_{w} \Delta \Phi_{W}\right)=\left(\tau_{w}\right)_{i, j+1 / 2}\left[\left(p_{o_{1, j}+1}-p_{o_{1, j}}\right)-\left(p c_{W_{1, j}+1}-p c_{W_{1, j}}\right)\right. \\
& \left.-\left(\bar{\rho}_{W} M W_{W}\right)_{1, j+1 / 2}\left(D_{1, j+1}-D_{1, j}\right) / 144\right]-\left(\tau_{W}\right)_{1, j-1 / 2}\left[\left(p_{0_{1, j}}-p_{0_{1, j-1}}\right)\right. \\
& \left.-\left(p c_{w_{i, j}}-p c_{w_{i, j-1}}\right)-\left(\bar{\rho}_{w} M W_{w}\right)_{1, j-1 / 2}\left(D_{l, j}-D_{l, j-1}\right) / 144\right]
\end{aligned}
$$

The aqueous phase interblock transmissibility ' $\tau_{w}$ ' in the $z$-direction is: 


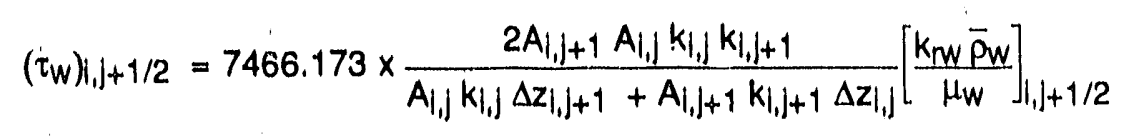

and

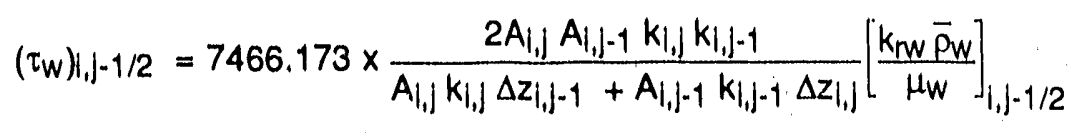

The steam interblock flow term in the z-direction is

$$
\begin{aligned}
& \Delta_{z}\left(\tau_{g_{z}} y_{s} \Delta \Phi_{s}\right)=\left(\tau _ { g _ { z } } h _ { 1 , j + 1 / 2 } ( y _ { s } ) l _ { , j + 1 / 2 } \left[\left(p_{o_{1, j+1}}-p_{o_{1, j}}\right)+\left(p c_{g_{1, j+1}}-p c_{g_{1, j}}\right)\right.\right. \\
& \left.-\left(\bar{\rho}_{g} M W_{g}\right)_{i, j+1 / 2}\left(D_{1, j+1}-D_{1, j}\right) / 144\right]-\left(\tau_{g_{z}}\right)_{1, j-1 / 2}\left(y_{s}\right)_{i, j-1 / 2} \\
& {\left[\left(p_{O_{1, j}}-p_{o_{1, j-1}}\right)+\left(p c_{g_{1, j}}-P c_{g_{1, j-1}}\right)-\left(\bar{\rho}_{g} M W_{g}\right)_{1, j-1 / 2}\left(D_{1, j}-D_{1, j-1}\right) / 144\right]}
\end{aligned}
$$

The interblock energy flow vector ' $R$ ' 5 is defined as follows:

$$
R_{5}=\Delta\left(\tau_{H} \Delta \Phi\right)+\Delta\left(\tau_{c} \Delta T\right)-q_{L}-\left(q_{0} H_{0}+q_{g} H_{g}+q_{w} H_{w}\right)
$$

Where

$$
\Delta\left(\tau_{H} \Delta \Phi\right)=\Delta\left(\tau_{0} H_{0} \Delta \Phi_{0}\right)+\Delta\left(\tau_{g} H_{g} \Delta \Phi_{g}\right)+\Delta\left(\tau_{W} H_{W} \Delta \Phi_{W}\right)
$$

and $\Delta\left(\tau_{c} \Delta T\right)=\Delta_{x}\left(\tau_{c} \Delta T\right)+\Delta_{z}\left(\tau_{c} \Delta T\right)$

Here $\tau_{c}$ is the interblock transconductivity (thermal transmissibility).

The $\mathrm{x}$-and $\mathrm{z}$-direction interblock heat flow terms are defined as follows:

$$
\begin{aligned}
& \Delta_{x}\left(\tau_{c} \Delta T\right)=\left(\tau_{c_{x}}\right) i+1 / 2, j\left(T_{i+1, j}-T_{i, j}\right)-\left(\tau_{c_{x}}\right) h_{-1 / 2, j}\left(T_{i, j}-T_{i-1, j}\right) \\
& \Delta_{z}\left(\tau_{c} \Delta T\right)=\left(\tau_{c_{z}}\right)_{i, j+1 / 2}\left(T_{i, j+1}-T_{i, j}\right)-\left(\tau_{c_{z}}\right) \text { i,j-1/2}\left(T_{i, j}-T_{i, j-1}\right)
\end{aligned}
$$

The $x$-direction transconductivities are given by

$$
\left(\tau_{c_{x}}\right)_{i+1 / 2, j}=\frac{2 A_{i+1, j} A_{i, j}}{A_{i, j} \Delta x_{i+1, j}+A_{i+1, j} \Delta x_{i, j}}\left(\lambda_{R}\right)_{i+1 / 2, j}
$$

and

$$
\left(\tau_{c_{x}}\right)_{i-1 / 2, j}=\frac{2 A_{i, j} A_{i-1, j}}{A_{i, j} \Delta x_{i-1, j}+A_{i-1, j} \Delta x_{i, j}}\left(\lambda_{R}\right)_{i-1 / 2, j}
$$


where $\lambda_{R}$ is the thermal conductivity of the reservoir (sandpack) formation.

Similarly, the z-direction transconductivity are given by

$$
\left(\tau_{c_{z}}\right)_{i, j+1 / 2}=\frac{2 A_{i, j+1} A_{i, j}}{A_{i, j} \Delta z_{i, j+1}+A_{i, j+1} \Delta z_{i, j}}\left(\lambda_{R}\right)_{i, j+1 / 2}
$$

and

$$
\left(\tau_{c_{z}}\right)_{i, j-1 / 2}=\frac{2 A_{i, j} A_{i, j-1}}{A_{i, j} \Delta z_{i, j-1}+A_{i, j-1} \Delta z_{i, j}}\left(\wedge_{R}\right)_{i, j-1 / 2}
$$

To illustrate the expansion of the interislock energy transfer term, we use the aqueous phase interblock energy flow term. Similar expressions can be writter for other phases.

The aqueous phase interblock energy flow is given by

$\Delta\left(\tau_{W} H_{W} \Delta \Phi_{W}\right)=\Delta_{x}\left(\tau_{W} H_{W} \Delta \Phi_{W}\right)+\Delta_{z}\left(\tau_{W} H_{W} \Delta \Phi_{W}\right)$

$$
\Delta_{x}\left(\tau_{w} H_{w} \Delta \Phi_{w}\right)=\left(\tau_{w}\right)_{i+1 / 2, j} H_{w} l\left(p_{o_{i+1, j}}-p_{o_{i, j}}\right)-\left(p c_{w_{i+1, j}}-p c_{w_{i, j}}\right)
$$

$$
\begin{aligned}
& -\left(\bar{\rho}_{w} M W_{w}\right)_{i+1 / 2, j}\left(D_{i+1, j}-D_{i, j} j / 144\right] \\
& -\left(\tau_{w}\right)_{i-1 / 2, j}\left(H_{w}\right)\left[\left(p_{o_{i, j}}-p_{o_{i-1, j}}\right)-\left(p c_{w_{i, j}}-p c_{w_{i-1, j}}\right)-\left(\bar{\rho}_{w} M W_{w i-1 / 2, j}\left(D_{i, j}-D_{i-1, j}\right) / 144\right]\right.
\end{aligned}
$$

and

$$
\begin{aligned}
& \Delta_{z}\left(\tau_{w} H_{w} \Delta \Phi_{w}\right)=\left(\tau_{w}\right)_{i, j+1 / 2}\left(H_{w}\right)\left[\left(p_{o_{i, j+1}}-\rho_{o_{i, j}}\right)-\left(p c_{w_{i, j+1}}-p c_{w_{i, j}}\right)\right. \\
& \left.-\left(\bar{\rho}_{w} M W_{w}\right)_{i, j+1 / 2}\left(D_{i, j+1}-D_{i, j}\right) / 144\right] \\
& \left.-\left(\tau_{w}\right)_{i, j-1 / 2}\left(H_{w}\right)\left(p_{o_{i, j}}-p_{o_{i, j-1}}\right)\left(p c_{w_{i, j}}-p c_{w_{i, j-1}}\right)-\left(\bar{\rho}_{w} M W_{w}\right)_{i, j-1 / 2}\left(D_{i, j}-D_{i, j-1}\right) / 144\right]
\end{aligned}
$$

The interblock transmissibilities were defined earlier.

In the evaluation of flow terms, $100 \%$ upstream weighting of physical properties and mole fractions were employed. For example:

$$
\begin{aligned}
\left(\frac{k_{w} \bar{P}_{w}}{\mu_{w}}\right)_{i+1 / 2, j} & =\left(\frac{k_{w} \bar{P}_{w}}{\mu_{w}}\right)_{i+1, j} \text { if }\left(P_{0}\right)_{i+1, j}>\left(P_{0}\right)_{i, j} \\
& =\left(\frac{k_{w} \bar{P}_{w}}{\mu_{w}}\right)_{i, j} \text { if }\left(P_{0}\right)_{i, j}>\left(P_{0}\right)_{i-1, j}
\end{aligned}
$$


In the case of thermal conductivity

$$
\begin{aligned}
\left(\lambda_{R}\right)_{i+1 / 2, j} & =\left(\lambda_{R}\right)_{i+1, j} \text { if }(T)_{i+1, j}>(T)_{i, j} \\
& =\left(\lambda_{R}\right)_{i, j} \text { if }(T)_{i, j}>(T)_{i-1, j}
\end{aligned}
$$

In the case of mole fraction

$$
\begin{aligned}
(x)_{i+1 / 2, j}= & (x)_{i+1, j} \text { if }(x)_{i+1, j}>(x)_{i, j} \\
& =(x)_{i, j} \text { if }(x)_{i, j}>(x)_{i-1, j}
\end{aligned}
$$




\section{APPENDIX E - DERIVATION OF THE PRESSURE EQUATION}

Here we illustrate how the parabolic difference equation in pressure (eq. 4.53) is manupulated into a single "pressure equation." The final equation may be solved for the change in oleic phase pressure $\delta p_{o}$ at the new time level $n+1$ at each grid block.

From chapter 4 , we have

$$
\begin{aligned}
U_{77} \delta p_{0}^{n+1}= & L_{72} \Delta\left(\tau_{1} \Delta \delta p \delta^{n+1}\right)+L_{73} \Delta\left(\tau_{2} \Delta \delta p^{n+1}\right)+L_{74} \Delta\left(\tau_{3} \Delta \delta p \delta^{n+1}\right) \\
& +L_{75} \Delta\left(\tau_{H_{2} O} \Delta \delta p B^{+1}\right)+L_{76} \Delta\left(\tau_{H} \Delta \delta p \delta^{n+1}\right)+R_{7}^{\prime}
\end{aligned}
$$

For the sake of clarity, the superscript ' $n+1$ ' has been suppressed in the following:

Now by the definition of difference operators

$$
\begin{aligned}
& \Delta\left(\tau \Delta \delta p_{0}\right)=\Delta_{x}\left(\tau \Delta_{x} \delta p_{0}\right)+\Delta_{z}\left(\tau \Delta_{z} \delta p_{0}\right) \\
& \Delta_{x}\left(\tau \Delta_{x} \delta p_{o}\right)=(\tau)_{i+1 / 2, j}\left(\delta p_{o_{i+1, j}}-\delta p_{o_{i, j}}\right)+(\tau)_{i-1 / 2, j}\left(\delta p_{o_{i-1, j}}-\delta p_{o_{i, j}}\right) \\
& \text { and } \\
& \Delta_{z}\left(\tau \Delta_{z} \delta p_{0}\right)=(\tau)_{i, j+1 / 2}\left(\delta p_{o_{i, j+1}}-\delta p_{o, j, j}\right)+(\tau)_{i, j-1 / 2}\left(\delta p_{o_{i, j-1}}-\delta p_{o_{i, j}}\right) \\
& \text { Now } \tau_{1}=\left(\tau_{0} x_{1}\right)+\left(\tau_{g} y_{1}\right) \\
& \tau_{2}=\left(\tau_{0} \times 2\right)+\left(\tau_{g} y_{2}\right) \\
& \tau_{3}=\left(\tau_{0} x_{3}\right)+\left(\tau_{g} y_{3}\right)
\end{aligned}
$$

Utilizing the definitions $E-1, E-2, E-3$, and E-4, we have

$L_{72} \Delta\left(\tau_{1} \Delta \delta p_{0}\right)$

$$
\begin{aligned}
&=L_{72} {\left[\left(\tau_{0} x_{1}\right)_{i+1 / 2, j}\left(\delta p_{o_{i+1, j}}-\delta p_{o_{i, j}}\right)+\left(\tau_{0} x_{1}\right)_{i-1 / 2, j}\left(\delta p_{o_{i-1, j}}-\delta p_{o_{i, j}}\right)\right.} \\
&++\left(\tau_{g} y_{1}\right)_{i+1 / 2, j}\left(\delta p_{o_{i+1, j}}-\delta p_{o_{i, j}}\right)+\left(\tau_{g} y_{1}\right)_{i-1 / 2, j}\left(\delta p_{o_{i-1, j}}-\delta p_{o_{i, j}}\right) \\
&++\left(\tau_{0} x_{1}\right)_{i, j+1 / 2}\left(\delta p_{o_{i, j+1}}-\delta p_{o_{i, j}}\right)+\left(\tau_{0} x_{1}\right)_{i, j-1 / 2}\left(\delta p_{o_{i-1, j}}-\delta p_{o_{i, j}}\right) \\
&\left.+\left(\tau_{g} y_{1}\right)_{i, j+1 / 2}\left(\delta p_{o_{i, j+1}}-\delta p_{o_{i, j}}\right)+\left(\tau_{g} y_{1}\right)_{i, j-1 / 2}\left(\delta p_{o_{i, j-1}}-\delta p_{o_{i, j}}\right)\right]
\end{aligned}
$$

$L_{73} \Delta\left(\tau_{2} \Delta \delta p_{0}\right)$

$$
=L 73\left[\left(\tau_{0} x_{2}\right)_{i+1 / 2, j}\left(\delta p_{o_{i+1, j}}-\delta p_{o_{i, j}}\right)+\left(\tau_{0} x_{2}\right)_{i-1 / 2, j}\left(\delta p_{o_{i-1, j}}-\delta p_{o_{i, j}}\right)\right.
$$




$$
\begin{aligned}
& +\left(\tau_{g} y_{2}\right)_{i+1 / 2, j}\left(\delta p_{o_{i+1, j}}-\delta p_{o_{i, j}}\right)+\left(\tau_{g} y_{2}\right)_{i-1 / 2, j}\left(\delta p_{o_{i-1, j}}-\delta p_{o_{i, j}}\right) \\
& +\left(\tau_{0} x_{2}\right)_{i, j+1 / 2}\left(\delta p_{o_{i, j+1}}-\delta p_{o_{i, j}}\right)+\left(\tau_{0} x_{2}\right)_{i, j-1 / 2}\left(\delta p_{o_{i, j-1}}-\delta p_{o_{i, j}}\right) \\
& \left.+\left(\tau_{g} y_{2}\right)_{i, j+1 / 2}\left(\delta p_{o_{i, j+1}}-\delta p_{o_{i, j}}\right)+\left(\tau_{g} y_{2}\right)_{i, j-1 / 2}\left(\delta p_{o_{i, j-1}}-\delta p_{o_{i, j}}\right)\right]
\end{aligned}
$$

$L_{74} \Delta\left(\tau_{3} \Delta \delta p_{0}\right)$

$$
\begin{aligned}
=L_{74} & {\left[\left(\tau_{0} x_{3}\right)_{i+1 / 2, j}\left(\delta p_{o_{i+1, j}}-\delta p_{o_{i, j}}\right)+\left(\tau_{0} x_{3}\right)_{i-1 / 2, j}\left(\delta p_{o_{i-1, j}}-\delta p_{o_{i, j}}\right)\right.} \\
+ & \left(\tau_{g} y_{3}\right)_{i+1 / 2, j}\left(\delta p_{o_{i+1, j}}-\delta p_{o_{i, j}}\right)+\left(\tau_{g} y_{3}\right)_{i-1 / 2, j}\left(\delta p_{o_{i-1, j}}-\delta p_{o_{i, j}}\right) \\
+ & \left(\tau_{0} x_{3}\right)_{i, j+1 / 2}\left(\delta p_{o_{i, j+1}}-\delta p_{o_{i, j}}\right)+\left(\tau_{0} x_{3}\right)_{i, j-1 / 2}\left(\delta p_{o_{i, j-1}}-\delta p_{o_{i, j}}\right) \\
& \left.+\left(\tau_{g} y_{3}\right)_{i, j+1 / 2}\left(\delta p_{o_{i, j+1}}-\delta p_{o_{i, j}}\right)+\left(\tau_{g} y_{3}\right)_{i, j-1 / 2}\left(\delta p_{o_{i, j-1}}-\delta p_{o_{i, j}}\right)\right]
\end{aligned}
$$

$\mathrm{L}_{75} \Delta\left(\tau_{\mathrm{H}_{2} \mathrm{O}} \Delta \delta \mathrm{p}_{\mathrm{o}}\right)$

$$
\begin{aligned}
&=L_{75} {\left[\left(\tau_{H_{2} O}\right)_{i+1 / 2, j}\left(\delta p_{o_{i+1, j}}-\delta p_{o_{i, j}}\right)+\left(\tau_{H_{2} O}\right)_{i-1 / 2, j}\left(\delta p_{o_{i-1, j}}-\delta p_{o_{i, j}}\right)\right.} \\
&+\left(\tau_{g} y_{4}\right)_{i+1 / 2, j}\left(\delta p_{o_{i+1, j}}-\delta p_{o_{i, j}}\right)+\left(\tau_{g} y_{4}\right)_{i-1 / 2, j}\left(\delta p_{o_{i-1, j}}-\delta p_{o_{i, j}}\right) \\
&+\left(\tau H_{2} O\right)_{i, j+1 / 2}\left(\delta p_{o_{i, j+1}}-\delta p_{o_{i, j}}\right)+\left(\tau H_{2} O\right)_{i, j-1 / 2}\left(\delta p_{o_{i, j-1}}-\delta p_{o_{i, j}}\right) \\
&\left.+\left(\tau_{g} y_{4}\right)_{i, j+1 / 2}\left(\delta p_{o_{i, j+1}}-\delta p_{o_{i, j}}\right)+\left(\tau_{g} y_{4}\right)_{i, j-1 / 2}\left(\delta p_{o_{i, j-1}}-\delta p_{o_{i, j}}\right)\right]
\end{aligned}
$$

It should be pointed out here that in equations E-5 through E-8, gravity and capillary pressure terms are dated explicitly (i.e., old time level).

Also,

$$
\begin{aligned}
& L_{76} \Delta\left(\tau_{H} \Delta \delta p_{o}\right)=L_{76}\left[\Delta\left(\tau_{0} H_{o} \Delta \delta p_{o}\right)+\Delta\left(\tau_{g} H_{g} \Delta \delta p_{o}\right)+\Delta\left(\tau_{H_{2} O} H_{H_{2} O} \Delta \delta p_{o}\right)\right] \\
& \Delta\left(\tau_{0} H_{0} \Delta \delta p_{o}\right)=\left(\tau_{0}\right)_{i+1 / 2, j} H_{0}\left(\delta p_{o_{i+1, j}}-\delta p_{o_{i, j}}\right)+\left(\tau_{0}\right)_{i-1 / 2, j} H_{o}\left(\delta p_{o_{i-1, j}}-\delta p_{o_{i, j}}\right) \\
& +\left(\tau_{0}\right)_{i, j+1 / 2} H_{0}\left(\delta p_{o_{i, j+1}}-\delta p_{o_{i, j}}\right)+\left(\tau_{0}\right) i, j-1 / 2 H_{0}\left(\delta p_{o_{i, j-1}}-\delta p_{o_{i, j}}\right)
\end{aligned}
$$

Similar expressions can be written for $\Delta\left(\tau_{g} H_{g} \Delta \delta p_{o}\right)$ and $\Delta\left(\tau_{H_{2} O} H_{H_{2} \mathrm{O}} \Delta \delta p_{o}\right)$

The west $(i-1 / 2, j)$ flow coefficients of equation 4.53 is given by

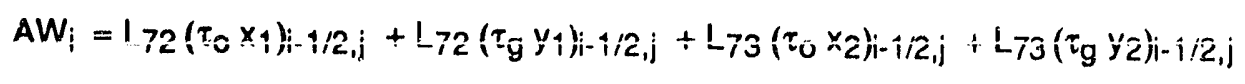




$$
\begin{aligned}
& +L_{74}\left(\tau_{0} x_{3}\right)_{i-1 / 2, j}+L_{74}\left(\tau_{g} y_{3}\right)_{i-1 / 2, j}+L_{75}\left(\tau_{H_{2} O}\right)_{i-1 / 2, j}+\left(\tau_{g} y_{4}\right)_{i-1 / 2, j} \\
& +L_{76}\left(\tau_{0} H_{0}\right)_{i-1 / 2, j}+L_{76}\left(\tau_{g} H_{g}\right)_{i-1 / 2, j}+L_{76}\left(\tau_{H_{2}} O H_{H_{2}} O\right)_{i-1 / 2, j}
\end{aligned}
$$

Collecting oil, water, and gas terms together, we have

$$
\begin{aligned}
& A W_{1}=\left(L_{72} \times 1_{1-1 / 2, j}+L 73 \times 2 \mid-1 / 2, j+L 74 \times x_{1-1 / 2, j}+L 76 H_{0}\right)\left(\tau_{0}\right) \mid-1 / 2, j \\
& +\left(L_{72} y_{1 i-1 / 2, j}+L_{73} y_{21-1 / 2, j}+L_{74} y_{3 \mid-1 / 2, j}+L 75 y_{4 i-1 / 2, j}+L_{76} H_{g}\right)\left(\tau_{g}\right) i-1 / 2, j \\
& +\left(\mathrm{L}_{75}+\mathrm{L}_{76} \mathrm{H}_{\mathrm{H}_{2} \mathrm{O}}\right)\left(\tau_{\mathrm{H}_{2}} \mathrm{O}\right) \mathrm{i}-1 / 2,1
\end{aligned}
$$

In equation E-12:

replace $i-1 / 2, j$ by $i+1 / 2, j$ to obtain the East $(i+1 / 2, j)$ coefficient $A E_{i}$

replace $i-1 / 2, j$ by $i, j-1 / 2$ to obtain the South $(i, j-1 / 2)$ coefficent $A S_{j}$

replace $\mid-1 / 2, j$ by $i, j+1 / 2$ to obtain the North $(i, j+1 / 2)$ coefficient $A N_{j}$

Equation 4.52 can then be written as

$$
\begin{aligned}
U_{77} \delta p_{0}^{n+1} & =A S_{j}\left(\delta p B_{i, j-1}^{+1}-\delta p_{i, j}^{+1}\right)+A W_{i}\left(\delta p B_{i-1, j}^{+1}-\delta p_{i, j}^{+1}\right) \\
& +A N_{j}\left(\delta p_{i, j+1}^{+1}-\delta p_{0 i, j}^{n+1}\right)+A E_{i}\left(\delta p_{i+1, j}^{+1}-\delta p_{i, j}^{+1}\right)+R_{7}^{\prime}
\end{aligned}
$$

Equation E-13 may be written in the form

$$
\begin{gathered}
A S_{j}\left(\delta p^{8+1}\right)_{i, j-1}+A W_{i}\left(\delta p \delta^{+1}\right)_{i-1, j}+A N_{j}\left(\delta p \delta^{+1}\right)_{i, j+1} \\
+A E_{i}\left(\delta p^{n+1}\right)_{i+1, j}+E \delta p_{i, j}^{+1}=B
\end{gathered}
$$

where

$$
\begin{aligned}
& E=-\left(A S_{j}+A W_{i}+A N_{j}+A E_{i}+U_{77}\right) \\
& B=-R_{7}^{\prime}
\end{aligned}
$$

Equation E-14 gives a Penta diagonal system of linear equations which can be solved by direct method. 


\section{APPENDIX F - OVER/UNDERBURDEN HEAT LOSS}

The heat loss to the surroundings is assumed to occur by conduction in a direction normal to the top and bottom of the reservoir. It is further assumes that the overburden thermal conductivity $\left(\lambda_{o b}\right)$ and heat capacity $\left(\rho c_{p}\right)$ ob are constant. The heat loss to the surrounding can then be considered to obey the onedimensional conduction equation

$$
\lambda_{o b,} \frac{\partial^{2} T^{\prime} T^{\prime}}{\partial Y^{2}}=\left(\rho C_{p}\right) o b \frac{\partial T^{*}}{\partial t}
$$

This approach yields a reasonably accurate result as has been shown by Coats. ${ }^{21}$

The implicit difference representation of equation F-1 is described. Smaller grid size is used close to the reservoir while large grid size is used away from the reservoir. The finite difference representation of $\mathrm{F}-1$ for a given block ' $\mathrm{j}$ ' is

$$
\frac{\partial^{2} T^{\prime}}{\partial Y^{2}}=\frac{2}{\Delta Y_{j}}\left[\frac{\left(T_{j+1}^{\prime}-T_{j}\right)^{n+1}}{\Delta Y_{j}+\Delta Y_{j+1}}-\frac{\left(T_{j}^{\prime}-T_{j-1}^{\prime}\right)^{n+1}}{\Delta Y_{j}+\Delta Y_{j-1}}\right]
$$

and $\frac{\partial T^{\prime}}{\partial t}=\frac{T_{j}^{n+1}-T !}{\Delta t}$

Here $\Delta Y=$ overburden grid block dimension

$\partial t=$ time increment

$n=$ time level

Then

$$
\begin{aligned}
& \frac{2}{\Delta Y_{j}\left(\Delta Y_{j}+\Delta Y_{j-1}\right)} T_{j-1}^{n+1}-\left[\frac{2}{\Delta Y_{j}\left(\Delta Y_{j}+\Delta Y_{j-1}\right)}\right. \\
& +\frac{2}{\Delta Y_{j}\left(\Delta Y_{j}+\Delta Y_{j+1}\right)}+\frac{\left(\rho C_{p}\right)_{o b}}{\lambda a b \Delta t} T_{j}^{n+1} \\
& +\frac{2}{\Delta Y_{j}\left(\Delta Y_{j}+\Delta Y_{j+1}\right)} T_{j+1}^{n+1} \\
& =-\left(\frac{\rho C_{p}}{\lambda}\right)_{o b} T_{j}^{\prime n}
\end{aligned}
$$


Equation $\mathrm{F}-4$ can then be written as

$$
E T_{j-1}^{n+1}+\dot{F} T_{j}^{n+1}+G T_{j+1}^{n+1}=H, j=2, N Y-1
$$

Where

$$
\begin{aligned}
& E=\frac{2 D}{\Delta Y_{j}\left(\Delta Y_{j}+\Delta Y_{j-1}\right)} \\
& F=\frac{2 D}{\Delta Y_{j}\left(\Delta Y_{j}+\Delta Y_{j+1}\right)}
\end{aligned}
$$

$G=-\frac{T^{\prime} !}{\Delta t}$

$H=-\left(E+F+\frac{1}{\Delta t}\right)$

$D=\left(\frac{\lambda}{\rho C_{p}}\right)_{o b}$

and $N Y=$ total number of overburden grid blocks.

Equation $\mathrm{F}-5$ represents a tridiagonal system of equations and solved by direct elimination.

The boundry conditions for the solution of the difference equation are as follows:

At time level ' $n$,' the temperature at the first and last block is known. That is

$T_{1}^{\prime}\left(X, Z, 0, t_{n}\right)=T\left(X, Z, 0, t_{n}\right)$, for $t_{n} \leq t \leq t_{n+1}$

$T_{1}^{\prime}\left(X, Z, Y, t_{n}\right)=T\left(X, Z, Y, t_{n}\right)$

and $T_{2}^{\prime}(X, Z, N Y, t)=T_{1}$ at any time

Here $T_{f}$ is formation temperature.

Actually, there is a temperature change $\delta T$ during the time-step $t^{n+1}-t^{n}$. Thus, an additional heat loss occurs as compared to no temperature change. As suggested by Coats, ${ }^{21}$ the solution to equation $\mathrm{F}-1$ can be written as

$$
T^{\prime}\left(X, Z, Y, t_{n+1}\right)=T^{\prime \prime}\left(X, Z, Y, t_{n+1}\right)+\delta T
$$


Where $T^{\prime \prime}\left(X, Z, Y, t_{n+1}\right)$ is the solution of equation F-5.

Under the conditions $\mathrm{F}-11$ and $\mathrm{F}-12$, the heat loss rate results in

$$
\left(\dot{Q}_{L}\right)^{n+1}=\left(\dot{Q}_{L}\right)^{n}+M \delta T
$$

Where $M$ and $\left(\dot{Q}_{L}\right)^{n}$ are obtained from Fourler's equation. Considering the heat loss from the top and bottom of the reservoir to be equal; then

$$
M=\frac{4 \lambda_{o b} \Delta X \Delta Z}{\Delta Y_{1}+Y_{2}}
$$

and

$$
\left(\dot{Q}_{L}\right)^{n}=2 \lambda_{o b} \Delta X \Delta Z \frac{\partial T^{\prime}}{\partial Y_{Y=h / 2}}
$$



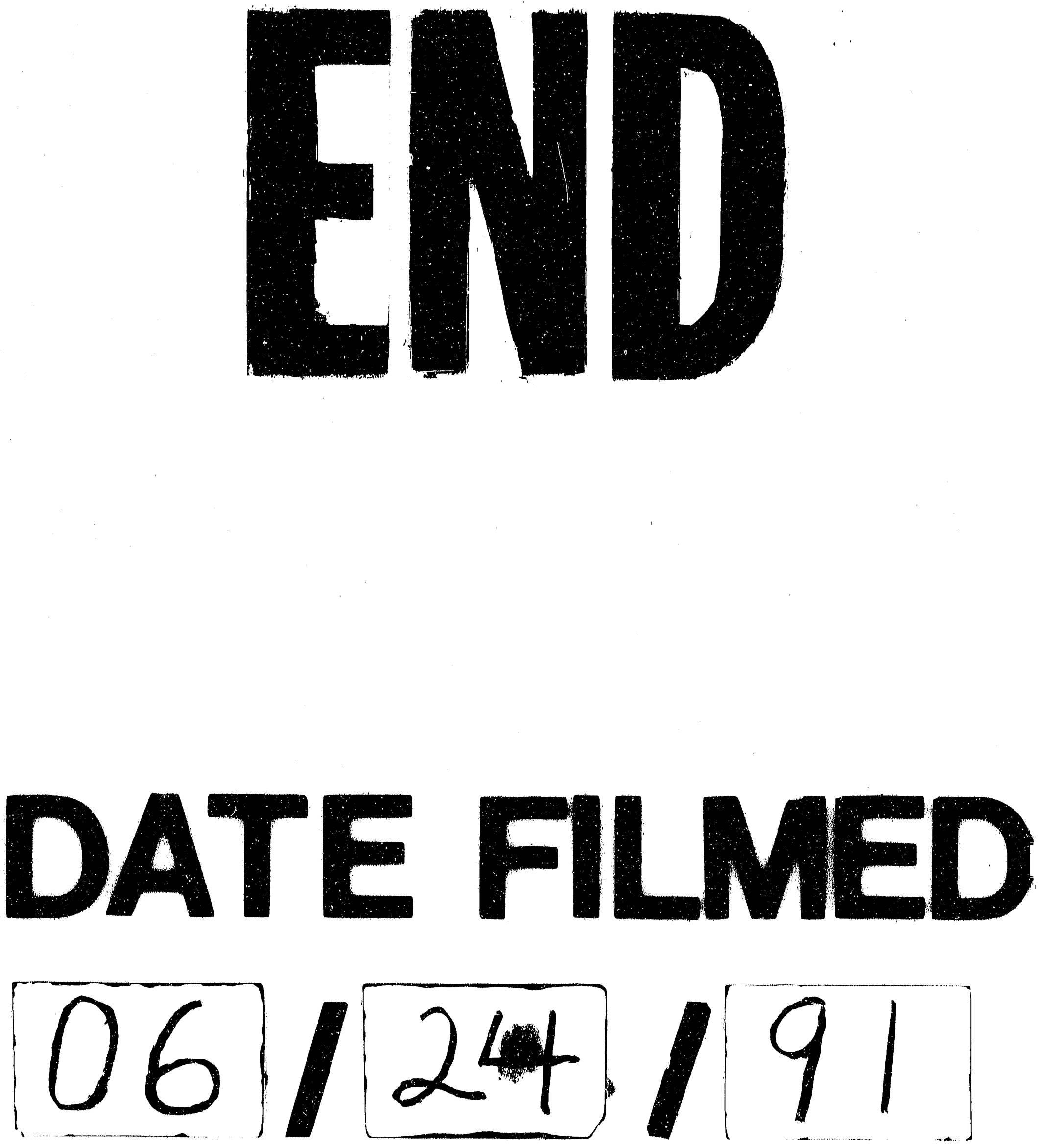
